\title{
The Matata earthquake sequence of 1977, Bay of Plenty, New Zealand
}

A thesis submitted for the degree of Doctor of Philosophy

in

Geophysics

Institute of Geophysics, Research School of Earth Sciences

Victoria University of Wellington

Wellington, New Zealand

March 1989 


\section{Abstract}

An $M_{L} 5.4$ earthquake and an associated sequence of smaller earthquakes, including foreshocks, were well recorded in 1977 by a network of 10 seismographs set for a microearthquake survey in the Bay of Plenty region, which is transitional between back-arc spreading regions of the Havre Trough and the continental North Island.

Upper crustal aftershock origins clustered and migrated within an area $7 \mathrm{~km}$ by $15 \mathrm{~km}$ elongated east-west. The aftershocks were relatively swarm-like, producing a $b$ value of $1.29 \pm 0.13$, and were apparently of long sequence duration, with decay coefficient $p=0.67 \pm 0.03$. A northeast-trending rupture fitted for the mainshock, originating close to where foreshocks were centred, and passing between tight concentrations of later aftershock activity to either side.

Teleseismic waveforms, in addition to providing a $10.5 \mathrm{~km}$ estimate of focal depth, helped to constrain the solution of focal mechanism for the mainshock. The preferred solution is for mainly right-lateral slip on a northeast-striking plane but with a normal component. The slip trend parallels the front of recent volcanism. Mechanisms for related events range from normal to strike-slip, on parallel and intersecting planes, and are indicative of the complexity of geological structure where north-trending faults of the North Island shear belt meet with the front of recent volcanism, as well as of a prevailing traction across the volcanic front.

The volcanic region is characterised by a low Poisson's ratio, suggested by the Wadati method to be $v=0.19 \pm 0.01$ in contrast to $v=0.27 \pm 0.01$ for the greywacke region to the southeast; this difference is attributed to contrasting rock types and other conditions either side of the volcanic front. The multiplicity of earthquake sequences in the volcanic region indicates a high degree of heterogeneous structure. A low stress drop of $2.8 \mathrm{MPa}$ inferred for the Matata mainshock suggests that the faulting occurs on pre-existing planes.- Off-fault aftershocks occurred where the failure stress increased as a result of the mainshock rupture.

A concurrent sequence of earthquakes originating near $50 \mathrm{~km}$ depth indicated thrusting on the lithospheric plate interface underlying the North Island; thrusting on the interface apparently extends to about $70 \mathrm{~km}$ depth, where the plates become decoupled. Oblique plate convergence and stick-slip motion on the weakly coupled interface provides the regional dextral shear component observed in the volcanic region for the Matata mainshock. An extensional component is therefore a necessary addition for the observed normal component of faulting, which predominated for the 1987 Edgecumbe mainshock.

Wave-mode conversions inferred for subcrustal earthquakes and the Matata sequence mainshock indicate that the Moho shallows from $28.5 \mathrm{~km}$ to $22 \mathrm{~km}$ northwestwards across the volcanic front, suggesting that new crust in the Bay of Plenty region is being created over a wide region rather than by active rifting along a sharp margin. 


\section{Acknowledgements}

Thanks are due to the supervisors of this thesis, Prof. F.F. Evison and Dr J.H. Ansell, for their encouragement. Thanks are due also to all those agencies who made available copies of seismograms; New Zealand Seismological Observatory seismograms were loaned on a long term basis.

I am very grateful to my family for their continued support and understanding. 


\section{Contents}

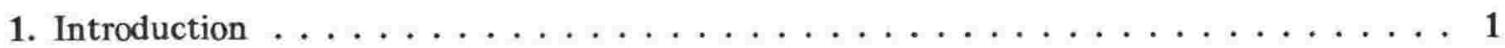

2. Matata sequence foreshocks, mainshock and aftershocks $\ldots \ldots \ldots \ldots \ldots$

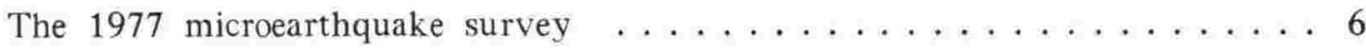

Data, sampling, model, and event location . . . . . . . . . 10

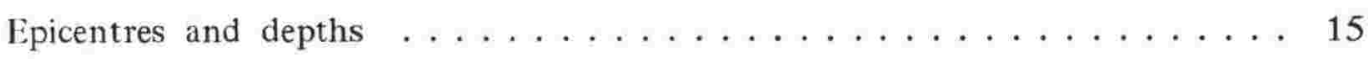

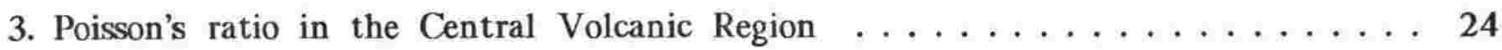

Search for a precursory velocity-ratio anomaly . . . . . . . . . . 24

The Central Volcanic Region . . . . . . . . . . . . . 28

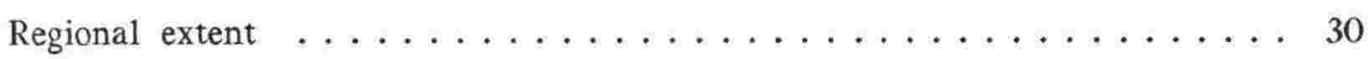

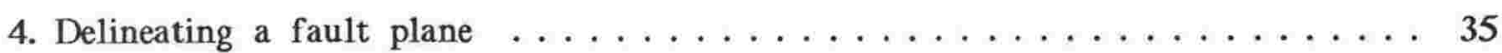

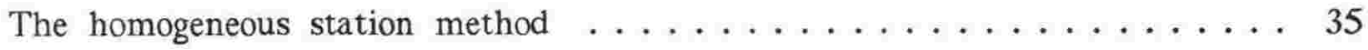

First-motion composites $\ldots \ldots \ldots \ldots \ldots \ldots \ldots \ldots \ldots \ldots \ldots$

Comparison with other results $\ldots \ldots \ldots \ldots \ldots \ldots \ldots$

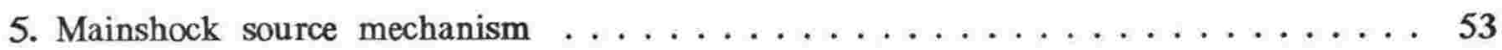

Free-surface reflections, and relative amplitudes $\ldots \ldots \ldots \ldots \ldots \ldots$

The inconsistencies ........................ 61

Reappraisal of focal mechanisms ................. 65

6. Earthquake and seismicity parameters . . . . . . . . . . . 77

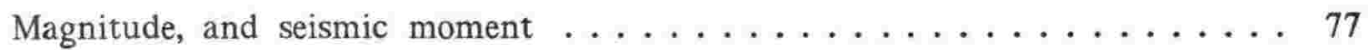

$b$-value, and the rate of decay of aftershocks $\ldots \ldots \ldots \ldots$

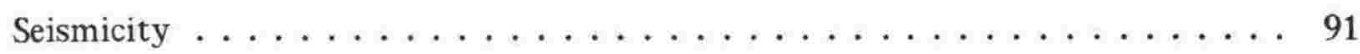

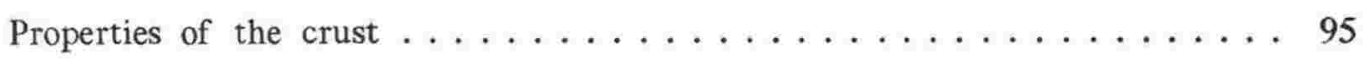

7. Crustal structure $\ldots \ldots \ldots \ldots \ldots \ldots \ldots \ldots \ldots \ldots \ldots$

Apparent velocity from earthquakes . . . . . . . . . . . . 98

Refraction from sources within the volcanic region ........... 99

Mode conversion at an interface . . . . . . . . . . . . 101

Subduction structure . . . . . . . . . . . . . . . . 108

The local model . . . . . . . . . . . . . . . . . . . 110

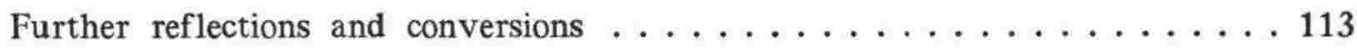

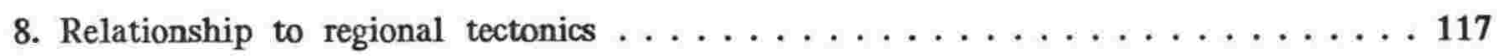

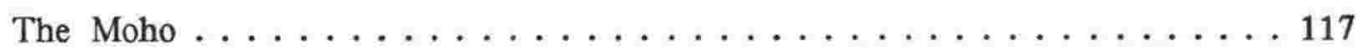

Off-fault aftershocks . . . . . . . . . . . . . . . . . 119

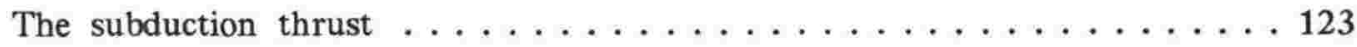

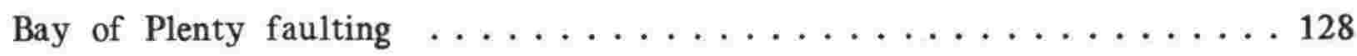

Back-arc spreading . . . . . . . . . . . . . . . . 129

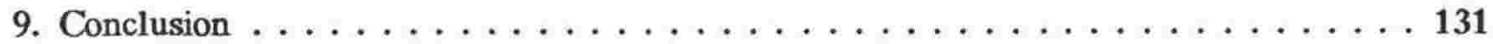

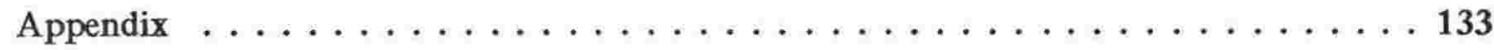

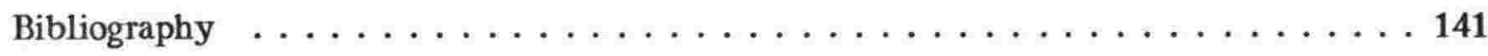




\section{List of Figures}

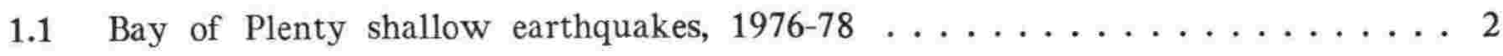

1.2 Records displaying the mainshock and first-day aftershocks . . . . . . . 3

1.3 Seismograms showing events later in the sequence $\ldots \ldots \ldots \ldots \ldots \ldots$

2.1 Generalised geology, and Bay of Plenty seismograph sites . . . . . . . . 7

2.2 Operational details of the portable seismographs $\ldots \ldots \ldots \ldots \ldots \ldots$

2.3 Epicentres for the three-day period starting May $26 \ldots \ldots \ldots \ldots$

2.4 Events leading up to the Matata sequence mainshock . . . . . . . 17

2.5 Aftershock epicentres for the first three days of June . . . . . . . . 18

2.6 Epicentres for the last three days of sampling . . . . . . . . . 19

2.7 Distributions of computed focal depths $\ldots \ldots \ldots \ldots \ldots \ldots \ldots \ldots \ldots \ldots$

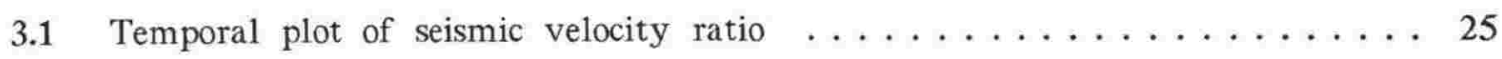

3.2 Residuals suggesting irregularity of velocity ratio $\ldots \ldots \ldots \ldots \ldots \ldots 27$

3.3 Examples of aftershocks recorded at western stations $\ldots \ldots \ldots \ldots \ldots \ldots$

4.1 Events selected for the homogeneous station method $\ldots \ldots \ldots \ldots \ldots \ldots$

4.2 Epicentres determined using the homogeneous station method . . . . . 38

4.3 A vertical section showing the relative depths $\ldots \ldots \ldots \ldots \ldots \ldots$

4.4 Relative location of the Matata mainshock .............. 41

4.5 First motions for the 1977 Matata sequence mainshock . . . . . . . . 44

4.6 Vertical-component seismogram of the mainshock at KRP . . . . . . 45

4.7 Composites of first motions for foreshocks and aftershocks . . . . . . 45

4.8 A composite for other shallow events, and overall $\ldots \ldots \ldots \ldots \ldots \ldots$

4.9 First motions and mechanism for subcrustal earthquakes . . . . . . . 48

4.10 Geographical first motions in the Bay of Plenty region $\ldots \ldots \ldots \ldots \ldots 2$

5.1 Teleseismic waveforms for modelling relative amplitudes $\ldots \ldots \ldots \ldots 6$

5.2 Results of search for the best-fitting source $\ldots \ldots \ldots \ldots \ldots \ldots$

5.3 Nodal planes suggested by the relative amplitudes . . . . . . . . 60

5.4 Reduced travel-times for the mainshock . . . . . . . . . . 62

5.5 Onsets of the mainshock and the largest aftershock at GNZ . . . . . 64

5.6 First motions of subcrustal events reported for AUC . . . . . . . 66

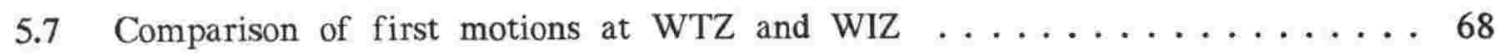

5.8 Composites of first-motion patterns for the sequence $\ldots \ldots \ldots \ldots \ldots \ldots$

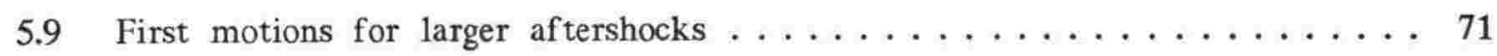

5.10 History of faulting-type against earthquake magnitude $\ldots \ldots \ldots \ldots \ldots 73$

5.11 Correspondence of faulting-type and epicentre $\ldots \ldots \ldots \ldots \ldots \ldots 74$

5.12 First motions for earthquakes near Kawerau and Te Teko . . . . . . 75

6.1 Long-period seismograms at WEL, and surface-wave envelopes . . . . . 83

6.2 Magnitude-frequencies . . . . . . . . . . . . . . . . 87

6.3 Rate of decay of aftershocks $\ldots \ldots \ldots \ldots \ldots \ldots \ldots \ldots$

6.4 Cumulate sum of aftershock magnitudes $\ldots \ldots \ldots \ldots \ldots \ldots \ldots$

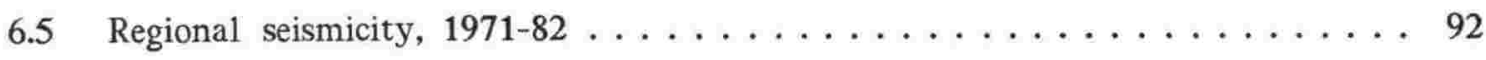


6.6 Foreshock and its microaftershocks at MDQ $\ldots \ldots \ldots \ldots \ldots \ldots$

7.1 Reduced travel-times from Bay of Plenty explosions . . . . . . . . . 100

7.2 Seismograms of the subcrustal sequence of earthquakes . . . . . . . . 103

7.3 The match of the intermediate phase and $S p$ arrival-time $\ldots \ldots \ldots \ldots 104$

7.4 Records at KRP of the 1977 June $02^{\mathrm{d}} 13^{\mathrm{h}} 17^{\mathrm{m}}$ mainshock . . . . . . . 106

7.5 Intermediate-depth seismicity on a vertical section $\ldots \ldots \ldots \ldots \ldots$

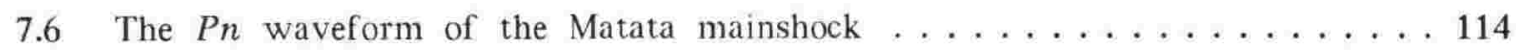

8.1 The phase $S p$ for the deep event of 1977 May $29 \ldots \ldots \ldots \ldots$

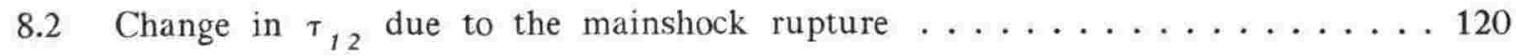

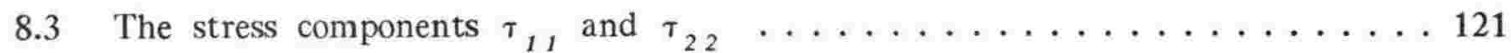

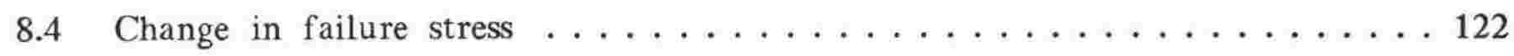

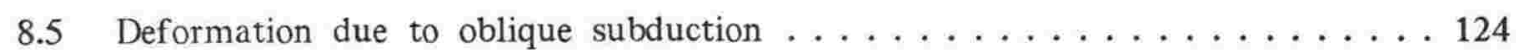

8.6 Earthquakes in the eastern North Island region, 1964-86 . . . . . . . . 125

8.7 Focal mechanisms with thrusting for events of 1965 and $1966 \ldots \ldots \ldots 126$

8.8 Deformation within the subducted plate, events of 1984 and $1985 \ldots \ldots 127$

A.1 TUA seismogram showing subcrustal mainshock and largest aftershock $\ldots 140$

\section{List of Tables}

2.1 Seismograph stations in the temporary network $\ldots \ldots \ldots \ldots \ldots \ldots$

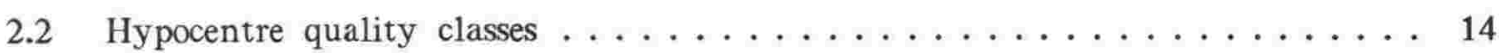

4.1 Hypocentre solutions for the 1977 Matata mainshock . . . . . . . . . . . 42

5.1 Amplitudes, and the preferred mechanism for the mainshock . . . . . . . 59

5.2 Teleseisms with a first motion recorded for GNZ . . . . . . . . 61

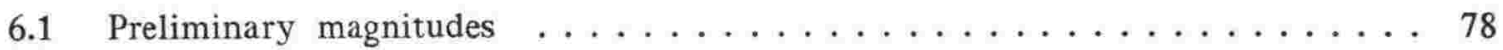

6.2 Station-magnitude calibration $\ldots \ldots \ldots \ldots \ldots \ldots \ldots \ldots \ldots$

6.3 Source parameters for the mainshock ............... 85

7.1 Times and amplitude ratios for the subcrustal mainshock . . . . . . . 105

7.2 Amplitudes in the $P n$ waveform for the Matata mainshock . . . . . 115

8.1 Origin and residuals for the deep event, May $29 \ldots \ldots \ldots \ldots \ldots \ldots$

A.1 List of earthquakes . . . . . . . . . . . . . . . . . 134

A.2 Hypocentres determined using the homogeneous station method $\ldots \ldots \ldots 138$

A.3 Arrival-time residuals for the homogeneous station method . . . . . . 139 


\section{Introduction}

Hypocentre estimation for shallow and deep earthquakes occurring near New Zealand generally falls to the Seismological Observatory of Geophysics Division, New Zealand Department of Scientific and Industrial Research (DSIR). To effect this for small, moderate and large earthquakes, a typical spacing of about $120 \mathrm{~km}$ for the thirty or so standard and contributing stations of the nationwide seismograph network necessitates that shallow origins commonly have epicentres determined with depths restrained at $12 \mathrm{~km}$ or $33 \mathrm{~km}$ as evidence from felt intensities, aftershocks and crustal phases suggests. By taking advantage of a greater frequency of smaller earthquakes sampled with a short-term deployment of closely-spaced, high-gain seismographs, use of the microearthquake technique allows more precise estimates for the seismicity in a region to be quickly gathered. It was just such a survey, similar to an earlier, more southern traverse of the North Island of New Zealand, that was undertaken as a research project by Robert B. Frith in 1977 but subsequently relinquished by him.

During a recording period in the Bay of Plenty region, there occurred, quite fortuitously, adjacent to the temporary network of portable seismographs, a magnitude 5.4 earthquake and an accompanying succession of aftershocks. The mainshock, felt strongly in the Bay of Plenty region at dawn on $1^{\text {st }}$ June 1977 , is described in the annual bulletin documenting analysis at the Seismological Observatory, the New Zealand Seismological Report, as having occurred near Edgecumbe, having produced a maximum intensity of $M M$ VIII and having led to some 360 insurance claims, the largest for $\$ 2,600$. Hitherto the principal shock may have been referred to informally as the Edgecumbe earthquake, but, as this study confirms the epicentre to be offshore, it may more aptly be named after the nearby coastal settlement at Matata. Localities are shown in Figure 1.1, as is shallow seismicity determined using the national seismograph network for a three-year period that embraces the mainshock origin-time.

The Matata earthquake, which is one of the larger in most recent times, is of special interest for its proximity to the lineament of andesitic volcanoes, including Mt Edgecumbe and White Island, which trends $\mathrm{N} 35^{\circ} \mathrm{E}$ through the Bay of Plenty region. This volcanic front (Adams \& Hatherton, 1973) defines the southeastern boundary of the Central Volcanic Region (Thompson, 1964), an area of Quaternary volcanism usually regarded as characterised by swarm-type seismic activity (e.g., Eiby, 1966a), such as the 1976 sequence near TePuke. The southeastern part of this region is known as the Taupo Volcanic Zone (Healy, 1962) and is a zone of extensive hydrothermal activity, with proven geothermal fields, such as that at Kawerau, where swarm-like seismicity is also frequent. In this respect reference to aftershocks for now signifies merely the time relationship to the principal event, since the assessment of seismological parameters to elucidate what affinity the Matata earthquake sequence may have had with the region of volcanism and high heat flow is yet to be presented. 


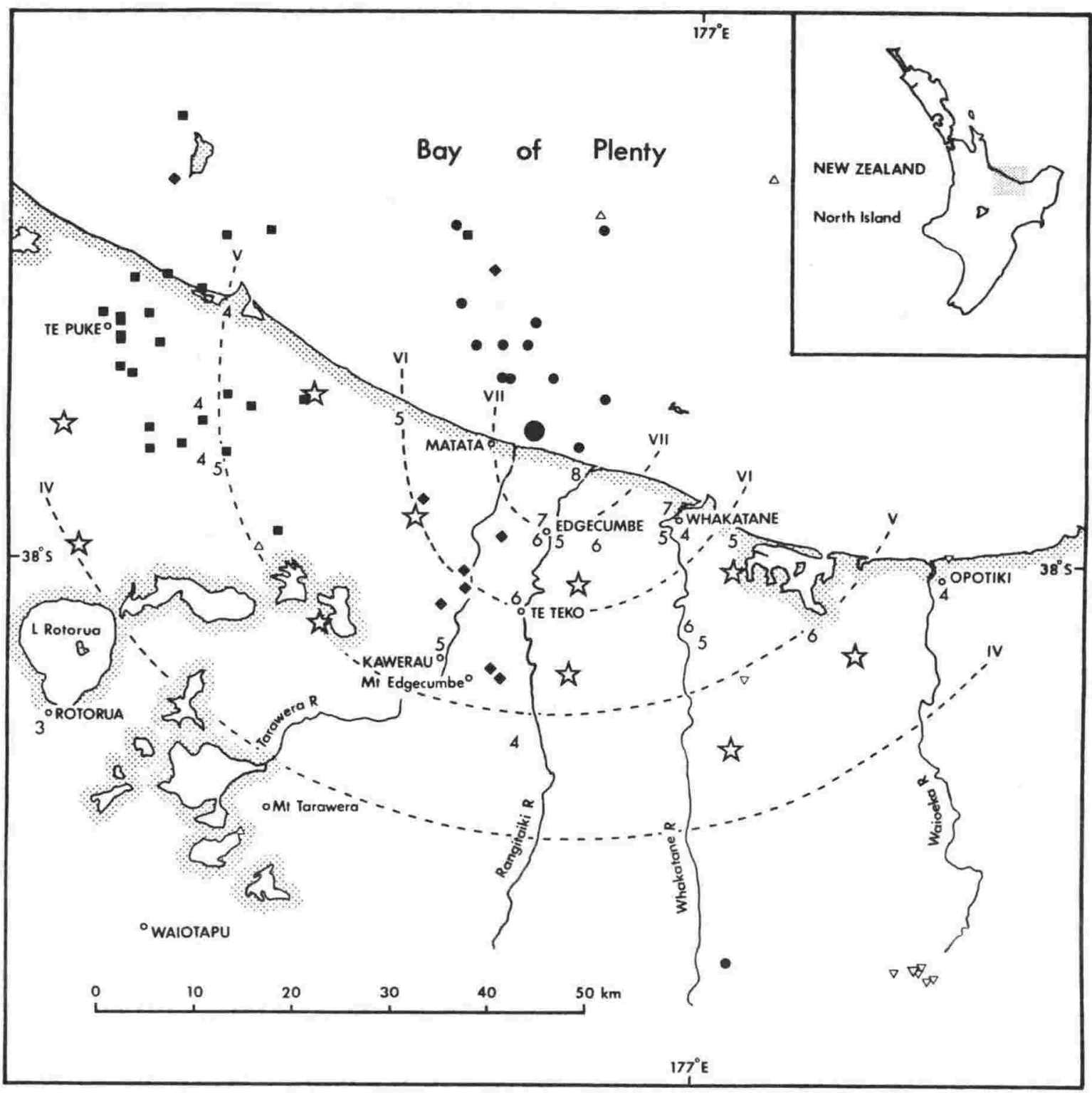

Figure 1.1. Bay of Plenty shallow earthquakes, 1976-1978. Solid symbols indicate Observatory epicentres of shallow earthquakes of magnitude four or greater for the years 1976, 1977 and 1978 shown by squares, circles and diamonds respectively. The arabic numerals are the reported felt intensities (Modified Mercalli; Eiby, 1966b) yielding approximate isoseismals (dashed lines, Roman numerals) for the Matata sequence mainshock (larger circle). Stars represent sites of temporary seismographs in operation at the time of the mainshock. Epicentres determined in this study and not shown elsewhere are given by the open triangles; foci greater than $40 \mathrm{~km}$ deep are those with a downward vertex $(\nabla)$.

The capriciousness of moderate and large earthquakes, and the limit to resources for observing them at close hand, are such that it is rare indeed to be able to collect, by means of a temporary network, so full and extensively detailed a set of seismograms, examples of which are shown in Figures 1.2 and 1.3. Here there were ten portable seismographs already installed at the best sites available, with a station spacing of about $15 \mathrm{~km}$, and, what is more, a satisfactory network of stations in 

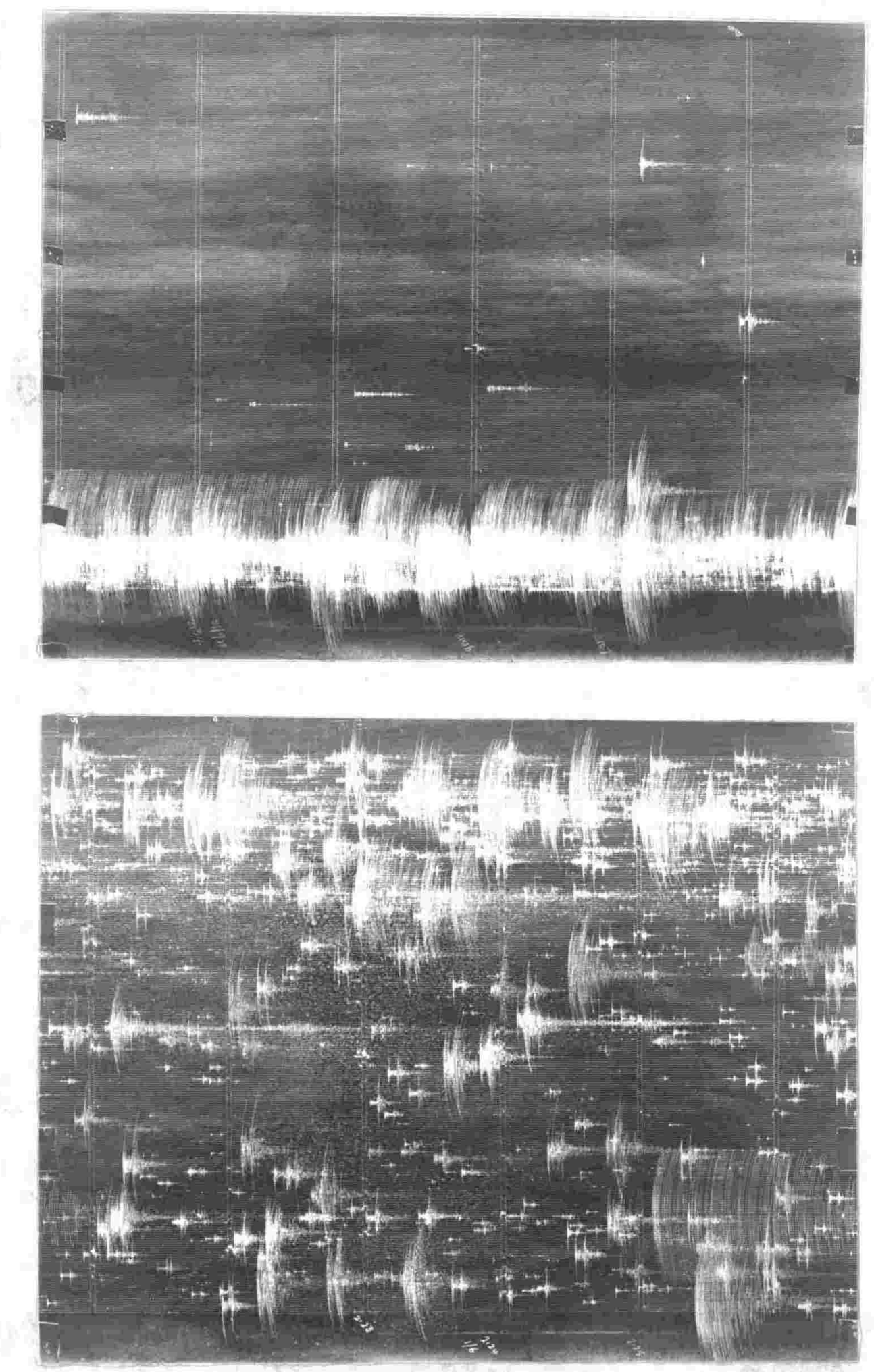

Figure 1.2. Specimen seismograph records displaying the mainshock and first-day aftershocks. These photographs of smoked-paper seismograms reproduce each a day's recording (of the short-period, vertical-component) at the Rawhiti Farm site (RAW); the length of a trace across a record represents six minutes. Onsets for many of the early aftershocks are masked by other events, recorded on adjacent traces; clipping of large trace amplitudes can also be seen. 

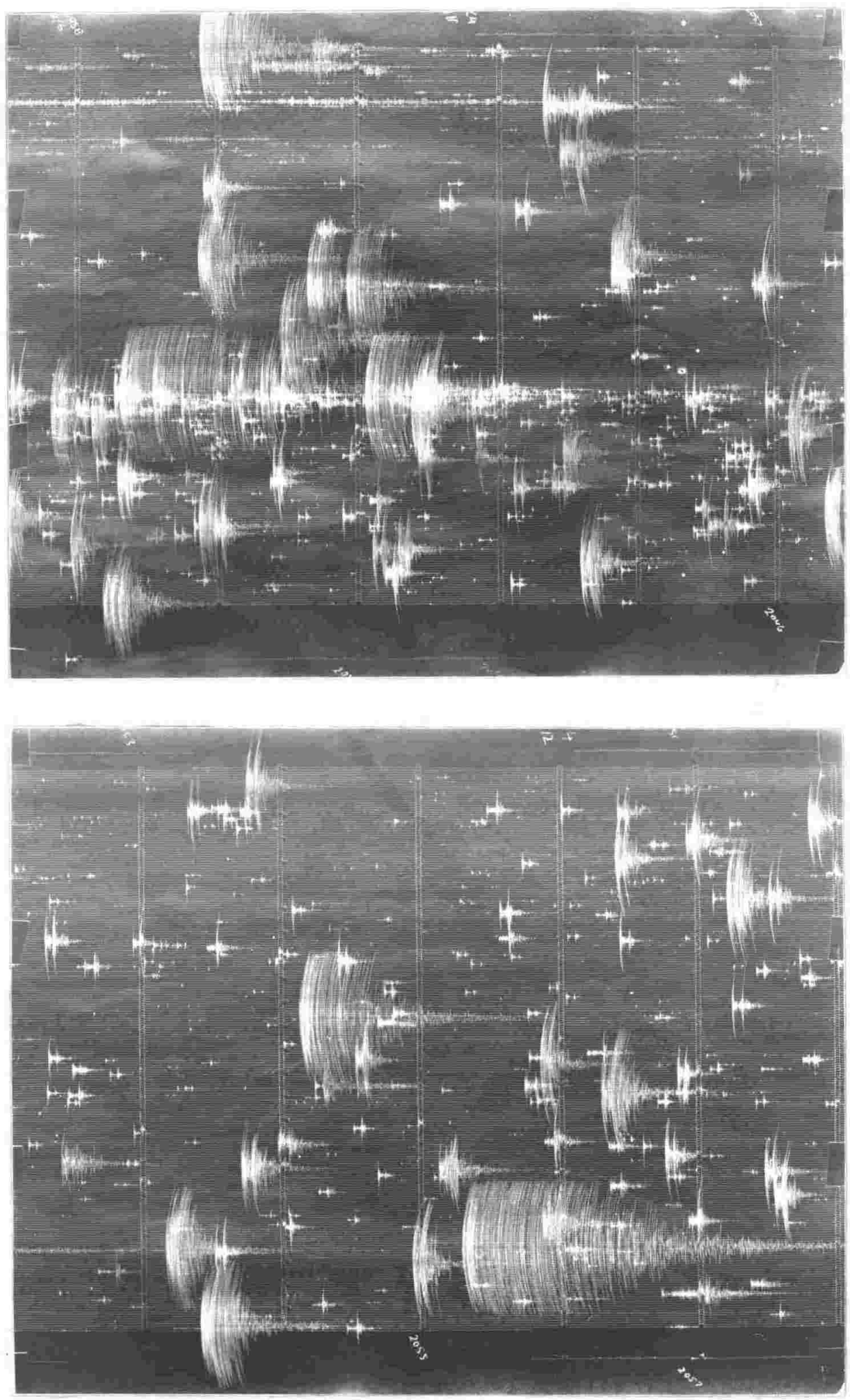

Figure 1.3. Further seismograms showing events later in the aftershock sequence. The secondary sequence recorded in the lower half of the top seismogram was apparently initiated by the magnitude 4.3 event of June $03^{\mathrm{d}} 11^{\mathrm{h}} 40^{\mathrm{m}}$ (U.T.); no such sequence followed the magnitude 3.9 event of June $04^{\mathrm{d}} 07^{\mathrm{h}} 36^{\mathrm{m}}$, recorded near the centre of the bottom seismogram. (The magnitude 5.1 event of June $04^{\mathrm{d}} 17^{\mathrm{h}} 25^{\mathrm{m}}$, prominent at the lower right, was located well outside the temporary seismograph network.) 
operation almost six days before the principal earthquake. Henceforth dates and times are specified in Universal Time (U.T.), this being 12 hours behind local New Zealand Standard Time; the sequential number prefixed by a year indicator, for events in the New Zealand catalogue (Smith, 1976) and the N.Z. Seismological Report, may also be given to facilitate reference.

This study, which begins with the analysis of the seismograms obtained during the Bay of Plenty survey, has the ultimate objective of placing the Matata earthquake sequence in context relative to the tectonics of the North Island of New Zealand, an environment of convergence along a lithospheric plate margin (Walcott, 1978a) with attendant geophysical anomalies (Hatherton, 1970). Detailed analysis for the 1977 Matata sequence will enable comparisons with the more recent, 1987, sequence near Edgecumbe (Staff of DSIR, 1987).

The Matata sequence proved to be more complicated than is usually observed, and not the purely normal faulting event often expected in the volcanic region (e.g., Evison et al., 1976). Recordings of the mainshock outside New Zealand were surveyed to help resolve several ambiguities in interpretation for the local data, which did not include an observed surface rupture. To supplement data provided by the New Zealand network, appropriate seismograms were requested from a variety of sources, including short-period array stations, and were received from Australian, Swedish and international data centres. But the mainshock, because of its size, was not well recorded on high-gain long period instruments of the global digital network in operation at that time, as indicated by a listing of headers supplied for the relevant day tape, and, indeed, no focal mechanism has been reported by the usual agencies undertaking waveform modelling. Hence relative amplitudes of phases in short period waveforms were used to provide appropriate constraints on the mainshock mechanism: this is the first application of this technique for a New Zealand mainshock.

The circumstances of the Matata sequence enabled the examination of the variation of the seismic velocity ratio. Some recent models for the Central Volcanic Region were critically examined and a new estimate of $22 \mathrm{~km}$ for the crustal thickness in the vicinity of the mainshock was deduced for the phase identified in the local and teleseismic waveforms as the $S$-to- $P$ conversion at the Moho. This phase conversion for the downward propagating wave will not often be observed for North Island earthquakes, which are mostly of subcrustal origin, but it may well be observable for shallow earthquakes of the central South Island. Only nearby stations were used for determining the locations of the earthquakes, and at these stations Moho-refracted waves were not observed as first arrivals. Hence the earthquake locations were independent of the crustal thickness and the mantle velocity, which were examined subsequently. 


\section{Matata sequence foreshocks, mainshock and aftershocks}

The microearthquake recorders were operated in the Bay of Plenty region during the last week of May and the first week of June, 1977, after which a more limited survey in the East Cape region of the North Island was undertaken. Observations made from the records obtained during the Bay of Plenty survey form the basis of this thesis and serve to limit interpretations made for observations at greater epicentral distances. Conversely, observations made for the greater distances provide constraints on quantities not well determined using the Bay of Plenty array of seismographs. An overview of events forming the Matata sequence of earthquakes is presented below, but as a matter of course it also includes events forming the background seismicity. Detailed characteristics of the seismicity and of particular earthquakes will be examined later.

\section{The 1977 microearthquake survey}

The temporary array of seismograph stations straddling the southeastern margin of the Central Volcanic Region, from near TePuke to near Opotiki (Fig. 1.1), was the result of a combined effort of personnel and resources from the Institute of Geophysics, Victoria University of Wellington, and Geophysics Division, as part of a long series of co-operative research programmes. Two seismograph networks, each comprising five similar instruments, were serviced daily for the purpose of changing seismograph records and maintaining a fresh supply of power from lead-acid cells. One network (which may be referred to as the western network) occupied an area inside the volcanic region. The other (the eastern network) had stations sited on or near Mesozoic greywacke adjoining the volcanic front. Hourly time-signals, emanating from the New Zealand Time Service under the control of the N.Z. Seismological Observatory (NZSO), and broadcast by the national radio system, were the source of time standard and were recorded automatically on seismograms for stations of the western network. For stations of the eastern network, time signals from the Australian short-wave station VNG (Lyndhurst, Victoria) were recorded at times of record change. It was against these time marks that a quartz chronometer internal to each of the portable seismographs was calibrated.

A summary of geological features in the Bay of Plenty region is shown in Figure 2.1; details about the temporary seismograph stations and of the array operation are given in Table 2.1 and Figure 2.2 respectively. As is usual with microearthquake surveys it took some time to install the portable seismographs and establish the servicing routes. Whereas some stations of the eastern network could be shifted to more favourable sites with a lower level of microseismic noise, there was of ten little opportunity for so doing in the volcanic region, since there are commonly few sites on suitably hard rock amidst the Quaternary volcanics. Western network stations were 


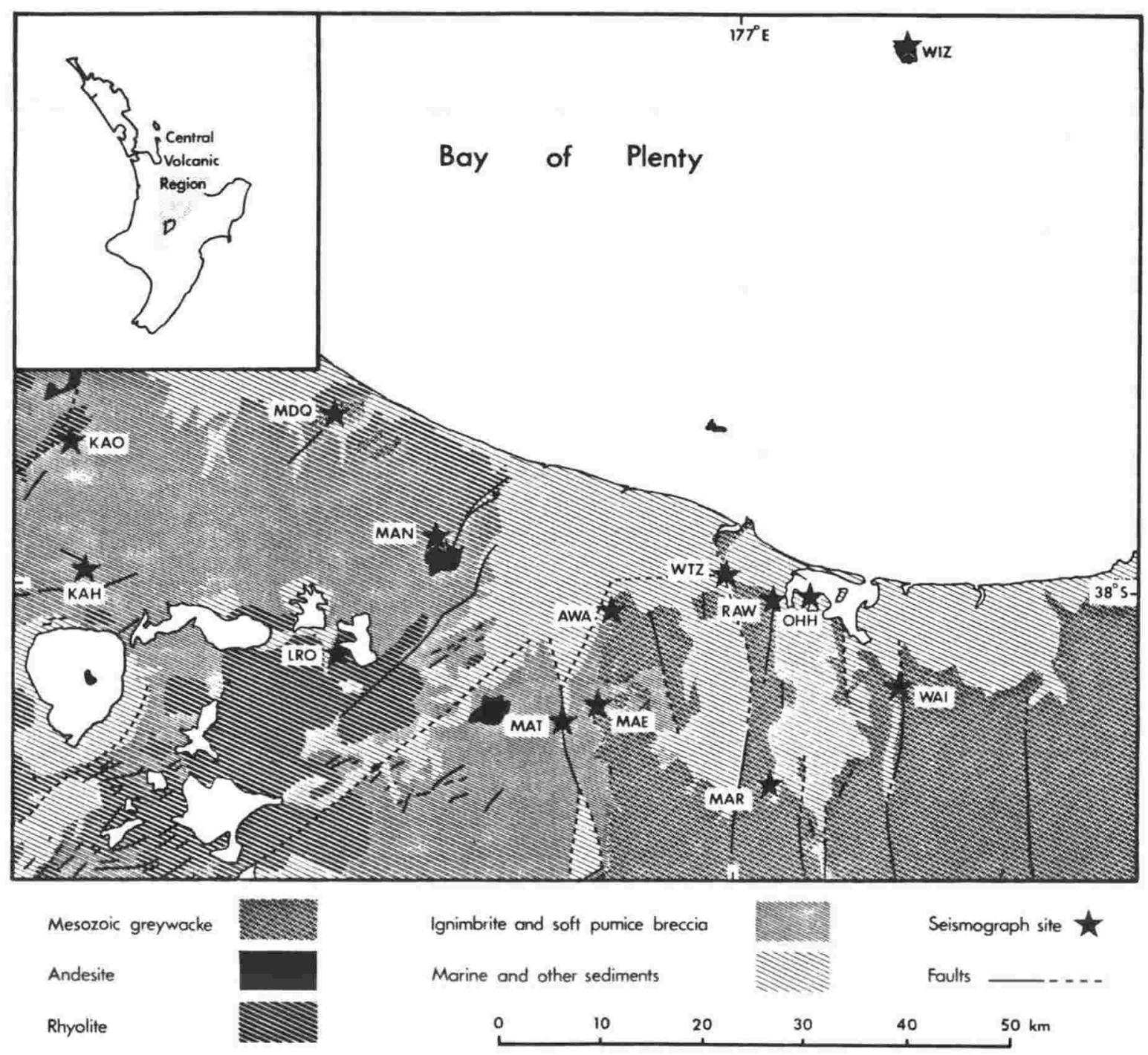

Figure 2.1. Generalised geology, and Bay of Plenty seismograph sites. Major lithologies, together with known and inferred fault traces, are abstracted after Healy et al. (1964). Permanent network seismographs at sites WTZ and WIZ are in addition to the sites used for the temporary network.

thus operated at much reduced gains at all sites except MDQ, which was situated on one of the rare outcrops of Mesozoic greywacke within the volcanic region. Although this lack of sensitive recording sites reduced the capability of locating the very small microearthquakes that are normally studied using the microearthquake technique, it was of no great disadvantage here for the larger Matata sequence aftershocks.

A majority of seismographs were installed and recording by the start of May 26 (Fig. 2.2). Most of the others were soon added, and although recording may have been intermittent and with sensitivity still to be enhanced for the expected microseismicity, all were in operation at the time of the Matata sequence mainshock. After that occurrence the temporary seismograph array was kept intact almost until the end of June 06, with only minor sensitivity adjustments made for varying noise levels. 


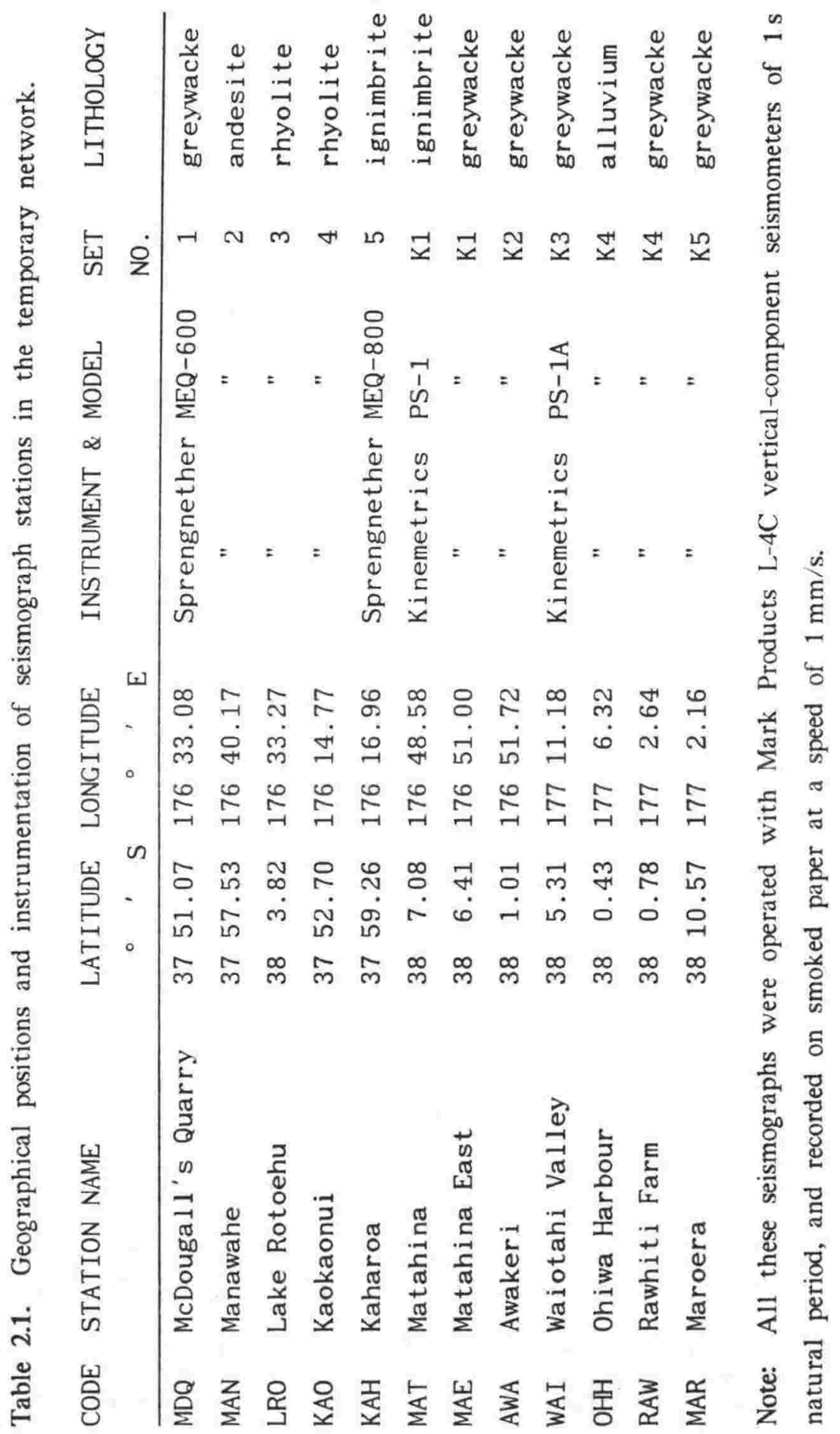




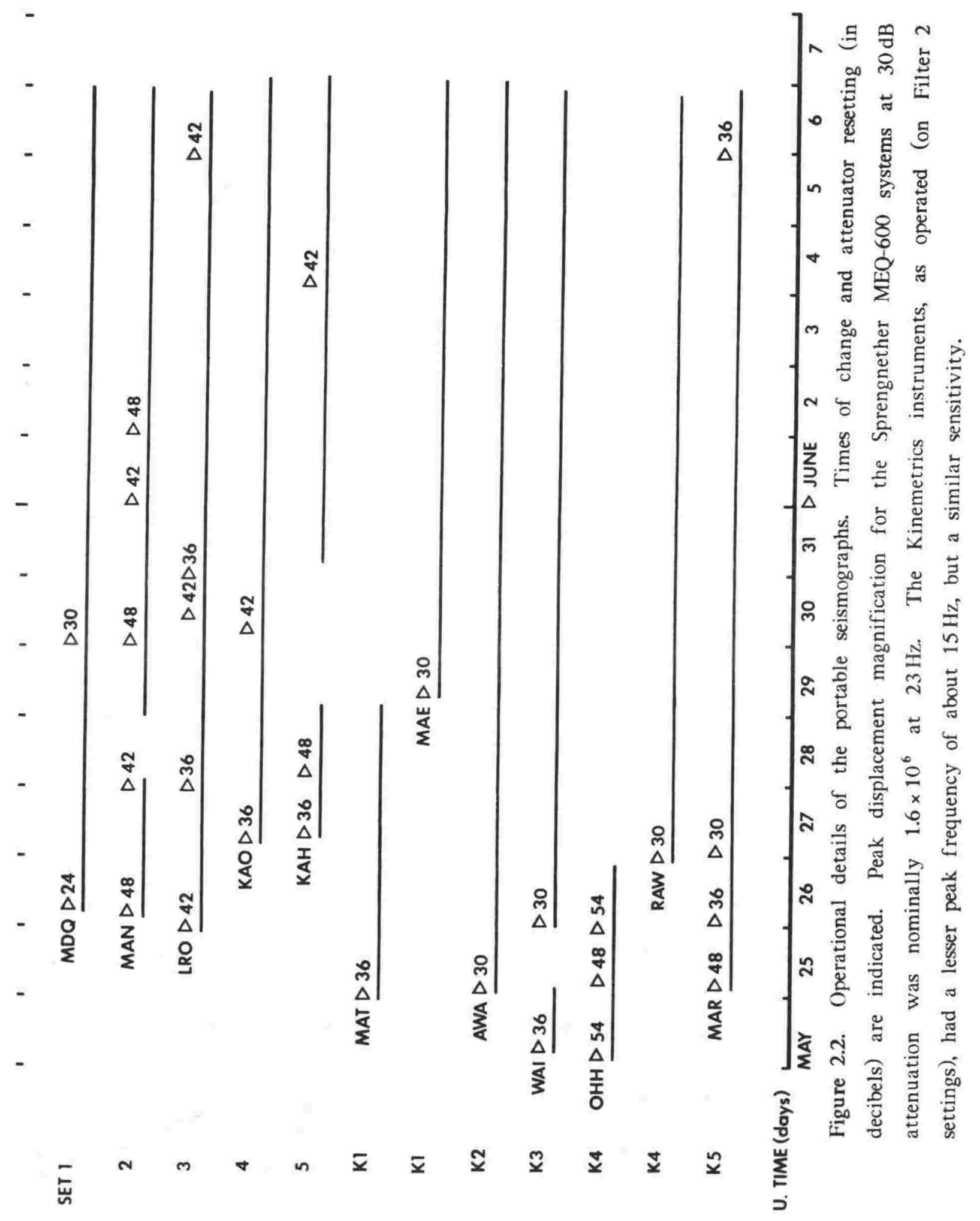


Throughout the same period, the two nearby stations of the permanent New Zealand seismograph network recorded continuously. The first, WTZ (Whakatane), recording on photographic paper, is a high-gain station of the standard network, and is a useful addition to the eastern network of stations. The other, WIZ (White Island), which was operated by the Geology Department of Victoria University of Wellington, with output telemetered to a pen and ink recorder, had volcano surveillance as its primary purpose, but it was helpful here through being situated opposite the Bay of Plenty array of stations with respect to the source region of the Matata sequence earthquakes. The positions of both permanent network stations are included in Figure 2.1; more distant stations of the permanent network were not so useful in that only the larger Bay of Plenty earthquakes were well recorded. Timing arrangements for these permanent seismograph stations were the same as already described for the western network stations; further details about permanent network stations can be found in the annual N.Z. Seismological Report of the N.Z. Seismological Observatory, and, together with other stations mentioned later, in the six-monthly Regional Catalogue of Earthquakes of the International Seismological Centre (ISC).

Data, sampling, model, and event location

Timing corrections for the seismograms were obtained when the radio time-marks recorded on the seismograms were read with reference to the time marks that were generated locally at each seismograph at $60 \mathrm{~s}$ intervals; timing corrections were read using a graticule and a $10 x$ magnifier, as were all seismic arrivals. Chronometer driftrates were less than $10 \mathrm{~ms} /$ hour, except at one station (LRO), where five times that amount of drift occurred. Further, an estimate of the scatter in timing corrections could be made when a sufficient number were determined. A standard deviation of $0.06 \mathrm{~s}$ was typically found for timing-correction errors for the Sprengnether MEQ-600 instruments of the western network, and, assuming chronometer drift to have been adequately corrected, this was also an estimate of the timing uncertainty for seismic arrivals of the best quality. (Timing uncertainty is unlikely to have been greater for other stations of the temporary network, as will be evident later.)

Estimation of origin-time, latitude, longitude and depth for an earthquake requires a suitable reference model for the earth; the HYP071 program (Lee \& Lahr, 1975), which was the algorithm used here, requires a laterally homogeneous earth model with a uniform ratio of compressional to shear velocity, and iteratively minimises a weighted sum of squared observed-less-calculated arrival-times. In the absence of any comprehensive study providing local velocities and station terms, the adopted model consisted of two layers, with thicknesses of $12 \mathrm{~km}$ and $21 \mathrm{~km}$ and compressional velocities of $5.5 \mathrm{~km} / \mathrm{s}$ and $6.5 \mathrm{~km} / \mathrm{s}$, respectively, above an $8.1 \mathrm{~km} / \mathrm{s}$ mantle halfspace. Corresponding shear velocities were those obtained by assuming a Poisson's ratio of 0.25 ; thus the shear velocity, $\beta$, was related to the compressional velocity, $\alpha$, by $\alpha=\sqrt{3} \beta$, everywhere in the model. (This Poisson solid assumption (equal Lamé moduli $\lambda$ and 
$\mu$ ) is the initial assumption made for elastic media throughout this study, as it is representative of most rock types.) Apart from the shear velocities, this has been the standard crustal model used routinely for the Observatory solutions of earthquake hypocentres determined using national network observations, and the model for the crust is similar to that assumed in the 1940 travel-time tables (Jeffreys, 1976: p. 102 \& p. 150), which are used for the ISC solutions (Adams et al., 1982). Hypocentres determined in this study may therefore be compared with the Observatory and ISC hypocentres.

A relatively simple model of few layers was desirable, as the hypocentre solutions could converge to local minima caused by velocity discontinuities in the model: most of the shallow earthquakes during the Bay of Plenty survey originated outside the temporary network of seismographs. At least one boundary at a crustal depth was needed to match observed refractions. Only the shallow, crustal part of this model was relevant for the shallow hypocentres, because the arrival-time observations were restricted to the 12 Bay of Plenty stations. Nevertheless, the earthquake origins should still be regarded as having been located with some undefined error, attributable to probable deficiencies of the assumed model.

Measured arrival-times comprised mainly the first arrivals of the compressional wave, $P$, and if practicable the shear wave, $S$, but if absolute timing was deficient at any station the difference between $S$ and $P$ arrival-time, $S-P$, could be used: for each event at least four arrival-times are generally required, and not less than three stations. Arrival-times of other distinct, intermediate phases were also important, as were observations of the directions of first motion, the maximum trace amplitudes and the durations of trace disturbance above the ambient noise level. Obviously (see Fig. 1.2 \& 1.3), it would have been too onerous to note systematically all of that data for every event recorded during the Bay of Plenty survey, and some limiting criteria were warranted.

To ensure the optimum of information was gained for the period before the Matata sequence mainshock, and in keeping with the original aims for the Bay of Plenty microearthquake survey, hypocentre solutions were attempted for all earthquakes occurring during that period, provided that sufficient arrivals were recorded by the Bay of Plenty seismographs, and provided that the $S-P$ interval was $15 \mathrm{~s}$ or less at any station of the array. A subsequent refinement, admitting only those earthquakes that were found to have originated at a depth less than $100 \mathrm{~km}$ and within $70 \mathrm{~km}$ epicentral distance of Edgecumbe, eliminated earthquakes having unreliable hypocentre solutions. Specifically, this procedure excluded several earthquakes, originating in the eastern Bay of Plenty region, that had similar appearances on the seismograms, but of which only the largest and best recorded earthquake sustained a subcrustal hypocentre. Earthquakes of deeper origin have less certain epicentres when they are located using a seismograph network of small aperture, and these earthquakes may better be studied using the permanent, nationwide network of seismographs. 
Complete analysis of earthquakes occurring immediately after the principal shock was far from practical, largely because over-writing of traces on the smoked-paper records obliterated the arrival onsets and the $60 \mathrm{~s}$ time-marks used for onset timing (see Fig. $1.2 \&$ 1.3). Arrival-times at WIZ were similarly unobtainable. For that period, that left WTZ, which, with sudden vanishings of the recorded trace, registered a multitude of impulsive arrivals that could of ten be timed only by referring to timing marks further along and across the seismogram. Fortuitously, the mainshock onset could be read to within a few trace widths for all but the White Island station (WIZ). About five hours of useful recording as a full array was then lost before comparative order returned. Even then, taken here as starting June $01^{\mathrm{d}} 00^{\mathrm{h}} 00^{\mathrm{m}}$, many small events were obscured by the recordings of larger aftershocks. Therefore a threshold to the size of the event to be analysed was set in addition to the previously stated requirements: a maximum peak-to-peak trace amplitude of $16 \mathrm{~mm}$ had to have been attained at either AWA or MAE, where that level was the threshold of signal clipping for the instruments in operation at those sites. Unobscured arrivals were mostly then non-emergent at all stations except WIZ, which was of relatively low magnification, and the reading of $S$ was usually possible for several stations for all except the very large aftershocks.

The events were further shared equally between two samples, on the basis of a random number assigned to each event. The first sample of events was destined for a full analysis, and the remainder for only those measurements of $S-P$, trace amplitude and signal duration contributing to an estimate of earthquake magnitude. A full set of observations was eventually compiled for an event in the latter sample, however, if a corresponding solution for the event had been published by the Observatory.

The above sampling scheme sufficed to establish the main features of the Matata sequence, and provided suitable data for additional analysis. To benefit the conditioning of the least-squares equations used in locating the sampled events, as many $S$ arrival-time readings as possible were included in the event solutions: an $S$ reading, when it is combined with the $P$ reading at a site, effectively constrains the event origin-time and the distance the hypocentre must be from the observing site. As only vertical-component seismograms were recorded, that objective was not always easy, especially if the microearthquake instruments had recorded at a saturated level. The picking of the $S$ onset was therefore often subtly distinguished by a change in frequency or an increased recording vigour. The reading of $P$, on the other hand, was comparatively straightforward. The quality of each arrival-time reading was assessed during the reading of arrival-onsets, according to the ambiguity of the picking of the onset, and whether or not the timing had to be interpolated or extrapolated from time marks other than those occurring within $60 \mathrm{~s}$ of the arrival. This a priori assessment of the reliability of an arrival-time, including the difficulty experienced in reading the onset, was used to weight the arrival-time in the solution.

For a selected event only the first arrival-times (of $P$ and $S$ ) were included when 
solving for the origin-time and hypocentre. The weight that was adopted for an $S$ time, or adopted for an $S-P$ interval, was never taken to be better than one quarter of that adopted for the best quality of $P$ time. Moreover, the azimuthal weighting (of stations by quadrant) option was not incorporated into the location algorithm, so that the weights that were assigned to the readings for the low gain White Island station (WIZ) were always commensurate with their real merit. The initial trial hypocentre was situated by default at a suitable depth near the earliest reporting station, such that first adjustments were usually to the epicentre; convergence then proceeded normally with adjustments to any combination of the four estimated focal parameters. However, if an arrival-time reading for $S$ from the worst quality of observational class ultimately attracted nil-weight under the Jeffreys downweighting of large residuals, the solution was entirely recomputed without that arrival-time being used in the solution. Of course, this procedure cannot ensure that correct choices for $S$ remained. Moreover, the uncertainty of the residuals, which are due to timing error and a component of the model traveltime error, may not truly have been twice that observed for the best quality of $P$ time, as was assumed in the relative variances. Some further problems with phase interpretation and with depth resolution nevertheless have important consequences when tracing directions of first motion back to the source region.

A strong $P$ arrival about $0.3 \mathrm{~s}$ after the first arrival was of ten recorded for the shallow earthquakes at the two westernmost stations of the temporary network, KA@ and $\mathrm{KAH}$, and frequently there was a similar pairing of $S$ arrivals. It is reasonable to take the earlier arrivals, given the epicentral distances, as having been critically refracted in a fast layer situated deeper than the source region, and to take the later, larger-amplitude arrivals as more direct-travelling phases. (At some closer epicentral distance, though, both phases should arrive simultaneously.) While such pairing of arrivals justified the inclusion of a refractor in the crustal model, and validated the assignment of refracted ray-paths for first-arrivals at the westernmost stations, the case was not so clear for several other stations that had refracted ray-paths assigned in the hypocentre solutions.

Trial hypocentres were started at a depth well below the refractor depth, and were usually placed above this velocity discontinuity in the model crust after a length-damped step; corresponding ray-paths to the stations were assigned by the algorithm in accordance with the computed focal depth and the hypocentral distances. Which of the alternative ray-paths were the more appropriate in any particular instance was not discernable from the appearance of the waveform given on seismograms for distant stations other than $\mathrm{KAO}$ or $\mathrm{KAH}$; such was the case for the outer stations of the eastern network, MAR and WAI, even when the epicentral distances were comparable. Some of the smaller events with less numerous arrival-times had insufficient control for the automatic step of trial hypocentre across the intracrustal boundary, and the hypocentral adjustments may therefore have finished prematurely. Suspect solutions were restarted on the opposite side of the velocity discontinuity, as is essential, and were finally 
accepted if a smaller standard error of residuals resulted. This procedure gave consistent results, although perhaps not always validly. Critically refracted arrivals may have added to the stability of a solution, by increasing the range of takeoff angles from the source, but the hypocentral errors, despite the ambiguity of ray-paths, still depend on the modelled velocities and the refractor depth.

Accurate earthquake location, as should be well known, requires that the velocity model be correct. Formal error estimates, relying on the arrival-time residuals having independently zero means and correctly weighted variances, are measures of the internal consistency of the readings and the solutions with respect to the assumed model, in the nonfulfilment of those statistical requirements. Notwithstanding this difficulty, an appraisal of solution quality could be made using the scheme intrinsic to the HYPO71 program; this scheme is reproduced in Table 2.2. Accordingly, the epicentres for the $B$ quality solutions could be described as good, and the focal depths as fair, but, for the preponderance of $C$ and $D$-quality solutions, the epicentres were otherwise no better than fair, and the focal depths poor. (No solution was of A-quality.) This situation was unavoidable, as it followed from the occurrence of most of the seismicity outside the network of observing stations. Good epicentre control requires that stations be evenly distributed about the epicentre, yielding a variety of departure azimuths from the source. Equally, good depth control requires a variety of takeoff angles, with at least some rays rising steeply to stations at an epicentral distance of less than twice the focal depth. These circumstances were not usually met for earthquakes of the Matata sequence, or for others analysed here, but the errors should still have been small enough that the general pattern of results emerges.

Table 2.2. Hypocentre quality classes, after Lee \& Lahr (1975). The quality of solution $Q$ is taken to be the average of a station distribution measure $(Q D)$ and a statistical error measure $(Q S)$, or the nearest lower category whenever that average is not a discrete level:

\begin{tabular}{lllllllll}
$Q D$ & NO & GAP $\left({ }^{\circ}\right)$ & DM & & QS & RMS $(\mathrm{s})$ & ERH $(\mathrm{km})$ & ERZ $(\mathrm{km})$ \\
\hline$A$ & $\geqslant 6$ & $\leqslant 90$ & $\leqslant Z$ or $5 \mathrm{~km}$ & & $A<0.15$ & $\leqslant 1.0$ & $\leqslant 2.0$ \\
$B$ & $\geqslant 6$ & $\leqslant 135$ & $\leqslant 2 Z$ or $10 \mathrm{~km}$ & & $B<0.30$ & $\leqslant 2.5$ & $\leqslant 5.0$ \\
$C$ & $\geqslant 6$ & $\leqslant 180$ & $\leqslant 50 \mathrm{~km}$ & & $C<0.50$ & $\leqslant 5.0$ & \\
$D$ & others & & $D$ others
\end{tabular}

wherein: NO $\equiv$ number of arrival-times used in the solution; GAP $\equiv$ largest angle subtended at the epicentre by contributing stations; DM $\equiv$ epicentral distance to the nearest seismograph; $\mathrm{Z} \equiv$ computed focal depth in kilometres; RMS $\equiv$ root-mean-square of (weighted) arrival-time residuals; ERH $\equiv$ root-sum-square of epicentral standard errors; and $E R Z \equiv$ the standard error of the focal depth. 


\section{Epicentres and depths}

The main epicentre maps, displayed in Figures 2.3 to 2.6 , are complete for shallow events of magnitude 1.8 and greater before the occurrence of the Matata sequence mainshock (Fig. $2.3 \&$ 2.4), and, for the later shown periods (Fig. $2.5 \& 2.6$ ), for events of magnitude 3.5 and above, together with about half of those down to and including magnitude 2.7, where (see later) the stated magnitudes are estimates of the Richter local magnitude, $M_{l}$. (Epicentres for the few earthquakes originating outside the region of Fig. 2.3 were included in Fig. 1.1.) Seismicity before the Matata sequence mainshock is dealt with first, and initially that south of the Bay of Plenty shoreline.

Shallow activity for the first three-day interval (Fig. 2.3) was minor, and rather dispersed, with no events greater than magnitude 2.4 , and with only three earthquake origins spatially close and within an hour of each other; this relative quiescence contrasted with the activity of the succeeding interval (Fig. 2.4), which leads up to the Matata mainshock occurrence. Activity during this latter interval occurred near Kawerau, and then further to the northeast near Te Teko, but lasted at each site for less than a day. The magnitude 3.2 earthquake of May $29^{\mathrm{d}} 18^{\mathrm{h}} 38^{\mathrm{m}}$ was the largest of these events, occurring near Kawerau, where it was felt. That earthquake was cited in the N.Z. Seismological Report as a possible foreshock to the Matata mainshock, but the epicentre (77/314) appears to have been mislocated by more than $30 \mathrm{~km}$, largely as a result of the observations that were made for the White Island station (WIZ). (The earlier, magnitude 4.1 earthquake of May $22^{\mathrm{d}} 15^{\mathrm{h}} 23^{\mathrm{m}}(77 / 294$, not reported felt) is a better candidate for a foreshock.) The activity detected may be characteristic of that known to frequent the district (e.g., Eiby, 1966a), and can be considered to belong to the Matata sequence of earthquakes only if related to the Matata mainshock.

Members of the Matata earthquake sequence are herein defined to be those earthquakes shown as originating within $15 \mathrm{~km}$ of the mainshock focus (Fig. 2.4). Events so qualifying near the mainshock position, and occurring ahead of the mainshock origin-time, were present from the start of temporary network coverage, were situated near the early centre of aftershocks, and included the magnitude 2.5 earthquake of May $31^{\mathrm{d}} 09^{\mathrm{h}} 19^{\mathrm{m}}$ and the magnitude 3.1 earthquake of May $31^{\mathrm{d}} 16^{\mathrm{h}} 43^{\mathrm{m}}$, each of which was followed by a smaller earthquake of magnitude 1.4. Merely for preceding the principal earthquake and occurring within the region occupied by the aftershocks might all these earthquakes be referred to as foreshocks of the Matata sequence, although Smith (1981) has formulated a wider definition for foreshocks of New Zealand mainshocks. In all, 23 foreshocks were detected using the temporary network of seismographs, 13 of them of magnitude 1.8 or greater, with the last, the magnitude 2.0 earthquake of May $31^{\mathrm{d}} 17^{\mathrm{h}} 55^{\mathrm{m}}$, occurring less than an hour before the mainshock (77/317).

Aftershock epicentres for events sampled from the first six days in June (Fig. 2.5 \& 2.6) delimit an area $7 \mathrm{~km}$ by $15 \mathrm{~km}$, elongated in the east-west direction, with the 


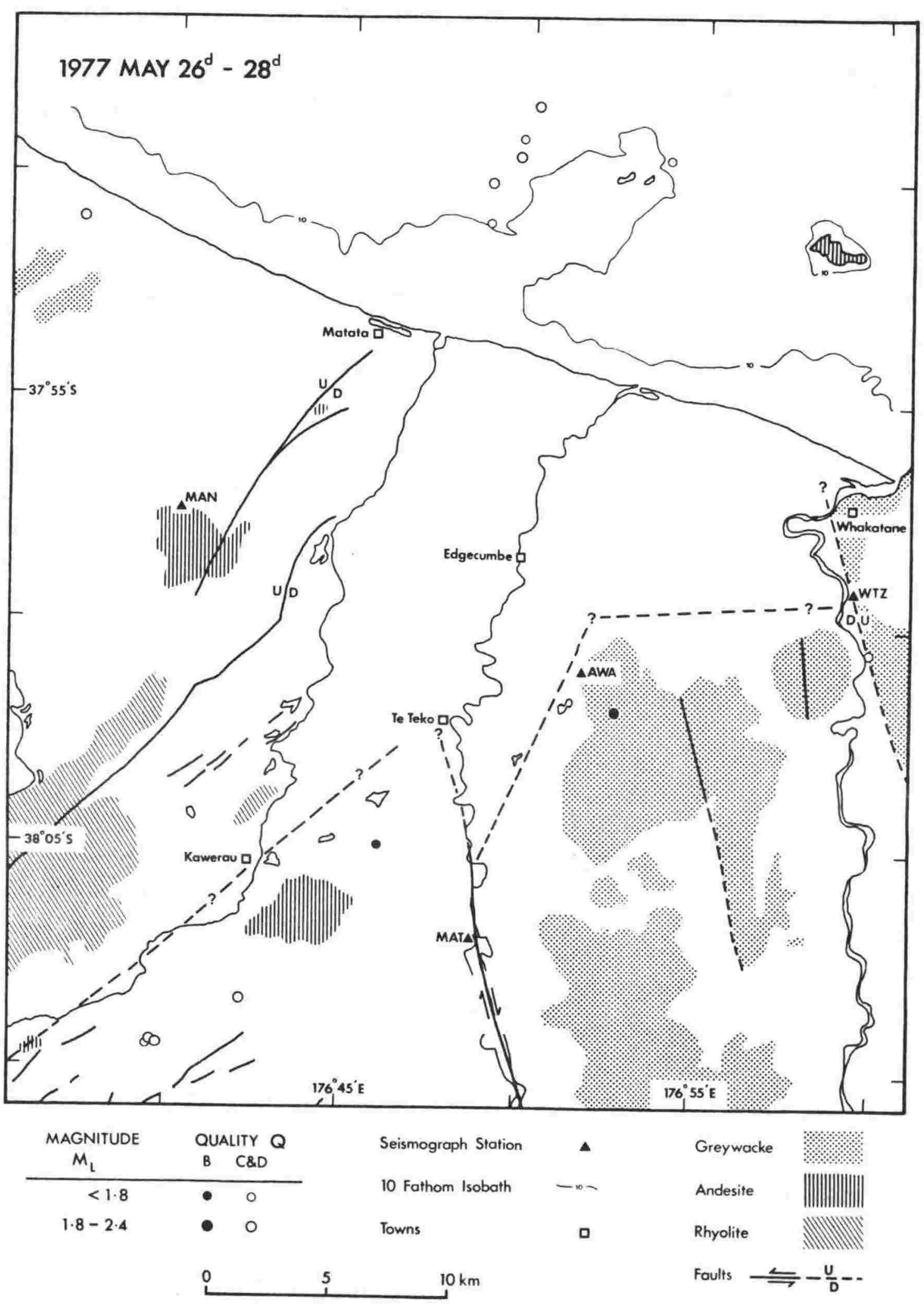

Figure 2.3. Epicentres of shallow events for the three-day period starting May $26^{\mathrm{d}} 00^{\mathrm{h}}$.

centre given approximately by the epicentres that were found for the early aftershocks, whic' included the largest, the magnitude 4.7 earthquake of June $01^{\mathrm{d}} 17^{\mathrm{h}} 07^{\mathrm{m}}(77 / 332)$. Earlier large aftershocks, originating near the centre of the source region, included the magnitude 3.6 earthquakes of June $01^{\mathrm{d}} 00^{\mathrm{h}} 07^{\mathrm{m}}(77 / 325)$ and June $01^{\mathrm{d}} 03^{\mathrm{h}} 22^{\mathrm{m}}(77 / 326)$. 


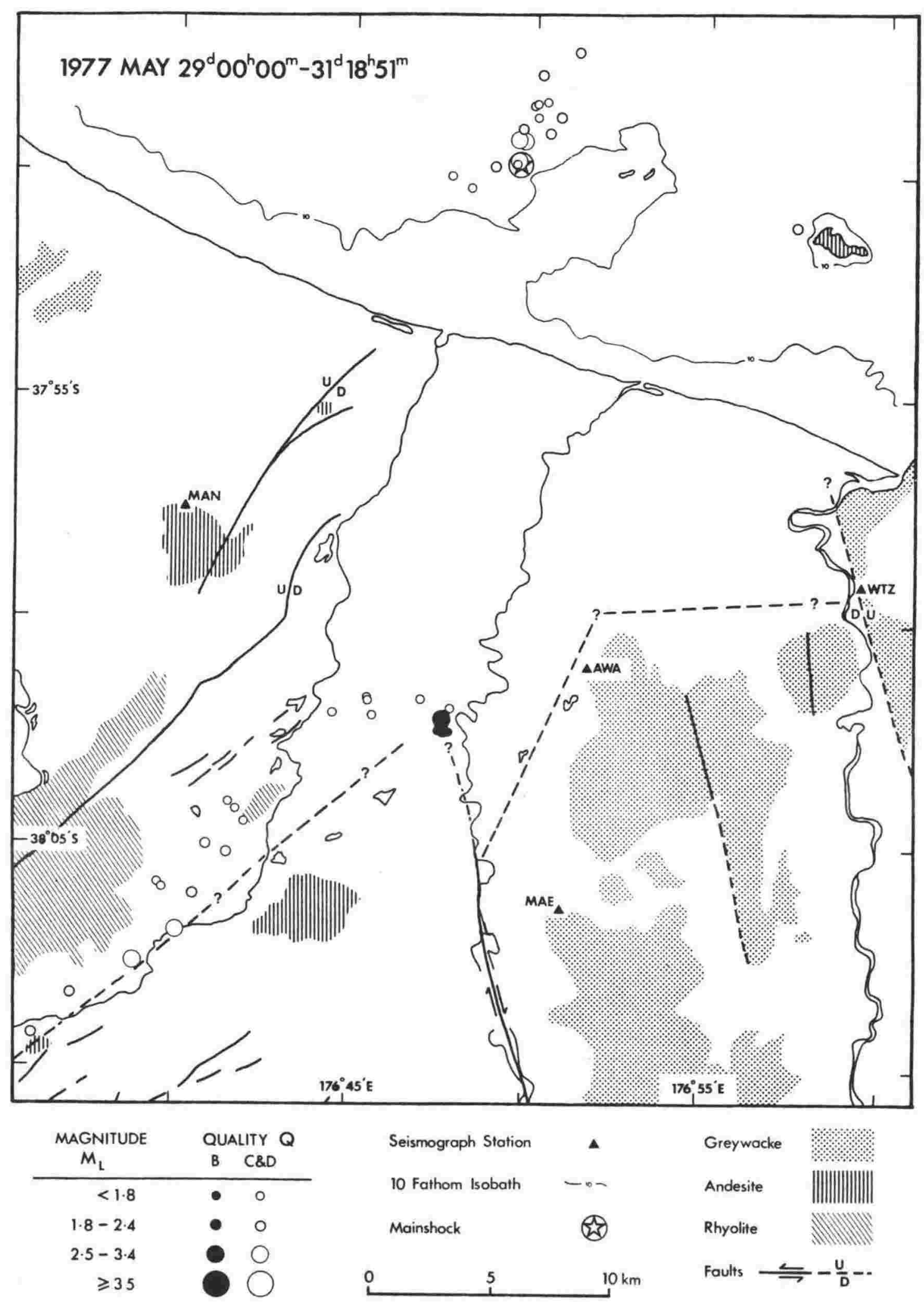

Figure 2.4. Epicentres of later events leading up to the Matata sequence mainshock.

Later aftershocks, originating towards the eastern side of the region, featured the magnitude 4.3 earthquake of June $03^{\mathrm{d}} 11^{\mathrm{h}} 40^{\mathrm{m}}$ (77/345), which was soon followed by the magnitude 3.8 earthquake of June $03^{\mathrm{d}} 11^{\mathrm{h}} 54^{\mathrm{m}}$ (77/346) together with many smaller aftershocks (see Fig. 1.3). In contrast, the magnitude 3.9 earthquake of June 


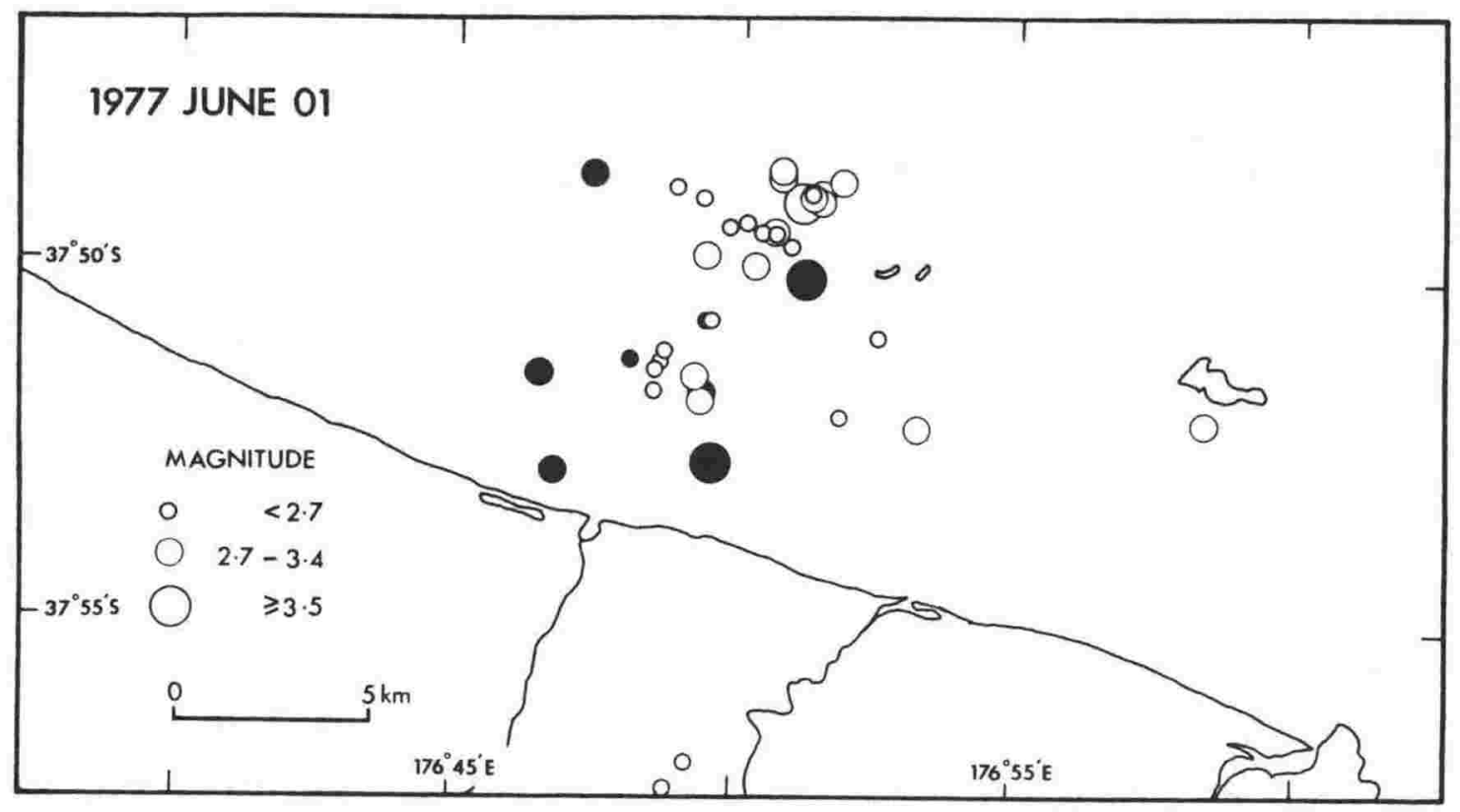

1977 JUNE 02
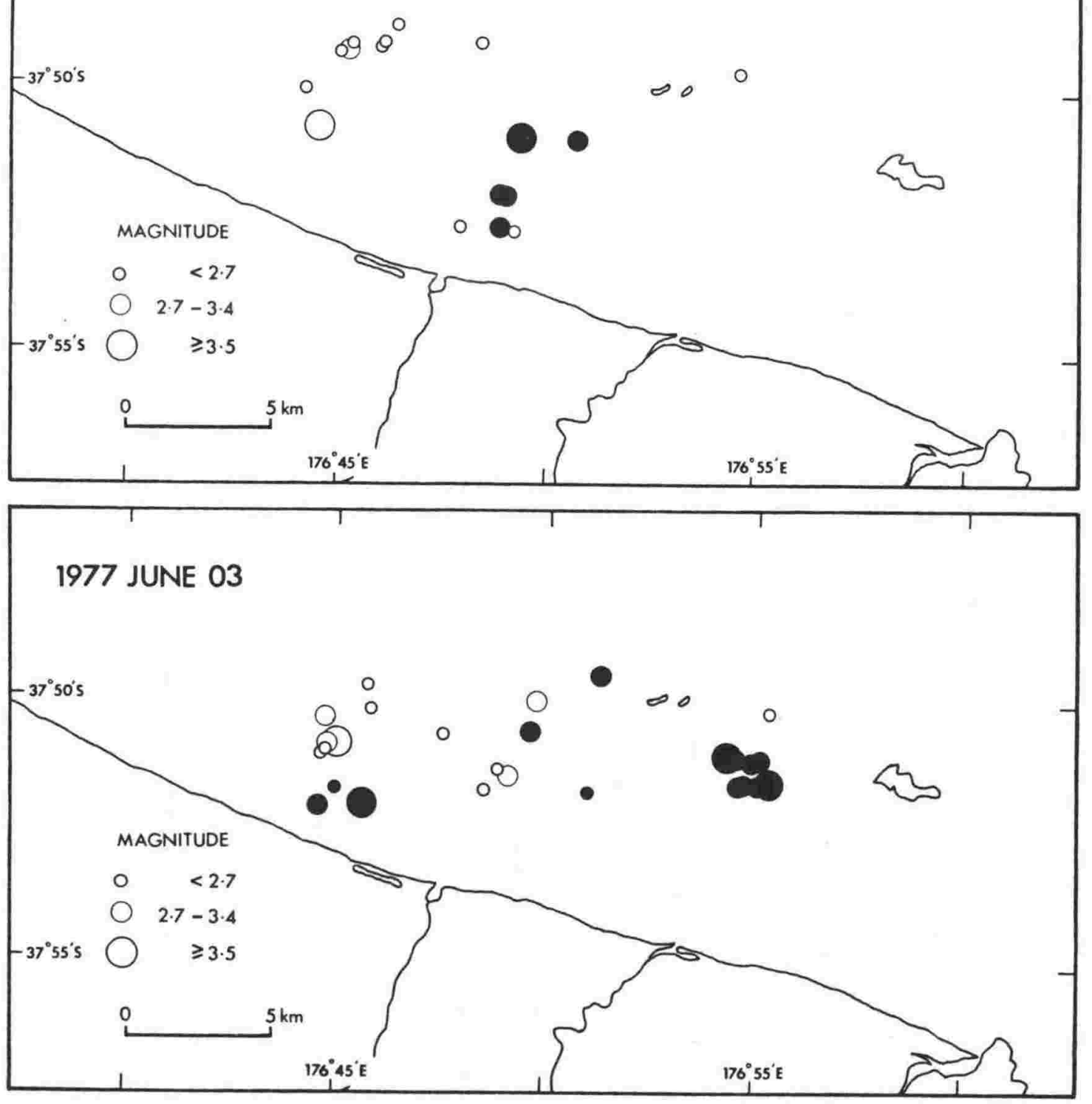

Figure 2.5. Aftershock epicentres obtained for the first three days of June, 1977. Solid symbols denote $B$-quality solutions. 

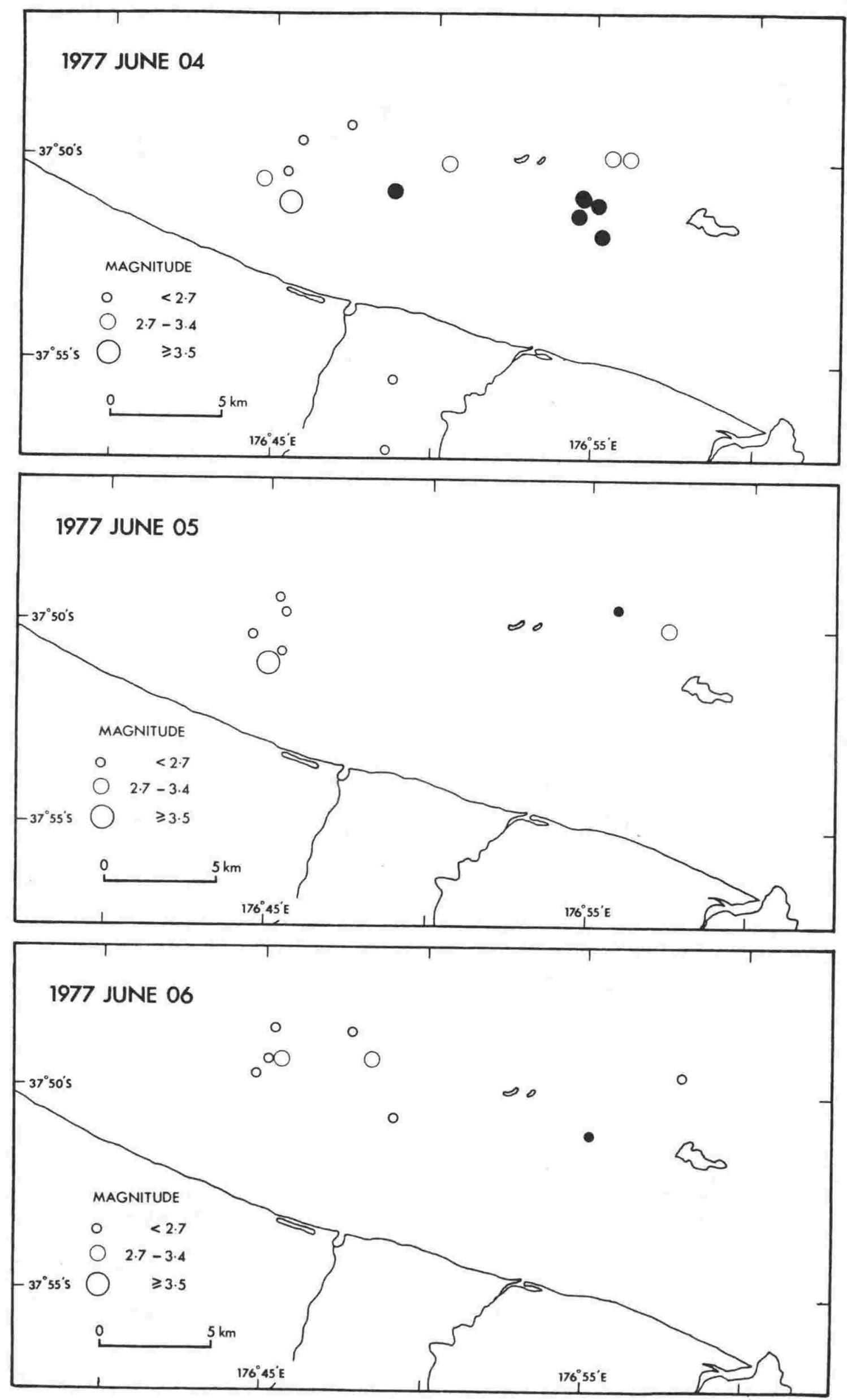

Figure 2.6. Subsequent epicentres for aftershocks from the last three days of sampling. Symbols are as for Fig. 2.5. 
$04^{\mathrm{d}} 07^{\mathrm{h}} 36^{\mathrm{m}}(77 / 349)$, the largest aftershock originating in the western side of the source region, was followed by the magnitude 3.5 earthquake of June $05^{\mathrm{d}} 15^{\mathrm{h}} 33^{\mathrm{m}}(77 / 356)$, along with several other aftershocks of much smaller magnitude, but, notably, they were preceded there by three earthquakes above magnitude 3.5 : the magnitude 3.6 earthquakes of June $02^{\mathrm{d}} 20^{\mathrm{h}} 58^{\mathrm{m}}(77 / 341)$ and June $03^{\mathrm{d}} 07^{\mathrm{h}} 17^{\mathrm{m}}(77 / 343)$; and the magnitude 3.7 earthquake of June $03^{\mathrm{d}} 09^{\mathrm{h}} 23^{\mathrm{m}}$ (77/344). The magnitude 3.5 earthquake of June $02^{\mathrm{d}} 03^{\mathrm{h}} 03^{\mathrm{m}}(77 / 336)$ was the last of the larger aftershocks originating near the centre of the aftershock region; few aftershocks originated near there after June $04^{\mathrm{d}} 00^{\mathrm{h}}$.

Calculated depths, corresponding to the epicentres in Figures 2.3 to 2.6, are indicated in Figure 2.7, showing that most of the seismicity was limited to the upper crust. Depths computed for the aftershocks (Fig. 2.7a), for all categories of hypocentre quality, fell predominantly within a $5 \mathrm{~km}$ range, from $7 \mathrm{~km}$ to $12 \mathrm{~km}$, although there may really have been little between those categories. For an aftershock solution to have been of $B$-quality (Table 2.2) there must have been an arrival-time observation included for the station WIZ (and this generally excludes the smaller events), but other solutions with an arrival-time observed for WIZ may have failed to meet the better azimuthal bound. Similarly, northern hypocentres may have failed on the judgement of better depth control. The foreshocks and the other early earthquakes originated mostly at about $10 \mathrm{~km}$ depth (Fig. $2.7 \mathrm{~b} \& 2.7 \mathrm{c}$ ), but some of them apparently originated at depths greater than assigned for the aftershocks. The ideal of observations for a site near the epicentre as well as observations of critically refracted arrivals for more distant stations was rarely achieved for the smaller earthquakes. Hence the deeper depths may have been vagaries of the location process. Conversely, some origins placed at shallow depths may actually have been deeper, since shallow depths can result from undetected mistakes in the observed arrival-times.

An attempt was made to determine hypocentres for the larger events occurring in the five or so hours immediately after the mainshock; the NZ. Seismological Report gave solutions for the seven earthquakes of magnitude 3.5 and above, which included the magnitude 4.0 earthquake of May $31^{\mathrm{d}} 18^{\mathrm{h}} 59^{\mathrm{m}}(77 / 318)$ and the magnitude 4.3 earthquake of May $31^{\mathrm{d}} 19^{\mathrm{h}} 26^{\mathrm{m}}(77 / 321)$. (Several of these Observatory solutions were poorly determined by Observatory standards.) However, of the solutions found, using a minimum of a $P$ arrival-time at WTZ and outlying stations of the western network (LRO, KAO \& KAH), all but one failed to match the standard set by the better recorded events, and this was also the case when the solutions were restrained at depths suggested (Fig. 2.7) as appropriate for members of the Matata sequence. Nevertheless, it seems (from $S-P$ intervals for smaller aftershocks) that these very early aftershocks must have originated near the centre of the aftershock source region rather than near the eastern and western margins.

Epicentres for earthquakes further removed from the centre of the temporary seismograph network were shown in Figure 1.1. (No explicit claim is made for their 
Number of earthquakes

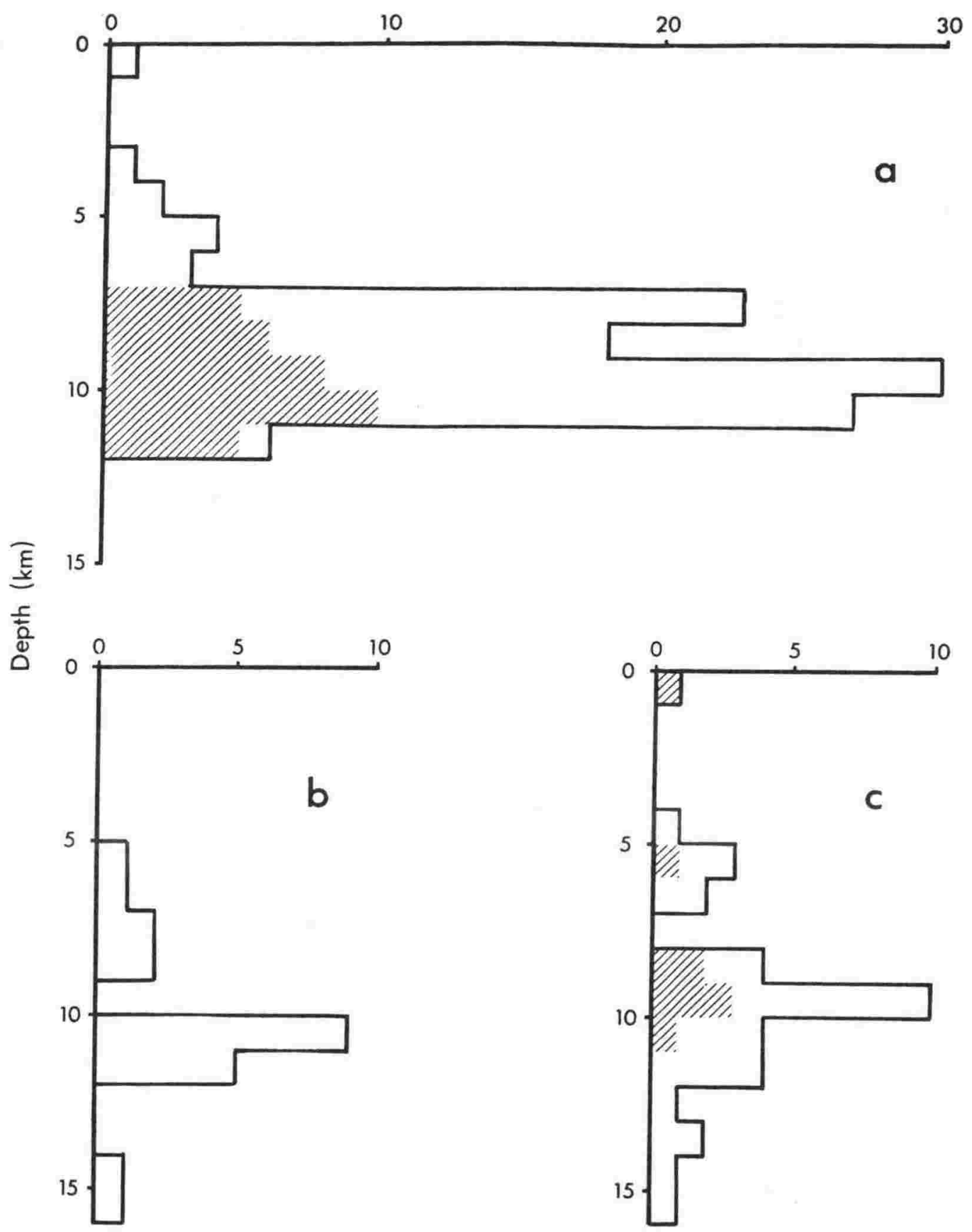

Figure 2.7. Distributions of computed focal depths for (a) aftershocks, (b) foreshocks and (c) all other shallow events shown in Fig. $2.3 \& 2.4$. Numbers of B-quality solutions are shaded.

completeness above a magnitude threshold.) A compact grouping was prominent southeast of the eastern network. Seven events occurring there, with computed focal depths near $50 \mathrm{~km}$, fell within the various sampling designs, two of them antecedent to the magnitude 4.4 mainshock of June $02^{\mathrm{d}} 13^{\mathrm{h}} 17^{\mathrm{m}}$ and the magnitude 3.8 earthquake of June $02^{\mathrm{d}} 13^{\mathrm{h}} 46^{\mathrm{m}}$. The Observatory solutions for these two larger earthquakes 
$(77 / 339,340)$ had focal depths restricted at $12 \mathrm{~km}$, and placed the epicentres almost $20 \mathrm{~km}$ farther to the west (see Fig. 1.1), more than twice the formal standard errors in longitude for the less precise set of solutions. It is perhaps surprising that this difference in hypocentre estimation occurred where there was the closest spacing of standard network stations (though neither of the solution sets is necessarily accurate). These subcrustal earthquakes constituted a sequence in their own right, with the two earlier events, the magnitude 2.7 earthquake of May $28^{\mathrm{d}} 18^{\mathrm{h}} 40^{\mathrm{m}}$ and the magnitude 2.2 earthquake of May $29^{\mathrm{d}} 01^{\mathrm{h}} 11^{\mathrm{m}}$, notable as foreshocks. Although seismograms were not specially scanned for other members amongst the more prominent Matata sequence aftershocks, to extend their number and to supplement the other two subcrustal events placed at around $70 \mathrm{~km}$ depth, three additional earthquakes were recognisable, from their waveforms and $S-P$ intervals, as aftershocks of the subcrustal mainshock. This association of events conflicts with the view (e.g., Evison, 1970; Robinson et al., 1976) that well developed aftershock sequences occur only at shallow depths.

The pattern of seismicity in the Bay of Plenty region during the 1977 microearthquake survey thus seems to have been one of some complexity, but with the Matata sequence of earthquakes by far the most prominent feature of the activity. Furthermore, more detail of apparent concentration and migration of activity is available than could be ascertained from the less precise standard network observations, at a higher threshold of earthquake magnitude (e.g., Fig. 1.1), or than could be deduced from variation in $S-P$ interval at a solitary nearby seismograph, for earthquakes down to a lower magnitude threshold. According to Bath's law (Richter, 1958: p.69) the difference between the mainshock magnitude and the magnitude of the largest aftershock is usually 1.2 , but here there were three aftershock occurrences within that span of magnitude, which possibly foreshadows a swarm-like aspect of the Matata sequence. A swarm of earthquakes, for example, is commonly considered to consist of a series of events of similar size, but with none of them outstanding. Any similarity of the Matata sequence with the 1976 sequence of earthquakes near Te Puke, however, stops with the observation that the largest earthquake there (76/970) came late in the sequence, just as it had previously (e.g., Eiby, 1966a).

The $15 \mathrm{~km}$ linear extent for the aftershock region of the Matata sequence is larger than the $8 \mathrm{~km}$ that is predicted by extrapolating down from the relationship, $\log D=0.5 M-1.8$, of Utsu (1961), which relates linear dimension, $D$ (in kilometres), to mainshock magnitude, $M$. This large linear dimension, in relation to the small indicated depth range (Fig. 2.7a), suggests the Matata sequence aftershocks originated in a flat, plate-like volume, of horizontal extent several times the thickness. A similar statement was made for early aftershocks of the large Inangahua, New Zealand, earthquake of 1968 (Adams \& Lowry, 1971), although a subsequent study of later micro-aftershocks, occurring 3.6 years after that magnitude 7.1 mainshock (Robinson et al., 1975), indicated a similar volume, but with less flatness, suggesting that depth control for the early aftershock hypocentres may have been poor. Thus a restricted range of computed 
focal depths may have been an artefact of the location model and process there (regardless of any contrivance that might be used for assigning depth in accordance with time residual at a close seismograph) just as it may have been also for the Matata sequence earthquakes.

- Despite clustering for the Matata sequence aftershocks (Fig. $2.5 \&$ 2.6), no relationship to faulting was immediately obvious, other than that which could perhaps be inferred from the east-west elongation of the aftershock source region: the aftershock epicentres were not closely relatable with the known or inferred faulting, either in the Mesozoic greywacke terrain or in the active volcanic region. Similarly, and in spite of the northeast trend roughly parallel to the volcanic front, the early activity in the vicinity of Kawerau, apart from the tight concentration near Te Teko, lay just as much away from as on the mapped fault traces (Fig. $2.3 \&$ 2.4). The relationship to faulting at depth, if any, may not have been simple, of course, and must be determined by other means (including adequate account of fault dip). Moreover, the errors of location will have to be carefully considered, to see if the aftershock source region indeed had some breadth. In particular, the apparent northeast-southwest scatter of epicentres, for the foreshock and aftershock clusters, could have resulted merely from the missing arrival-time observations (for the smaller earthquakes) at the remote station to the northeast (WIZ) and missing $S$ arrival-readings (for the larger events) at the nearer seismographs, situated along the Bay of Plenty coast. 


\section{Poisson's ratio in the Central Volcanic Region}

Foreshocks may be easy to identify with the benefit of hindsight, but their identification in advance of an impending mainshock is another matter. Several different phenomena, however, have shown promise towards the important goal of prediction in seismology. The Matata earthquake sequence and the adjacent array of seismographs in the Bay of Plenty region affords an opportunity to test whether any seismic forerunners to the Matata mainshock could have been recognised as such. The phenomenon investigated here (in some detail) involves variation in seismic velocity.

\section{Search for a precursory velocity-ratio anomaly}

Early accounts (e.g., Savarensky, 1968; Semenov, 1969; Aggarwal et al., 1973; Whitcomb et al., 1973) indicated periods of low values either in compressional velocity or in the ratio of compressional velocity to shear velocity before the occurrence of earthquakes of small and moderate magnitude; the low values also defined an anomalous region with respect to the surrounding country, near where the principal earthquake eventually occurred. These observations have been attributed to a process embracing rock dilatancy and fluid flow (Nur, 1972). In light of reports of conditions returning to normal when the main earthquake was imminent, and of sizes of anomalous regions exceeding a "fault-length" in dimension, it seems the circumstances for the Matata earthquake sequence are suited to investigation of similar premonitory behaviour.

The most appropriate method of determining velocity ratio (using a set of closely spaced seismograph stations) is to plot observed $S-P$ arrival-intervals against the $P$ arrival-times for each earthquake. If the ratio of the bodywave velocities, $\gamma=\alpha / \beta$, is constant for media along the ray-paths, then this Wadati diagram, as it is referred to, yields a straight line with gradient $\gamma-1$, and the intercept on the $P$ arrival-time axis yields the origin-time for the earthquake. This simple technique has the major advantage that values of velocity ratio are independent of errors of earthquake location and travel-time model. Temporal variations can then be studied by graphing the slope results against time; spatial variations may also be studied by surveying regions for differences in velocity ratio, but here, with the approximate region of the mainshock already known, the initial concern was one of determining if there was any sign of the return to normality.

Estimates of velocity ratio were calculated for Matata sequence foreshocks from Wadati diagram data, using a least-squares method which assumed that uncertainties could be ascribed equally to measurements of the ordinate variable $(S-P)$. Many low values of velocity ratio were indeed noted. As a measure of the regular velocity ratio was required in order to demonstrate a temporal trend, the analysis was extended to the aftershocks, although Semenov (1969) had indicated chaotic variation after some events. A sample of the values that were obtained is shown in Figure 3.1; from such 


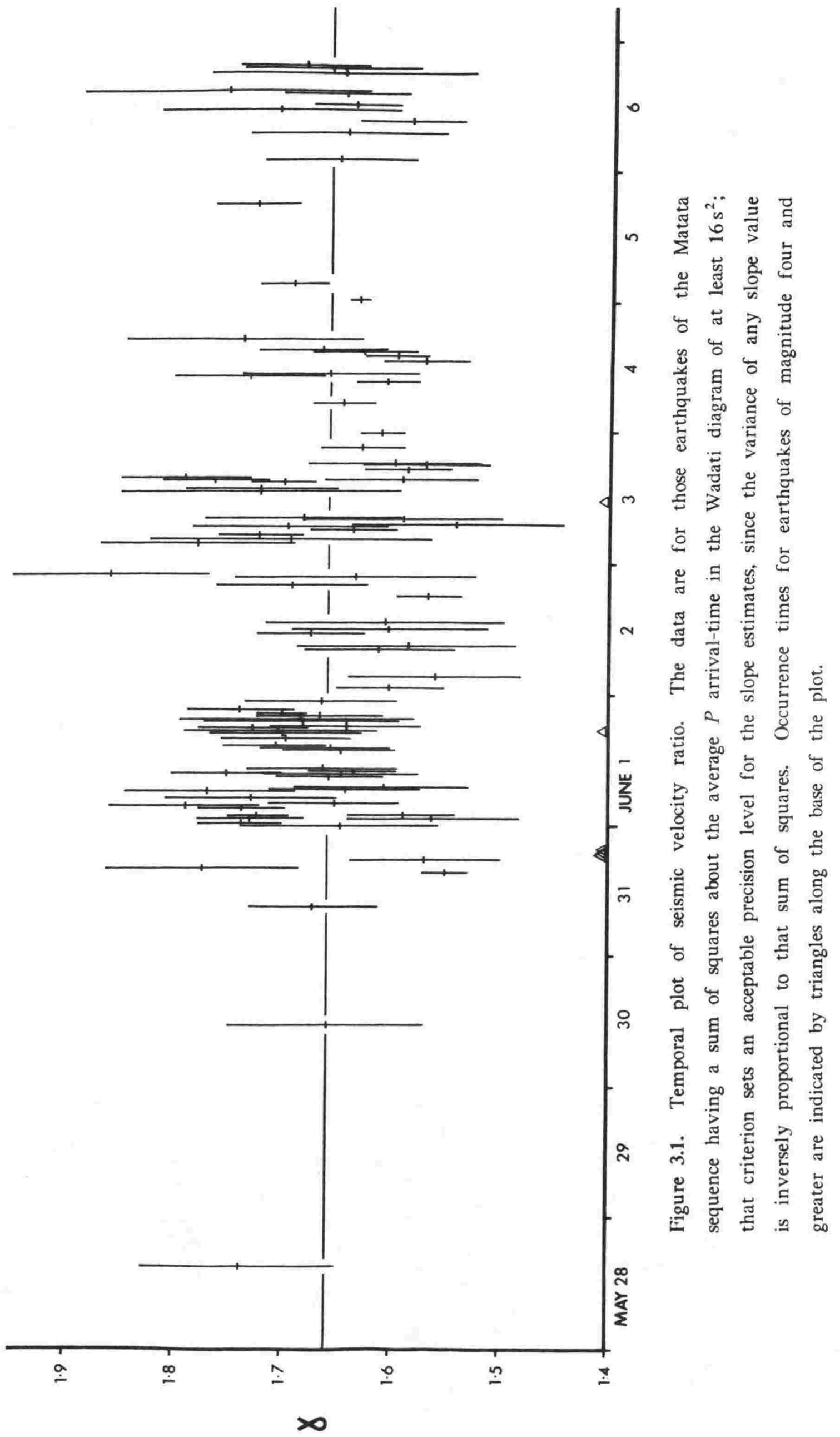


a plot it is customary to elicit a temporal correlation between low values of velocity ratio and the later occurrence of large earthquakes, and a similar trend might be discerned for a later aftershock, if conditions were favourable. Formally, suitable procedures exist as a case of testing a linear hypothesis (e.g., Seber, 1977: p. 198), if the variance of observations about each regression is common, or is known, and if, for the purposes of significance testing, those errors have a normal distribution. In spite of a negative result, in that Wadati diagram parallelism was not rejected, the figure of $0.38 \mathrm{~s}$ was a disappointing value for the average observational error, estimated from the variation about the least-squares regression lines and from the statistically independent variation between slopes (by classical analysis-of-variance with 566 and 89 degrees of freedom respectively). Further analysis was needed to reconcile this result, especially considering that it was the $S$ timing-errors that were expected to have been dominant.

Twenty-three earthquakes were well recorded by virtue of having at least ten data points compose their Wadati diagrams; nondescript arrivals precluded use of a more uniform sample. The assumption was that the $S-P$ interval errors for any $P$ time should have had zero expectation. It appears from Figure 3.2, which depicts the average $S-P$ residuals accruing to the stations for that subset of Matata sequence earthquakes, that this assumption may have been invalid. In that presentation, the general validity of which derives from the comparative source region and seismograph network dimensions, and their relative dispositions, the zero-residual line can be thought of as the regression line that is fitted to the Wadati diagram data but rotated away from the uncommon origin-time intercepts. This generalised Wadati diagram thus emphasises the residuals rather than the actual arrival-time intervals. The two stations furthermost above the line, MAR and WAI, were readily partitioned, and the slope that was estimated from the Wadati diagrams without their contribution was less than that obtained when they were included, with the sample standard deviation of the slope differences about the 0.036 average being 0.030 . That difference in slope was highly significant ( $t=5.8,22$ degrees of freedom), using the uniformly powerful test for paired observations, and requiring only that the slope differences had an approximately normal distribution. Therefore, since the least-squares estimator of Wadati-diagram slope produced biased estimates, the velocity ratio could not be taken as uniform, and this non-uniformity may have led to the large excursions in Figure 3.1, in accord with whichever stations were used in determining individual values of Wadati diagram slope. That estimates of earthquake origin-time may also have been biased follows directly.

The suspicion was that the results were somehow affected by azimuth of path from the source region. When full sets of data from the temporary seismograph networks on either side of the volcanic front were used in Wadati diagrams, each station set internally having similar instrumentation and timing arrangements, 17 estimates of velocity ratio were obtained for the western network. Then the average ratio was 1.608 , with a sample standard deviation of 0.086 about that average. 


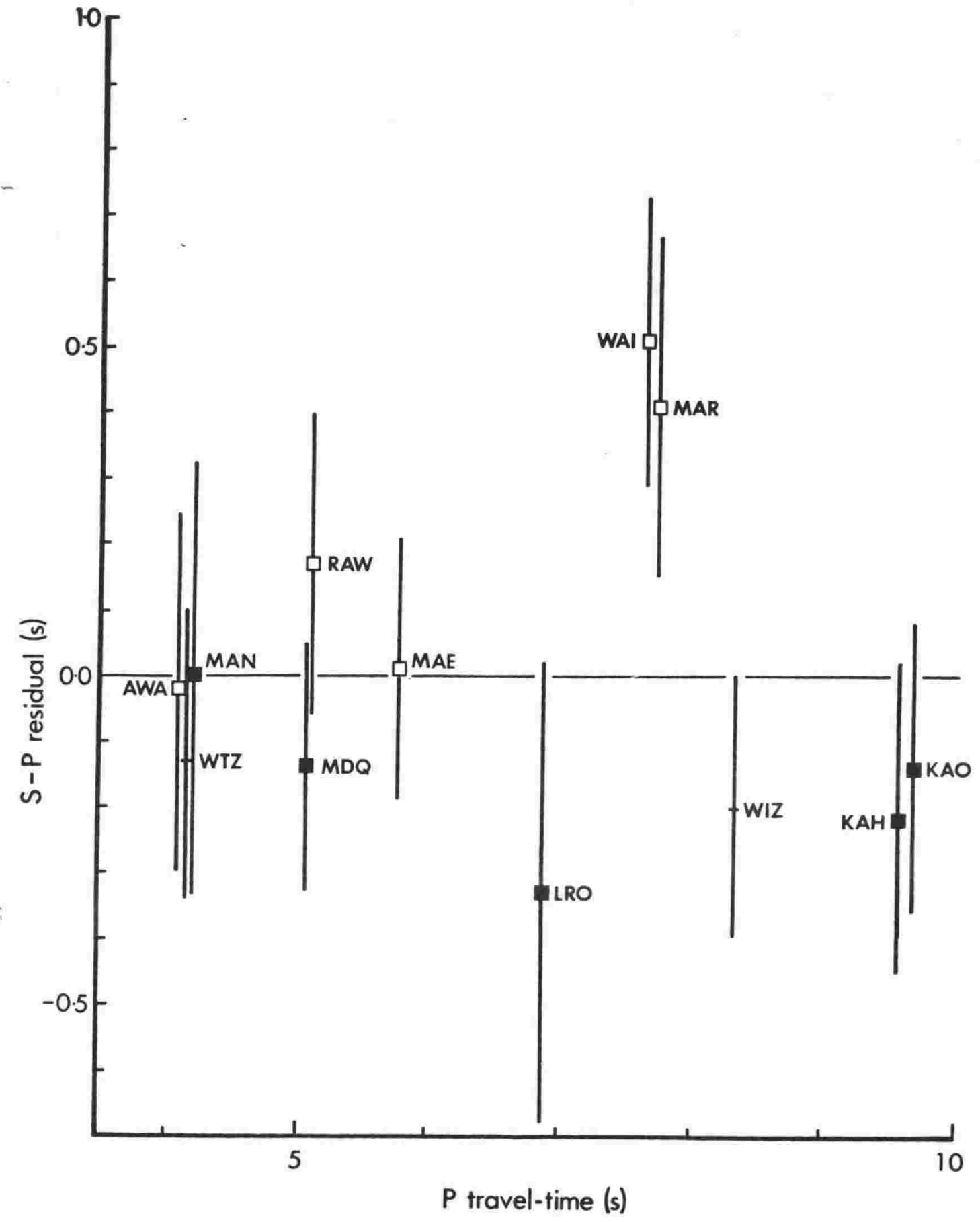

Figure 3.2. Wadati diagram residuals suggesting irregularity of velocity ratio, $\gamma$. The average $S-P$ residual (observed-minus-calculated) from the subset of 23 Wadati diagrams for well recorded earthquakes is here plotted by station against the average $P$ traveltime determined in the HYPO71 solutions. The error bars denote standard deviations of residuals about the station averages, with solid, square symbols indicating western network data. The zero-residual line represents $\gamma=1.65$.

Likewise, 28 estimates were obtained for the eastern network, giving an average ratio of 1.770 and a sample standard deviation of 0.082 . These figures too yielded a significant difference in slope estimate, irrespective of whether the underlying population variances were the same or not (as given by the test of Welch (1947); $t=6.2,33$ degrees of 
freedom), except that a correct subdivision of stations may not have been made, and the assumed uniformity of velocity ratio may no longer have held anywhere.

Low values of velocity ratio occur, under the dilatancy-diffusion model for earthquake generation, when microcracks, opening within the rock due to increasing stress, are partially devoid of groundwater until later, before the main earthquake occurs, when the velocity ratio returns to a more normal value, because inflow of water into the anomalous region fills the vacant pore spaces. However, here it seems that a large region to the west remained in a substantially different state to that to the east, after the principal earthquake had occurred. Poisson's ratio, $v$, is the fundamental quantity in elasticity theory that determines the velocity ratio:

$$
\frac{\alpha^{2}}{\beta^{2}}=\gamma^{2}=\frac{2(1-v)}{1-2 v}
$$

Values of Poisson's ratio corresponding to the given velocity ratios are $v=0.19 \pm 0.01$ for the western network and $y=0.27 \pm 0.01$ for the eastern network. It may be that differences in Poisson's ratio reflect contrasting rock types or other conditions either side of the volcanic front.

\section{The Central Volcanic Region}

Two competing structural models have been proposed for the central North Island volcanic region. The average heat flow in the active volcanic belt, at about $0.8 \mathrm{~W} / \mathrm{m}^{2}$, is about 20 times the typical continental amount (Studt \& Thompson, 1969). Mast of this natural heat output occurs convectively in highly active hydrothermal fields, but zero and near-zero values elsewhere in the region are attributable to a downward flow of groundwater that naturally recharges the hydrothermal systems. Localised bodies of molten magma at about $10 \mathrm{~km}$ depth have been postulated (e.g., Grindley, 1960) to account for the volcanism and the hydrothermal activity, such as that found at the economically important Wairakei geothermal area, which is situated about $80 \mathrm{~km}$ southwest of MtEdgecumbe along the active volcanic front, and is inferred to be as much as 0.5 million years in age on geological grounds (Grindley, 1965). In this model - the batholith model - extensive but isolated intrusions of igneous material into pre-existing crustal rocks are the norm, and older, upper-crustal rocks, exposed as Mesozoic greywacke on the flanks, underlie the whole of the volcanic region, except where replaced by the intrusive materials (e.g., Healy, 1961). Calhaem (1973) suggested, however, primarily from the apparent southeastward migration of volcanism (Kear, 1959; Healy, 1964), that intrusion and rifting along the volcanic front has essentially created new crust within the Central Volcanic Region; Evison et al. (1976) similarly inferred a thinner and younger magma crust towards the southeast, in order to explain the shallow seismicity in the vicinity of Wairakei. Proponents of this latter model - the spreading model - recognise andesite to be first in the volcanic sequence (e.g., Thompson, 1964), and submit hat andesite or dioritic rocks should 
underlie the cover of acid volcanics, instead of the Mesozoic greywacke of the other model. For both models, it may be from partial melting of greywacke or similar rock that the rhyolites and the ignimbrites have been formed (Ewart \& Stipp, 1968). Swarms of earthquakes in the volcanic belt have been envisaged as due to thermal contraction (Evison et al., 1976).

An experiment conducted in the Wairakei region (Robinson et al., 1981) to discriminate between the two modes of emplacement was inconclusive. Travel-time residuals of $P$ from local mantle-zone earthquakes were investigated, wherein relative delays of 1-2s were sought for anomalous volumes that were expected to be confined to crustal depths. Anomalies of that amount seem to be rather optimistic, considering the small travel-times for near-vertical passage through ordinary crust, but the absence of such delays is not indicative of a preference for either of the models, especially since effects due to both deeper structures and the near-surface site corrections need to be accurately taken into account, together with thermal and compositional effects that may occur at any level. Furthermore, no significant $S$ attenuation attributable to volumes of melt or partial melt at shallow depths could be demonstrated. (Note, however, other claims made for the limited data obtained during that experiment (e.g., Grindley \& Hull, 1986: p. 148).)

The matter of structure is not resolved by gravity methods, which require that mass anomaly distributions be correctly specified. Most interpretations of residual anomalies (e.g., Modriniak \& Studt, 1959; Rogan, 1982) have been in terms of depth to basement, with basement relief given by block-faulted structures and infilled collapse structures, by assuming a density contrast of $-0.5 \mathrm{Mg} / \mathrm{m}^{3}$ for the few kilometres of volcanic overburden with respect to some basement lithology. The problem of defining the regional anomaly field is in itself not trivial, and the regional has usually been determined from outcrops of greywacke adjoining the Central Volcanic Region, or has sometimes been corrected for points at the southeastern margin by way of drillhole density data (e.g., Stern, 1979). Moreover, density measurements for cores from the drillholes show that hydrothermal alteration causes lateral density variation within individual rock units (Hochstein \& Hunt, 1970; Stern, 1986), the effect of which might otherwise be incorrectly interpreted as basement relief. Thus there is already enough difficulty in mapping structures within the volcanic cover, quite apart from the difficulty in detecting a body of magma, or an associated fault system deeper within the crust. Nevertheless, a general association between geothermal heat-flow, rhyolitic intrusions and basement faulting has been made for the Kawerau district (Studt, 1958). Similarly, magnetic anomalies from deeper sources are masked by near-surface variations in magnetisation (Hochstein \& Hunt, 1970; Rogan, 1982).

Surface-wave dispersion indicated the average New Zealand crust to be of continental type (Thomson \& Evison, 1962), but the technique lacks the resolution that is needed to elucidate the structure over such a small part of the wave guide as may be involved for the volcanic region. Drillholes, mainly situated along the southeastern 
margin in order to tap the resources of the presently active hydrothermal areas, have been too shallow to resolve the question of overall structure, and may have terminated either in greywacke, possibly spalled from the margin, or in volcanic rock, of various lithology and degree of hydrothermal alteration. Neither gravity methods nor seismic methods have been useful for tracing structural details across the margin, the main difficulties with the seismic methods being the severely attenuated phase-arrivals, and the poor correlations of refracted and reflected phases (Hochstein \& Hunt, 1970).

Thus, through incorporating $S$ data, Poisson's ratio may help to distinguish between the two types of basement for the volcanic region, where this has been difficult to resolve by the usual geophysical means, because of the similarity and overlap of densities and compressional velocities for andesite and dioritic rocks with those for Mesozoi greywacke (grading to schist), such as found in the eastern North Island ranges. Poisson's ratio is itself variable, depending on the amount and the nature of the porosity (e.g., O'Connell \& Budiansky, 1974, 1977; Hyndman, 1979), though notably low ratios have been observed for glassy rocks and for quartz (e.g., Birch, 1966; Ukawa \& Fukao, 1981). Low values of velocity ratio are unlikely to result from purely a temperature effect, because the compressional and shear velocities both vary, leaving the ratio relatively unchanged (e.g., Kern \& Richter, 1981), or to result from the presence of a molten fraction, because the ratio $(\alpha / \beta)$ then tends to increase as both velocities decrease (e.g., Murase \& McBirney, 1973; Mavko, 1980).

\section{Regional extent}

Kisslinger \& Engdahl (1973) showed that the slope from a Wadati diagram, for epicentral distances large compared to the focal depth, should approximately indicate the velocity ratio in the lowermost layer traversed, if the paths the two types of bodywaves took to individual stations were not too different, and if all arrivals were from the same branch of the travel-time curve. Other methods examining variation in velocity ratio have been used to some effect (e.g., Evison, 1975; Smith, 1983), but the results are here already apparent: Figure 3.2 gave a relative indication of the average velocity ratio for the passage to individual stations, provided the ray-paths for the two wave-types, $P$ and $S$, were not too different.

The most distant of the eastern stations (MAR \& WAI) were isolated as unusual when showing the velocity ratio to be irregular (Fig. 3.2), but really it was the western network results that should have been taken as anomalous. Figure 3.3 exemplifies the waveforms for the two westernmost stations: it can be appreciated from Figure 3.2 that an $S-P$ interval longer by at least $0.6 \mathrm{~s}$ was needed at the two westernmost stations, KAO and $\mathrm{KAH}$, for a closer agreement with the data for the two most distant stations of the eastern network. Picks for $S$ had already been taken as late as practicable, although, for the earthquakes near Kawerau, the results for which similarly suggest low velocity ratio for the western network, a later, larger amplitude $S$ phase could be chosen for KAO without compromising that result (though 

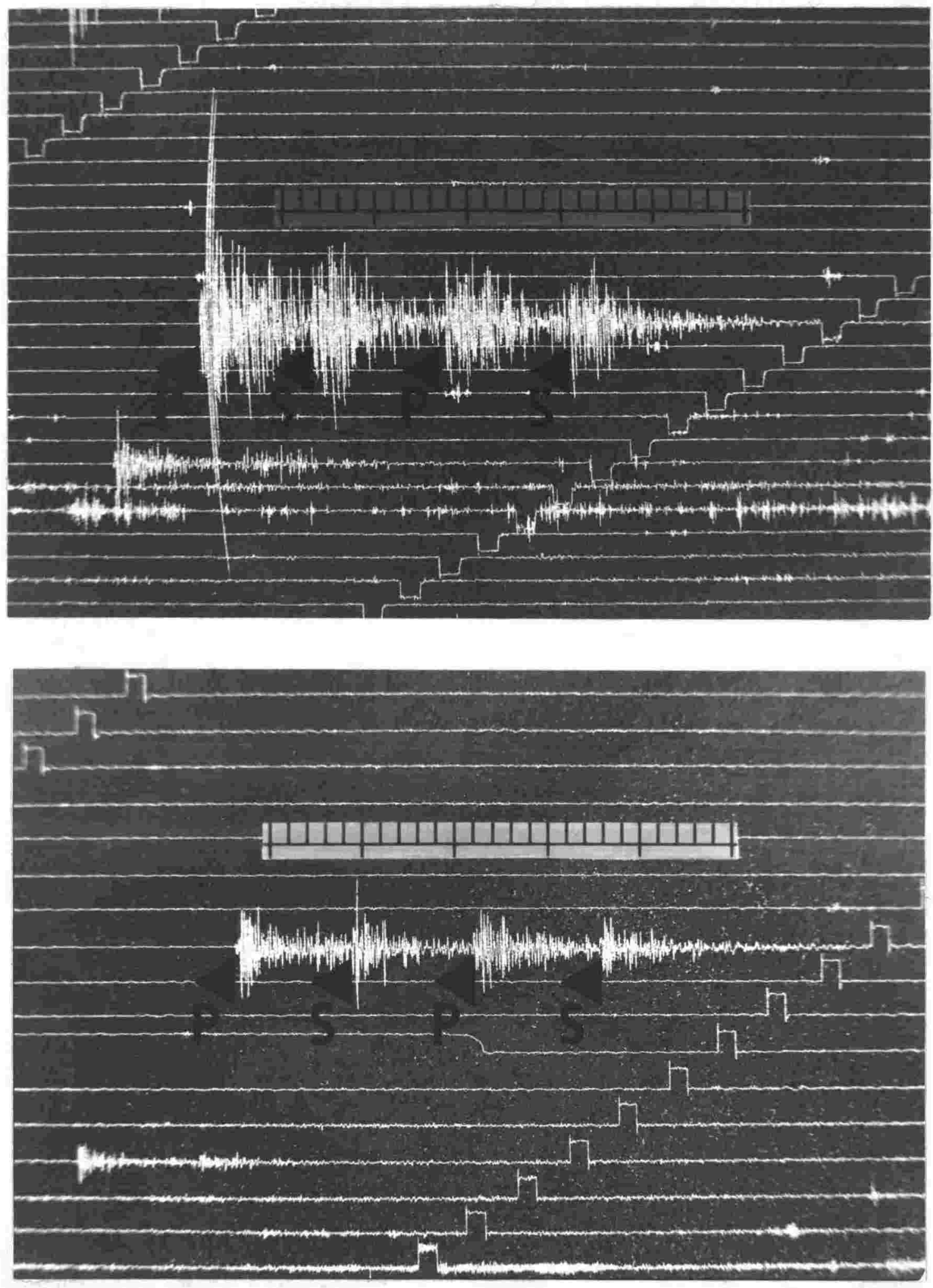

Figure 3.3. Examples of Matata sequence aftershocks recorded at western stations. First arrival-time picks are indicated for the two earthquakes of June $03^{\mathrm{d}} 18^{\mathrm{h}} 24^{\mathrm{m}}$, of magnitude 2.8 and 2.9 and originating in the central and eastern part of the aftershock source region, respectively, recorded at the sites KAO (upper) and KAH (lower). The included bar scales are graduated in seconds; the seismographs clearly record much higher frequencies than is asserted in Stern (1986: p. 92). 
possibly with some prejudice to the hypocentre locations). Although only verticalcomponent seismograms were available, the possibility that a phase conversion was consistently mistaken as $S$ seems unlikely, given the amplitudes in the following $S$ coda, and the frequent pairing of direct and refracted phases; moreover, the most suitably generative interface of semi-molten or molten rock for such conversions should be situated beneath the active hydrothermal belt at the southeastern margin of the Central Volcanic Region rather than near the westernmost seismograph sites.

Ray-paths from the Matata sequence earthquakes to the stations KAO and KAH passed beneath the exposure of greywacke near the station MDQ (Fig. 2.1), situated within the Central Volcanic Region. That greywacke block is regarded in the asymmetric spreading proposal as a remnant of unconsumed basement that has been detached from the southeastward-migrating margin of the volcanic region, but it is regarded in the earlier model as merely an elevated block of basement projecting through the acid volcanic plateaux, and, indeed, expresses no residual gravity anomaly (Stern, 1979), consistent with both models. Seismic waves to the two westernmost stations (the ray-paths being critically refracted) sampled crust deeper on average than the source region, at about $10 \mathrm{~km}$ depth, and thus sampled material deeper than the basements of $2-3 \mathrm{~km}$ depth determined by magnetic and gravimetric means. The low values of velocity ratio inferred for those first-arrival ray-paths suggest that greywacke was but a small proportion of media encountered along those ray-paths, or that it was somehow different to that presumed to exist beneath the eastern network.

Observations of Poisson's ratio for the continental crust fall mostly in the range 0.22-0.28 (e.g., Hyndman, 1979; Ukawa \& Fukao, 1981), but relevant observations under appropriate conditions for the rock types of interest here are scarce and not always directly comparable with field observations. Low values of Poisson's ratio that are associated with free quartz, however, seem to rule out the existence of a major body of andesite or dioritic rock, unless it occurs as a quartz diorite or as a granodiorite.

Extension of the Wadati-diagram analysis to data (for only the larger aftershocks) from the two westernmost stations of the temporary network and from the station of the permanent seismograph network at the western margin of the Central Volcanic Region, KRP (Karapiro), yielded a velocity ratio of $\gamma=1.87 \pm 0.02 \quad(v=0.30 \pm 0.01)$. This higher value suggests, if $S$ was not picked too late for KRP (where horizontal components of motion were recorded), a variation with depth in addition to the regional variation, or that proportionately less of the volcanic overburden had been sampled.

One of the problems in understanding the nature of the heat source for the volcanic region has been the maintenance of the heat flow for the inferred geological age of the hydrothermal systems (Banwell, 1963; Calhaem, 1973). A shallow source requires new magma to be regularly injected, and some mechanism for the efficient transfer of that heat content from the magma system to the higher hydrothermal system. With age and with cooling of an upper magmatic crust, that transference 
must be primarily by conduction, since there are serious objections to meteoric water continuously reacting with magma; indeed, the even spacing of the hydrothermal systems has led to the concept of a regional hot plate (e.g., Elder, 1965). The major geothermal field recently discovered (Bibby et al., 1984) at Mokai, northwest of Wairakei, would then be attributable to a remanent centre of high heat conduction. Fresh intrusion only along the southeastern margin of the volcanic belt, as in the spreading model, does not account, however, for the bodies of magma postulated to lie well within the Central Volcanic Region and towards its western margin on the basis of gravity interpretation (Rogan, 1982; Stern, 1986). Andesite is not more thermally conductive than greywacke (Pandey, 1981: p.45), and greywacke itself commonly contains (up to $35 \%$ ) quartz, which should give it a low Poisson's ratio (though only comparable to that indicated for the eastern ranges). This suggests it is rock fabric and not just mineralogical composition that plays an important role.

An efficient hydrothermal system requires flow in a permeable medium in which joints and fissures may constitute an effective permeability. It is noteworthy, therefore, that Foisson's ratio increases for fluid-filled, interconnected cracks, but decreases for pore spaces in a strong framework, such as for vesicles and other poorly connected porosity (e.g., O'Connell \& Budiansky, 1977; Hyndman, 1979). Deposition of secondary minerals should lead to poorly connected porosity with ageing of a hydrothermal system, until finally, with recrystallisation and hydrothermal alteration, all the pore spaces will have been filled, whether these be in rhyolite, in some other volcanic or hypabyssal rock, or in shattered greywacke. Closing pressure of cracks in rocks is about $200 \mathrm{MPa}$ (e.g., Kern \& Richter, 1981), corresponding to a depth of about $8 \mathrm{~km}$, and, of course, any crack porosity will tend to anneal at even moderate temperatures, except where the porosity is maintained by either thermal or tectonic action. Such annealing may explain the implied depth variation of velocity ratio, which may also find some association with the detected refractor.

The regional extent required for the source of the velocity-ratio anomaly favours the spreading model for the Central Volcanic Region. The hydrothermal systems may well go deeper than is usually considered, possibly with considerable lateral flow of groundwater; thus the heat source can also be deeper than hitherto assumed, with heat emanating by conduction from lower crustal depths (yet still with some crustal melting). Whatever the cause, the effect is to mask any predictive temporal variation in seismic velocity ratio, and these results show the importance of identifying spatial causes before claiming any temporal pattern. No precursory trend was evident, however, when the Wadati-diagram data were limited to common subsets of observing stations, although the quantity of data was then much reduced. Similar results may also be common near other geothermal areas; Chatterjee et al. (1985) recently related low velocity-ratio in the Yellowstone National Park region to the presence of hot water and steam at the water-steam transition at shallow levels, with the partial steam-vapour volume reducing the bulk modulus and thus the effective velocity ratio. 
It is more important in the present work to recognise that, as part of the model error, the variation in velocity ratio contributes to the mislocation of the Matata sequence earthquakes, and may have resulted in hypocentre locations with a larger dispersion than is desirable. 


\section{Delineating a fault plane}

Aftershocks are usually understood to result from adjustments occurring after the mainshock due to a redistribution of stresses, or to result from a continuation of the mainshock slip-motion on a smaller scale. Hence precise studies may establish planar zones that can be associated with the plane of rupture. Alternatively, a swarm of earthquake activity within a volcanic region might be related to the pervasive cracking of a cooling magma crust, or be related to incipient intrusion of magma between two cooled surfaces. A couple of simple techniques can be employed in attempts to resolve any such plane. The first method considered here is concerned with the earthquake hypocentres.

\section{The homogeneous station method}

Wadati-diagram residuals (Fig. 3.2) suggested that the seismic velocity ratio could not be considered uniform within the study region. Such a departure from the velocity model used in determining the source locations of the earthquakes constitutes a modelling error, which could have led systematically here to a greater spread in the epicentres (Fig. 2.3 to 2.6) than should ideally have been the case. Without an independent and unbiased estimate of any origin-time, absolute correction of the hypocentres is difficult, and the inferred lateral and depth variations of velocity ratio are indeed difficult to model accurately. However, all that are really needed in order to draw some inferences from the detail of the ruptured zone are not the absolutely known locations of the earthquake foci but the relative locations. One convenient means of obtaining these is the homogeneous station method, the theory for which has been given extensively by Smith (1977). Briefly, if the sets of stations and arrival phases used in locating a group of earthquake foci are kept uniform then adjacent foci will be mislocated by similar amounts. The homogeneous station method has here been used in its generalised form, to include $S$ observations.

A suitably large set of high-quality arrival-times was gained by setting, for each event to be included in the analysis, the condition that a $P$ time, having suffered minimal or no downweighting in the quality assessment of arrival-time observations, was recorded for all except two (KAH \& WIZ) of the Bay of Plenty seismographs, together with an $S$ time at one, at site RAW. These criteria resulted in the selection of 44 events, of which 2 had subcrustal depths, and were therefore discarded: the further requirement of an additional $S$ (for site LRO) would have reduced the sample size to 38 , but without any great advantage to the outcome.

The velocity model used previously was retained, for want of an appropriate and improved alternative. It was also assumed, more particularly for some later results, that the arrival-time residuals were uncorrelated, by station and by phase, and had jointly normal distributions about the components of some mean vector of residuals, 
with a common variance for the $P$ times, and four times that variance for the $S$ times. The result of Figure 3.2 gave an upper-bound estimate for the reading and timing error of the $S$ arrivals, which generally had clear onsets (see Fig. 1.2 \& 1.3), and the benefit of their weighted inclusion should have outweighed any adverse effects caused through small error in the relatively assumed variances. (Use of incorrect weights in the least-squares analysis should still yield unbiased estimates for the relative locations, but they may no longer be of minimum variance; it is advisable nevertheless to disengage all other weighting schemes in the location algorithm.)

The selected events in no way constituted a random sampling of the whole sequence, and so there is a need to judge the degree to which they were representative, by comparing the chosen subset, indicated in Figure 4.1, with the fuller set given previously (Fig. 2.3 to 2.6). Although evenly distributed throughout the main sampled period of activity, and distributed across the aftershock source region, most of the selected events were smaller than magnitude three, with many of them smaller than the accepted threshold of certain detection. Figure 4.2 gives the corresponding set of epicentres that were determined using the homogeneous set of arrival-time observations; some immediate encouragement for the method comes from the closer grouping of western events, and from the narrowing of the central zone of events.

The formal standard errors in latitude and in longitude with respect to the adopted crustal model are shown in both presentations (Fig. $4.1 \& 4.2$ ), but they are indicative of the errors in relative locations for the homogeneous case alone (Fig. 4.2), only insofar as they reflect a consistency in arrival-times between events. Naturally, the formal standard errors were smaller in the former case (Fig. 4.1), since all the local arrival-times were included in those solutions, but they likewise neglect the correlation between error in latitude and error in longitude, which, for fixed depth, is determined by the distribution of contributing seismograph stations (Flinn, 1965). Hence the sizes and orientations of joint marginal confidence regions for relative epicentres at the $95 \%$ level of confidence are also displayed in Figure 4.2 for typical reference events.

The confidence regions are based on (e.g., Flinn, 1965; Seber, 1977)

$$
\frac{(x-\hat{x})^{\mathrm{T}} A^{\mathrm{T}}\left[A\left(B^{\mathrm{T}} V^{-1} B\right)^{-1} A^{\mathrm{T}}\right]^{-1} A(x-\hat{x})}{k \hat{\sigma}^{2}}
$$

having an $F$-distribution with $k$ and $l$ degrees of freedom, where $B$ is the regression (or condition) matrix used in determining the least-squares estimate $\hat{x}$ of a vector of relative hypocentral coordinates $x, B^{\mathrm{T}}$ denotes its transpose, and $B^{-1}$ the inverse matrix. $V^{-1}$ is the diagonal weight matrix, with phase weights scaled in inverse proportion to the variances assumed for the arrival-time residuals, $A$ here initially selects the epicentral part of the hypocentral parameter space, and is thus of rank $k=2$, and $l$ is the number of degrees of freedom associated with $\hat{\sigma}^{2}$, an estimate of the variance of residuals about the station means. An unbiased estimate of $\hat{\sigma}$ can be 


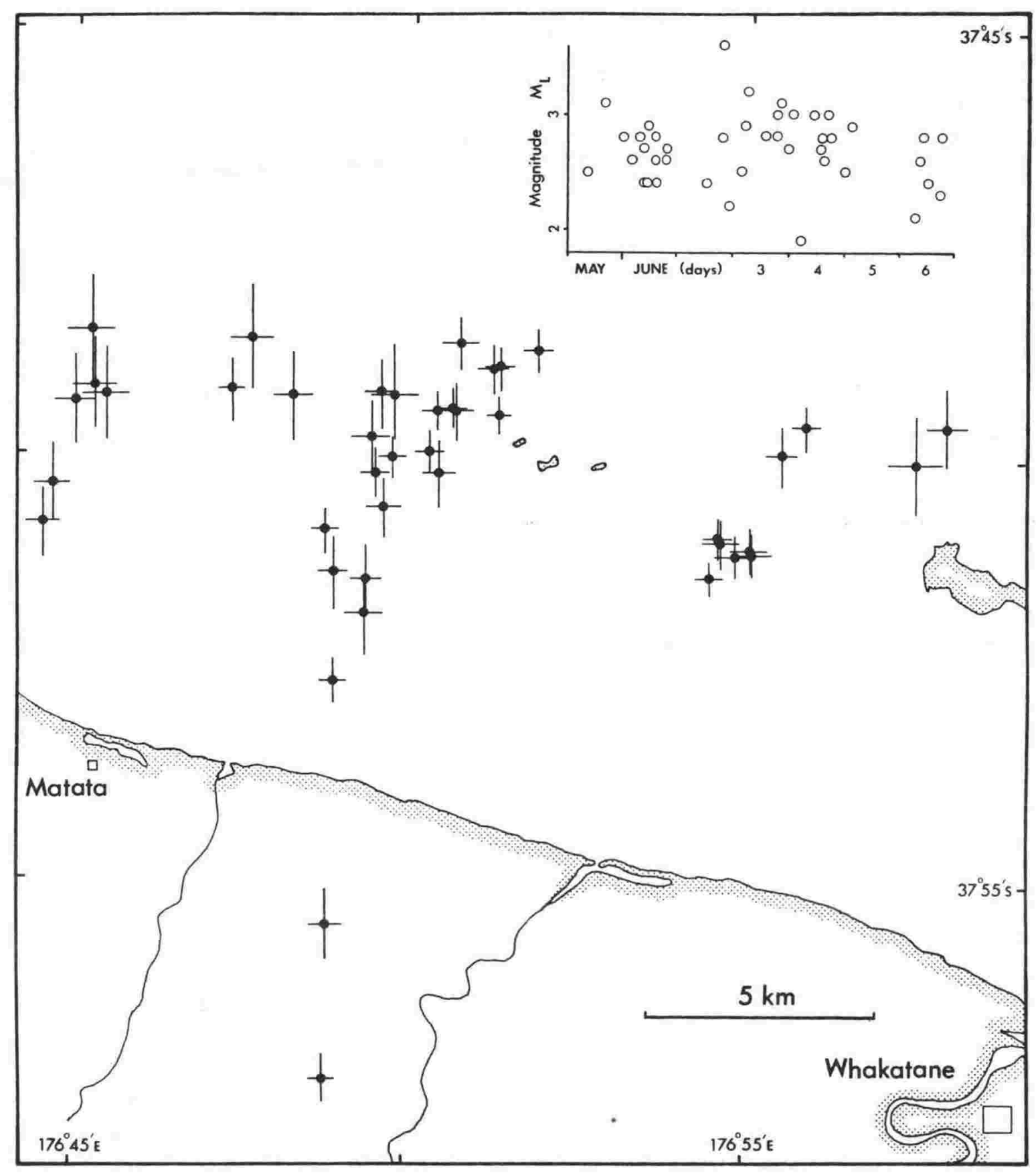

Figure 4.1. Events selected for study using the homogeneous station method. The epicentres shown were determined using the original, heterogeneous, station-phase datasets of arrival-times, and the error bars denote the marginal standard errors in latitude and longitude for each of those solutions. The inset diagram indicates the magnitude and time distribution of the sample.

obtained from the expression

$$
\hat{\sigma}^{2}=\frac{\sum_{m}\left(y_{i}-\bar{y}\right)^{\mathrm{T}} V^{-1}\left(y_{i}-\bar{y}\right)}{m(n-4)-(n-1)},
$$

where the $y_{i}$ are the arrival-time residual vectors (of $n$ components) for a group of $m$ earthquakes having $\bar{y}$ as their average. For the 42 earthquakes of the present case, 


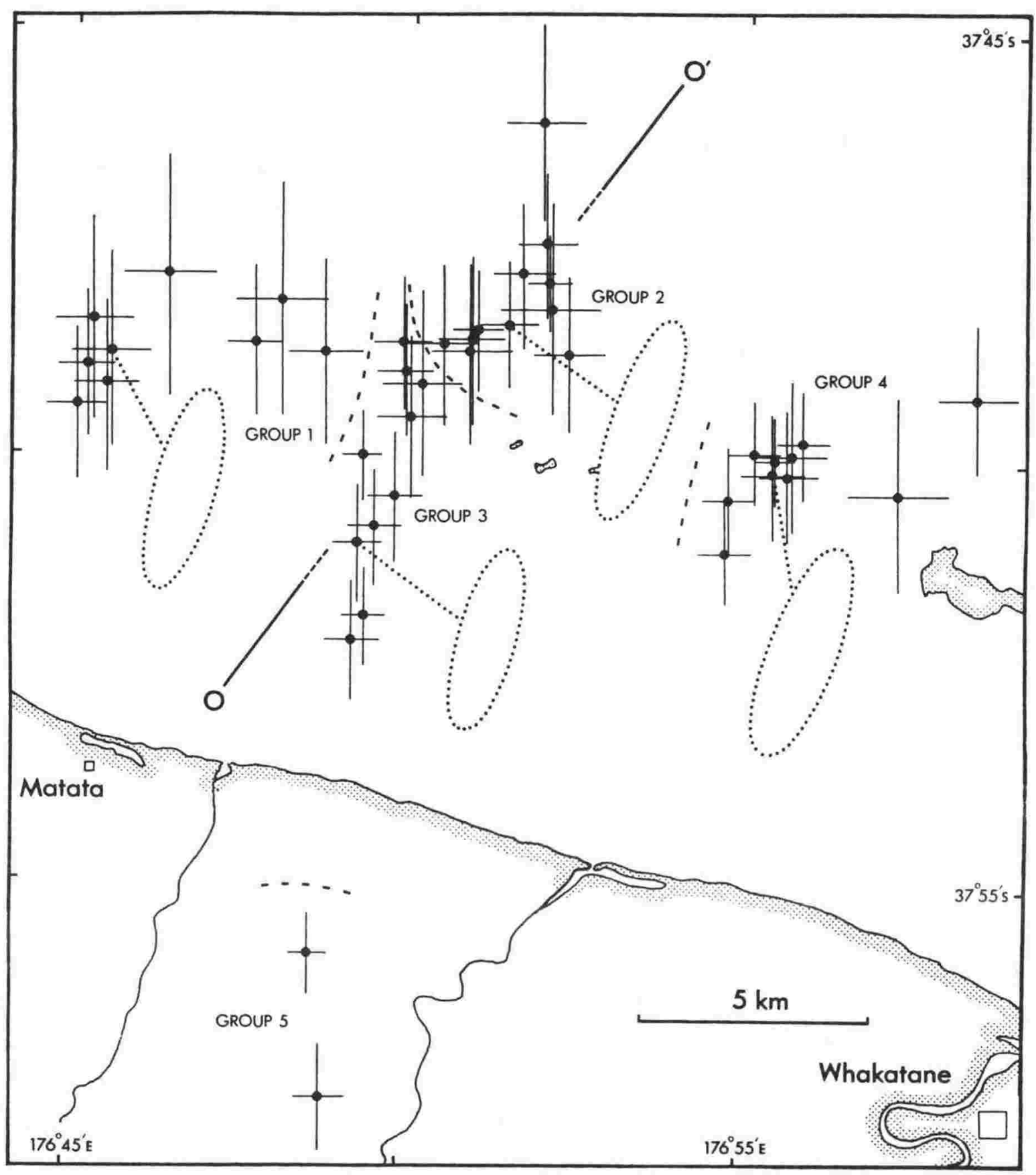

Figure 4.2. Epicentres determined using the homogeneous station method. The 95\% confidence ellipses found for the relative epicentres are displaced (without rotation) from their actual positions (as indicated), so as not to obscure the epicentres. Dashed lines separate the groupings used in the analysis of arrival-time residuals. Remote, eastern events of Group 1 were later than June $04^{\mathrm{d}} 15^{\mathrm{h}}$, $\mathrm{O}-\mathrm{O}^{\prime}$ gives the maximumlikelihood trend for events of the two central groups.

each with the same set of 11 phases, that expression gave $\hat{\sigma}=0.117 \mathrm{~s}$ (284 degrees of freedom). Instead, however, estimates of $\hat{\sigma}$ for five smaller groupings of adjacent earthquakes were not different from one another, and so a pooled estimate of $\hat{\sigma}=0.102 \mathrm{~s}$ has been used. This reduction in $\hat{\sigma}$ suggests (by a standard analysis-ofvariance result) that the model travel-time error had been seen in changing the average 
residuals across the region (variance ratio $F=3.1,40$ and 244 degrees of freedom). Moreover, if the reading and timing error of arrivals is taken to be $\hat{\sigma}_{\epsilon}=0.06 \mathrm{~s}$, then in the relationship

$$
\hat{\sigma}^{2}=2 \hat{\sigma}_{\epsilon}^{2}+\hat{\sigma}_{\delta s}^{2}
$$

for the total error, the variance in model travel-time errors to stations, $\hat{\sigma}_{\delta s}^{2}$, is less than twice the reading and timing variance (i.e., $2 \hat{\sigma}_{\epsilon}^{2}$ ), implying that the groups over which the residuals were pooled were small enough that the effect of correlation in model travel-time error to neighbouring stations was not serious.

The relative epicentres delineate a central band of activity with a tight clustering of activity to either side (Fig. 4.2). Apart from these three main features, and leaving aside the two southernmost occurrences, the remaining more diffuse activity did not begin until well into the fourth day of aftershock occurrence. This activity was later than the start of aftershock occurrence near the eastern and western margins of the aftershock source region, and therefore, as previously noted, later than that near the centre, which, because of its early start, had the closest affinity with the principal shock. The epicentres comprising the two central groups may therefore define the trend of the mainshock rupture. The maximum likelihood estimate for this trend (e.g., Creasy, 1956) is $\mathrm{N} 37^{\circ} \mathrm{E}$, with the $95 \%$ confidence interval given by the bounds $\mathrm{N} 26^{\circ} \mathrm{E}$ and $\mathrm{N} 63^{\circ} \mathrm{E}$. The average perpendicular distance of the epicentres from that trend was greater than the marginal standard error of relative location indicated by the arrivaltime residuals (Fig. 4.2), suggesting there may have been some curvature of the rupture surface or some variation of its position with depth.

The corresponding depths are indicated in Figure 4.3, showing that no centrally defined plane is immediately obvious. Figure 4.3 also shows how the ellipsoids for the error of relative location changed across the source region, and particularly with depth. (The earlier result concerning the change in model error across the region was not dependent on the inclusion of the Group 5 events.) Some corroborative evidence for the decrease in depth with distance eastward across the aftershock region was given by an observed uniformity of arrival-time interval between direct-travelling and critically refracted phases at the two westernmost stations of the Bay of Plenty network (e.g., Fig. 3.3). Such a depth correlation might be related to the cooling limb of a spreading centre located eastward.

Now that the mainshock hypocentre has been associated with the central trend of earthquake hypocentres, it is worthwhile investigating what can be done to improve its relative position. The Matata mainshock was not included among the earthquakes selected for study using the homogeneous station method, because the hypocentre was determined from $P$ arrivals alone at 11 of the 12 Bay of Plenty seismograph stations. Hence (by treating each of the earthquakes of the homogeneous arrival-set sample in turn as the reference event) Figure 4.4 shows the values of 


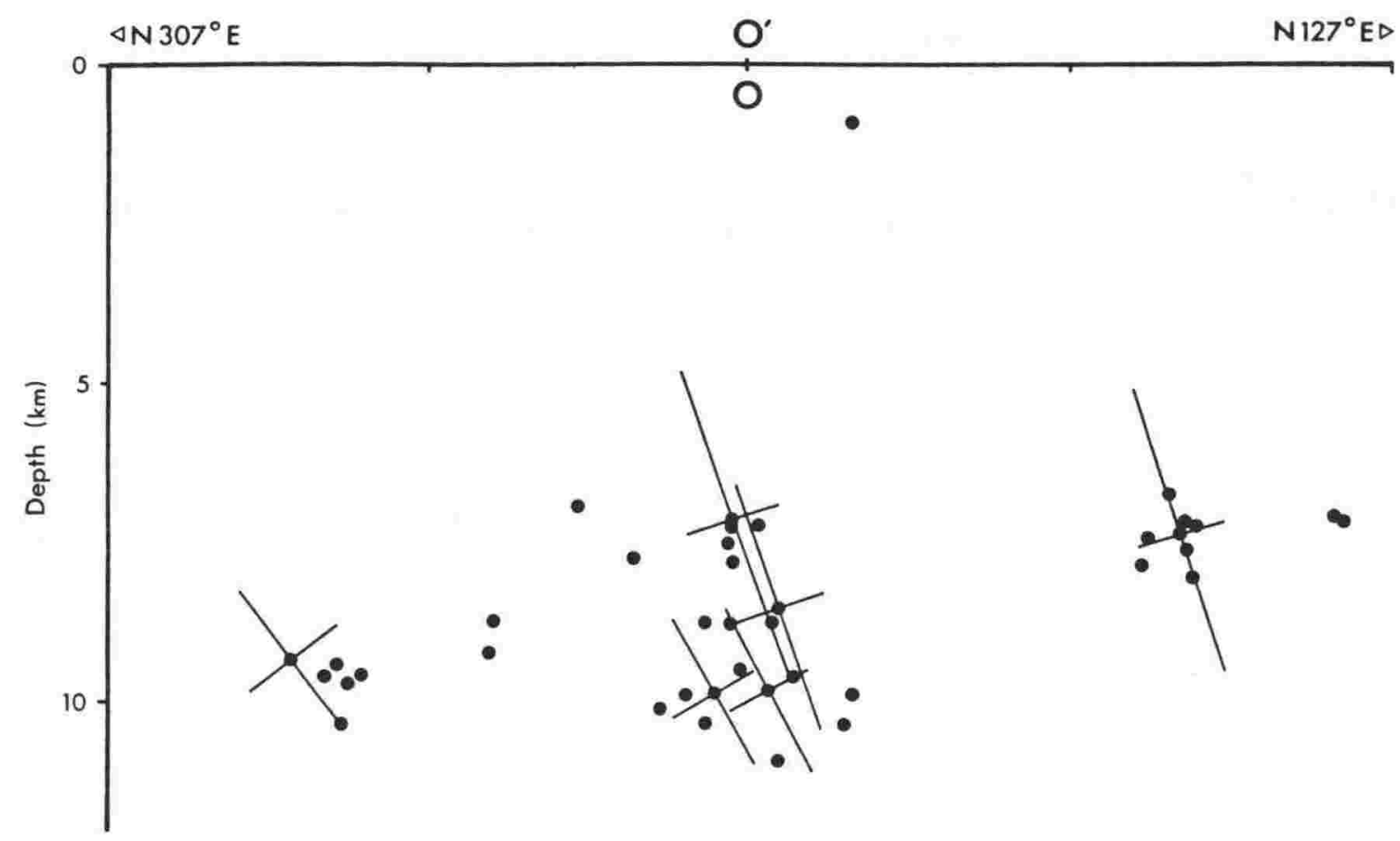

Figure 4.3. A vertical section showing the relative depths. Earthquake hypocentres determined using the homogeneous set of arrival-times are here projected onto a plane normal to the line $\mathrm{O}^{-} \mathrm{O}^{\prime}$ of Fig. 4.2. The error bars indicate major and minor axes of $95 \%$ confidence regions for the relative locations in that plane. The two points for Group 5 shown in Fig. 4.2 are not plotted.

$$
d_{i}=\left[\frac{\sum_{n}\left[\left(t_{M n}-\bar{t}_{M}\right)-\left(t_{i n}-\bar{t}_{i}\right)\right]^{2}}{n-1}\right]^{1 / 2}
$$

that were found using not the arrival-time residuals but the raw (i.e., unweighted) differences in arrival-times that were measured for the mainshock and the $i^{t h}$ reference event, $t_{M n}$ and $t_{i n}$ respectively, summed over the $n=10$ pairs of common stations, and corrected for the average arrival-time difference, $\overline{t_{i}-t_{M}}$. The squared values of $d_{i}$ should give some indication of the sum-of-squares surface for the error of the relative location of the mainshock, and should at best approximate twice the reading and timing variance $\left(2 \hat{\sigma}_{\epsilon}^{2}\right)$ for the highest quality in arrival-time measurement. That the minimum $d_{i}$ is greater, however, is not too surprising, considering the difficulty in observing the arrival-onset and the timing marks for the mainshock on some of the seismograms, and considering also that the arrivals used for events in the homogeneous data-set were not all from the highest quality of arrival-time observation. Although less certainty thus attaches to the relative location of the mainshock hypocentre, it is noteworthy that the minimum $d_{i}$ falls near where the foreshock hypocentres of the sample were placed. This central position suggests a bilateral rupture for the mainshock. Similar analysis for the largest aftershock confirms a source position for it further south.

The above analysis also provided some justification for the downweighting of the less-easily measured arrivals that were used in determining the position of the 


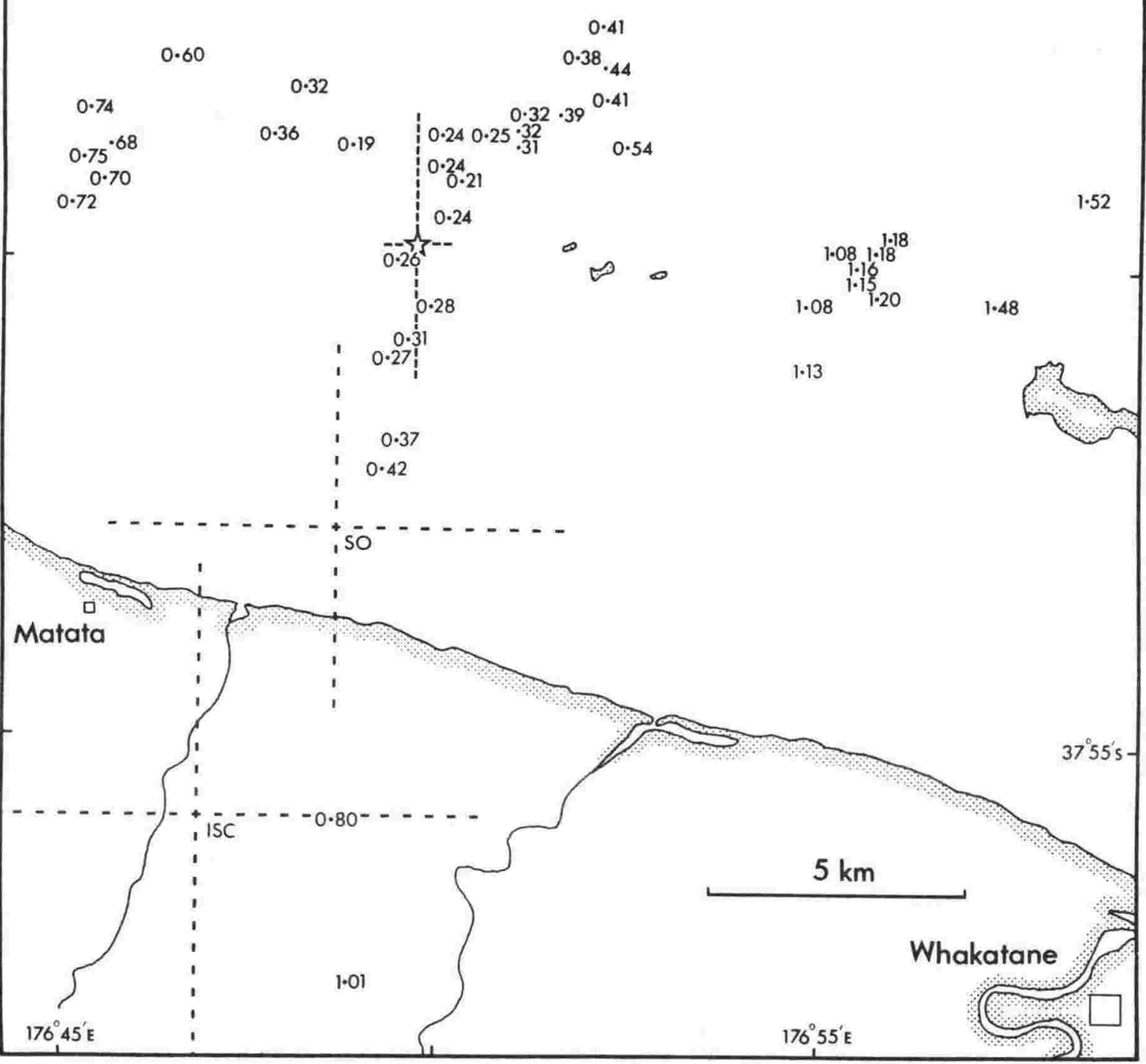

Figure 4.4. Relative location of the Matata mainshock. The standard deviation $\left(d_{i}\right.$, in seconds about the average) of $P$ arrival-time differences, between the mainshock and each of the earthquakes included in the analysis of arrival-time residuals (at the ten common stations), is plotted at the earthquake epicentre obtained using the homogeneous station method (Fig. 4.2). The star denotes the mainshock epicentre determined using arrivals at the Bay of Plenty seismographs. Also shown are the mainshock epicentres determined at the N.Z. Seismological Observatory (SO) and at the International Seismological Centre (ISC); the dashed bars represent the formal standard errors for the solutions.

mainshock origin, the formal solution for which is given in Table 4.1, together with the solutions determined at the N.Z. Seismological Observatory (NZSO) and at the 
Table 4.1. Hypocentre solutions for the 1977 Matata sequence mainshock.

\begin{tabular}{llllll} 
SOURCE & DATE AND ORIGIN TIME & LATITUDE ${ }^{\circ} S$ & LONGITUDE ${ }^{\circ} E$ & DEPTH & NO \\
\hline This study & MAY $31^{\mathrm{d}} 18^{\mathrm{h}} 50^{\mathrm{m}} 55^{\mathrm{s}} .3 \pm 0^{\mathrm{s}} .1$ & $37.83 \pm 0.02$ & $176.83 \pm 0.01$ & $9 \pm 2 \mathrm{~km}$ & 11 \\
NZSO & MAY $31^{\mathrm{d}} 18^{\mathrm{h}} 50^{\mathrm{m}} 56.9 \pm 0.5$ & $37.88 \pm 0.03$ & $176.81 \pm 0.05$ & $12 \mathrm{R} \mathrm{km}$ & 22 \\
ISC & MAY $31^{\mathrm{d}} 18^{\mathrm{h}} 50^{\mathrm{m}} 56^{\mathrm{s}} 5 \pm 0.4$ & $37.93 \pm 0.04$ & $176.78 \pm 0.06$ & $12 \mathrm{R} \mathrm{km}$ & 50
\end{tabular}

Note: NO is the number of arrivals used, and $\mathrm{R}$ indicates a restrained depth.

International Seismological Centre (ISC). The United States Geological Survey (USGS) also gave a solution (in their monthly Preliminary Determination of Epicentres) in which the focal depth was put at $125 \mathrm{~km}$. Initially the ISC solution followed the USGS solution (R.A. Adams, written communication, 1979). However, the difference in hypocentre probably resulted from an error of more than $20 \mathrm{~s}$ in the preliminary arrival-time received for KRP (Karapiro), together with errors of about $10 \mathrm{~s}$ for two stations to the southeast, GNZ (Gisborne; too late) and CIZ (Chatham Islands; too early), the last for which were retained in the solution that was finally presented in the Bulletin of the International Seismological Centre. (Not all of these errors originated with the observers, and other changes to the phase descriptors can also be found, along with truncation of the tenths of seconds in some of the timings.)

Other evidence for the shallow depth includes the reported-felt area having been limited mainly to the Bay of Plenty region and not extending much south of Rotorua (see Fig. 1.1), and an interval of $3.5 \mathrm{~s}$ between the first compressional phase and that after reflection at the free surface near the source, interpreted at the ISC for the Australian station WRB (Warramunga Array). That interval for $p P-P$, where the lowercase letter $p$ (or $s$ ) signifies a path-leg of wavetype $P$ (or $S$ ) for other than the general ray-path leading upwards from the source to the Earth's surface, implies a focal depth of about $10.5 \mathrm{~km}$, although at least three consistent observations of that type are usually required by that agency before a focal depth determined by that method is adopted.

The interpretation of a northeast-trending rupture is different to the one that was initially offered (for epicentres shown in Fig. $2.5 \& 2.6$ ), but it has the backing of a rigorous analysis of the errors of relative location. Although the error ellipses were elongated in the northeast direction, and away from the temporary network of seismograph stations, there was still sufficient information in mainly the $P$ times for detailing the source region of aftershocks. Aftershocks may serve, of course, to extend a main plane of rupture. Here, for a centrally defined plane, this rupture can be taken to have been $7 \mathrm{~km}$ in length, and not more than $5 \mathrm{~km}$ in vertical extent, with the initial mainshock rupture near the middle of its length, and possibly near its lower edge. No plane was defined by the hypocentres for the central groupings of the events, however, but corroborative evidence for that association of strike direction 
should come from an analysis of first motions, which may also provide an indication of fault dip and sense of slip.

\section{First-motion composites}

The orientation of the well known quadrantal pattern of dilatations and compressions for an earthquake source may be found when the radial first-motions of $P$ for the earthquake are referred back to a sphere around the focus. Which of the orthogonal nodal planes so resolved represents the fault plane can be deduced from other evidence, such as that given by a lineation of aftershocks. Furthermore, the centres of the dilatational and compressional quadrants define the $P$ and $T$ axes (for pressure and tension respectively), which correspond to the most and least compressive principal axes, $\sigma_{1}$ and $\sigma_{3}$, of the stress tensor for fracture of homogeneous rock without internal friction: the null axis, defined by the intersection of the two nodal planes, then aligns along the intermediate principal axis, $\sigma_{2}$. Consistent first-motions from several events can all be plotted on the same projection of the focal sphere, and indicate a consistent sense of slip on the same plane of faulting, or similar slip on several planes with the same orientation. Alternatively, if the first-motion data from a single event are not so as to permit a well constrained solution for the focal mechanism, a composite of first motions for events spread over a wider region may suggest the character of the regional stress, and the degree of homogeneity of subsurface conditions.

Directions of first motion observed for the Matata mainshock are shown in Figure 4.5 (on an equal-area projection of the focal sphere): the data for stations of the permanent network of seismographs in New Zealand are in addition to the teleseismic observations, taken from the ISC Bulletin. (Each data point projects to its antipode on the plot of the upper focal hemisphere, because the radiation pattern is symmetric.) Only two observations of first-motion direction were undertaken at the Observatory; notice, however, that the dilatational first-motion that is plotted for the nearby station west of the source region, KRP, conflicts with the compression that was recorded in the N.Z. Seismological Report for 1977.

The short-period, vertical-component seismogram recorded at KRP is reproduced in Figure 4.6. The drum-motion for the short-period seismograms at KRP differed from that at all other permanent seismographs of the standard network, in that the later traces were recorded above the earlier ones, for time increasing to the right along the traces. Consequently, the convention of having a trace deflection towards the later traces represent a recorded direction of ground motion towards the source may sometimes be overlooked (cf. Smith, 1984: p. 8). The dilatational first-motion recorded at KRP was confirmed by the initial eastward motion recorded on the short-period, east-west seismogram (by a similar trace deflection in the same sense as the above), and similarly by the long-period seismograms (recorded in the normal sense); it was corroborated by the dilatation for the sole temporary station yielding a first motion (KAH), which projects near the point plotted for KRP in Figure 4.5. Although these 


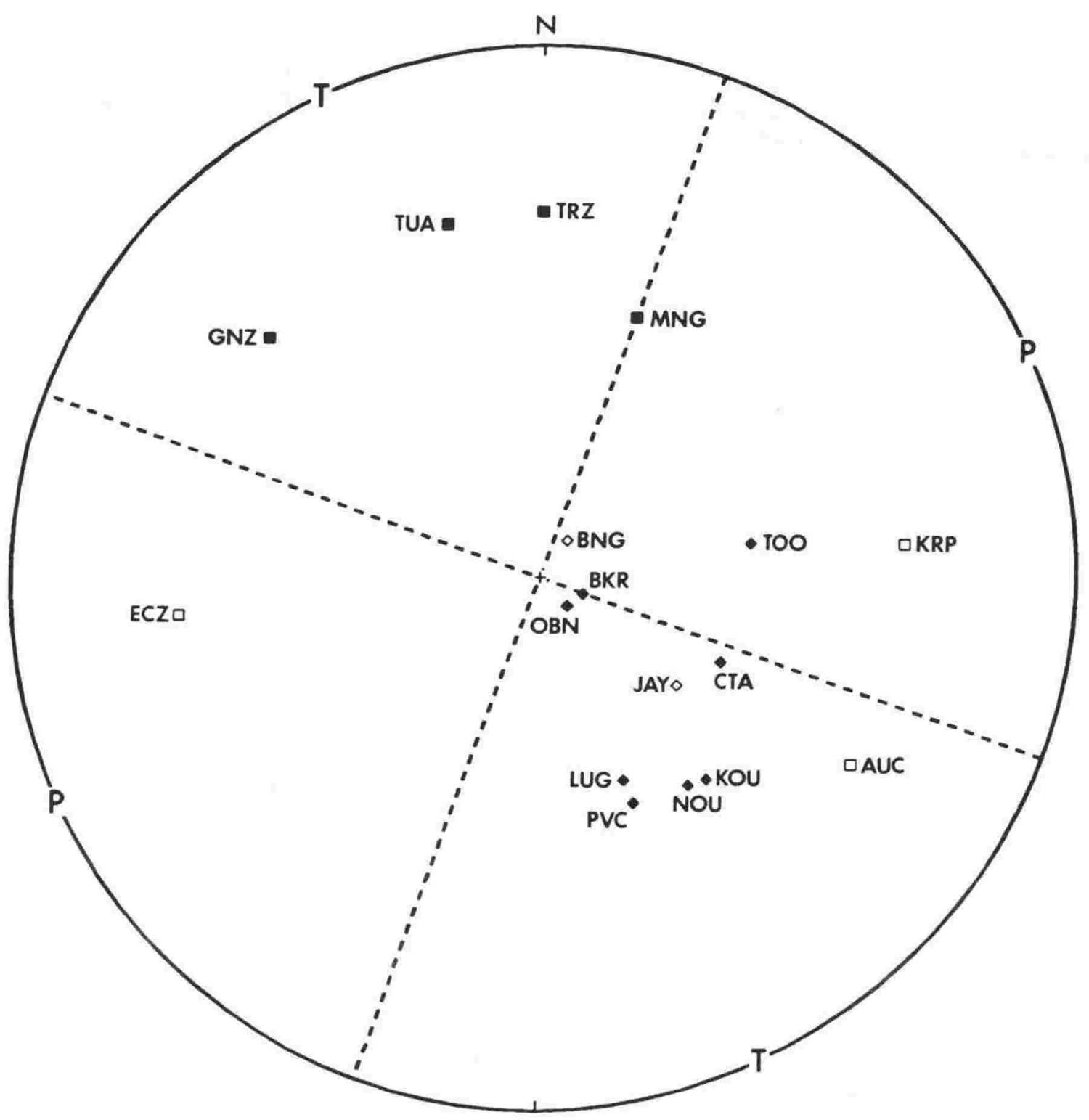

Figure 4.5. First motions for the 1977 Matata sequence mainshock. Observations for overseas stations are denoted by diamonds, New Zealand stations by squares; each observation is identified by its three-letter station code. Solid symbols represent compressions, and unfilled symbols dilatations, all plotted on an equal-area projection of the upper focal hemisphere. A tentative pair of nodal planes is shown dashed (pending subsequent revision); the corresponding $P$ and $T$ axes are horizontal.

dilatational first-motions restrict the range of possible solutions, the first motions shown were not sufficient for the purpose of constraining a focal mechanism for the mainshock. However, recourse was possible here to first-motion composites for other earthquakes in the Matata sequence.

Composites of first-motions (Fig. 4.7) that were observed for foreshocks and aftershocks provided substantial information in regions of the focal sphere not covered by the data for the mainshock (Fig. 4.5). (Remember, however, that first motions for rays interpreted in the model as critically refracted below the source to the more 


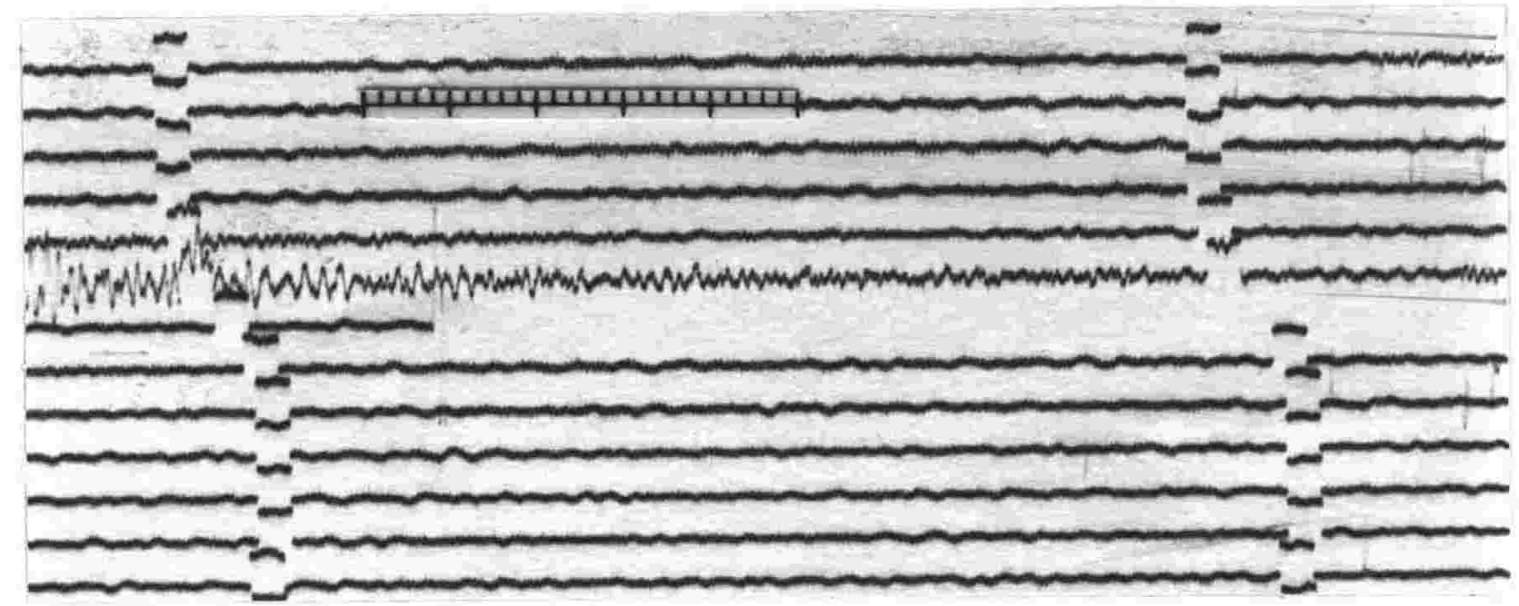

Figure 4.6. The short-period, vertical-component seismogram of the Matata mainshock recorded at KRP, showing first motion. Time increases to the right and progressively on higher traces, as indicated by the aftermath of the mainshock. Timing deflections of the recorded trace are at $60 \mathrm{~s}$ intervals, and are of $2 \mathrm{~s}$ duration.

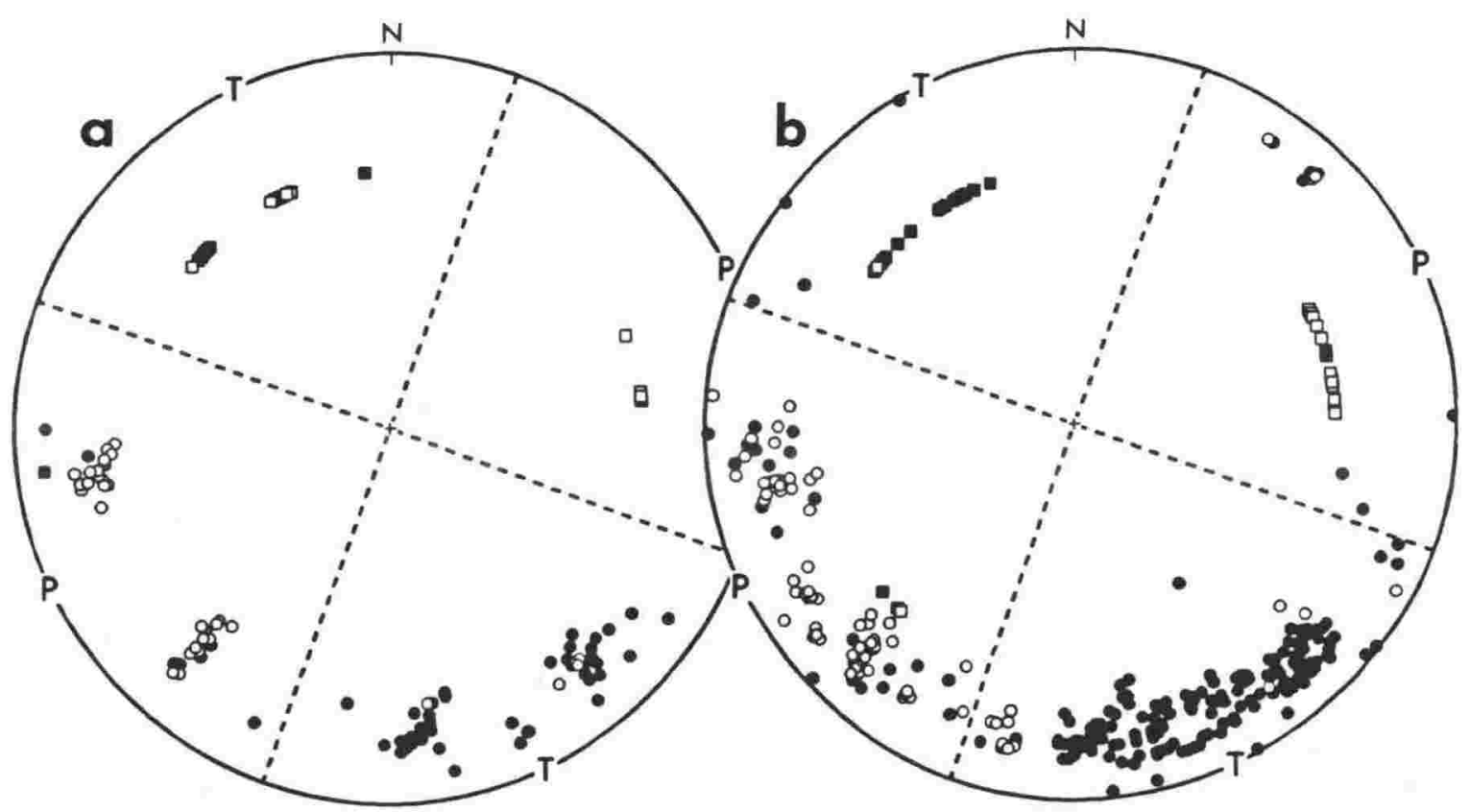

Figure 4.7. Composites of first motions for (a) foreshocks, and for (b) aftershocks used for Fig. 4.2. Circular symbols are for rays departing upwards from the source, while squares are for rays critically refracted below the source (according to the assumed crustal model and the derived hypocentres). Solid symbols record compressions, open symbols dilatations, and crosses $(x)$ the first $P$ arrivals adjudged near-nodal on the basis of the recorded amplitudes.

distant southeastern stations (i.e. WAI \& MAR) should possibly have been plotted at the opposite azimuth, at an inclination appropriate to the direct ray leaving the source above the horizontal.) The median orientation for the nodal planes, found by minimising the number of inconsistent first-motions and taking the null axis to be vertical, had one plane striking at $\mathrm{N} 20^{\circ} \mathrm{E}$, with uncertainties such that a rotation of $20^{\circ}$ about the vertical axis reduced the $77 \%$ consistency to $67 \%$. These best strike- 
directions for the nodal planes accepted, a tilt of about $45^{\circ}$ in the null axis towards most azimuths was possible before a similar reduction in the apparent errors occurred: the uncertainties result from a lack of data for steeply departing rays, and from a lack of observational sites north of the source region.

The first-motion directions (Fig. 4.8a) for other shallow events occurring during the 1977 microearthquake survey appeared not too inconsistent with the nodal-plane solution determined (Fig. 4.7) for the Matata sequence events. Moreover, the additional information seemed especially promising for a regional solution for the stress regime in the Bay of Plenty region, in view of the doubt about the nature of the first arrivals to the outer stations of the eastern network for the Matata sequence events. Also, the addition of this first-motion information remedied some of the problems with data

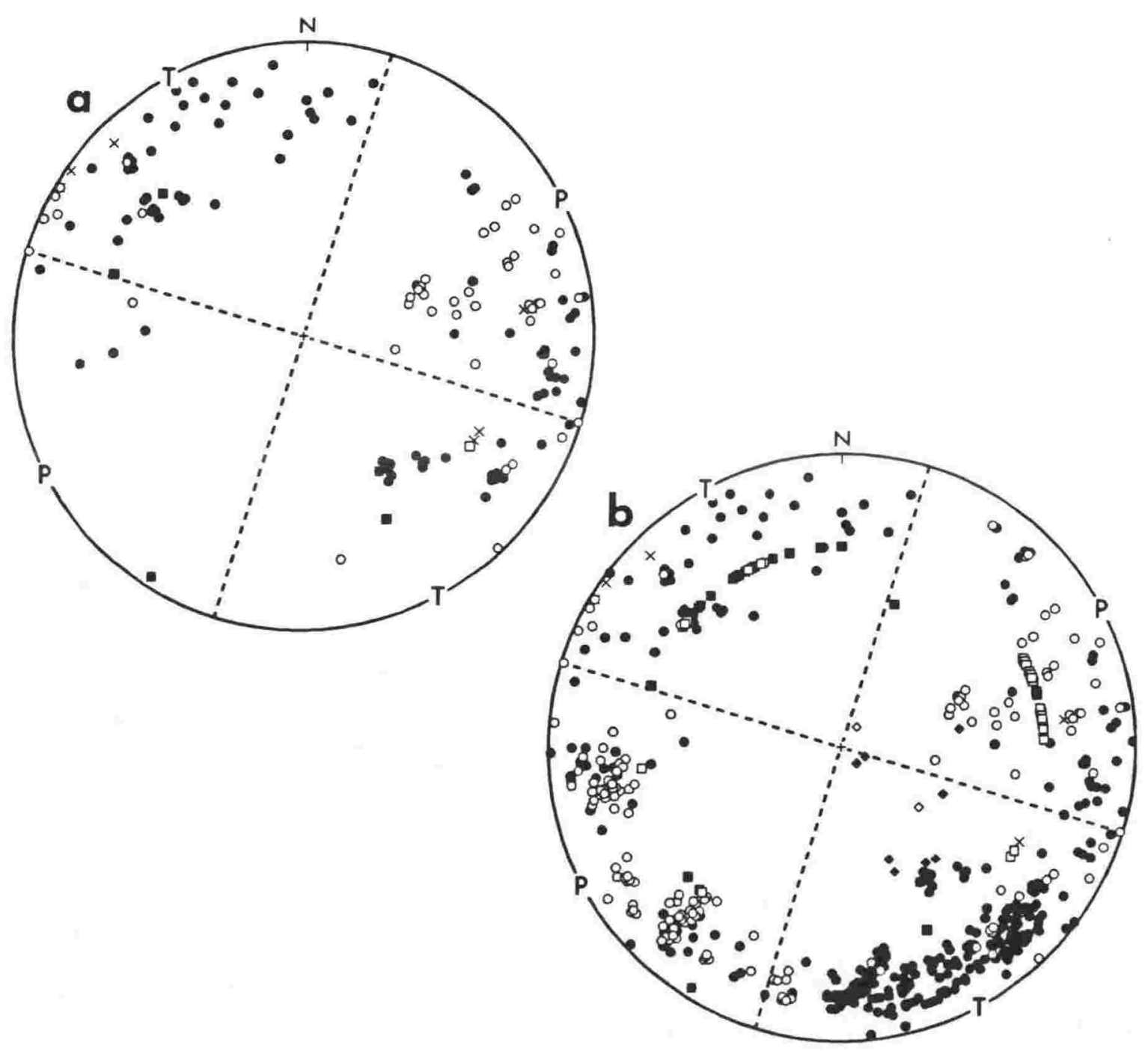

Figure 4.8. A composite of first motions for (a) other shallow events, and (b) an overall composite. First motions in (a) are for the earthquakes in Fig. $2.3 \& 2.4$ that were other than members of the Matata sequence. The overall composite (b) comprises all the first motions from Fig. 4.5, 4.7 \& 4.8a. Refer to Fig. 4.5 \& 4.7 for the plotting convention. The consistency of the first-motion data with the solution shown in (b) is $77 \%$. 
distribution on the composite focal sphere, as is shown in Figure 4.8b. However, the uncertainties for the focal mechanism remain unchanged. There was little point in adding first motions from the subcrustal events.

The mostly dilatational first-motions produced by the subcrustal events at the Bay of Plenty seismograph stations were incompatible with the indications given by the shallower seismicity, as is seen from Figure 4.9. Again, because of the limited coverage on the focal sphere, observations for permanent network stations are of importance, including KRP and GNZ, as well as TUA and TRZ to the south. It may seem that there is insufficient information for any solution, but the opposite directions in first motion recorded at WAI and at TUA for events of the subcrustal sequence suggest the proximity of a nodal plane. An alternative solution has a steeply plunging null-axis, but this possibility can be discounted using data for a later event occurring in the region of the subcrustal sequence.

The magnitude 5.1 event of 1979 October $17^{\mathrm{d}} 07^{\mathrm{h}} 16^{\mathrm{m}}$ had the depth assigned to $33 \mathrm{~km}$ in Observatory solution of hypocentre (79/726), but had a depth of $72 \pm 5 \mathrm{~km}$ in the ISC solution. The ISC solution has to satisfy teleseismic arrival-times, as well as local readings of arrival-times, together with an average Earth model for the traveltimes. Hence, so long as there are no problems with the arrival-times, the focal depths for such events may be better controlled in the ISC solutions of hypocentre, because of the steep departure angles of the teleseismic rays (though obviously not as well as when there are correctly identified depth-phases, such as $p P$ and $s P$ ). (For this event, a dilatation at WTZ (no timing) and a compression at GNZ (determined from the eastwest seismogram) supplemented the reported first-motions.)

For the solution indicated in Figure 4.9, other (circumstantial) evidence included the dilatations that were recorded for the subcrustal earthquakes in the eastern Bay of Plenty region, which were mentioned earlier when discussing the sampling of the seismicity but were ultimately excluded from final analysis (e.g., the earthquake of 1977 May $27^{\mathrm{d}} 13^{\mathrm{h}} 36^{\mathrm{m}}$ ). With the broad area of predominantly dilatational firstmotions to stations of the temporary network, and with a north-striking nodal plane, the solution is distinct from the category in which Harris (1982) placed a majority of intermediate-depth earthquakes, mainly on the basis of as few as four first-motions. Still, the takeoff angles used in plotting the data may have been in error for actual velocity structures not laterally homogeneous.

In summary, focal mechanism solutions determined from first-motion composites (Fig. $4.7 \& 4.8$ ) for the Matata sequence earthquakes and other crustal earthquakes in the Bay of Plenty region indicated that the $P$ and $T$ axes were near-horizontal, in spite of the high level of inconsistent first-motions. Thus slip was mainly along strike rather than with dip. Moreover, the solution for the Matata sequence mainshock could not have been simply one of purely normal faulting on a northeast-striking fault, mainly because of the dilatations for stations to the west, and because of the 


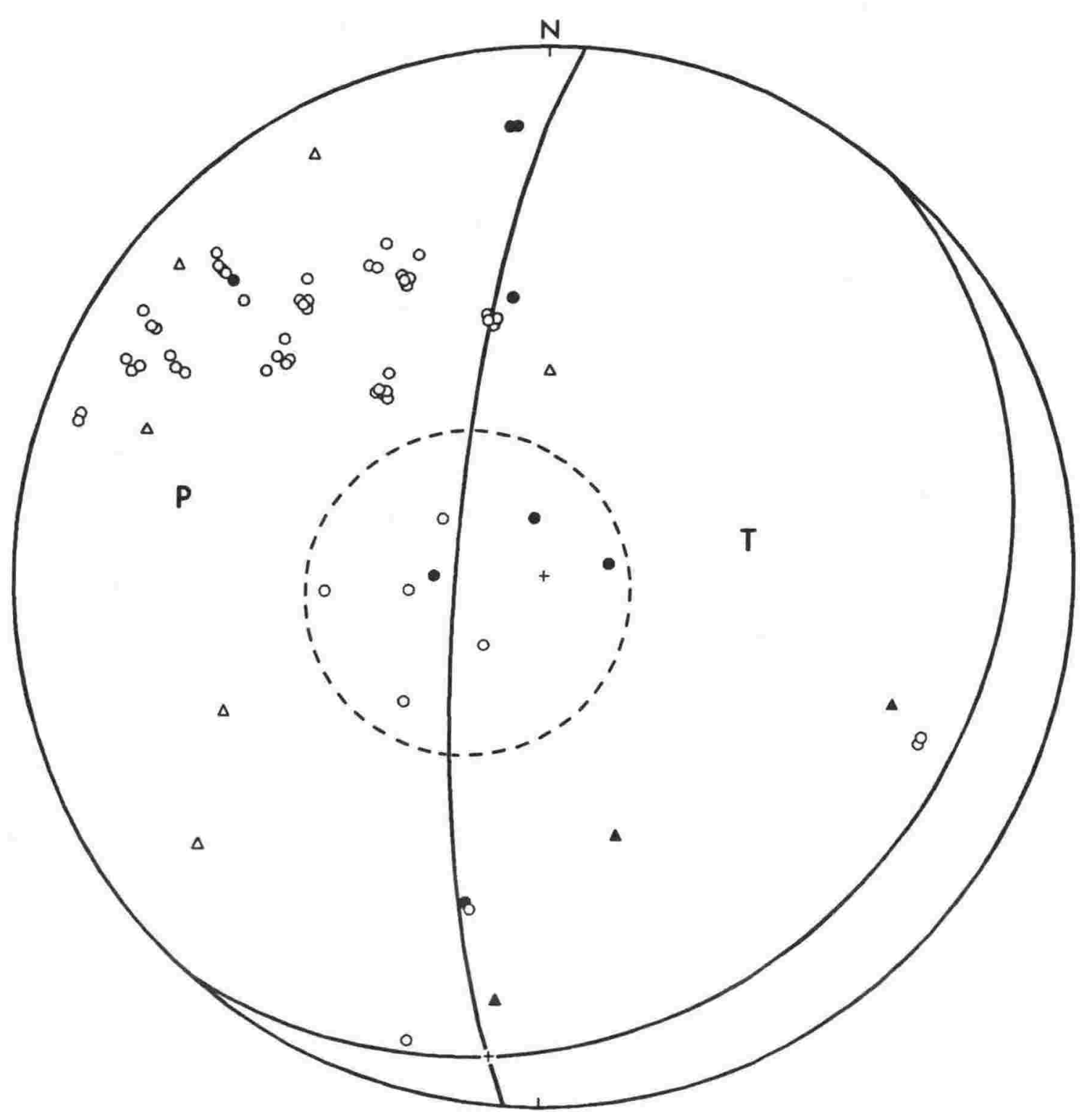

Figure 4.9. First motions, and the source mechanism for the subcrustal earthquakes. The dashed line encloses first motions for the two deeper events that were not part of the subcrustal sequence. Triangles give the first motions for the ISC solution for the earthquake of 1979 October $17^{\mathrm{d}} 07^{\mathrm{h}} 16^{\mathrm{m}}$ (79/726). Symbols are otherwise as for Fig. 4.7, and are plotted on an equal-area projection of the upper focal hemisphere.

teleseismic compressions. However, this strike-slip faulting result contrasts with results cited (e.g., Walcott, 1978a) as evidence for crustal spreading in the Taupo Volcanic Zone.

\section{Comparison with other results}

To investigate deformation across the Bay of Plenty region, Sissons (1979) used measurements of horizontal angles from the geodetic surveys, made to first-order precision, for the years 1925-29 and 1976. The method of simultaneous reduction, due to Bibby (1973, 1975), yielded $0.20 \pm 0.06 \mu \mathrm{rad} / \mathrm{year}$ for the rate of engineering shear- 
strain, when it was applied to subnetworks containing six resurveyed marks in the region, from WTZ across to MDQ (Fig. 2.1), and extending southwestward, together with an azimuth of $\mathrm{N} 120 \pm 8^{\circ} \mathrm{E}$ for the principal axis of relative extension. As shearstrains were not significantly different from zero in adjacent areas, that result was attributed to spreading at an extensional rate of $7 \pm 3 \mathrm{~mm} /$ year across the $40 \mathrm{~km}$ width spanning the Taupo Volcanic Zone, by assuming lengths were unchanged along a northeast-southwest azimuth. However, for the same region, a negligible shear-strain rate of $0.04 \pm 0.13 \mu \mathrm{rad} /$ year was also found, using the method of Frank (1966), which analyses changes in remeasured angles, together with an indefinite azimuth of $\mathrm{N} 126 \pm 63^{\circ} \mathrm{E}$ for the principal axis of relative extension (Sissons, 1979: p.66). The difference in those results can, in effect, be likened to the difference between earthquake locations determined using heterogeneous sets of seismograph stations and locations determined using the homogeneous station method, when the assumed velocity model is inappropriate: the latter method gives more reliable results for the relative locations, together with well founded errors that are relatively independent of those model assumptions, even though individual locations may be biased.

The method simultaneously reducing the triangulation data estimates station coordinates and the shear-strain components, assuming a uniform strain field. Inclusion of stations situated outside the region defined by the common ones (see Sissons, 1979: p.116) risks introducing errors in the estimates due to inhomogeneity of strain: such error is reflected in an increase in the standard deviation of adjustment residuals above that found for individual triangulation networks, with an unknown trade-off between calculated station positions and shear-strain components. (Inhomogeneity of strain was evident also in displacement solutions (Adams, 1984) for the same region.) The first method (Bibby, 1981, 1982) cannot be expected to be immune from that source of bias, whereas the other method (Frank, 1966; Prescott, 1976) yields the shear strains directly, with a standard error reflecting any departure from the assumed uniformity of the local strain signal. In other words, as the first method is no more powerful in the statistical sense when the strain field is inhomogeneous, the significance of the spreading result is questionable.

Only two of the six reobserved points that were included in the central, firstorder networks spanning the volcanic front could properly be considered to be southeast of the volcanic front; one of them was sited near WTZ, and the other on Mt Edgecumbe. The estimates of shear strain were therefore particularly susceptible to bias from movements local to those sites. The only other non-zero results (for both methods of estimating shear strain) were for the region further eastward along the Bay of Plenty coast, where the major geological trends are north-south (Fig. 2.1). Although of ten misleadingly referred to as the principal axis of tension, and its horizontal counterpart at right angles the principal axis of compression (e.g., Bibby, 1976; Walcott, 1984), whether the principal axis of relative extension so derived should correspond to $\sigma_{3}$ or to $\sigma_{2}$ is, of course, unknown, since distance measurement was not common to 
the two geodetic surveys, and no measure of dilatational strain was thus available. The resulting shear strains are therefore of limited value, for the region is clearly one of some geological complexity (Fig. 2.1). Nevertheless, Walcott (1984) obtained non-zero rates of shear strain along the whole length of the Bay of Plenty coast, using essentially the same data, and incorporated those results into an interpretation of North Island kinematics.

Observations of faulting within the Central Volcanic Region are made difficult by poor exposures within the weak volcanic ash and debris, and by a lack of suitable reference markers for horizontal displacements (e.g., Grindley, 1965). These difficulties are compounded by the effects of caldera collapse structures, block rotations, gravitational slumping and local subsidence. Some recent pointers for dextral transcurrency have been the left-stepping arrangement of dikes within the $\mathrm{N} 57^{\circ} \mathrm{E}$ chasm formed by the 1886 eruption of Mt Tarawera (Nairn \& Cole, 1981), and in surficial cracks associated with an earthquake swarm occurring southwest of Wairakei in 1983 (Otway et al., 1984: Plate 4). The region has also been extensively mapped for the purposes of geothermal exploitation (e.g., Grindley, 1965). However, the principal axes that have been inferred for vent alignments and for displacements on intersecting faults are not directly relatable to deformation at depth. Hence it seems the underlying cause of the surface features should perhaps best be indicated by seismology, and possibly through studying earthquake mechanisms.

"Noisy recording conditions" seems to have been the reason for the absence of any focal mechanism in the study of Evison et al. (1976), conducted near Wairakei: this is certainly a problem special to the volcanic region (and whenever the earthquakes are small). For the same region, Hunt \& Latter (1982) gave a solution for a composite plot of 24 first-motions from 14 microearthquakes, asserted to be consistent with dextral strike-slip faulting on a plane striking at about $\mathrm{N} 35^{\circ} \mathrm{E}$, dipping steeply northwestwards but downthrown to the southeast. Three of the onsets were inconsistent with that solution, but it was not mentioned that those points would still have been largely inconsistent, even had they been plotted either in the opposite hemisphere, as stated, or differently at the opposite azimuth (since it is uncertain what the ray-paths were). Also, none of the faults in the geological cross-section showed any component of the indicated thrust.

The northeast-trending nodal-plane for the 1983 earthquake near Waiotapu (83/1231; Smith et al., 1984), near the middle of the Taupo Volcanic Zone (Fig. 1.1), was constrained only by the few observations mapping to the northeastern sector on the upper-hemisphere plot. Nodality was inferred for a mixture of aftershock firstmotions plotting near the centre of the plot, but the mainly sinistral solution for that plane was otherwise dependent on the interpretation of direct ray-paths for the first motions at the few eastern stations of the permanent seismograph network. Smith \& Webb (1986) reported solutions for composites of first motions determined for swarm sequences west and southwest of Wairakei in 1983, which had opposite senses of 
lateral slip for similar strike of nodal plane but with a common thrust component that contrasted with surface evidence; Webb et al. (1986) indicated a different orientation of focal mechanism for the western swarm. Thus it seems that reliable focal mechanisms are far from easy to obtain in the volcanic region, and that the elucidation of stress regime is by no means straightforward.

Similar difficulties apparently occur in studies of other crustal earthquakes in New Zealand. The focal-mechanism solution that was given in Robinson et al. (1975) for the early Inangahua sequence earthquakes, for example, showed no sign of the variation in first motion reported by Adams \& Lowry (1971) for the nearer seismographs of the permanent network (i.e., $\mathrm{KAI} \& \mathrm{COB}$ ) and nearby seismographs installed temporarily to study the aftershocks. In some studies it is acknowledged that some of the data have been omitted (e.g., Robinson, 1978: Fig. 7), while in others the reasons for the particular takeoff angles used may not always be clear (e.g., Reyners, 1983: Fig. 11). In this study, first motions have been plotted strictly according to the assumed crustal model and the derived solutions for the origins, but it is nevertheless recognised that the assigned ray-paths may be a real source of error, even though the proximity of the temporary seismograph array assisted in constraining the source depths. The emergence angles used for the first-motion plots therefore remain open to question.

Could the solution derived for the Bay of Plenty region (Fig. 4.8b) have been atypical? Figure 4.10 shows published first-motions at the permanent station WTZ for earthquakes that were deemed to be of crustal origin. For regionally uniform strikeslip faulting, that long-term indication should match the pattern for the Matata sequence, whatever the ray-paths. The epicentral pattern (Fig. 4.10) shows the northeastern sector to be almost devoid of data, the northwestern sector solidly compressional, the southwestern sector mixed (though just as for the composites of Fig. $4.7 \& 4.8$ ), and the southeastern sector incompatible (but according with first motions shown in Fig. 4.9 for subcrustal earthquake origins). Evison \& Webber (1986) have developed and applied this method for data accepted as appropriate to head-waves, but it is the focal-depth problem that limits the method for all but the special case of strike-slip faulting. Several examples of the focal-depth problem have already been highlighted: it was from a survey of regional first-motions that the 1979 earthquake (used for Fig. 4.9) first became evident as an event of deeper origin (and of magnitude five or more) that was well recorded in terms of reported first-motions. Other events of deep origin may similarly have had crustal depths assigned, in error because of inadequacies of the assumed velocity model and because of the large station-spacing of seismographs in the national network.

The solution of shallow source mechanism indicated by first motions (Fig. $4.7 \&$ 4.8) during the 1977 survey suggested mainly dextral faulting, if the north-trending nodal-plane represented planes of faulting, or sinistral faulting on a more east-trending set, by interchange of the roles of the nodal planes. Thus no great amount of crustal spreading was indicated, unless the latter case represented a transform fault, with large 


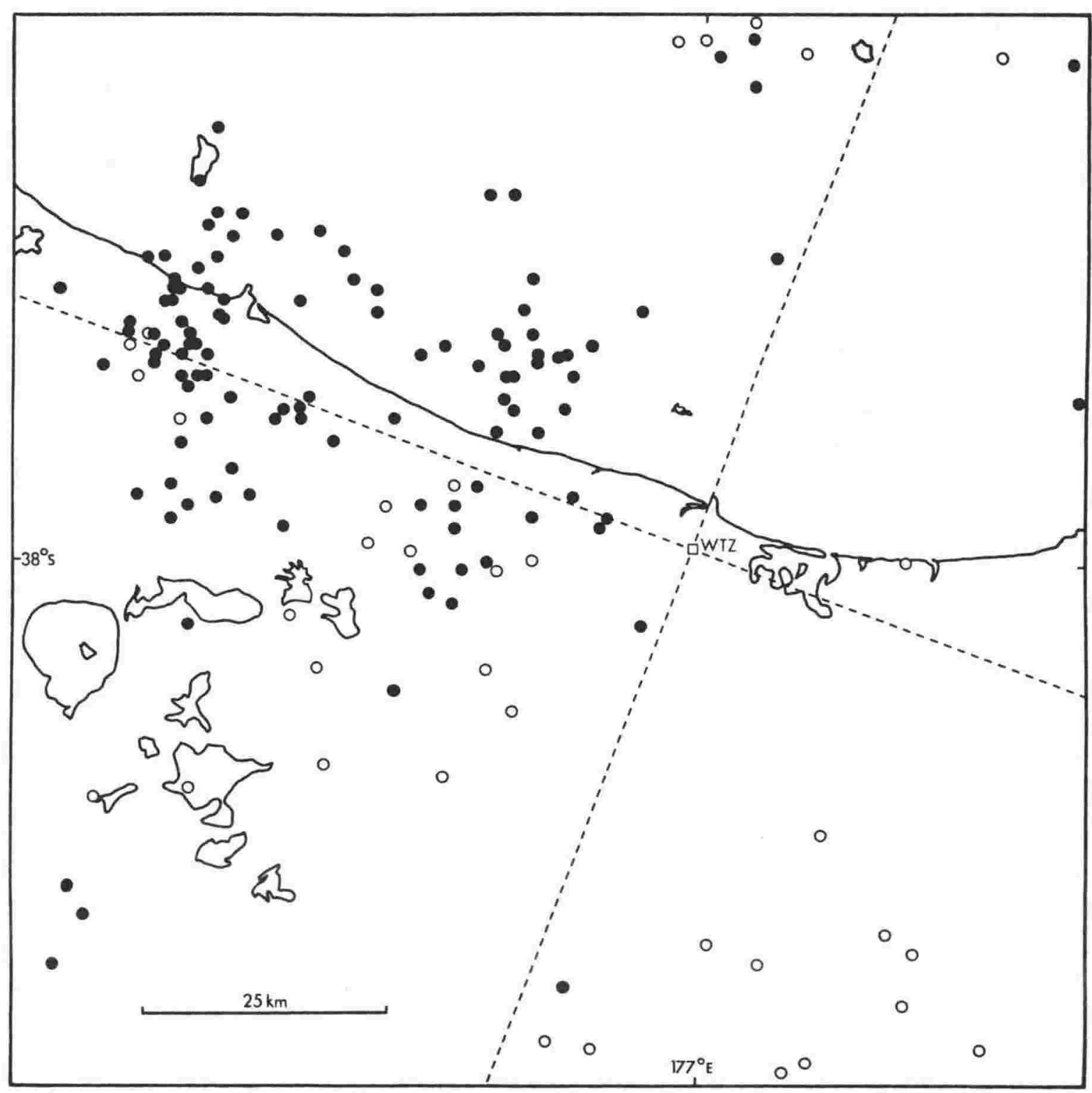

Figure 4.10. Geographical distribution of first motions from shallow earthquakes in the Bay of Plenty region. Directions of $P$ first-motion, reported for WTZ in $N Z$. Seismological Reports for the years 1971-82, are plotted at the earthquake epicentres: symbols are solid for compressions, open for dilatations. The dashed lines are the nodal lines corresponding to the solution of focal mechanism shown in Fig. 4.8b.

portions of it aseismic late in the sequence, and with associated spreading centres southwest and northeast. The epicentral trend deduced for central events studied using the homogeneous station method (Fig. 4.2) favoured a northeast-trending plane, providing a better association with faults of the volcanic region than with the older, northtrending faults within the adjacent greywacke region to the east (see Fig. 2.1). It is evident, however, that a composite first-motion solution may not have adequately constrained, nor have necessarily represented the focal mechanism for the mainshock. Moreover, severe disparities of first-motion direction at nearby stations for large foreshocks and aftershocks of the Matata sequence could not be easily disregarded. The southwest spread of inconsistent first-motions is in need of explanation. 


\section{Mainshock source mechanism}

Problems in satisfactorily determining a focal mechanism from local observations for the Matata mainshock and related earthquakes stemmed largely from the shallowness of the earthquake origins and their location outside the local network of seismographs. Methods searching for some "best" average solution, by minimising the number of polarity violations, may be unsatisfactory in the case of a single earthquake and for a composite of first motions from related shocks, because of the discreteness of the polarity observations, the dependence on the data distributions, and the problem of assessing what weight should be placed on teleseismic observations. Although the first motions may often be difficult to observe reliably, the teleseismic waveforms possibly offer the best chance for the recovery of the focal mechanism for the Matata sequence mainshock, and thus, by inference, the focal mechanisms for other events in the sequence.

\section{Free-surface reflections, and relative amplitudes}

The Matata sequence mainshock, at the assigned bodywave magnitude of $m_{b} 5.3$ (1SC Bulletin), was too small to have been well recorded on long-period instruments of the World-Wide Standard Seismograph Network (WWSSN). Modelling of the long-period bodywave waveforms of about $5 \mathrm{~s}$ period was therefore impractical for the purposes of determining the focal depth and the source mechanism, and even at the longer periods of body and mantle waves recorded by the more sensitive SRO (Seismic Research Observatory) stations of the Global Digital Seismograph Network, which had a capability threshold of about $m_{b} 5.5$ (Dziewonski \& Woodhouse, 1983). Indeed, the Matata mainshock did not feature in a review of centroid-moment tensor solutions for earthquakes of 1977 (Dziewonski et al., 1987), and the local SRO station (SNZO) failed to trigger for short-period recording.

The signals were similarly too small for analysis of either $S$ polarisations or surface-waves. This left seismograms of about $1 \mathrm{~s}$ period recorded by short-period seismographs at WWSSN sites and other sites at teleseismic range. Few sensitive stations exist within the Pacific Ocean region; this lack of coverage frequently results in an inadequate sampling of the focal sphere, with solutions of source mechanism for events of moderate magnitude either incompletely specified or strongly dependent on key observations of $P$ polarity (e.g., Smith et al., 1984). More than just first-motion direction is available in the teleseismic waveforms, however: information that is useful also as a means of distinguishing shallow earthquakes from underground nuclear detonations (Douglas, 1981).

The method used here to constrain source mechanism is in essence similar to that of Pearce (1977, 1980). For the size of event and at the wavelengths concerned, the seismic emission of the source should be of short duration, effectively lasting about $1 \mathrm{~s}$. 
Further, if a source has some depth, the discrete pulses of $P$ and the free-surface reflection and conversion, $p P$ and $s P$, recorded at a teleseismic distance, should also be simple and well separated, even when the earthquake source is intracrustal. Then the time intervals between pulses provide an ectimate of the focal depth, and the relative amplitudes impose strong constraints on the orientation of the causative fault, in addition to constraints provided by the $P$ and depth-phase polarities. Observed amplitudes can simply be related back to the focal sphere by multiplicative factors that account for the energy partitioning of a plane wave incident at seismic discontinuities above the source, together with a correction, where necessary, for an incident spherical wavef ront.

The free surface is the most important boundary when no great water depth exists above the source region. Effects of structure below the source are relatively unimportant, as are the expected losses further along the ray paths, because relative amplitudes are used, and because the ray parameter is virtually the same for each of the three main phases in the $P$ waveform for a shallow source. The low coefficient for the conversion from vertically polarised $S$ to $P$ at the free surface is usually more than compensated by the strength of the $S$ radiation. Subsequent modelling could be employed to learn about the crustal structure in the source region, from the impulse response of the local crust, and about anelastic attenuation above the source, from modification of the pulse shape, but the relative amplitudes of $P$ and the free-surface reflections recorded at a few well distributed seismograph stations are all that are required to constrain the orientation of the assumed shear dislocation. Moreover, the gaining of usable data is feasible even when the signal-to-noise ratio is low and where the unambiguous observation of onset polarity is difficult (Barley \& Pearce, 1977).

The relative amplitude method contrasts with the analysis of long-period bodywaves from shallow sources, in which the whole waveform (including crustal reverberations) must be matched, and in which the focal depth is only given indirectly, because there is no visible separation of the depth phases. It thus avoids corresponding trade-offs between modelled depth, synthetic waveform, far-field time function and attenuation operator (e.g., Forsyth, 1982; Christensen \& Ruff, 1985). The relative amplitude method also bypasses the problem of instrument response, and the effect of receiver structure is similarly negligible. In extreme cases the amplitude at a relevant part of the signal envelope might be used (e.g., Forsyth, 1982).

A systematic search is made over all fault-plane orientations on a grid; the aim is to eliminate incompatible solutions and to enhance the more promising ones. By performing a complete search over all fault orientations for some sufficiently small size of mesh, the uniqueness of trial solutions is tested, with some estimate of the uncertainties being provided, and the likelihood of overlooking any solution not previously considered as a possibility is greatly reduced. However, the method used here differs slightly from that described by Pearce (1977, 1980), in sign convention, and in that an objective criterion related to a measure of root-mean-square error is 
employed rather than the setting of bounds of acceptability for the amplitudes of the modelled phases.

Representative waveforms, given in Figure 5.1, were chosen from among those made available, to give a suitable coverage of the focal sphere and to illustrate some points of interpretation. Several of the short-period, vertical-component seismograms are from Australian seismograph stations (ASP, WRB, MUN \& TOO), another two (SBA \& MAW) from Antarctica, and one (UME) from Scandinavia. The main signatures in these records are the arrivals of $p P$ and $s P$ following $P$ by about $3.5 \mathrm{~s}$ and $5.0 \mathrm{~s}$ respectively, implying a focal depth of about $10.5 \mathrm{~km}$ for the mainshock when referred to the crustal model and the travel-times (Jeffreys-Bullen, 1958) adopted for the model Earth. In some cases, however, the small initial onset of $P$ was inferred from the depth phases and their intervals, or from other more subtle aspects in the waveforms. The inferred arrival-times may therefore differ slightly from readings that were made by the station operators, as indicated by the annotations preserved on the seismograms (e.g., MAW \& UME) or by the timings that were reported to the international agencies. The station in western Australia, MUN (Mundaring), did not have any arrival recorded in the ISC listing, however, but the estimated arrival-time of May $31^{\mathrm{d}} 18^{\mathrm{h}} 59^{\mathrm{m}} 44^{\mathrm{s}} .8$ that was picked for $P$ yields a $-2.0 \mathrm{~s}$ residual in respect of the ISC solution of mainshock hypocentre. Later arrivals in the waveforms are mainly of multiple reflections and conversions within near-source crustal layering: there should have been no interference from $P c P$, the first-arriving phase reflected from the Earth's core, since the smallest $P c P-P$ interval that was observed for the given seismograms was that of about $35 \mathrm{~s}$ for the station MAW.

In the case of UME it is not the inferred first arrival of $P$ that is indicated, but more specifically, because of the large geocentric distance, that of the phase that travelled through the Earth's core, $P^{\prime}$ (or $P K P$ ), and the particular intervals between the $D F, G H, I J$ and $A B$ branches of its travel-time curve (Adams \& Randall, 1964). Although the arrival of the first depth-phase is clear, and its arrival-time appeared (though associated differently) in the ISC listing, the later more prominent phase, while corresponding in time, was not likely to have been $s P^{\prime}$, but the later $P^{\prime}$ arrival of the $G H$ branch. Had that larger amplitude phase been of $s P_{D F}^{\prime}$, that would have been highly significant for the determination of the focal mechanism (see Pearce, 1980), given the low coefficient for the conversion of $S$ to $P$ for near-vertical incidence at the free surface. The phase $P_{G H}^{\prime}$ is usually strongly recorded at that large geocentric distance, with New Zealand earthquakes and Scandinavian seismograph stations having played an important role in determining its travel-time (Adams \& Randall, 1964). It was the particularly sharp character of the $P_{G H}^{\prime}$ phase and the well established intervals for the various branches of the travel-time curve for $P^{\prime}$ that gives some confidence for the pick of the earlier $P_{D F}^{\prime}$ phase, and hence the identification of $p P_{D F}^{\prime}$.

The pertinent observations were taken as the common logarithm of independent ratios of $P, p P$ and $s P$ amplitudes observable in the seismograms. Provision was made 


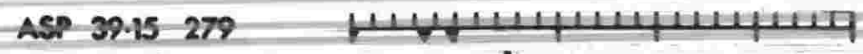

An $\sim a$ an an

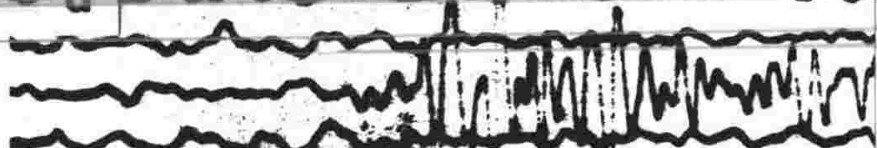

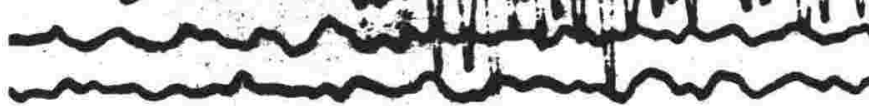

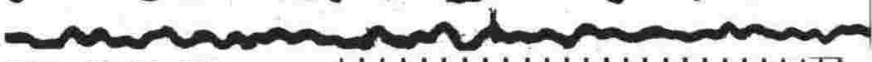
SBA 40.36183 A 40.83284 (n) whrsm

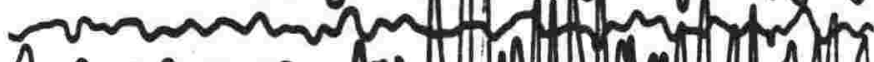
nam

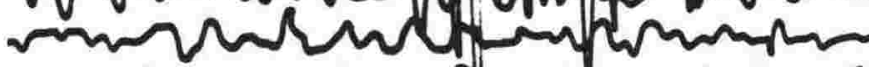

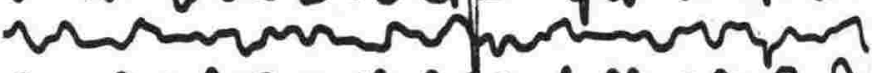

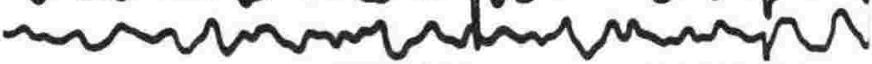

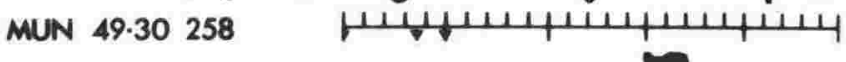

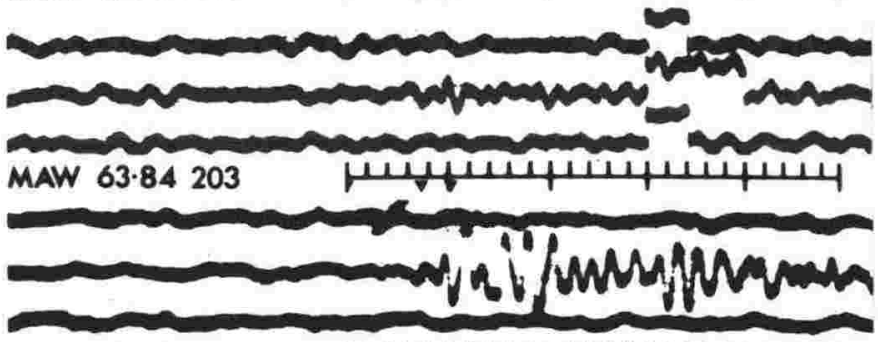
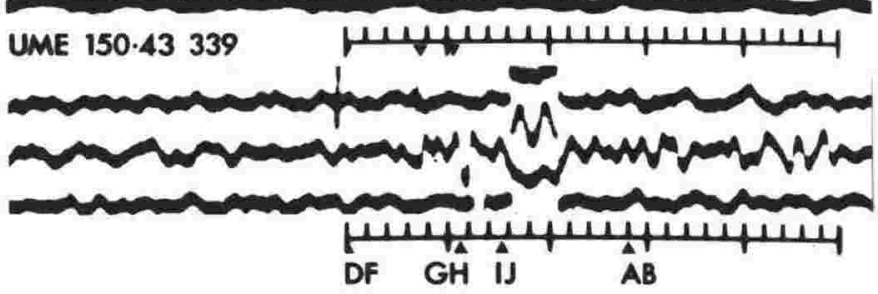

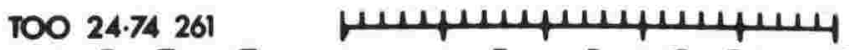
Hon in

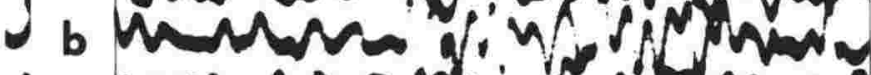

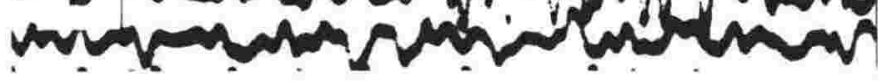

Figure 5.1. Teleseismic waveforms selected (a) for modelling relative amplitudes and (b) as a check on a reported first-motion. Seismograms are identified by the station code, geocentric distance ( $\Delta$ in degrees) and azimuth $\left(N^{\circ} \mathrm{E}\right)$ from the source. Bar scales are graduated in seconds: triangles show the inferred times of arrival of $P, p P$ and $s P$ respectively. For UME, phases corresponding to the different branches of the $P^{\prime}$ travel-time curve are indicated on a bar scale below. 
in the searching algorithm for incorporating the bodywave polarities, by weighting the observed-minus-calculated residuals according to the correctness of the match of sign between observed and computed polarity, but this option has not been used here. The difficulty in picking the direction of first motion for either $P$ or subsequent arrivals can be seen in the seismograms recorded at the mutually close stations in central Australia. The record shown (Fig. 5.1) for WRB (Warramunga Array) is not an array-processed signal but from a single seismometer, that of location WB3, for which the signal onset was just above noise level. A pick made for the polarity of the $p P$ first-motion at this site would have been of opposite sign to that for ASP (Alice Springs), yet this is not merely just a problem of record polarity, since the seismograms for both stations included a clear compressional first-motion for an $m_{b} 5.5$ earthquake occurring in the Santa Cruz Islands region earlier in the day (ISC origintime: May $31^{\mathrm{d}} 14^{\mathrm{h}} 48^{\mathrm{m}} 02.8$ ). The approach taken here was therefore more conservative than that of Langston \& Franco-Spera (1985), for instance, where some reliance was placed on motions of comparable and less-clear onset.

The amplitude-ratio observations constrain the orientation of the assumed shear faulting in meridional planes defined by the azimuths of the stations from the source and the angles of emergence (measured from the downward vertical) of the respective phases from the focal sphere. Three angular variables specify the orientation of the source: dip, rake, and strike. Strike is the azimuth of the rupture plane measured eastward of north; dip is the inclination measured downwards from the horizontal and to the right when looking in the strike direction; and the slip angle (i.e., rake) is measured in the fault plane from the strike azimuth towards the direction of negative dip. A mesh size of $5^{\circ}$ in each of those parametric variables was appropriate, given the distribution of the stations and the uncertainties in takeoff angles. A systematic trial-and-error search of the model space is preferable to convergency schemes, because of the inherent non-linearity of the problem and the non-uniqueness of the solutions.

For a complete trial of fault orientations, it was convenient to let the (nonnegative) quantities of dip and rake increment to $180^{\circ}$, and for strike to go full circle. In Figure 5.2 the goodness-of-fit criterion is displayed graphically: at each Cartesian point in the model space of dip and rake, the locus of the measure of fit is plotted against strike, with the distance of the curve from a local origin in inverse proportion to the root-mean-square error. Better fits are thus apparently indicated by a longer stroke at the particular azimuth of strike for a trial solution. Dips less than $90^{\circ}$ imply a reverse-thrusting component, whilst rakes less than $90^{\circ}$ imply a component of left-lateral shear. However, because no bodywave polarities have been specified, conjugate solutions and solutions of opposite slip are also represented. Table 5.1 indicates the data that were used and the preferred set of solutions.

The sense of slip may be resolved using other polarity data, available locally (e.g., Fig. 4.5), though which of the two nodal planes actually represents the fault plane remains ambiguous on the basis of that information alone. Of the two different 


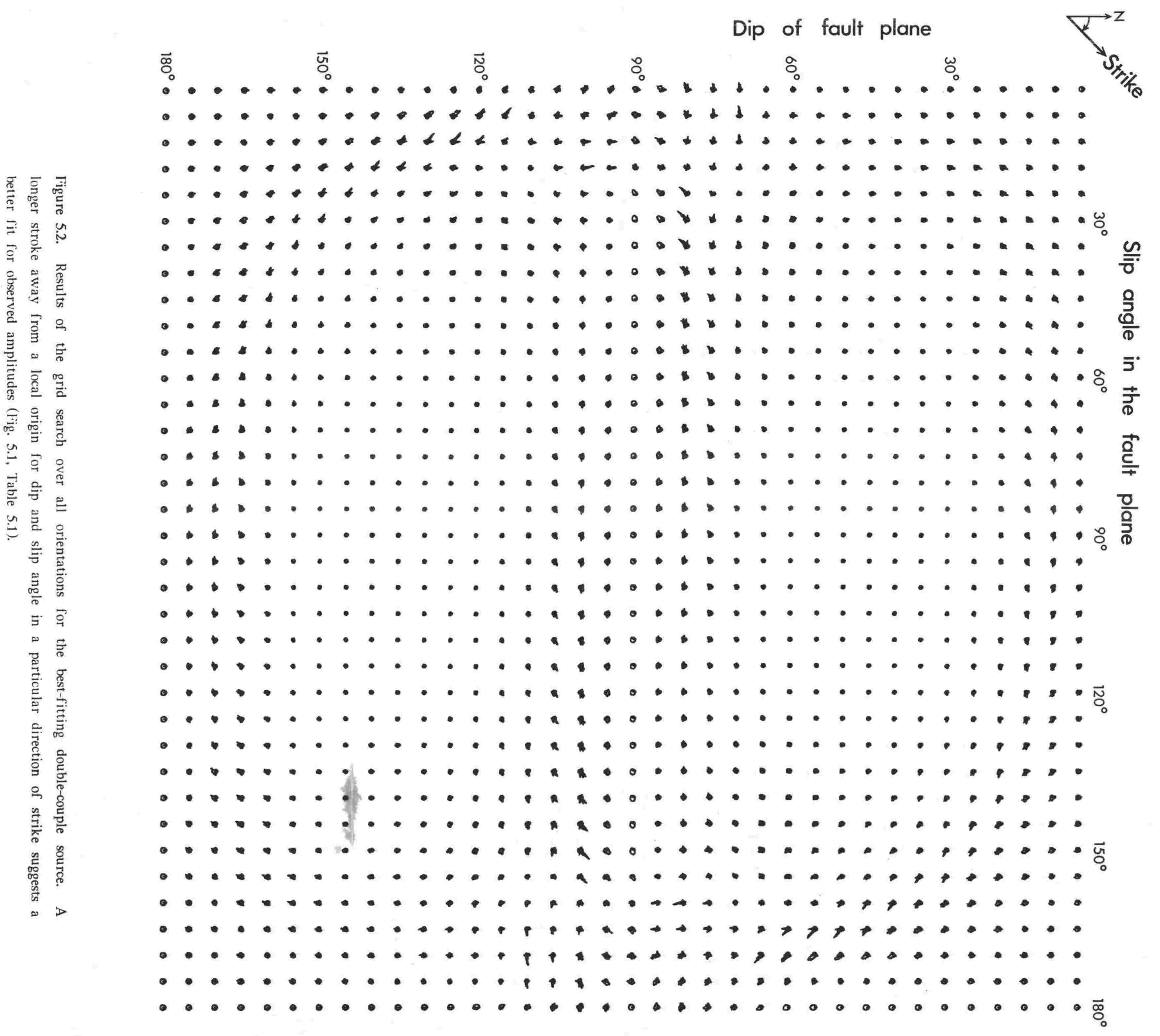


Table 5.1. Observed and calculated amplitudes, and the preferred focal mechanism for the Matata sequence mainshock.

\begin{tabular}{lrrrrrrr} 
STATION & $\Delta$ & AT & PHASE & TAKEOFF & logIPHASE RATIOI & PATH \\
CODE and NAME & ${ }^{\circ}$ & $N^{\circ} E$ & RATIO & ANGLES $^{\circ}$ & OBS. & CAL. & FACTOR \\
\hline ASP Alice Springs & 39.15 & 279 & $p P / P$ & $156 / 24$ & 0.85 & 0.70 & -0.742 \\
SBA Scott Base & 40.36 & 183 & $s P / P$ & $166 / 24$ & 0.65 & 0.66 & -0.282 \\
& & & $s P / p P$ & $166 / 156$ & 0.95 & 0.73 & 0.378 \\
\multirow{2}{*}{ WRB Warramunga Array } & 40.83 & 284 & $p P / P$ & $156 / 24$ & 0.60 & 0.61 & -0.751 \\
& & & $s P / P$ & $166 / 24$ & 0.90 & 0.85 & -0.281 \\
MUN Mundaring & 49.30 & 258 & $s P / p P$ & $167 / 158$ & 0.25 & 0.21 & 0.343 \\
MAW Mawson & 63.84 & 203 & $s P / p P$ & $169 / 161$ & 0.75 & 0.61 & 0.278 \\
UME Umea & 150.43 & 339 & $p P^{\prime} / P^{\prime}$ & $176 / 4$ & 0.30 & 0.27 & -0.992
\end{tabular}

Focal mechanism:

Slip with DIP $100^{\circ}, \operatorname{RAKE} 150^{\circ}$ and STRIKE $\mathrm{N} 45^{\circ} \mathrm{E}$ (axis plunges $29^{\circ}$ at $\mathrm{N} 39^{\circ} \mathrm{E}$ ); or with DIP $119^{\circ}$, RAKE $12^{\circ}$ and STRIKE $\mathrm{N} 309^{\circ} \mathrm{E}$ (axis plunges $10^{\circ}$ at $\mathrm{N} 135^{\circ} \mathrm{E}$ ).

That is: the null axis plunges $59^{\circ}$ at $N 242^{\circ} \mathrm{E}$, and the remaining axes plunge $13^{\circ}$ at $\mathrm{N} 354^{\circ} \mathrm{E}(T)$ and $28^{\circ}$ at $\mathrm{N} 91^{\circ} \mathrm{E}(P)$.

Opposite slip mechanism (violating first motions):

DIP $80^{\circ}$, RAKE $30^{\circ}$, STRIKE $N 225^{\circ}$ E; or DIP $61^{\circ}$, RAKE $168^{\circ}$, STRIKE N129 ${ }^{\circ} \mathrm{E}$.

solution sets most favoured the set with steeply dipping planes and with strikes more towards the cardinal points (e.g., that with a dip of $80^{\circ}$, rake of $160^{\circ}$, and a strike of $\mathrm{N} 170^{\circ} \mathrm{E}$ ) were made inadmissible, because of the greater number of polarity violations that are caused for stations within New Zealand and teleseismically in southeast Asia and the southwest Pacific. The preferred solution is shown in Figure 5.3, together with the first-motion data (reproduced from Fig. 4.5) that helped resolve the sense of slip. Figure 5.2 indicated the solution to be nominally resolved to within $10^{\circ}$ in each of the orientation parameters. Several disparities of first motion remain, however, although the difficulty in making the teleseismic observations was seen in Figure 5.1, especially for $P^{\prime}$. The central trend of hypocentres (Fig. 4.2) suggested it was the northeast-striking plane that represented the fault plane, further discounting the other prospective family of solutions. If so, the solution is one of dextral faulting, but with an appreciable normal component. Although the northeast-striking plane is poorly constrained by the polarity data, it seems the auxiliary plane should pass between the compressional point recorded for the Australian station TOO (Toolangi) and the dilatations recorded for the local stations west of the source (i.e., KRP \& KAH), thereby severely restricting the rake of the slip solution.

The waveform recorded at TOO was given in Figure 5.1b; despite a high noise level, a compressional direction of first motion was apparently confirmed. The +3.9 residual which that arrival onset attracted in the ISC solution, and the nature of the 


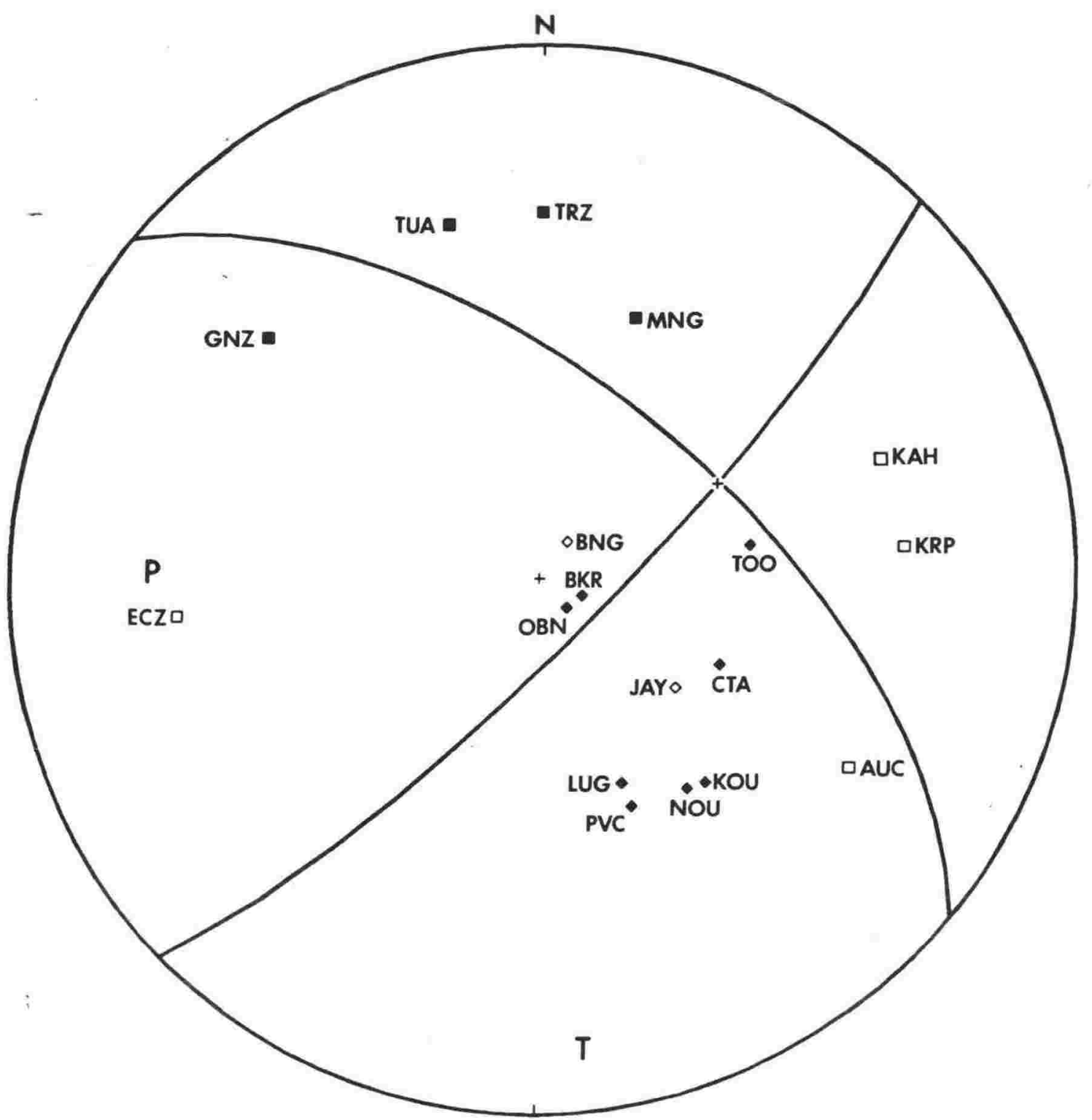

Figure 5.3. Nodal planes suggested by the modelling of relative amplitudes. This solution was one suggested by relative amplitudes in the mainshock waveform (Fig. 5.1, 5.2); the first-motion data from Fig. 4.5 helped select it from among the alternative solutions. Correspondence of the northeast-trending plane with the mainshock rupture is suggested by the central trend of aftershocks in Fig. 4.2.

other waveforms, suggested, however, that the apparent onset was the first motion not of $P$ but of $p P$. This association also fits well with $P$ for TOO being near the null axis, and thus near-nodal in the preferred solution (Fig. 5.3). The polarity of motion observed for TOO should probably therefore have been plotted as a dilatational firstmotion (after correction for the free-surface effect), at the point with similar inclination but with opposite azimuth, consistent with the position for $p P$. Although the motion observed for TOO was thus still consistent with the derived solution of focal mechanism, others occurring locally were not (i.e., GNZ \& AUC). It was important that these cases be examined closely, especially since a double-couple force system has been assumed: in a volcanic region significant departures might signify a 
compensated linear-vector dipole system of forces, related with fluid injection into a tensile crack, such as might be expected for dike intrusion (Julian, 1983).

\section{The inconsistencies}

The first of the inconsistent first-motions examined is that for the station GNZ. For a check on the correctness of polarity of the GNZ seismograms, Table 5.2 gives a comparison of teleseismic first-motions reported for GNZ and other stations of the New Zealand seismograph network: from time to time the recording polarity at a site may inadvertently become reversed, as seems to have been the case for the particular month shown for 1981. On balance, however, the data for 1977, and for both the preceding and the following year, suggest that recording polarity was not a problem at GNZ at the time of the Matata sequence. Although the first-motion direction found for GNZ must therefore continue to be accepted, the compilation does show further examples of mistakes being made in reporting first motions for KRP, possibly arising from the different format of short-period records for that station (see Fig. 4.6, and earlier discussion).

Table 5.2. Teleseisms with a first motion recorded for GNZ in the ISC Bulletin.

\begin{tabular}{|c|c|c|c|c|c|c|c|}
\hline YEAR, & DATE & $\begin{array}{r}\mathrm{AN} \\
\mathrm{d}\end{array}$ & & $\begin{array}{r}\text { TIME } \\
\mathrm{h} \quad \mathrm{m} \\
\end{array}$ & $\begin{array}{c}\text { SIZE } \\
m_{b}\end{array}$ & SOURCE REGION & N.Z. FIRST-MOTIONS \\
\hline \multirow[t]{4}{*}{1976} & JAN & 09 & 23 & 54 & 5.7 & New Hebrides & all up \\
\hline & MAR & 02 & 10 & 51 & 5.7 & Solomon Islands & all up, except KRP \\
\hline & JUN & 02 & 10 & 24 & 5.3 & Taiwan & KRP up; MNG, GNZ down \\
\hline & SEP & 01 & 13 & 25 & 5.6 & New Hebrides & all up \\
\hline \multirow[t]{4}{*}{1977} & JUL & 08 & 08 & 48 & 5.7 & Solomon Islands & all down \\
\hline & OCT & 14 & 12 & 29 & 5.7 & New Hebrides & all up, except GSP \\
\hline & OCT & 17 & 17 & 26 & 6.2 & North of New Zealand & all up \\
\hline & OCT & 29 & 20 & 15 & 5.9 & E. New Guinea Region & all down \\
\hline \multirow[t]{5}{*}{1978} & JAN & 24 & 15 & 32 & 5.7 & New Britain Region & all up \\
\hline & FEB & 21 & 07 & 14 & 5.8 & Banda Sea & all down \\
\hline & FEB & 21 & 07 & 47 & 5.6 & Banda Sea & all up \\
\hline & JUL & 28 & 10 & 46 & 5.2 & New Hebrides & all down \\
\hline & NOV & 10 & 13 & 25 & 5.6 & Solomon Islands & all up \\
\hline \multirow[t]{2}{*}{1981} & JUL & 06 & 03 & 08 & 6.3 & Loyalty Islands & all down, except GNZ \\
\hline & JUL & 21 & 11 & 47 & 5.8 & Vanuatu & all up, except GNZ \\
\hline
\end{tabular}

Because the point plotted for GNZ lies near the northwest-southeast nodal-plane, it may have been that the initial motion for GNZ was not of the first arrival. As travel-times may give an indication of ray path, Figure 5.4 indicates $P$ times picked 


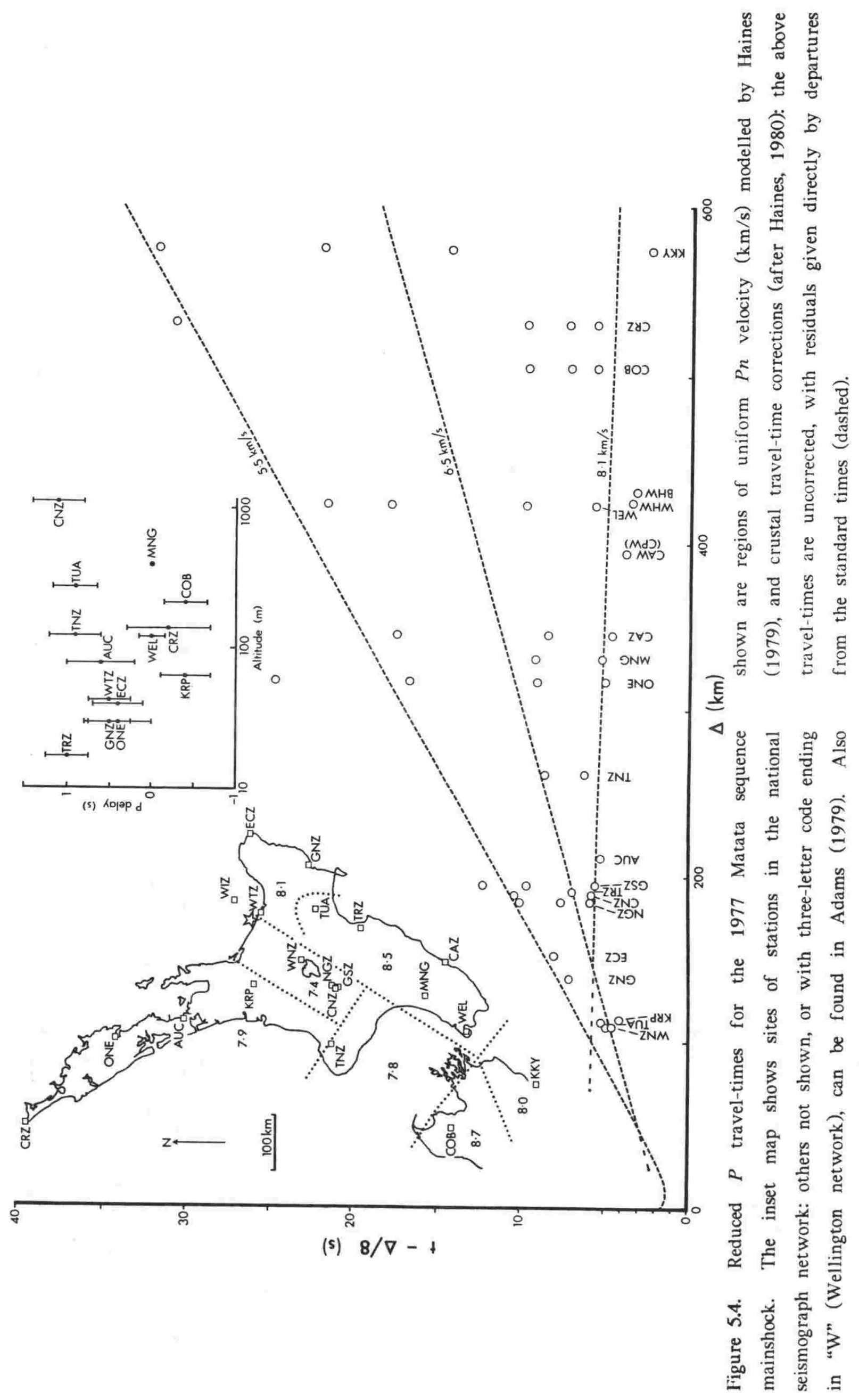


for the mainshock with respect to the hypocentre solution of this study (Table 4.1). It appears that the first arrival at GNZ was relatively delayed, but also that the delay was a feature common to the eastern stations of the permanent seismograph network. It may therefore have been that the mainshock was located too far to the west (at the expense of stations west of the source region), or that the eastern arrivals were truly late for reasons of slow ray-path. As GNZ has the highest magnification of the east coast stations, the best chance of seeing a small critically refracted arrival would be at that station, unless the first-arriving wave to GNZ always follows the more direct path. (For a direct path, the first motion would be plotted at the southeastern azimuth on the upper-hemisphere plot of the focal sphere, near to horizontal and close to the auxiliary plane.)

The three components of ground motion recorded at GNZ for the two largest earthquakes in the Matata sequence are shown in Figure 5.5. The initial motion at GNZ for the mainshock was evidently up, to the south and west, whereas motion for the largest aftershock was down, to the north and east. The onsets seem impulsive enough and without any small forerunner that might have been taken for microseismic noise. However, these sets of first motions are incompatible with the principle that the direction of first movement on all three components should either be consistently away from or be consistently towards the source. Thus for GNZ, being to the southeast of the source region, the components of motion should have been either up, south and east, or else down, north and west. Although it therefore seems that it was the east-west component that was somehow in error, closer inspection reveals that the first arrivals on the vertical-component seismograms were at least $1.0 \mathrm{~s}$ in advance of abrupt onsets recorded on the horizontal-component seismograms, and that any corresponding signal on the latter seismograms was barely perceptible.

Timing error was not the cause of the arrival-time differences, since the timing correction was common and all three components registered on the same recording drum, as is evidenced (Fig. 5.5) by the drift offsets in the timing marks. The delay suggests that two branches of the travel-time curve were involved, and not merely a case of just a direct arrival. Moreover, two distinct observations of first-motion polarity would be available, were it not for the contradictory indications from the horizontal components: one for the direct path; and the other for an indirect path.

GNZ frequently has first-motion directions for $P$ reported for it that are internally inconsistent, though the reason for that cannot be known for sure without examining the seismograms. A check could be made on first-motion consistency, nevertheless, using onsets of other well recorded earthquakes occurring during the 1977 microearthquake survey, each without measurable difference in onset arrival-time between components. This check suggested it was the north-south component that was incongruously of reversed polarity: the magnitude 4.3 aftershock of the Matata sequence (June $03^{\mathrm{d}} 11^{\mathrm{h}} 40^{\mathrm{m}}$ ) had first-motions up, north and east; the subcrustal mainshock of magnitude 4.4 (June $02^{\mathrm{d}} 13^{\mathrm{h}} 17^{\mathrm{m}}$ ), also northwest of GNZ, yielded first-motions down, 
(

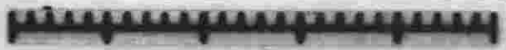

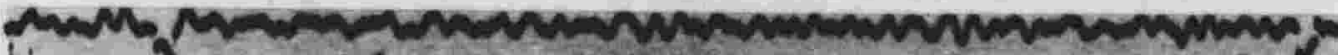
Nhim

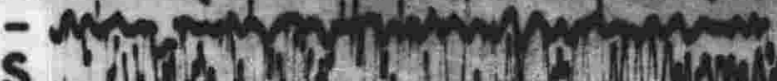

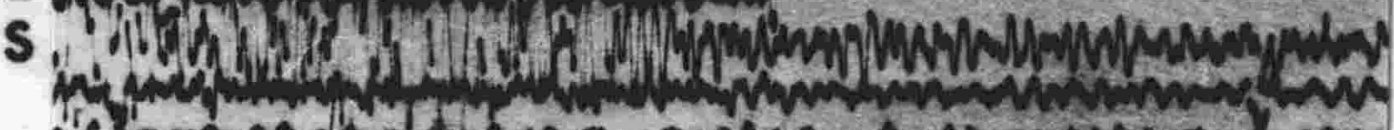

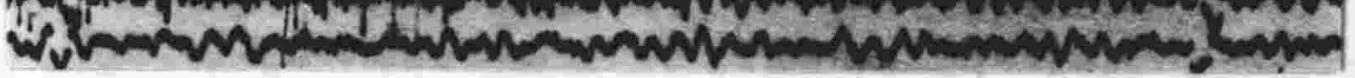

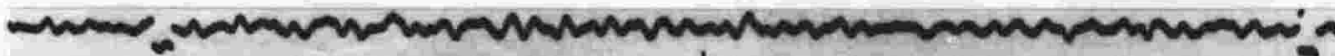

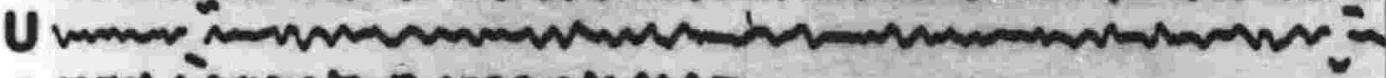

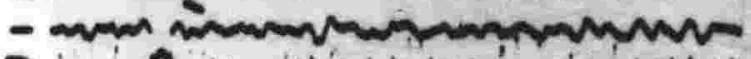

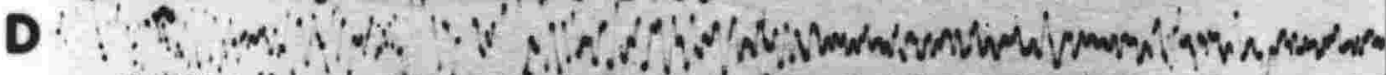

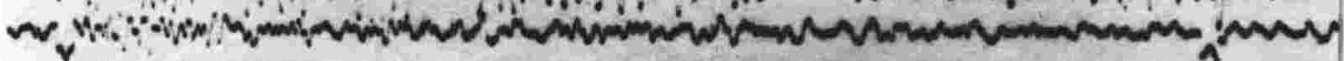

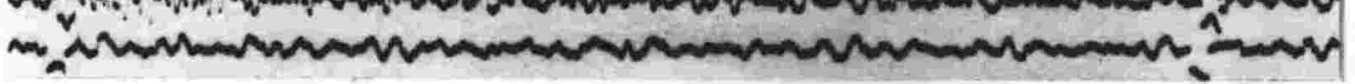

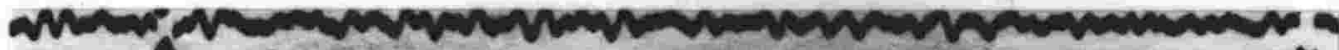

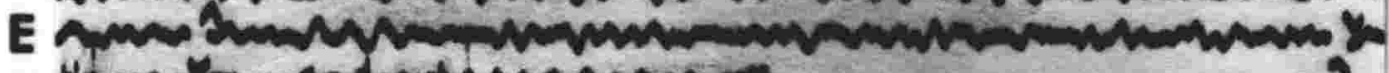

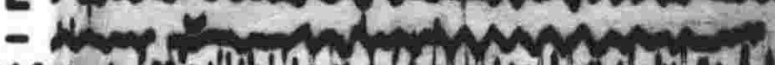

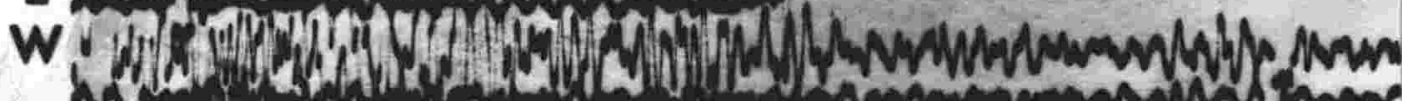

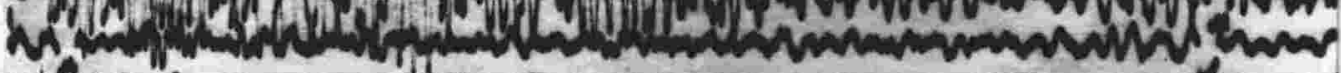

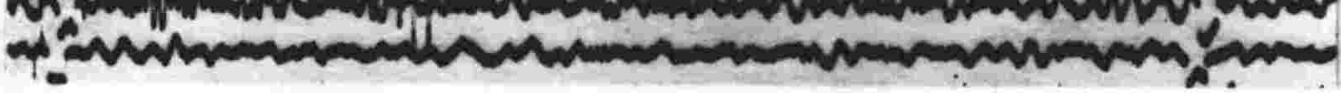

e.

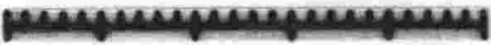
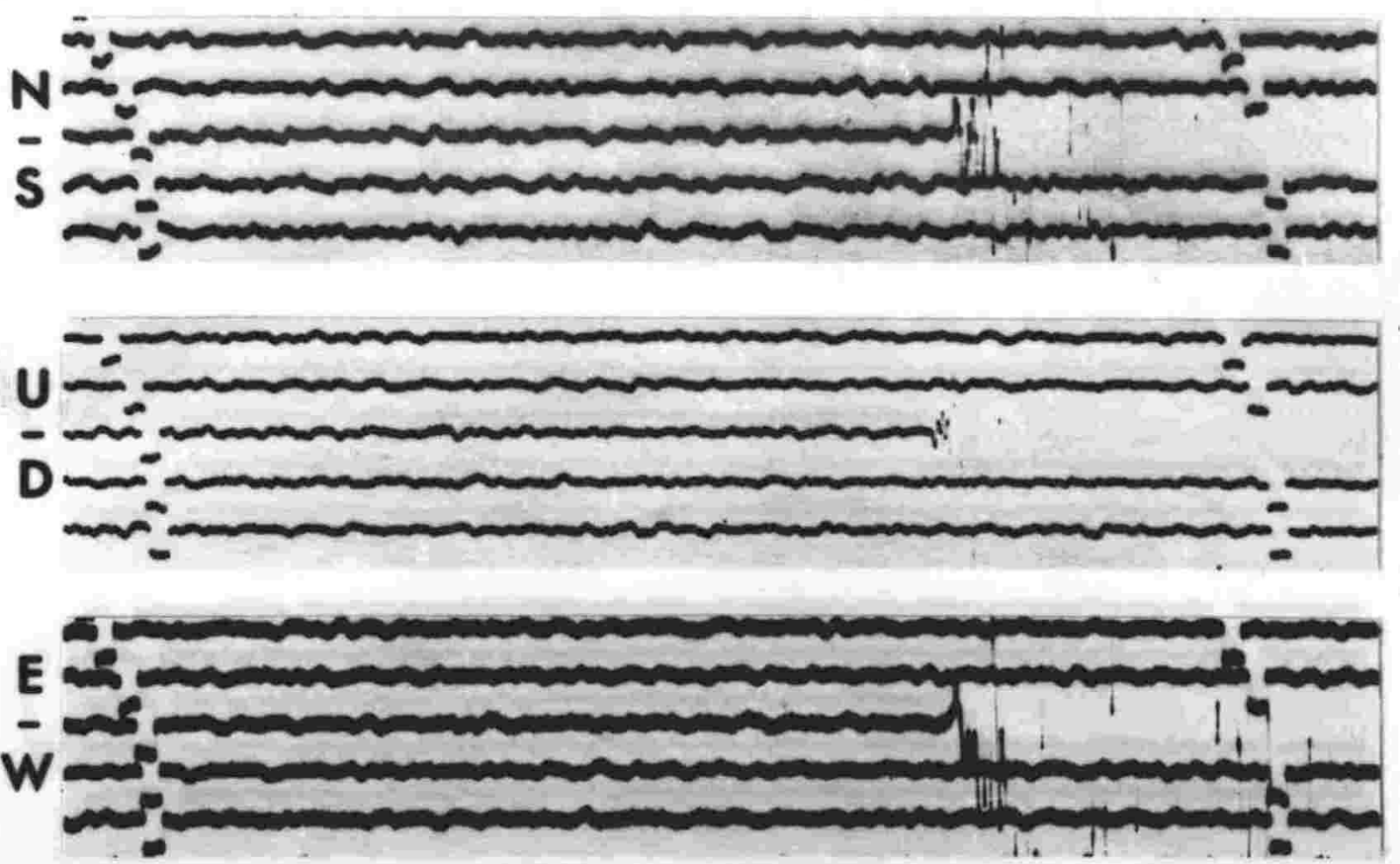

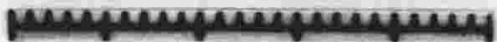

Figure 5.5. The onsets of (a) the mainshock and (b) the largest aftershock at GNZ. Timing marks are $60 \mathrm{~s}$ apart. The three components of ground motion are labelled. Components are aligned to show differences in arrival-times. 
south and west; and a magnitude 5.1 earthquake (June $04^{\mathrm{d}} 17^{\mathrm{h}} 25^{\mathrm{m}} ; 77 / 352$ ) occurring south of GNZ yielded first-motions clearly down and north. Thus the additional firstmotion direction that may be plotted for GNZ in the southeastern sector of Figure 5.3 is that of a dilatation with takeoff angle almost horizontal.

The other apparent inconsistency examined is the first motion at AUC (Auckland). That station, however, is of low sensitivity, so that data for it rarely appear in the ISC Bulletin; this made a similar check on the correctness of its recording polarity using teleseismic observations impractical. Some comparison of reported first-motions could nevertheless be made with first motions expected from the dominant type of focal mechanism found by Harris (1982) for earthquakes originating deep beneath the central North Island. First motions are plotted in Figure 5.6 for those events for which an indication was given for AUC: the region from which the earthquakes were drawn was identical to that sampled in the earlier, pioneering study. The nodal planes in Figure 5.6 are those of Harris (1982: Fig. 6), determined from a composite diagram for earthquakes categorised as of Group A and originating between $150 \mathrm{~km}$ and $200 \mathrm{~km}$ depth. (None of the earthquake first-motion patterns matched as well with the other frequent mechanism (i.e., Harris, 1982: Fig. 8, Group B).) Observations for AUC lie near the null axis of the solution. However, discrepancies become most evident if the dip of the north-striking plane decreases (as has been supposed) with increase in depth of earthquake origin. Although not proven decisively, this irregularity sufficed to indicate that the data for AUC at the time of the Matata mainshock was of doubtful merit.

The first-motion discrepancy for GNZ, as already asserted, may have arisen for the Matata sequence events because that station was near-nodal for $P$ for direct and indirect ray-paths; the opposite directions of motion at GNZ for the largest aftershock (Fig. 5.5b) similarly suggested that station was near-nodal. Moreover, a slight steepening of the null axis in the plane that was suggested (Fig. 5.3) as the fault plane by the early aftershock lineation, together with a small rotation about the null axis, can be easily accommodated, given the uncertainties of the relative amplitude method (Fig. 5.2), without introducing further polarity violations. The stations examined (i.e., GNZ and AUC) could then be even more near-nodal. Furthermore, inconsistent first-motions may result from a non-planar rupture (e.g., Sipkin, 1986), of which there was some hint (Fig. 4.2). Hence no clear, indisputable departures from the assumed double-couple model can be claimed, and thus no clear evidence exists in favour of the alternative dike-intrusion model. It is appropriate now that another look be taken at the first motions for other earthquakes in the Matata sequence, to account for the mix of first motions for the Bay of Plenty region (Fig. 4.8 \& 4.10).

\section{Reappraisal of focal mechanisms}

A search for the best-fitting solution of focal mechanism could, in principle, have been made for other earthquakes in the sequence, by matching the observed ratios of $P$ and 


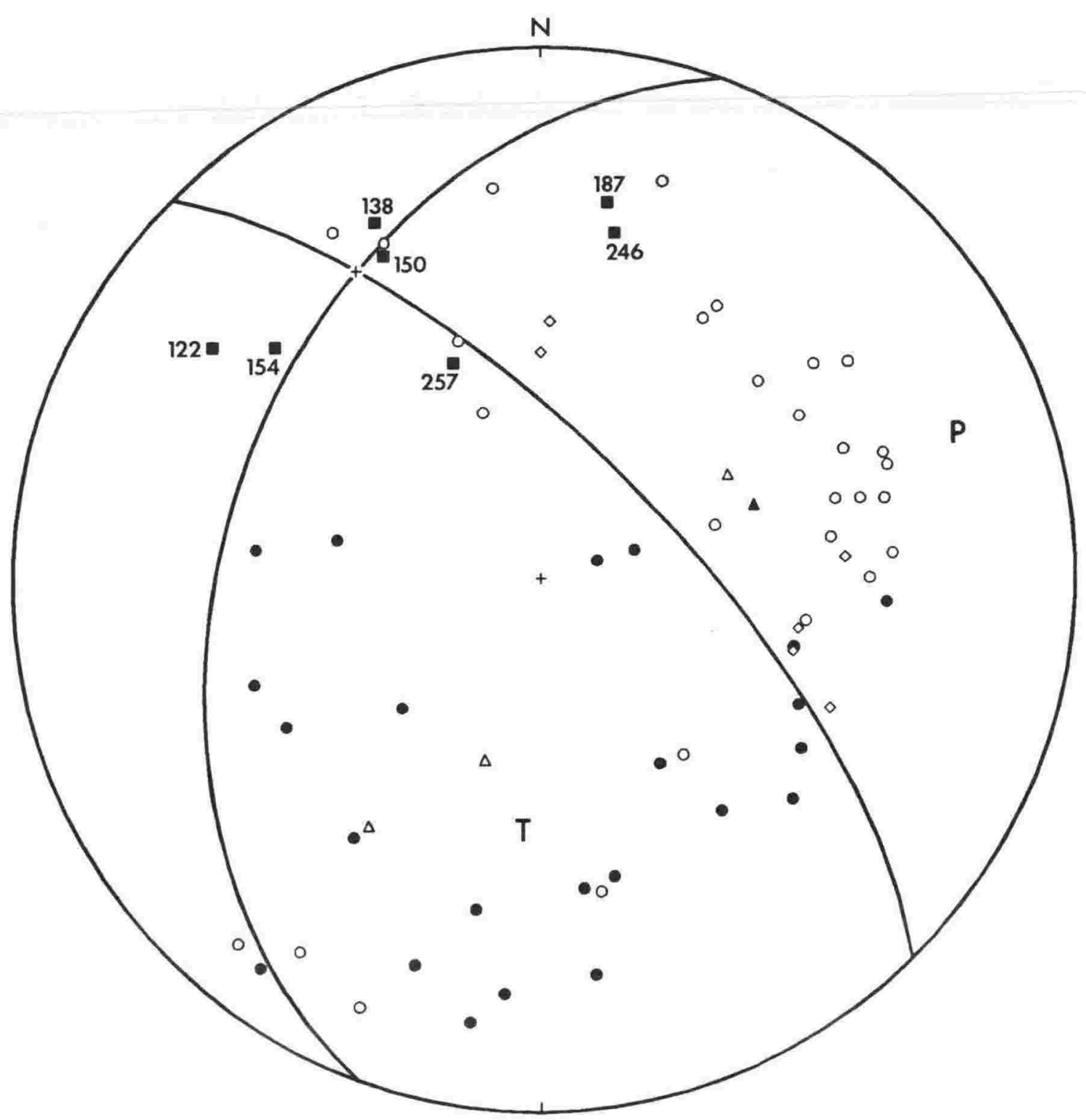

Figure 5.6. First motions of subcrustal events between latitudes $38^{\circ} \mathrm{S}$ and $40^{\circ} \mathrm{S}$, where reported for station AUC of the national seismograph network (N.Z. Seismological Reports for the years 1976-78 inclusive). Symbols are as in Fig. 4.5, except that squares show the data for AUC, the associated numerals giving the corresponding focal depths; triangles show the data for CNZ, which also seems anomalous.

$S$ amplitudes from the vertical-component seismograms against those modelled (e.g., Kisslinger, 1982); indeed, the procedures of Kisslinger et al. (1981, 1982) are but a special case of the relative amplitude method already described for the teleseismic waveforms. Some limitations existed in practice, however. For example, the signals for the more important, larger foreshocks and aftershocks were nearly always clipped on the high-gain records from the temporary seismograph array. Even where that was not the case, there were of ten the practical difficulties of establishing the onset of the $S$ having the same ray-path as the first-arriving $P$, and of measuring the amplitudes of its first half-cycles. Besides, such solutions for strike-slip mechanisms may be poorly constrained by the amplitude data, in the absence of a nodal observation (see 
Kisslinger, 1980).

Complete modelling of the waveform is rather difficult without detailed knowledge about the velocity structure; even when recorded digitally, the signal is usually low-pass filtered before any comparison with synthetic waveform, in order that it be more pulse-like and less dependent on near-surface structure (e.g., Saikia \& Herrmann 1985). Instead then an attemnt, was, made to discriminate hetwegen distinct 


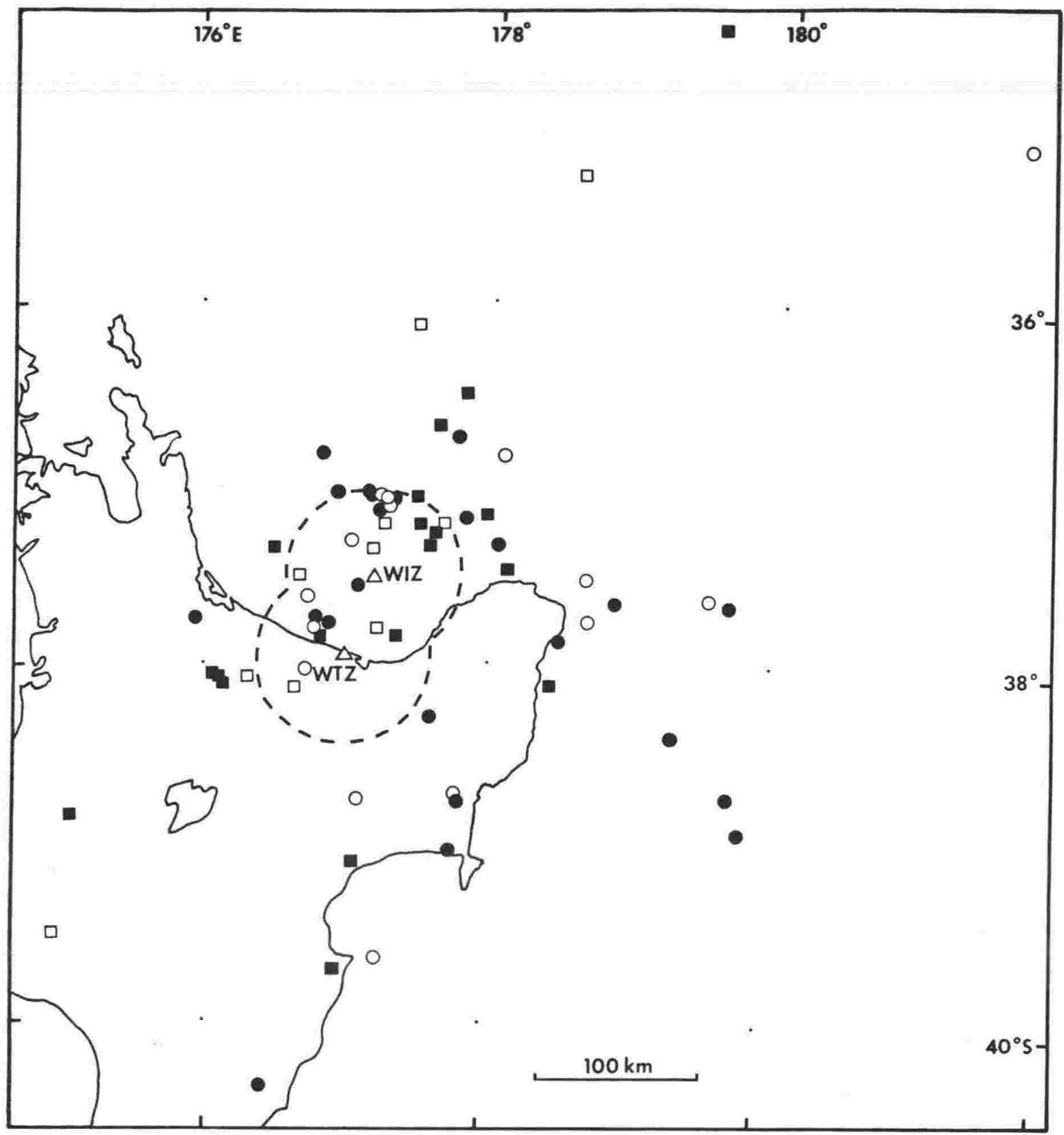

Figure 5.7. Comparison of first motions at WTZ and WIZ for the years 1977-82: solid symbols denote that opposite first-motions were reported in the NZ. Seismological Reports. Symbols are plotted at the earthquake epicentres; squares denote that computed focal-depths were greater than $40 \mathrm{~km}$. The dashed line gives $50 \mathrm{~km}$ epicentral range from either WTZ or WIZ.

proximity of a nodal-plane striking northwest-southeast. First motions at the nearby station to the west, MDQ, were almost exclusively dilatational, and required that the other nodal-plane trend roughly northeast-southwest, to isolate those dilatational firstmotions from adjacent compressions. The dip and strike of the latter nodal-plane were not well constrained by the data for individual earthquakes. Nevertheless, a strike of nodal plane is suggested approximately by the mixture of first motions plotting to the southwest, and a vertical plane suffices.

Next - Type 2 - were the patterns with a dilatation recorded at either of the 


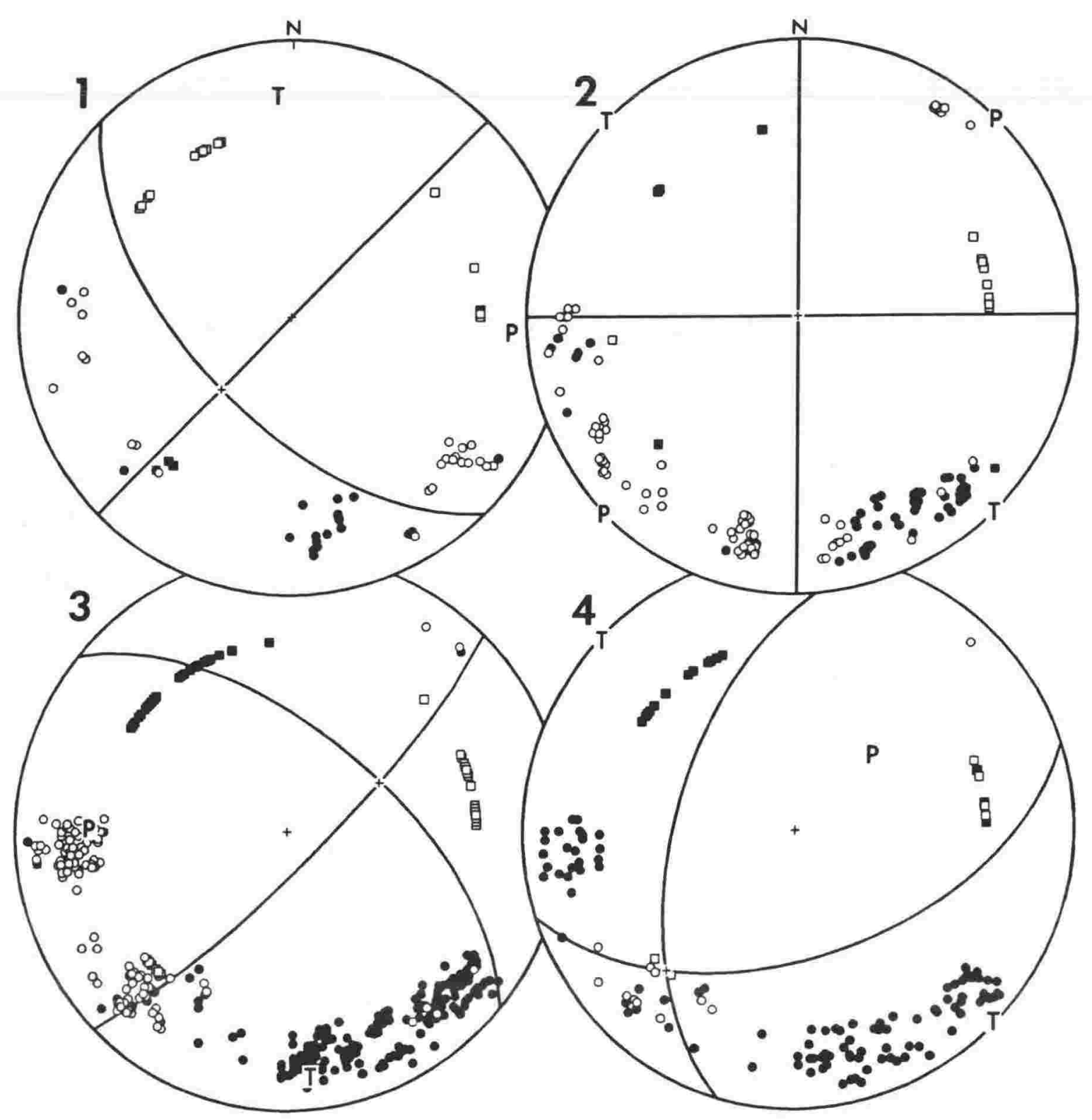

Figure 5.8. Composites of first-motion patterns for earthquakes of the Matata sequence. The plotting convention is as for Fig. 4.7. Numerals identify the different types of pattern. Type 3 is the mainshock mechanism from Fig. 5.3: uniform interpretation of arrivals at southeastern sites near the crossover distance for first-arriving direct and critically refracted rays as only of direct arrivals reconciles the apparent inconsistencies plotted in the northwestern quadrant. The other orientations of nodal plane were suggested by contrasting polarities at adjacent stations for particular cases merged in these composites, the data shown in northwestern quadrants having been similarly transposed to positions appropriate to more direct arrivals.

stations to the south, AWA and MAE. As these dilatational first-motions abut the strongly compressional region to the southeast on the composite focal sphere, a partitioning nodal-plane was warranted: moreover, in the 7 out of the 16 cases for the earthquakes for which first-motion directions were picked for both stations, the first motion plotting further eastward was compressional. Furthermore, the first motion at 
MDQ was often also dilatational, leaving no option, given the orthogonality constraint on the nodal planes, and the predominance of dilatational first-motions to the southwest, but to admit a solution with nodal planes striking towards the cardinal points, with the planes steeply dipping. This solution thus differs in orientation from that of the mainshock mechanism.

The remainder of the Matata sequence first-motion patterns could be divided on the basis of whether it was a dilatation or a compression that was recorded at MDQ: Types 3 and 4, respectively. By far the more numerous, the Type 3 patterns were adequately represented by the mainshock mechanism. The Type 4 patterns, on the other hand, commonly demanded that both nodal-planes strike somewhere in the northeast-southwest sector, in order that they intervene between the dilatational firstmotions recorded at sites of southwestern azimuth and the compressional first-motions recorded at sites to the south and to the west. Oppositely signed directions of first motion were observed in 8 out of the 20 occasions where picks were clear at the two southwestern stations (MAN \& LRO) for constituent earthquakes of Type 3, thus apparently confirming the strike of the mainshock plane. Similar opposites were observed in 2 out of the 6 pairs for constituent earthquakes of Type 4 .

The above is intended only as a broad classification. Obviously, it is incomplete in that not all earthquakes could be considered due to missing observations, which may also, together with the sparse coverage of the focal sphere, have contributed to any mismatch of category for individual earthquakes. Generally, though, suitable variations could be tailored, given the constraints already noted, by slightly altering the dip of one of the nodal planes, as first motions in specific instances dictated. Cases where a nodal plane should pass between the points for critical refractions to the more distant stations to the west, KAO \& KAH, were usually then easily satisfied. Note, however, that first-motions observed for distant stations to the southeast, MAR and WAI, were more consistent with direct ray-paths than with the critically refracted ray-paths of ten assigned in the hypocentre solutions. Moreover, the observed variation of first-motion directions was not limited to the smaller earthquakes such as were sampled for the epicentre relocations (Fig. 4.1) and used for the initial first-motion composites (Fig. 4.7 $\& 4.8$ ), as can be seen from Figure 5.9 .

A Type 2 pattern (Fig. 5.9a) was observed for the second-largest aftershock, the largest aftershock occurring within the eastern clustering of activity. An additional constraint on one of the nodal planes was that offered by the first-motions up and west at KRP, which contrasted with the dilatations at the other stations of western azimuth (i.e., KAO \& KAH): moreover, the amplitude of the first $P$ half-cycle observed at GNZ was four times that for the largest aftershock, in spite of the difference in magnitudes. In contrast, the largest of the western aftershocks had a first-motion pattern of Type 3 (Fig. 5.9b), with a nodal plane of similar orientation to that for the mainshock necessarily projecting close to the seismograph sites to the southwest; a more north-striking nodal-plane was not possible for that pattern, largely because of the 


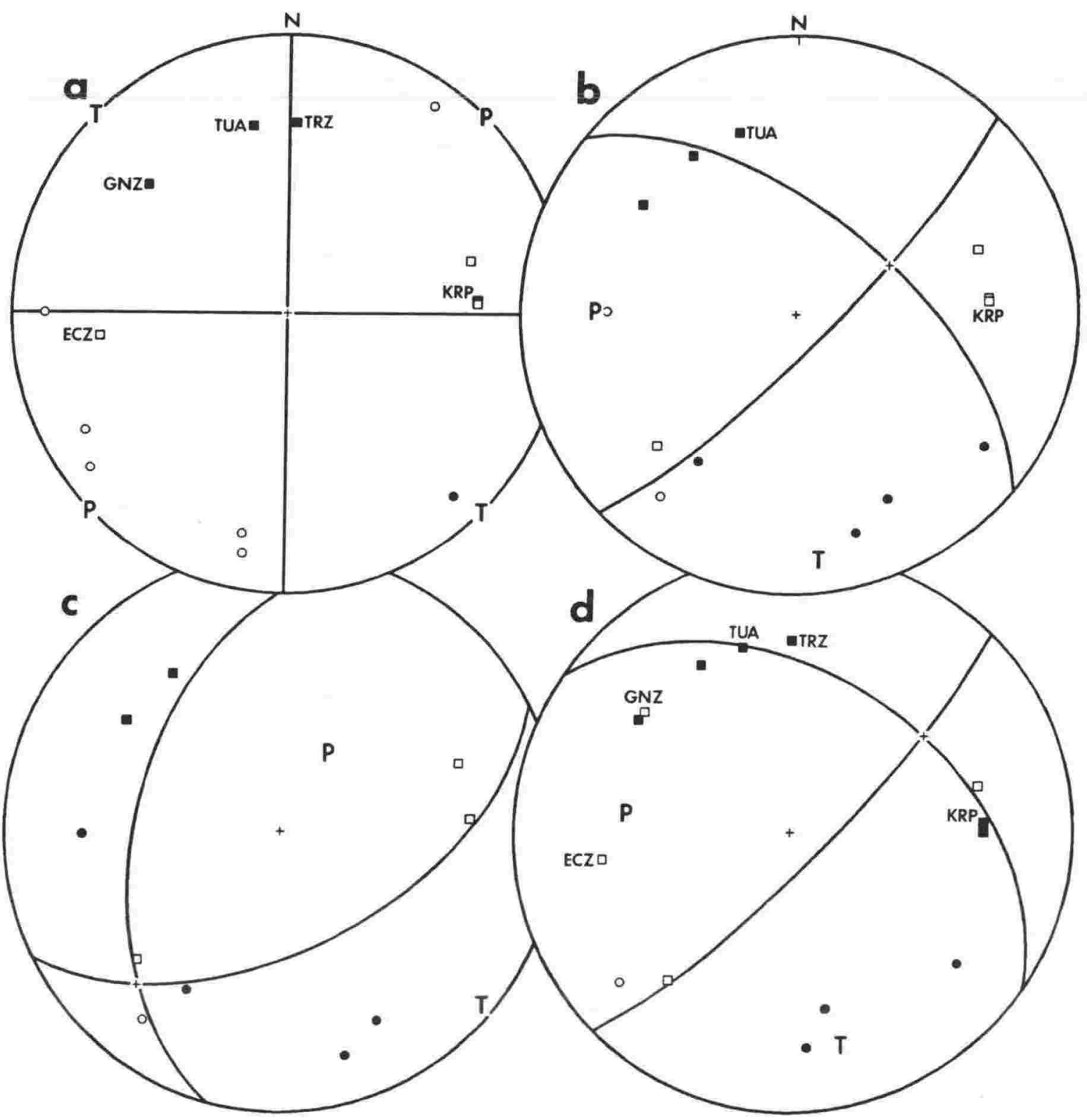

Figure 5.9. First motions for the larger aftershocks of (a) June $03^{\mathrm{d}} 11^{\mathrm{h}} 40^{\mathrm{m}}$, magnitude 4.3, to the east; (b) June $04^{\mathrm{d}} 07^{\mathrm{h}} 36^{\mathrm{m}}$, magnitude 3.9 , and (c) June $03^{\mathrm{d}} 07^{\mathrm{h}} 17^{\mathrm{m}}$, magnitude 3.6, to the west; and (d) the largest of June $01^{\mathrm{d}} 17^{\mathrm{h}} 07^{\mathrm{m}}$, magnitude 4.7. Compare with Fig. 5.8. Data for more distant stations of the national network (labelled) are more assured as critical refractions: nodal planes were constrained with the other (unlabelled) data shown in northwestern quadrants reinterpreted as of direct arrivals and transposed accordingly.

dilatational first-motion observed for MDQ. However, this latter pattern also contrasted with the Type 4 pattern observed for an earlier large aftershock originating also in the west; for that case (Fig. 5.9c) one nodal-plane was required to isolate the compressional first-motion at site MAN from the dilatation at LRO, while the compression at MDQ forced the other nodal-plane to pass also within the southwestern region. Finally (Fig. 5.9d), the largest aftershock of the sequence remained uncategorised for want of an observation for MDQ. Compressions at KRP and KAO, as opposed to a dilatation at 
$\mathrm{KAH}$, restricted one nodal-plane, and dilatations at GNZ (Fig. 5.5) and ECZ prevented the solution from otherwise being of Type 4 or Type 2. The focal mechanism for the largest aftershock therefore appears similar to that determined for the mainshock, but with less dip for the nodal plane striking northwest-southeast.

A common attribute imposed by the first motions for the source mechanisms seems to have been that the null axis lay in, or near, a plane paralleling the steeply dipping, northeast-striking plane of the mainshock, as exemplified for all the variation found necessary in fitting the orthogonal nodal-planes of a double-couple source mechanism. Figure 5.10 shows the temporal and magnitude distribution for the various categories of first-motion pattern, and Figure 5.11 the spatial distribution; the arrangements exhibited should not have been so orderly, had the observations been purely random or resulting from consistently poor observations of first motion attributable to small signal onsets. Originating near the northern and southern limits of the volume defined by the aftershock hypocentres, the earthquakes of Type 1 mechanism were commonly small in magnitude; other than the few that were foreshocks, they were confined to the interval between the occurrence time of the largest aftershock (June $01^{\mathrm{d}} 17^{\mathrm{h}} 07^{\mathrm{m}}$ ) and the next largest, originating to the east (June $03^{\mathrm{d}} 11^{\mathrm{h}} 40^{\mathrm{m}}$ ). Type 2 mechanisms predominated in the region of the eastern events, almost to the exclusion of the others, but they were found also amongst the central groupings of activity. The events of Type 4 mechanism, on the other hand, were rather more interspersed with those of Type 3. Generally, though, and also throughout the foreshock activity, the earlier or otherwise anomalous occurrences of Type 2 and Type 4 mechanisms tended to be for the events away from or at the margins of the main clusterings then current.

The earlier inclusion of first motions from other nearby earthquakes in the composite for shallow Bay of Plenty earthquakes (Fig. 4.8b) may have been erroneous. Hence first motions of these other earthquakes should also be reconsidered. Events contributing observations to Figure 5.12 were grouped on a regional basis: events of May 29 occurring near Kawerau; and events occurring thereafter, from May $30^{d} 00^{\text {h }}$, near Te Teko (see Fig. 2.4). A Type 4 mechanism seemed most appropriate for the Kawerau earthquakes (Fig. 5.12a), since one nodal plane must project between nearby and more distant seismograph stations of the eastern network for the case of the magnitude 3.2 event of May $29^{\mathrm{d}} 18^{\mathrm{h}} 38^{\mathrm{m}}$; a Type 2 mechanism apparently best satisfied first motions produced at northern and southern stations of the eastern network for the Te Teko earthquakes (Fig. 5.12b). The solutions shown also better fitted observations of nodal $P$. Actually, the distinction between these groups of earthquakes was early recognised from the clearly different waveforms at stations of the western network, and the disclosure and explicit presentation here of the different mechanisms just awaited sufficient cause. The distinctly different solutions - normal contrasting against strike-slip mechanisms - suggest local conditions were important at this low level of earthquake magnitude, indicating that these earthquakes may not be directly relatable to those of the Matata sequence. 


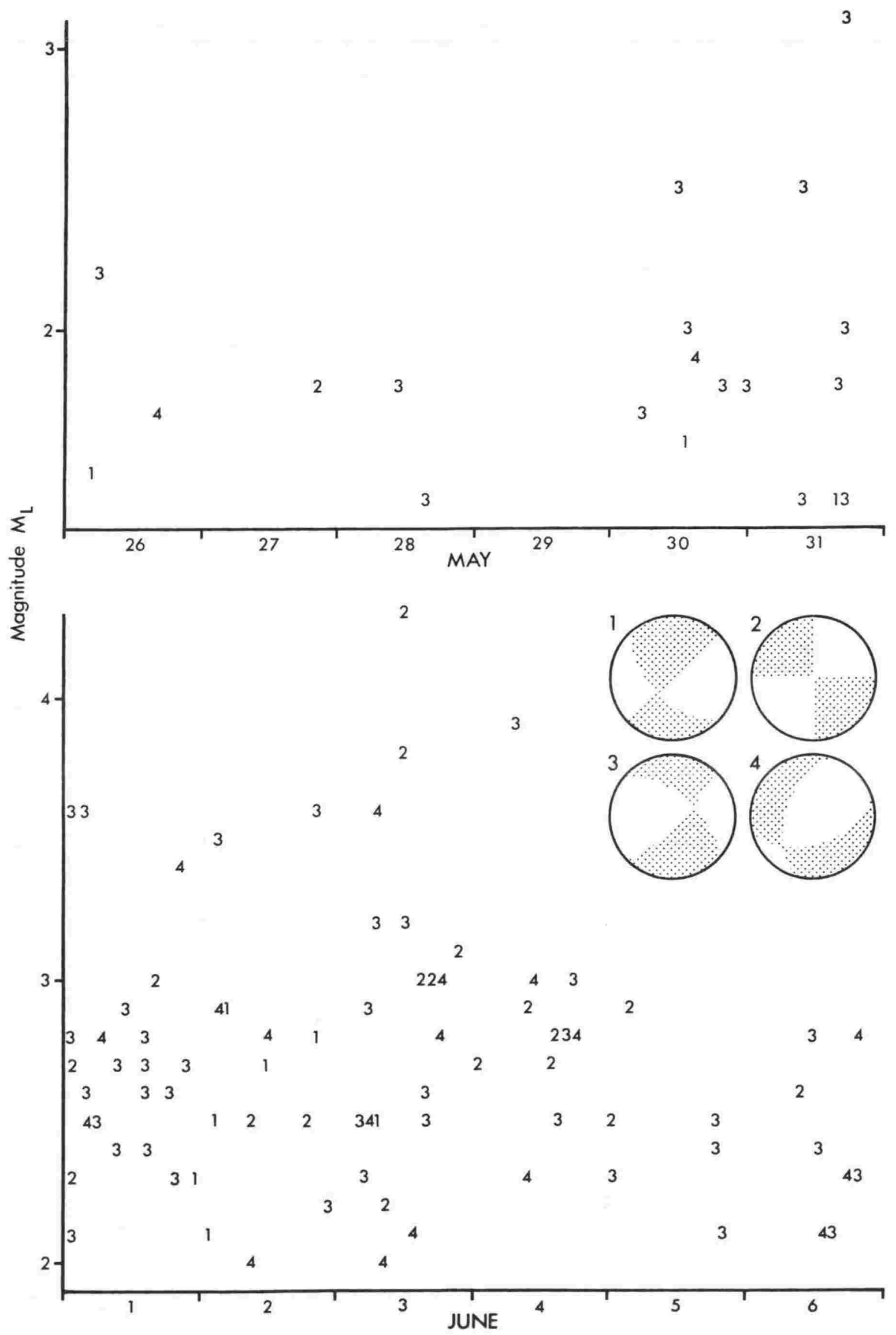

Figure 5.10. History of faulting-type against earthquake magnitude. Type solutions (shown by the upper-hemisphere projections) have compressional quadrants shaded. 


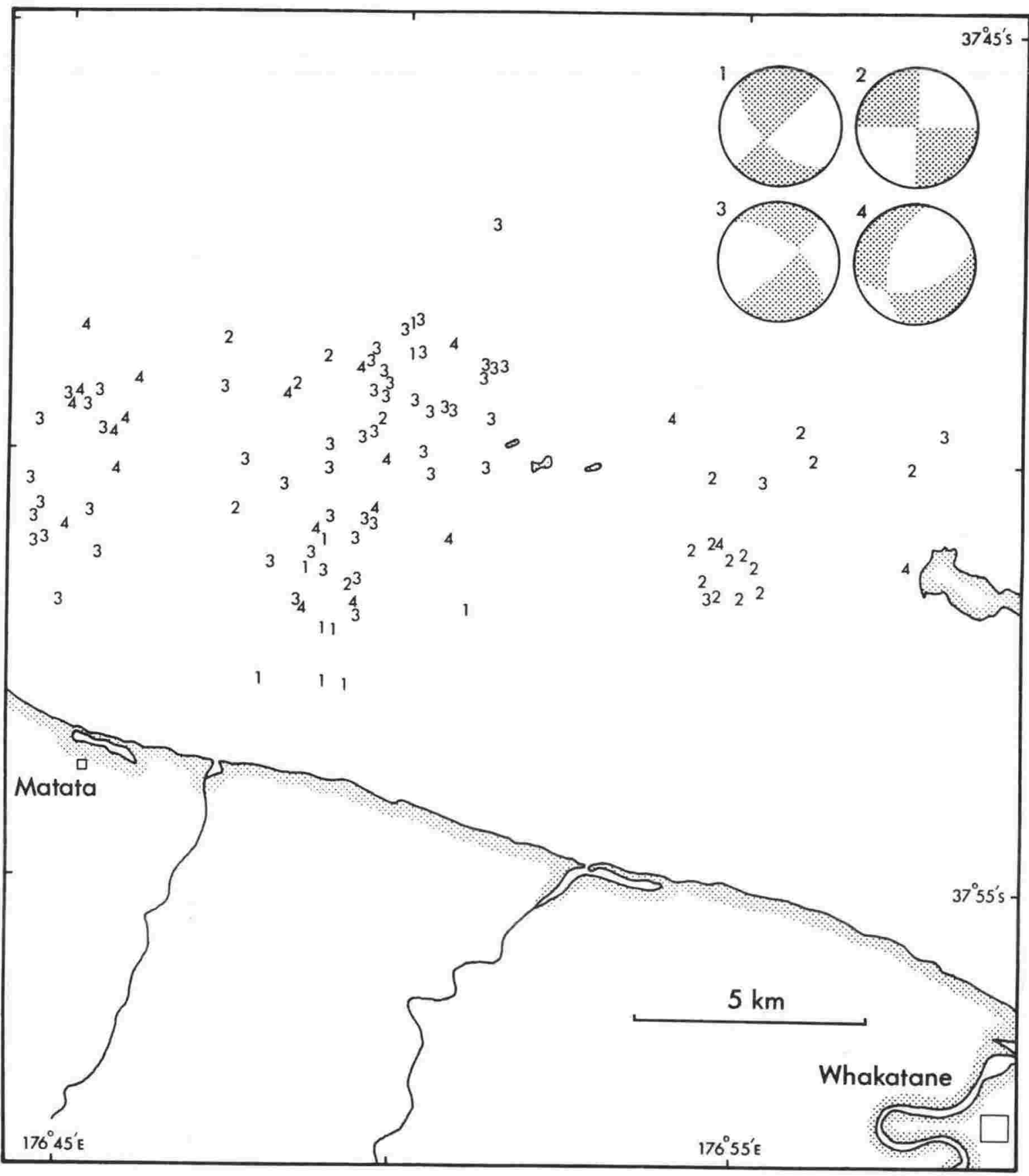

Figure 5.11. Correspondence of faulting-type and epicentre. Composites of the firstmotion data, and the suggested solutions, were shown in Fig. 5.8.

The relative amplitude method, by helping to find a tenable solution for the nodal planes using teleseismic waveforms, has provided valuable insight towards the focal mechanism of the Matata sequence mainshock in otherwise difficult circumstances. This objective was achieved independently of observations of first motions, with only rough approximations having been applied for the effects of crustal structure in the neighbourhood of the source, and without reliance on more marginal aspects of the observed waveforms (e.g., $P$ at MAW \& MUN). It must be conceded, nevertheless, that $P$ was near-nodal for the stations in Australia and in Antarctica, so that at least one of the nodal planes passed through the teleseismic $P$ annulus on the focal sphere, 


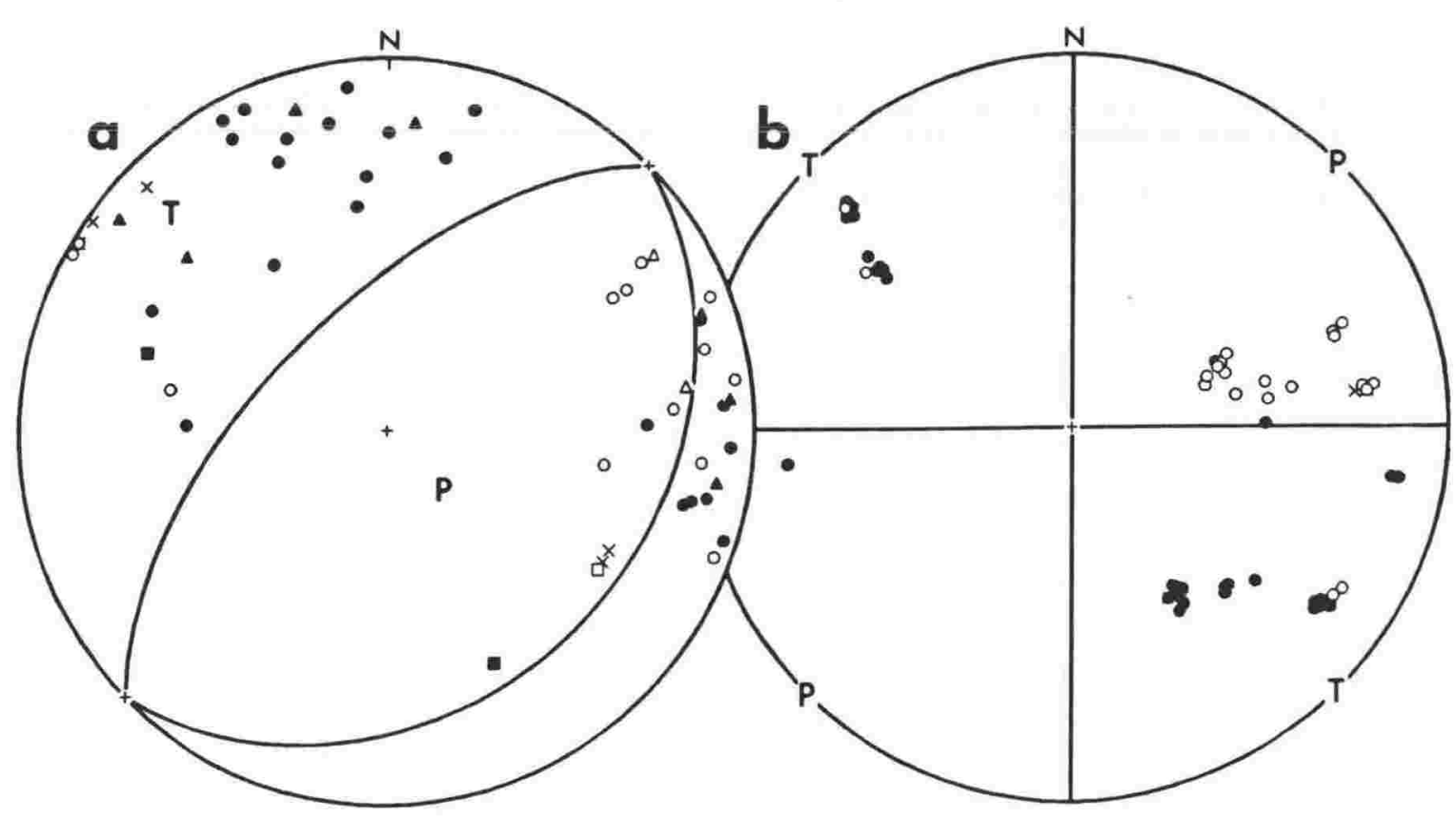

Figure 5.12. Composites of first motions for earthquakes (a) near Kawerau and (b) near Te Teko. Triangles distinguish first motions for the largest of the Kawerau earthquakes: symbols are otherwise as in Fig. 4.7.

which is advantageous wherever it occurs, because of the greater control over the source solution than is usually offered. Further, the solution for the mainshock has helped resolve a wide variation in focal mechanism among the aftershocks and other shallow earthquakes in the Bay of Plenty region. This situation contrasts with that reported for the 1968 Inangahua sequence (Robinson et al, 1975), for which slip appeared (given the source volume and the uncertainties of aftershock locations) to have occurred on sub-parallel planes immediately after the magnitude 7.1 mainshock, and similarly on planes of very different orientation under altered conditions of stress 3.6 years later.

Variations of $P$ and $S$ amplitudes manifest in the seismograms (see Fig. $1.2 \& 1.3$ ), attributable to the variation in source mechanisms (Fig. $5.8 \& 5.9$ ), are presumably the reason why all initial attempts to find a significant change in characteristic $\log (S V / P)_{Z}$ at any of the recording sites failed. Usually, a less pronounced change of fault-plane orientation is sought as an indicator that particular earthquakes were foreshocks, but so far only with the benefit of hindsight, and by comparing them against aftershocks (e.g., Lindh et al., 1978; Imoto, 1986). The rejection of a unique source mechanism for the Bay of Plenty events also has clear implications for the adoption of less well constrained solutions of earthquake mechanism within the volcanic region, for which inference of a nodal plane from mixed polarities of onset at a single seismograph station and the usual assumption of homogeneity of stress conditions (e.g., Smith et al, 1984) may be unjustified. It suggests also that some consideration of the recorded amplitudes (e.g., Adams et al., 1972) may indeed be necessary.

The finding here of focal mechanisms other than the main one (Fig. 5.3) has been 
assisted by the dispositions of the earthquakes and local seismograph stations, and the integrity of recording of the Bay of Plenty networks. If the northeast-striking plane suggested by the relative amplitude method represents the fault plane of the mainshock, the Type 1 earthquakes may be described as of "end-fault" type, and those of Type 2 as "secondary." The Type 3 earthquakes evidently paralleled the mainshock mechanism, and may thus have represented a continuation of that dextral "stick-slip" mechanism, either on that mainshock plane or on an adjacent one. The Type 4 earthquakes were of the "opening" type, and, indeed, were it not for the mix of firstmotion directions at the southwestern stations (e.g., Fig. 5.9c), the first-motion patterns for these events would come closest to allowing a compensated linear-vector dipole type of solution. Some association of the full range of the different kinds of solution, from purely strike-slip to purely normal faulting, and the partitioning of fault slip between those extremes, may be found with the intersecting nature of the geological faults in the region (Fig. 2.1). It can now be seen how the solutions for the initial composites of first motions (Fig. 4.7 \& 4.8) were but crude averages and quite deceptive. A component of normal faulting was at least indicated in the mainshock source mechanism, in contrast to the thrust component in other solutions of source mechanism published for the Central Volcanic Region (see Smith \& Webb, 1986). 
for Matata sequence earthquakes fell short of the magnitudes finally adopted (see later), by $0.41 \pm 0.03$ for a sample size of 34 ; such a deficiency could be serious when estimating the slope, $b$, in the magnitude-frequency (Gutenberg-Richter, 1944) relation. Furthermore, the problem did not lie with the source mechanisms of the earthquakes, since the complementary $M_{P}$ and $M_{S}$ estimates were affected alike, and seemed to be exacerbated by close range and local structure.

Robinson et al. (1975) similarly determined and promoted the relation

$$
M_{c}=-1.51+1.74 \log \tau+0.019 R
$$

for magnitude $M_{c}$ given by the coda duration, $\tau$ (in seconds; see Lee et al., 1972), of the earthquake signal above the ambient noise level. While use of this relationship may alleviate difficulties caused through clipping of recorded trace amplitudes, and site corrections may indeed be less important for small dependence of $M_{c}$ on distance $(R)$ and focal mechanism, some of its usefulness was lost here through aftershocks occurring too soon after earlier shocks (see Fig. 1.2, 1.3 \& 3.3). That aside, it is important not to overlook the effect of different spectral content for events larger in size than microearthquakes, the consequent differences of anelastic attenuation, and the inappropriateness of defining duration with respect to $P$ arrival-time (rather than event

Table 6.1. Preliminary magnitudes for two earthquake subsets, determined using the Robinson et al. (1975) formulae for stations equipped with Sprengnether MEQ-600 instruments.

(a) Magnitude estimates $M_{P}, M_{S}$ and $M_{c}$ for events of $50 \mathrm{~km}$ depth.

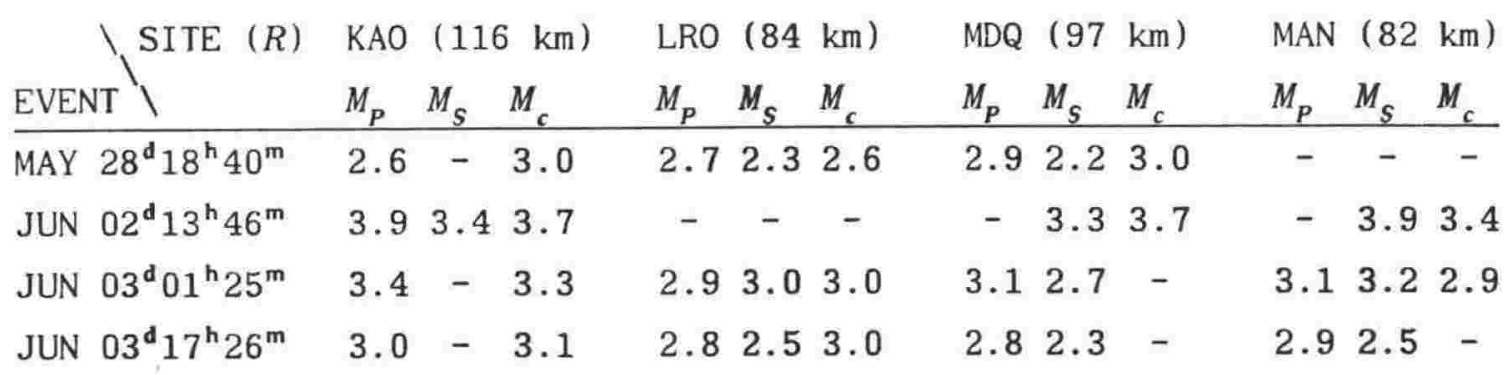

(b) Station magnitude estimates $\bar{M}=\left(M_{P}+M_{S}\right) / 2$ and $M_{c}$ relative to estimates at station $\mathrm{KAO}$ for shallow earthquakes: negative terms denote that station estimates were smaller than for KAO.

\begin{tabular}{lcccccccr} 
SITE & \multicolumn{2}{c}{ DISTANCE $R(\mathrm{~km})$} & \multicolumn{2}{c}{$\bar{M}$ DIFFERENCE } & \multicolumn{4}{c}{$M_{c}$ DIFFERENCE } \\
CODE & Average & Std dev. & Average & Std dev. & No. & Average & Std dev. & No. \\
\hline KAO & 54.2 & 4.5 & - & - & - & - & - & - \\
LRO & 37.4 & 3.6 & -0.49 & 0.16 & 30 & -0.35 & 0.11 & 21 \\
MDQ & 27.8 & 3.9 & -0.64 & 0.10 & 18 & -0.23 & 0.18 & 15 \\
MAN & 24.4 & 3.0 & -0.04 & 0.16 & 16 & -0.26 & 0.12 & 17
\end{tabular}


origin-time) if coda duration is a function of scattering from the medium (e.g. Herrmann, 1975). It was found, nevertheless, that the given formula seriously underestimated the magnitudes adopted for Matata sequence earthquakes (by $0.68 \pm 0.03$, for 33 average comparisons); conversely, durations predicted for the larger earthquakes were grossly excessive (cf. aftershocks in Fig. 1.2 \& 1.3).

The above relationships, for all that, are not necessarily valid for the other (Kinemetrics) seismographs of the temporary network. Further, they may not be applicable within the volcanic region, because of that distinctive geological environment, or be generally applicable, in view of changes made for constants at Wellington Network stations (compare pages 33 of the N.Z. Seismological Report, 1978, 1979). Ideally, some scheme was required whereby magnitudes could be estimated using the local observations. It was also desirable that these estimates of magnitude should be unbiased by whichever sets of stations had to be used for reasons of signal clipping and truncation, and yet, because of the large range of magnitudes encountered, that they be compatible with Observatory estimates of magnitude for the larger earthquakes. In practice, a local amplitude-distance curve was required. Such a relationship was sought in this study, by calibrating stations of the Bay of Plenty array against national network observations for 33 of the smaller aftershocks.

New procedures for assigning local magnitudes were introduced at the Observatory for earthquakes occurring after 1976 (Haines, 1981a, b). (The changes occurring then possibly explain the discrepant example given in Smith (1979: 77/091), in which the foregoing expression for $M_{P}$ was applied for the Kinemetrics instruments, but with empirical site corrections.) However, the newly calculated magnitudes retain links to the former scale through continued use of Wood-Anderson seismographs as standard at Wellington. Magnitudes of crustal New Zealand earthquakes are now estimated, for epicentral distances $(\Delta)$ greater than $0.3^{\circ}$, by assuming a headwave mode of propagation, and by applying empirical station corrections to account for instrumental magnifications and site effects.

The calibrating earthquake magnitudes for the Matata sequence were taken as the average magnitudes determined for nearby short-period, vertical-component, Benioff and Willmore seismographs of the standard network, at range $106 \mathrm{~km}$ to $144 \mathrm{~km}$ (i.e., KRP, TUA \& GNZ). These magnitudes were determined in strict accordance with the procedures outlined in Haines (1981a), including the corrections for inelastic attenuation deemed necessary for paths through the Central Volcanic Region (though not ascertained for the station pair KRP-WTZ). The calibration earthquakes were mostly above (final) magnitude 3.0, and were as great as magnitude 3.7: the events selected for the magnitude calibration had to be of such a size that trace amplitudes were suitably large at the distant stations, yet not so large that trace amplitudes were either above individual levels of signal clipping on all of the nearer field stations or photographically underexposed at WTZ. Nevertheless, it was found that magnitude estimates from station KRP were $0.45 \pm 0.05$ less (from 16 pairs) than the estimates 
from GNZ. (Several examples of this difference in estimation can be found in the NZ. Seismological Report for 1977.) Such differences possibly contribute to the intrinsic standard error of New Zealand magnitudes, but they had to be tolerated here, as it was impossible to say which of the estimations were the more correct. (It should also not be too surprising if station corrections changed for other sets of earthquakes, with corresponding trade-offs in other modelled quantities.)

The calibration results are summarised in Table 6.2 , in which the $-\log A_{0}$ term is now the local approximation appropriate to seismographs in the Bay of Plenty array, including all factors for differences in magnification and site effect. Not all the

Table 6.2. Station-magnitude calibrations, ${ }^{a}$ for zero-to-peak trace amplitudes $A_{0}$.

\begin{tabular}{lcccccccc} 
SITE & PHASE & NO. & $-\log A_{0}$ & $\left(A_{0}\right.$ in mm $)$ & DISTANCE $R(\mathrm{~km})$ & CORR. $^{b}$ & GRADIENT $^{c}$ \\
CODE & GROUP & OBS & Average & Std dev. & Average & Std dev. & $r$ & $\times 10^{-5} \mathrm{~m}^{-1}$ \\
\hline \multirow{2}{*}{ WTZ } & $P$ & 25 & 2.19 & 0.20 & 23.2 & 4.0 & -0.23 & - \\
& $S$ & 31 & 2.11 & 0.20 & 23.4 & 3.7 & -0.27 & - \\
\multirow{2}{*}{ RAW } & $P$ & 22 & 1.65 & 0.25 & 28.3 & 4.0 & 0.01 & - \\
& $S$ & 14 & 1.52 & 0.25 & 28.5 & 4.6 & -0.30 & - \\
LRO & $P$ & 21 & 1.61 & 0.31 & 37.8 & 3.0 & 0.58 & $6.0 \pm 1.9$ \\
& $S$ & 22 & 1.47 & 0.32 & 37.5 & 3.2 & 0.65 & $6.5 \pm 1.7$ \\
WAI & $P$ & 21 & 1.61 & 0.25 & 41.8 & 4.8 & -0.05 & - \\
& $S$ & 15 & 1.69 & 0.26 & 43.9 & 3.4 & -0.14 & - \\
MAR & $P$ & 20 & 1.64 & 0.29 & 42.7 & 3.0 & -0.19 & - \\
& $S$ & 21 & 1.63 & 0.26 & 42.4 & 3.0 & -0.23 & - \\
KAH & $P$ & 26 & 1.59 & 0.36 & 51.4 & 5.1 & 0.30 & - \\
& $S$ & 21 & 1.59 & 0.29 & 51.1 & 5.2 & 0.44 & $2.3 \pm 1.1$ \\
KAO & $P$ & 26 & 1.33 & 0.35 & 52.8 & 5.2 & 0.54 & $3.6 \pm 1.0$ \\
& $S$ & 21 & 1.49 & 0.41 & 53.2 & 5.5 & 0.83 & $6.2 \pm 1.9$
\end{tabular}

Second-order calibration ${ }^{e}$

$\begin{array}{lllllllll}\text { MAN } & P & 25 & 0.57 & 0.34 & 23.2 & 3.9 & 0.74 & 6.6 \pm 1.2 \\ & S & 20 & 0.52 & 0.35 & 23.8 & 3.3 & 0.81 & 8.5 \pm 1.5 \\ \text { MDQ } & P & 29 & 1.36 & 0.29 & 27.2 & 3.9 & 0.79 & 5.8 \pm 0.9 \\ & S & 29 & 1.24 & 0.28 & 27.3 & 3.9 & 0.75 & 5.4 \pm 0.9\end{array}$

Notes:

${ }^{a}$ normalised to $30 \mathrm{~dB}$ below full gain for the field instruments;

${ }^{b}$ correlation coefficient $r$ between $-\log A_{0}$ and $R$ (hypocentral distance);

' local correction for the change of $-\log A_{0}$ with distance;

${ }^{d}$ made against permanent station estimates (see text);

$e^{e}$ by comparison with first-order, western-network magnitudes. 
stations appear in Table 6.2, two of them (AWA \& MAE) because of their lower threshold of signal clipping (used as the criterion for aftershock sampling). Stations of the eastern network provided only isolated points of the local function calibrating amplitude with distance, but the likelihood of significant station terms hinders the fitting of some general amplitude-distance curve parallel to even those parts of the curve indicated by the western network stations. Hence the format in Table 6.2 is such as to emphasise that the results apply only to stations of this study. (Two stations (MAN \& MDQ) were of some assistance for estimating magnitudes for the small shocks occurring before the Matata mainshock, but they could not be directly calibrated against the national network.) A direct comparison of results for WTZ cannot be fairly made, since the asymptotic form

$$
A \propto \Delta^{-2} \exp (-\alpha \Delta) \quad(\text { for attenuation coefficient } \alpha \text { ) }
$$

assumed for the New Zealand calibration function for crustal earthquakes is invalid at short distances; moreover, the maximum trace amplitudes did not in fact correspond to headwave-phase arrivals at any of the permanent stations. The local rates of amplitude fall-off with distance, for the western network stations, were larger than implied in the expressions for $M_{P}$ and $M_{S}$, and were larger than implicit in the original curves for California (see Richter, 1958).

Magnitude estimations qualified for inclusion in the final determination of earthquake magnitude without distance extrapolation. For a station of the first-order calibration, local slope approximations for the amplitude-distance correction (Table 6.2) were limited to hold only within two standard deviations about the sampled average of hypocentral distances, provided that the least-squares regression of $-\log A_{0}$ on $R$ was significant at the $95 \%$ level of confidence. Otherwise, a one standard deviation bound was taken as acceptable, and the average correction of $0.05 / \mathrm{km}$ was applied whenever the local function remained undefined. Several events, of course, fell outside this set of rules. For subcrustal sequence earthquakes, it was possible to make a comparison with magnitudes recalculated as appropriate for eastern North Island stations, again assuming headwave propagation, but with slant distance measured from the base of the crust, together with different station terms (see Haines, 1981a). Magnitudes for another 14 earthquakes were assigned either by using the Robinson et al. (1975) formulae, together with empirical station corrections, or by directly comparing amplitudes for similar distances; these determinations were effectively linked to the local magnitude scale by just one reading and were therefore less reliable. Empirical relationships between $S-P$ and $R$ were used for unlocated events.

The magnitude finally assigned to an earthquake was the average estimate determined either by using the national network observations or by using one of the above methods, according to whichever method contributed most observations (so as to maintain statistical independence). The magnitudes should not have been too biased: the use of permanent network estimates in the calibrations ensured consistency of results 
and a smooth transition of magnitude scale. Six or more individual amplitude observations normally led to each final estimate of magnitude; the uncertainty from individual observations, estimated from the pooled differences of the computed magnitude observations about their averages (but including national network observations), was 0.22 of a unit (1432 degrees of freedom).

The Matata sequence mainshock magnitude $\left(M_{L} 5.4\right)$ was itself rather uncertain, despite checks made (Haines, 1981a) for earthquakes during the first six months of 1977: estimates for it from Wood-Anderson stations ranged from $M_{L} 5.9$ at ONE (Onerahi) to $M_{L} 5.0$ at GPZ (Gebbies Pass). Also, cases with long path-lengths within the volcanic region tended to give the larger magnitude estimates. For example, TNZ (Tarata) gave an $M_{L} 6.0$, and $\mathrm{COB}$ (Cobb River) an $M_{L} 5.7$, suggesting that any appreciable inelastic attenuation must have occurred at deeper levels, if the original attenuation model was correct. The low $M_{L} 5.2$ at CRZ (Cape Reinga), in comparison to the figure given for ONE, may be partly explained by the azimuths being nearnodal for $P$, together with the predominantly strike-slip mechanism (Fig. 5.3); a similar explanation remains unsatisfactory for the differences between KRP and GNZ for the smaller events, given the range of focal mechanisms (Fig. 5.8). The uncertainty in magnitude could adversely affect estimations of mainshock source parameters that are determined in conjunction with the estimate of (scalar) seismic moment, $M_{0}$, which represents the spectral level at zero frequency rather than the level at the WoodAnderson peak displacement response $\left(0.8 \mathrm{~s}\right.$ period) that is represented by $M_{L}$.

Seismic moment is defined also by the product of the shear (or rigidity) modulus for the source medium, the displacement across the fault plane, and the surface area of dislocation $\left(M_{0}=\mu \bar{u} a\right)$. For a characteristic inverse-square fall-off of spectral level at high frequencies and a flat spectrum at lesser frequencies, source size can be deduced from the corner frequency of the source spectrum, characterised by the long and shortperiod spectral levels, for the purpose of providing estimates of average rupture offset, stress drop and seismic energy (e.g., Brune, 1970, 1971; Randall, 1973). This quantification of source attributes was attempted for the Matata sequence mainshock, following the procedures of Gibowicz $(1975 \mathrm{a}, \mathrm{b})$, for which $M_{0}$ is proportional to areas of surface-wave envelopes on WWSSN long-period seismograms recorded at WEL (Wellington).

Surface waves recorded at WEL and their envelopes are shown in Figure 6.1. Because the Matata mainshock occurred at the standard reduction distance $\left(\Delta=3.8^{\circ}\right.$; see Gibowicz, 1975b), no additional correction for attenuation, dispersion or geometrical spreading was necessary, and a seismic moment of $2.9 \times 10^{17} \mathrm{Nm}$ was therefore indicated directly. As recommended (to eliminate radiation effects), the estimate of $M_{L}$ used for the other spectral parameter was that determined for the Wood-Anderson at WEL, but using $M_{L}=\log (5.0 \mathrm{~mm})+4.5=5.2$, as for the old method of determination, rather than the $M_{L} 5.1$ that was published for WEL. The estimates derived for the mainshock were $r=14 \mathrm{~km}$ for the radius of an equivalent circular source area, an 
average rupture displacement of only $1.6 \mathrm{~cm}$, the correspondingly small stress drop $\Delta \sigma=7 M_{0} / 16 r^{3}$ of $5 \times 10^{4} \mathrm{~Pa}(0.5$ bars $)$, and a seismic energy of $1.6 \times 10^{11} \mathrm{~J}$, all assuming a rigidity modulus of $\mu=3 \times 10^{10} \mathrm{~N} / \mathrm{m}^{2}$. Compared to New Zealand earthquakes of similar moment studied by Gibowicz \& Hatherton (1975), this represents a source of large dimension, implying a weak medium, such as one that was already strongly faulted.

All is not well, however. The large source dimension is inconsistent with the result given by the homogeneous station method (Fig. $4.2 \& 4.3$ ), which suggested a fault length of $7 \mathrm{~km}$ or less, together with a fault width of not more than $5 \mathrm{~km}$. Similarly, the radial dimension of $16 \mathrm{~km}$ asserted for the 1972 Te Aroha earthquake (Gibowicz, 1975b: Table 5), near the western margin of the Central Volcanic Region, was inconsistent with the observation that $94 \%$ of the recorded aftershocks occurred within $4 \mathrm{~km}$ of the focus of that $M_{L} 5.1$ mainshock (Adams et al., 1972), even after allowance for possible errors of magnitude and moment. Moreover, it is not as if the Matata mainshock was a slow earthquake generated in a medium of low rigidity, giving an unusually large proportion of long-period energy: high frequencies were relatively well represented in the waveforms, the two estimates of surface-wave magnitude reported (ISC Bulletin) being only $M_{s} 4.6$ (CHG, Chieng Mai) and $M_{s} 4.8$ (TUC, Tucson). Rather, the anomaly seems to be related to the way in which rupture area is determined using the Gibowicz $(1975 \mathrm{a}$, b) approximations to theoretical responses given by Randall (1973). Stress drops derived for New Zealand earthquakes thus tend to be about an order of magnitude less than Californian counterparts studied by Thatcher \& Hanks (1973). (However, this difference cannot be verified without direct knowledge of the source spectra for New Zealand earthquakes.)

Considerable uncertainty thus exists in the estimation of source characteristics of New Zealand earthquakes, in addition to uncertainty caused through differences in surface-wave excitation, attributable to differences in focal depth. These uncertainties may be of little consequence for the relative source parameters of earthquakes having similar focal depth, such as occurring along the southeastern coast of the North Island, where microearthquakes surveys have indicated only sparse activity in the upper crust (e.g., Reyners, 1980). Nevertheless, they do have some bearing for particular investigations of engineering interest (e.g., Robinson et al., 1976), as well as for assessments of the likely source medium (e.g., Adams, 1982). The absolute level of seismic moment used here was given by spectral measurements for several KermadecArc earthquakes (Molnar \& Wyss, 1972). However, none of the many magnitudemoment relations formulated (e.g., Hanks \& Kanamori, 1979) serve to check that reference level, because of inherent differences between sources, and the simplified method of Bolt \& Herraiz (1983) for moment estimation from coda decay was neither reliable nor appropriate for the complicated signatures recorded at distant WoodAnderson stations for the Matata mainshock. Estimates of rupture size determined from the distributions of aftershock hypocentres (e.g., Gibowicz, 1973) will tend to 
have been overestimates, without quantification of the relative location errors, and possibly more so with the inclusion of later aftershocks.

Source attributes preferred for the Matata mainshock are given in Table 6.3: the geometric shape factor used for approximating the stress drop for the near-vertical, mainly strike-slip fault (Fig. 5.3) was that from Boore \& Dunbar (1977). These estimates also accorded with values found for the 1979 Homestead Valley (California) sequence, for which there was some geodetic control (Stein \& Lisowski, 1983). Although it has been suggested that the derived quantities of stress drop and relative fault-slip may vary during the course of a sequence, and thus reflect changes in stress conditions in source regions (e.g., Gibowicz, 1975a), determination of seismic moment for smaller events in the sequence was far from practical. Nevertheless, some indication of near-source conditions may come from the pattern of aftershock occurrence.

Table 6.3. Source parameters for the Matata mainshock based on the early aftershock distribution and a seismic moment (after Gibowicz, 1975b) of $M_{0}=2.9 \times 10^{17} \mathrm{~N} \mathrm{~m}$, assuming the rigidity modulus $\mu=3 \times 10^{10} \mathrm{~N} / \mathrm{m}^{2}$.

QUANTITY

ESTIMATE

Fault half-length (maximum, northeast strike), $L / 2$ $3.5 \mathrm{~km}$

Fault half-width (maximum, down-dip), w/2 $2.5 \mathrm{~km}$

| Average dislocation displacement $\mid, \bar{u}=M_{0} /(\mu L W)$ $0.28 \mathrm{~m}$

Depth to upper edge (down-dip), $z_{d}$ $6.0 \mathrm{~km}$

Rectangular shape factor (strike-slip approximation), C $\approx 1.7$

Static stress drop, $\Delta \sigma=C \mu \bar{u} / W$ $2.8 \mathrm{MPa}$ (28 bars)

Radius of equivalent circular rupture area, $r$ $3.34 \mathrm{~km}$

Seismic energy (circular source) $1.2 \times 10^{13} \mathrm{~J}$

\section{b-value, and the rate of decay of aftershocks}

The slope-parameter $b$ in the relation

$$
\log n(M)=a-b M
$$

between earthquake magnitude $M$ and frequency $n(M)$ about $M$ gives the relative proportion of small and large earthquakes. Equivalently, $b$ may be determined (e.g., Utsu, 1961) from

$$
\log N(M)=a^{\prime}-b M,
$$

where $N(M)$ is the number of shocks of magnitude $M$ and greater, and where

$$
a^{\prime}=a-\log (b \ln 10)
$$

is a seismicity constant. Alternatively, so long as the hypocentral distances are 
identical, $b$ may be determined from the Ishimoto-Iida (1939) relationship

$$
n(A)=k A^{-m}
$$

between maximum trace amplitude $A$ and frequency $n(A)$, for which $k$ is a constant and $b=m-1$. The former expressions were preferable here, because of the small range of measurable amplitudes recorded at any particular site, and because of the ranges in hypocentral distance. Best estimates of $b$ come through use of the maximum likelihood method (e.g., Aki, 1965), in which

$$
b=\log e /\left(\bar{M}-\left(M_{m i n}-\delta M / 2\right)\right)
$$

for mean magnitude $\bar{M}$ of events not less than the smallest class considered complete, $M_{m i n}$, when $b \delta M$ is smaller than about $1 / 4$ (Utsu, 1966) for magnitude class interval $\delta M$ : approximate $95 \%$ confidence intervals are given by $\pm 2 b / \sqrt{N}$ (Aki, 1965) for samples of size $N$ about 30 and more. The value taken by $b$ is usually near unity (Utsu, 1961), but a greater value can be expected for swarm-like activity.

It is essential that the samples be complete above correctly set thresholds of magnitude. The thresholds here were carefully estimated from analyses of the seismograph stations providing the data, the times of their operation and the various gains at which they recorded (Fig. 2.2), and conservatively with due regard to the uncertainties of magnitude and variation of focal mechanism. Figure 6.2 shows the magnitude distributions for the Matata sequence during the sampled period of the 1977 microearthquake survey, and compares them with the longer sampling of seismicity in the Bay of Plenty region (i.e., the region of Fig. 1.1). (Post-1976 procedures were used for magnitudes of the earthquakes before 1977: contrary to assertions (Haines, 1981a, b) the raw observations were not irretrievably lost, and they formed the basis for the new magnitudes in the New Zealand catalogue.)

The $b$-value of $1.29 \pm 0.13$ for the sample of 98 aftershocks was found, using the $F$-distribution test of Utsu (1966), to be not significantly different from the $b$-value of $1.38 \pm 0.14$ for the 95 earthquakes of the macroseismic sample. (Note, however, that two earthquakes of the latter sample were in common with the aftershock sample, and that the regional sample included other Matata sequence events.) The 95\% confidence intervals for the samples each excluded unity, and thus indicated a greater proportion of smaller earthquakes than is normal for large mainshock-aftershock sequences, such as the 1968 Inangahua, New Zealand, sequence (Adams \& Lowry, 1971; $b=0.93 \pm 0.06$ ), or for tectonic seismicity in general. The same cannot be said, however, about some earlier results for microseismicity and swarm sequences within the volcanic region (e.g., Hunt \& Latter, 1982; Webb et al., 1986), in which the sample numbers were too small to enable rejection of the null hypothesis, and in which low values of $b$ may well have resulted from incomplete sampling.

The foreshocks of the Matata sequence were similarly too few to show that the $b$-value of $1.27 \pm 0.35$ differed from that of the aftershocks and that of the regional 


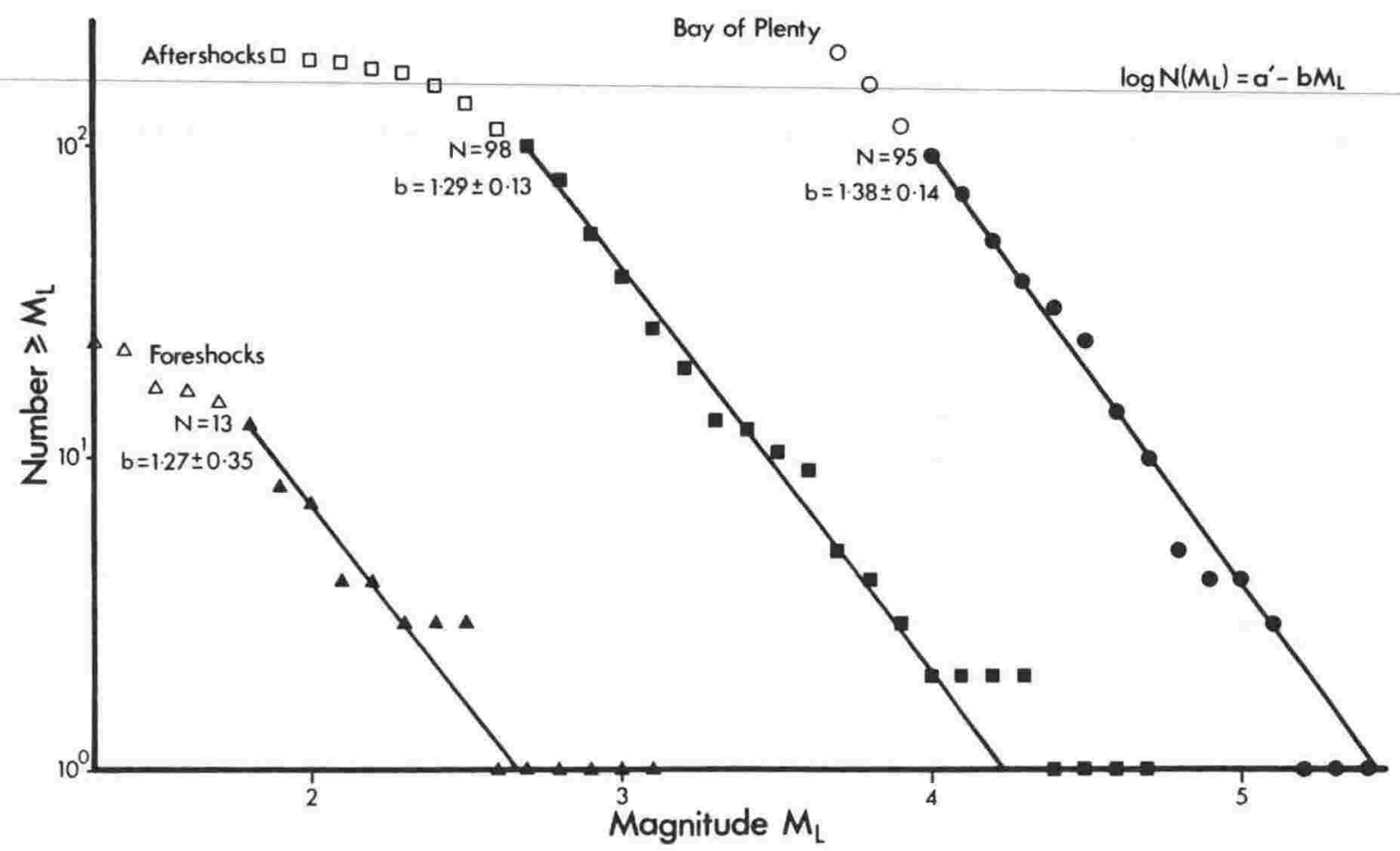

Figure 6.2. Magnitude-frequencies for Matata sequence foreshocks and early aftershocks, and for shallow $(Z \leqslant 40 \mathrm{~km}$ ) Bay of Plenty earthquakes for the years 1971-82. Open symbols are for magnitude thresholds below that for which sampling was judged complete.

seismicity: differences in $b$-value (e.g., Suyehiro, 1966 Utsu, 1966, 1971) are investigated in the promise that such foreshock seismicity may truly be forewarning. Moreover, the foreshock $b$-value was indistinguishable from the $b$-value of $1.06 \pm 0.27$ for the other 15 events of Figures 2.3 and 2.4 at and above the $M_{L} 1.8$ threshold, and the $b$ value of $1.15 \pm 0.22$ for all those 28 events combined was still not significantly different from the other Bay of Plenty values. These small sample sizes typify the difficulties in finding significant regional and temporal $b$-value variations, even at microearthquake levels of detection.

The decay coefficient $p$ in the Omori formula

$$
n(t)=n_{1} t^{-p}
$$

giving the rate of aftershock occurrence at time $t$ after the mainshock, where $n_{1}$ is the rate of events at unit time interval, commonly takes a value close to unity (e.g., Utsu, 1961), indicating a hyperbolic decay in aftershock occurrence rather than a more rapid exponential decay. Events recorded on field instruments during the unsampled period immediately after the Matata sequence mainshock would have been underestimated, since they could not all be distinguished in the coda of the larger shocks (see Fig. $1.2 \&$ 1.3). Hence the permanent station close to the source region, WTZ, served best to indicate a result (Fig. 6.3), since small, high-frequency events recorded there could easily be discerned from the longer-period coda of larger 


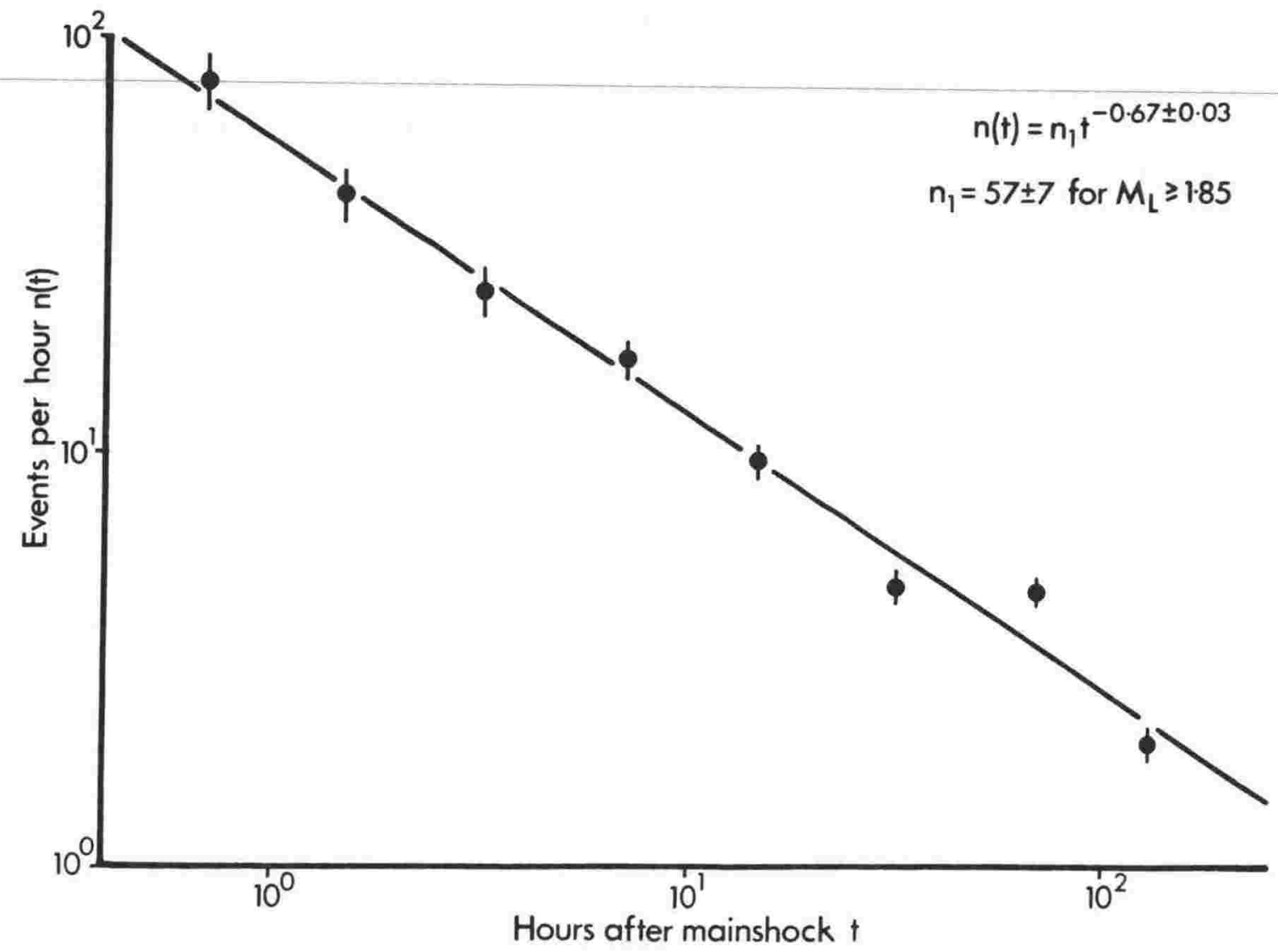

Figure 6.3. Rate of decay of aftershock occurrence, from first-week aftershocks of $M_{L} \geqslant 1.85$ recorded at WTZ.

aftershocks, from about 20 minutes after the mainshock until 7 days later (after which the activity may not have been confined to the known source region).

The results in Figure 6.3 correspond roughly to a threshold equivalent to $M_{L} 1.85$ (Table 6.2), assuming that all events recorded on WTZ with peak-to-peak amplitudes of $1 \mathrm{~mm}$ and more were recognised, and assuming that events that were not members of the Matata sequence were excluded from the interval counts. A least-squares reduction of the interval counts yielded an aftershock occurrence rate $\left(n_{1}\right)$ of $57 \pm 7$ events/hour after 1 hour, and a $p$-value of $0.67 \pm 0.03$, implying a sequence of longer duration than is normal (e.g., Inangahua sequence $p=1.05 \pm 0.06$ : Adams \& Lowry, 1971). This low $p$-value for the Matata sequence, for all that, subsumes bursts of renewed activity, such as those at about 4,22 and 65 hours after the mainshock, in association with larger aftershocks (e.g., Fig. 1.2 and 1.3).

A high $b$-value and long sequence duration of aftershock sequence supposedly relates to a high stress drop for the mainshock leaving only low stress levels in the main aftershock region (Gibowicz, 1973). This relationship was not satisfied for the stress drop initially found for the Matata mainshock using the Gibowicz (1975a, b) method of determining source dimension. Moreover, sufficient strain energy remained for aftershocks larger than usually expected, say, from Bâth's Law (e.g., Richter, 1958: p.69). The 1974 Opunake (New Zealand) sequence, following an $M_{L} 6.1$ mainshock 
(Robinson et al., 1976: a "relatively high" $\Delta \sigma$ of $1.2 \mathrm{MPa}$ ), was a similar example with high $b$-value and long duration: it too had an auxiliary aftershock sequence. Nevertheless, the presence of secondary sequences does not preclude incomplete stress drops in regions adjacent to the mainshock rupture region, with a succession of subsequences each having a more normal decay rate but possibly with varying $b$-value during their course. It has been claimed, after all, that $b$-value changes with time correlate with changes in stress level (e.g., Gibowicz, 1973, 1975a), even in the absence of any recognisable subsequence.

The cumulate sum technique of process control (e.g., Page, 1954; Davies \& Goldsmith, 1976) is well suited to detecting changes in an average value, by plotting accumulated differences, $\sum_{n}\left(\bar{m}_{n}-\hat{m}\right)$, from a reference mean, $\hat{m}$, against consecutive sample number, $n$. Since $b$ is inversely proportional to the mean magnitude $\bar{M}$ above the true minimum threshold $\left(M_{m i n}-\delta M / 2\right)$, changes in $b$-value should show as a change in slope along the sampling path of average magnitude $\bar{m}_{n}$. The reference magnitude $\hat{m}$ need not be exact but may as well be so here. Thus, in Figure 6.4, the final sum of all deviations is zero, and a negative gradient represents an interval of lower than average magnitude and therefore apparent high $b$-value.

The one impressive feature in Figure 6.4, counterbalanced by the long-term downward trend, is the rapid rise at a time of increased seismicity, suggesting an interval of comparatively low $b$-value and therefore (Gibowicz, 1973) high stress. More likely, however, it results from clustering of larger, off-fault aftershocks, with 9 events of $M_{L} \geqslant 3.0$, and 5 of them of $M_{L} \geqslant 3.5$, occurring within a 16 hour interval more than 2 days after the mainshock. Smaller events could still be detected during that period (see Fig. 1.3), and indeed many were sampled below the accepted threshold of completeness, so that there is no reason to suspect that any should have been missed, unless they were so close in time as to have been indistinguishable. This suggests the available strain energy may have been locally depleted, at least temporarily, with small cracks deprived of growth potential by larger amalgamations and a preference for larger slips. The $b$-value is then related more to the aftershock process than to the stress drop for the sequence mainshock.

The temporary network of seismographs in the Bay of Plenty region was ideally placed to resolve the seismicity spatially. Moreover, the outbreak of fresh activity away from the central rupture was good cause to expect further high stress drops and apparent variation of $b$-value with time. However, the finer detailing of any such phenomena, and the attributing of its source, would require further effort in determining magnitudes to a lower threshold. Some correlation between stations would be needed to overcome problems in assigning magnitudes, just as some would be necessary to specify the locations, especially since events in other regions may produce similar $S-P$ intervals. Nevertheless, it seems that multiple sequences may be characteristic of the volcanic region, and that study of others in the region may give further insight into the origin of the high $b$-value. 


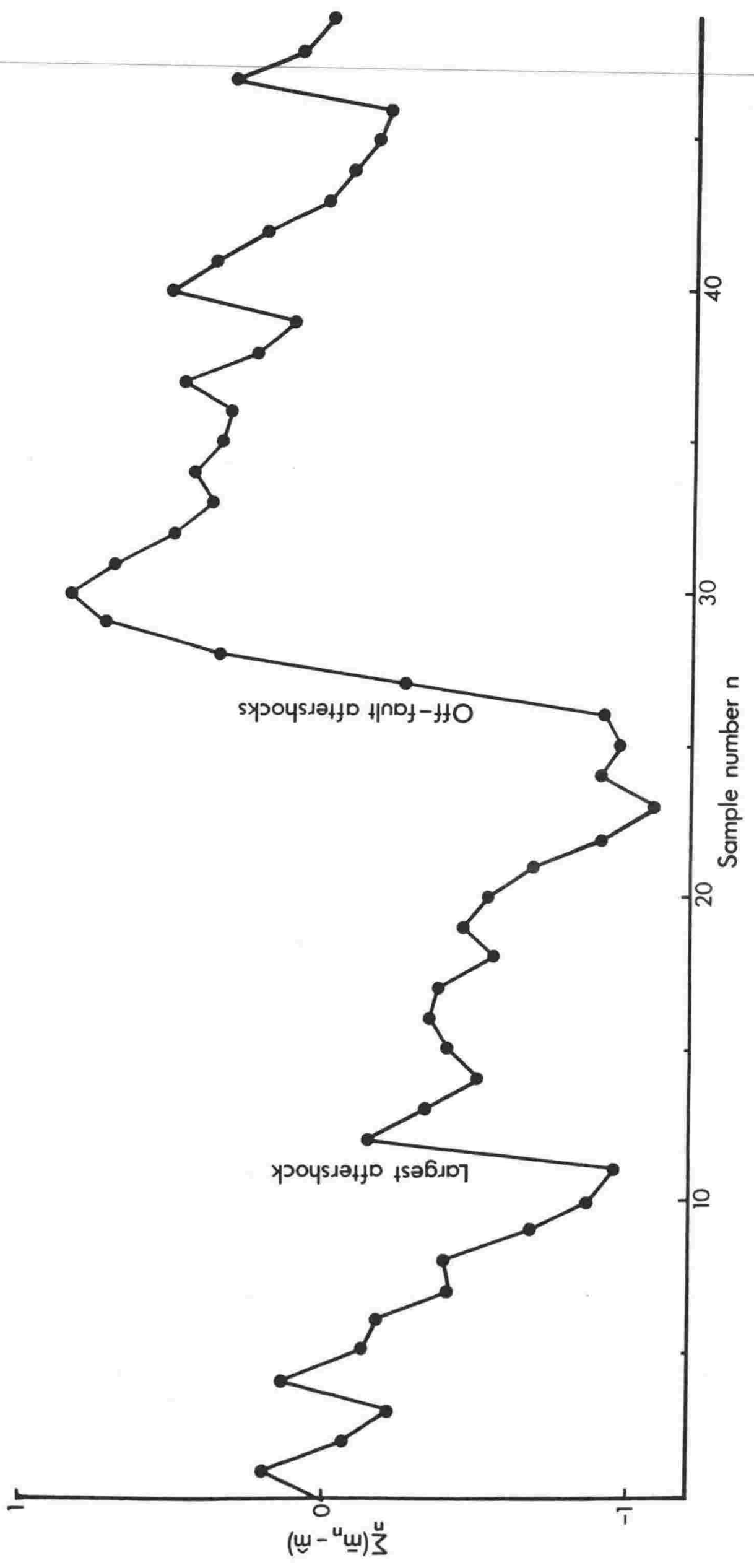

空 


\section{Seismicity}

Presentations of North Island seismicity (e.g., Gibowicz \& Hatherton, 1975; Hatherton, 1980) may often be biased in that multiple-event sequences of related earthquakes are overrepresented through not being distinguished as such. Hence, in Figure 6.5, an attempt is made to indicate relationships between neighbouring earthquakes, though to a finer extent than was given in Figure 1.1, and over a longer period. The parameters used for the presumed associations were somewhat arbitrary, but they were tempered by experience with the given level of seismicity. An estimate of $20 \mathrm{~km}$ for the possible relative mislocation error seemed appropriate, for related earthquakes close in time and with epicentres consequently determined with similar sets of arrival observations, since the broad groupings of epicentres in Figure 1.1 were distinct. Also, an estimate of seven days for the maximum interval between events in a sequence seemed reasonable, given that the distributions (Fig. 6.2 \& 6.3) for Matata sequence aftershocks suggested the rate of events of $M_{L} \geqslant 3.7$ then should be less than one per day after a comparable mainshock.

The stated criteria should eliminate most spurious associations, while still allowing for sequences of long duration and the possibility of subsequences at nearby regions. A more serious deficiency is in not being able to show sequence membership for other events near the $M_{L} 3.7$ cutoff, or below the $M_{L} 4.0$ threshold of catalogue completeness, because of missing observations (see Fig 6.2). The same fault was inherent to the analysis of Smith \& Webb (1986), which attempted to show similarities between the activity within (and adjacent to) the volcanic region and the activity within the adjoining region along the southeastern margin of the North Island: no such similarities were found for the sequences defined with 4 or more events $\left(M_{L} \geqslant 4.0\right)$ within 15 days and $50 \mathrm{~km}$ of each other. However, the purpose here is merely to portray the essence of the seismicity - the multiplicity of upper-crustal sequences - and to show that larger events in a sequence are of ten preceded by one of smaller magnitude.

Principal features of Figure 6.5 include shallow sequences mentioned previously: their dominance remains unsurpassed even when the observation period is extended to include the 1983 Waiotapu sequence, which, for a mainshock of $M_{L} 5.1$ (83/1231), had only four shocks at or above the target threshold of completeness then current for the New Zealand catalogue (i.e., $M_{L} \geqslant 3.7$ ). Events of the southeastern region, on the other hand (but as for Evison et al. (1976)), were usually assigned depths in the lower crust, and were apparently without related shocks. However, as has already been seen, the southeastern events may have occurred at even greater depths. Thus, since Smith \& Webb (1986) made no such distinction and admitted all the events $\left(M_{L} \geqslant 4.0\right)$ given depths to $70 \mathrm{~km}$, only to find no regional difference in $b$-value, the inclusion of the deeper events must have contaminated the statistics for comparisons of the seismicity in that study, just as it must have (to a lesser extent) for Figure 6.2. Different sequences within the volcanic region may also have contributed differently. By comparison in Figure 1.1, for example, the 1976 earthquakes were more numerous at 


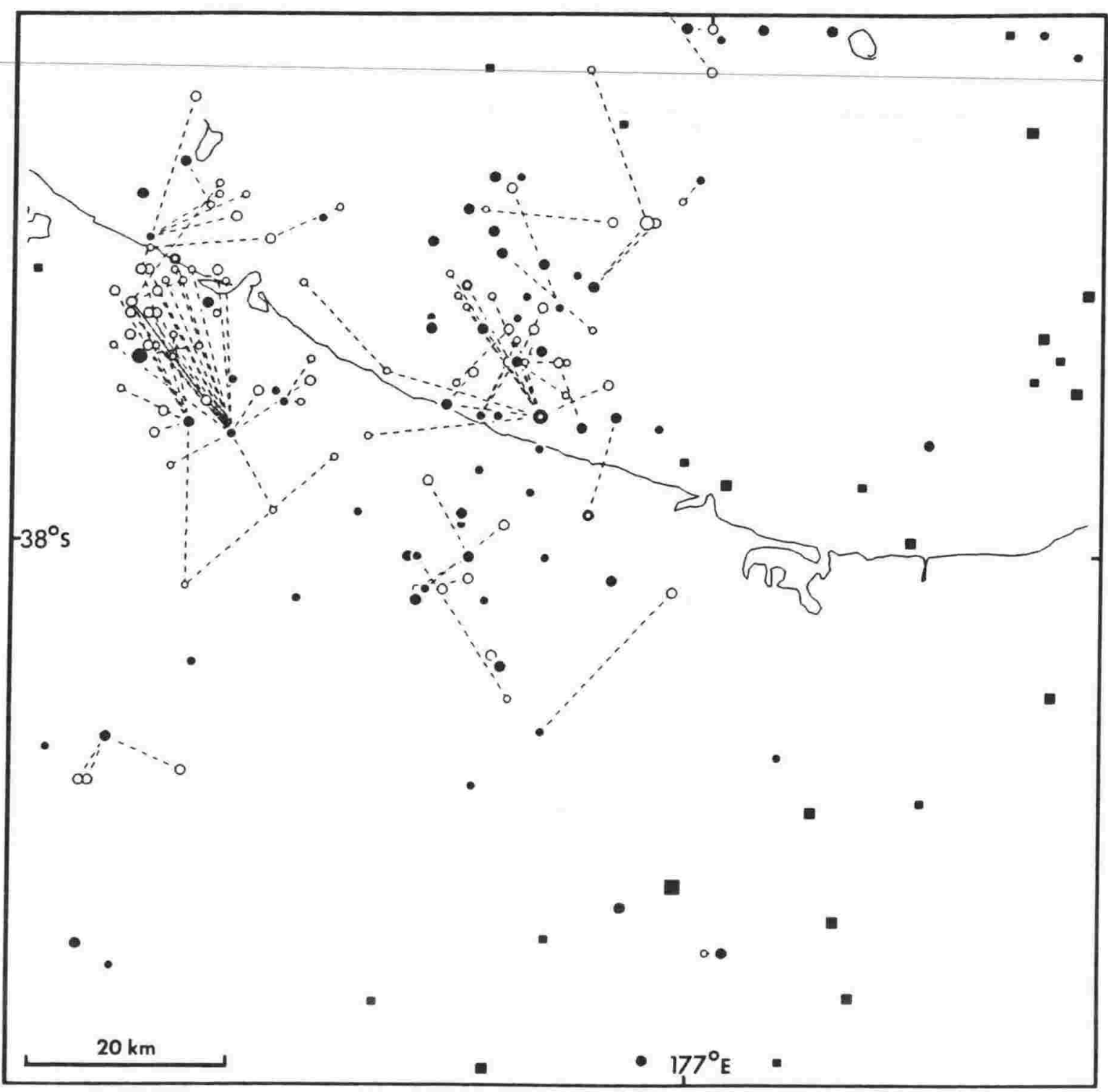

Figure 6.5. Regional seismicity with (new magnitude) $M_{L} \geqslant 3.7$ and assigned focal depths $\leqslant 40 \mathrm{~km}$, for 1971-1982 in the New Zealand catalogue. The epicentre symbols are larger for events of $M_{L} \geqslant 4.0$ and $M_{L} \geqslant 5.0$ : circles denote upper crustal foci. Symbols are solid if no predecessor $\left(M_{L} \geqslant 3.7\right)$ occurred within 7 days and within $20 \mathrm{~km}$; dashed lines link later events to their earliest predecessor within the same ranges. Apparent differences in epicentre for the TePuke earthquakes from those shown in Fig. 1.1 are so merely because of different magnitude assignments.

$M_{L} \geqslant 4.0$ than earthquakes of 1977 , suggesting a greater $b$-value and thus more of a swarm-like character for the 1976 sequence, for which the (new) magnitude of the largest of the earthquakes (76/970) was only $M_{L}$ 5.0.

The Te Puke earthquakes were apparently in three main groupings, the first two of which, starting August 10 (76/687, new $\left.M_{L} 4.0\right)$ and September $02\left(76 / 764, M_{L} 3.9\right)$, consisted of eight or more events of $M_{L} \geqslant 4.0$ in sequences lasting at least ten days; the last grouping, associated with the largest shock on October 27, had only three such events, though many, much smaller shocks through into December were reported felt 
and were therefore included in the catalogue. A variety of character was thus manifest even within that series; but this broad view lacks the detail already presented for the Matata sequence. (A report on the Te Puke earthquakes was foreshadowed in the N.Z. Seismological Report for 1976, but its fate is unknown.)

For the Matata sequence, by the same criteria, only five events of $M_{L} \geqslant 4.0$ were closely linked, the final one being the $M_{1} 4.1$ event of June $07^{\mathrm{d}} 18^{\mathrm{h}} 11^{\mathrm{m}}(77 / 363)$, which was accompanied by yet another increase in fore and after activity that included the $M_{1} 3.8$ shocks of June $07^{\mathrm{d}} 02^{\mathrm{h}} 14^{\mathrm{m}}(77 / 360)$ and June $08^{\mathrm{d}} 04^{\mathrm{h}} 23^{\mathrm{m}}(77 / 366)$. (Presumed) aftershocks recorded on WTZ seismograms then abated, such that into early July the $M_{L} \geqslant 1.85$ event count was never more than ten a day, and it was usually less than three a day (i.e., an average rate lower than would be predicted from Fig. 6.3). However, a further six events of $M_{L} \geqslant 4.0$ occurred near the mainshock aftershock region in the remaining months of 1977. Moreover, these events were of ten accompanied by, or were members of, complex foreshock-aftershock sequences recorded with $S-P$ intervals of $2.8 \mathrm{~s}$ to $3.6 \mathrm{~s}(R \approx 19.3-27.2 \mathrm{~km})$ at WTZ. The various rates of activity associated with larger events can be compared quantitatively, by adopting the approximations that were used earlier for Figure 6.3.

The $M_{L} 4.7$ event of July $31^{\mathrm{d}} 16^{\mathrm{h}} 52^{\mathrm{m}}$ (77/479), which was preceded by just one event of $M_{L} \geqslant 1.85$ in the prior five-hour period, was similar to the largest aftershock of the main sequence, in that related activity was relatively low and short-lived $\left(n_{1}=11\right.$ events/hour, $\left.p=0.88 \pm 0.11\right)$, and in that dilatational first-motions were again recorded at WTZ. Only sporadic activity followed, including the two $M_{L} 3.4$ events of August $02(77 / 482,483)$. It was not until August $06^{\mathrm{d}} 07^{\mathrm{h}} 29^{\mathrm{m}}$ that another event as large as $M_{L} 3.7$ occurred (77/492), leading to the $M_{L} 3.9$ event of August $06^{\mathrm{d}} 14^{\mathrm{h}} 13^{\mathrm{m}}$ (77/493), the $M_{L} 3.6$ event of August $06^{\mathrm{d}} 22^{\mathrm{h}} 09^{\mathrm{m}}(77 / 495)$, the $M_{L} 4.4$ event of August $07^{\mathrm{d}} 04^{\mathrm{h}} 29^{\mathrm{m}}\left(77 / 496\right.$ ), and one other event greater than $M_{L} 3.4$ (August $06^{\mathrm{d}} 22^{\mathrm{h}} 10^{\mathrm{m}}$ ). Three events of $M_{L} \geqslant 1.85$ occurred in the five-hour period before the $M_{L} 4.4$ event of August 07; the ensuing sequence $\left(n_{1}=22\right.$ events/hour, $\left.p=0.66 \pm 0.13\right)$ included the $M_{L} 3.7$ event of August $07^{\mathrm{d}} 09^{\mathrm{h}} 46^{\mathrm{m}}(77 / 503)$ and another five events of $M_{L}>3.4$ on the same day.

A further three events of $M_{L} \geqslant 3.7$ occurred before the next main sequence. Then the $M_{L} 4.4$ event of November $11^{\mathrm{d}} 17^{\mathrm{h}} 17^{\mathrm{m}}$ (77/754) was preceded by 32 events in the prior 5 hour period, including the $M_{L} 3.7$ event of November $11^{\mathrm{d}} 13^{\mathrm{h}} 09^{\mathrm{m}}(77 / 752)$, and it was followed by a sequence $\left(n_{j}=29\right.$ events/hour, $\left.p=0.46 \pm 0.05\right)$ that included the $M_{L} 4.0$ event of November $11^{\mathrm{d}} 17^{\mathrm{h}} 57^{\mathrm{m}}(77 / 755)$ and 5 others of $M_{L} \geqslant 3.4$ over the next 2 days. Although preceded by 24 events in the prior 5 hour period, 2 of them of $M_{L} \geqslant 3.3$, the next event of $M_{L} \geqslant 4.0$, the $M_{L} 4.1$ event of December $04^{\mathrm{d}} 01^{\mathrm{h}} 44^{\mathrm{m}}(77 / 809)$, did not initiate much activity $\left(n_{1}=6\right.$ events/hour, $\left.p=0.97 \pm 0.16\right)$. There were, nevertheless, another three events of $M_{L} \geqslant 3.4$ spread over the same day, including the $M_{L} 4.0$ event of December $04^{\mathrm{d}} 16^{\mathrm{h}} 30^{\mathrm{m}}(77 / 812)$. In contrast, the foreshock of 1977 May $22^{\mathrm{d}} 15^{\mathrm{h}} 23^{\mathrm{m}}(77 / 294)$ had just one event near the $M_{L} 1.85$ threshold about ten hours 
before it (and no others for the previous day), only two in the following five-hour period, and subsequently a further three before May $26^{\mathrm{d}} 00^{\mathrm{h}}$.

The Matata mainshock was, therefore, at the forefront of a long period of deformation and readjustment near the eastern margin of the volcanic region. Shallow sequences of 1978 were centred mainly in the Edgecumbe-Kawerau district in two episodes during May, and then again on November 15 near Mt Edgecumbe and offshore in the Bay of Plenty, but never with any shock larger than $M_{L} 4.4$. Later sequences included the $M_{L} 5.1$ shock of 1979 April $19^{\mathrm{d}} 18^{\mathrm{h}}\left(11^{\mathrm{m}}\right.$ (79/247) together with an associated $M_{L} 4.2$ foreshock and an $M_{L} 4.5$ aftershock, originating approximately midway between Matata and White Island. Sequences occurring west of White Island on 1980 February 28 and April 19 consisted of at least two shocks of $M_{L} \geqslant 4.0$, but with none larger than $M_{L}$ 4.7. Activity thus apparently spread along the volcanic front, but not far southwest of Kawerau. Furthermore, it is evident from the relative numbers of sequences and other unassociated earthquakes of $M_{L} \geqslant 4.0$ in Figure 6.5, when earthquakes to the southeast are recognised as originating deeper, that the shallow events were concentrated along that zone.

It is unlikely, however, that the imminence of a moderate, damaging earthquake near Matata could have been specifically foreseen: the data from the national network of seismographs were too few for detecting changes in seismicity. Forewarning earthquakes under the precursory swarm hypothesis (Evison, 1977), though never envisaged as applicable to volcanic regions, might have attained listing in the New Zealand catalogue, but the only candidates were of small magnitude, and had, with the reinterpretation of later phases at WTZ as $S$, a closer affinity with the earthquakes of 1976 near Te Puke. Still, it is noteworthy that there were just three earthquakes of $M_{L} \geqslant 4.0$ in the region of Figure 6.5 for the three-year period from 1973 August 01 . The average rate of occurrence from earthquakes of $M_{L} \geqslant 4.0$ without a predecessor of $M_{L} \geqslant 4.0$ within $20 \mathrm{~km}$ and 7 days was 14 events in 3 years, and the probability of less than 4 such events under the Poisson model, with that average rate of occurrence, is less than 0.0005 . However, this result may follow from the long-term trends in seismicity unaccounted for in the removal of related earthquakes.

The difficulty in Figure 6.3 was that event counts from substantial subsequences were absorbed into the average rates determined for logarithmically uniform intervals of time, so much so that the gross model of a long sequence seemed quite appropriate. More normal values of unity for $b$ and $p$ may have held for the central region, as suggested by the virtual absence of activity there after three days (Fig. 2.6); some of the secondary activity away from the central region may have had a swarm character if taken in isolation. There were parallels also in the later sequences, which, in spite of their various rates of activity and decay, can be considered to share some relationship with the Matata mainshock, if not directly. It suggests that separate processes may be involved: one a localised triggering of a normal aftershock sequence acting in the short term; and the other a more remote initiation of shocks resulting 
from longer-term readjustments. This complexity may explain why the difference between the magnitudes of the two larger shocks in a sequence was usually less than that typical of tectonic sequences (i.e., Băth's Law).

\section{Properties of the crust}

Proposing molten or semi-molten material to within a few kilometres of the surface near the southeastern margin of the Central Volcanic Region, Evison et al. (1976) argued that earthquakes occur in strong rock in which the stress increases to equal the strength, so that a lack of earthquakes indicates an insufficiency of either strength or stress. Another view can also be put: earthquakes occur at weak points within the brittle crustal medium where the strains are greatest and the stresses concentrated. The difference in these viewpoints depends on the properties of the rock, on the distributions of strengths and weaknesses, and on the nature and origin of the stresses.

Rock strength depends on temperature, pressure, pore pressure, and rheology (e.g., Brace \& Kohlstedt, 1980). In the brittle upper part of the crust, failure occurs by shear fracture, or by stick-slip frictional sliding with corresponding small stress drops if the rock is already sufficiently fractured; high pore pressures will reduce the effective normal stress and thus the frictional strength. At deeper levels temperature effects dominate, and ductile behaviour becomes the norm. Characteristic profiles of intraplate strength and seismicity (e.g., Chen \& Molnar, 1983) therefore show a seismic upper crust, with strength increasing with normal stress, over an aseismic lower crust of lower strength. It is near the transition zone from brittle to ductile deformation that most large earthquakes initiate, because of the increase of normal stress with depth (e.g., Das \& Scholz, 1983). Frictional sliding will occur before shear fracture if the rock medium is already fractured; thus the strength of fractured rock is determined by the frictional resistance. Internal thermal stresses in unfractured rock will arise only for a nonuniform temperature distribution, or for differing thermal coefficients (Warren \& Latham, 1970).

For the Bay of Plenty earthquakes, the focal depth distributions (Fig. $2.7 \&$ 4.3) were not atypical of regions of recent strike-slip and extensional tectonics (e.g., Chen \& Molnar, 1983; Sibson, 1986), where the seismogenic layer extends to about $10 \mathrm{~km}$ depth for a quartz rheology together with a temperature gradient of $30^{\circ} \mathrm{C} / \mathrm{km}$ (e.g., Brace \& Kohlstedt, 1980). The $15 \mathrm{~km}$ focal depths for earthquakes in the Evison et al. (1976) study were hardly consistent with the molten magma region of the model in which they occurred. A further problem with an elevated body of molten material seems to be in isolating it from the regional stress, since this stress should be concentrated in the overlying "high strength" layer. Webb et al. (1986) required a postulated normal component of faulting to be aseismic in a complex system involving interconnected strike-slip and normal faults for deformation within the volcanic region (Smith \& Webb, 1986).

The 1977 sequences were intermediate between classical swarm and mainshock- 
aftershock patterns (e.g., Utsu, 1970). This multiplicity of sequences is relatable, through its association with high $b$-value and the presence of foreshocks, to heterogeneous structure and nonuniform stress in the seismogenic medium (e.g., Mogi, 1963a \& b, 1967), a low stress level generally (e.g., Scholz, 1968), or a heterogeneous distribution of fault strength (e.g., Mikumo \& Miyatake, 1979). The stress drop of 2.8 $\mathrm{MPa}$ inferred for the Matata mainshock (Table 6.3) was small by standards for intraplate events (Kanamori \& Anderson, 1975), suggesting displacement occurred on a pre-existing fault plane.

The source of the heterogeneity in the eastern Bay of Plenty region can be found in the intersecting nature of the north-trending faults within the Mesozoic greywacke east of the volcanic region, and the northeast-trending faults along the volcanic front (see Fig. 2.1, 2.4); focal mechanisms (Fig. 5.11) suggested that the north-south structure seen east of the volcanic region was preserved within the volcanic region. For low deviatoric stress levels, the ambient field may be modified and accentuated by localised sources of thermal and structural anomaly, such as may be found in the Kawerau and Te Teko districts. Various frictional strengths may then apply, with the effective scale of the heterogeneities serving to limit earthquake magnitudes.

Utsu (1970) noted that swarms of ten resembled a rapid succession of mainshockaftershock events, with or without foreshocks. This multiplicity of sequence is well illustrated in Figure 6.6 for foreshocks of the Matata sequence; these sequences are all the more impressive for the longer periods of intervening quiescence, such as the twoday interval without foreshocks of $M_{L} \geqslant 1.8$ when activity was centred in the Kawerau district. Investigation for temporal and spatial changes in earthquake coda duration

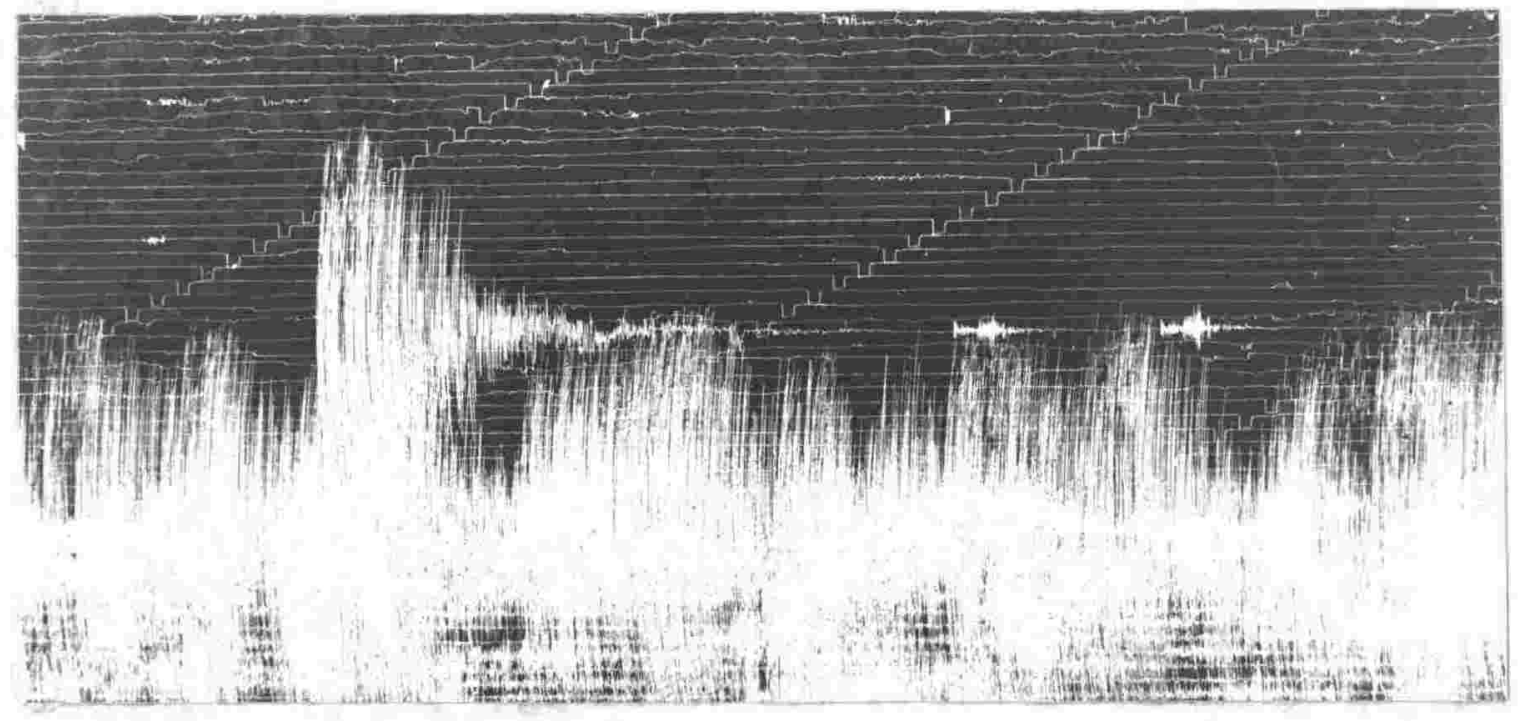

Figure 6.6. The $M_{L} 3.1$ foreshock of 1977 May $31^{\mathrm{d}} 16^{\mathrm{h}} 43^{\mathrm{m}}$ and its two $M_{L} 1.4$ microaftershocks, as recorded at the nearby station, MDQ, west of the source region. Note the dilatational first-motions of direct-arriving $P$; these provided important constraints for the predominant type of focal mechanism (e.g., Fig. 5.9b). 
(e.g., Jin \& Aki, 1986), relating coda $Q$ to heterogeneity in the medium, would, however, need to account for different patterns of scattering caused through different orientations of source radiation. The low average results for $M_{c}$, if valid in comparison to $M_{L}$, suggest heterogeneous structure and the presence of open cracks, in accord with the indications that were given by $b$-value and Poisson's ratio. 


\section{Crustal structure}

The Matata mainshock, being comparable to a moderately sized nuclear detonation, was a source of seismic energy equivalent to some tens of kilotonnes of chemical explosive. If well enough located and recorded, it could provide important information about crustal structure, as well as serve as a master event for relocation studies. The task here is to seek improvements to the local model, by interpreting arrivals at stations of the New Zealand seismograph network. Inferences about crustal structure derive from an understanding of the velocity distribution.

\section{Apparent velocity from earthquakes}

Knowledge of upper-mantle velocities in New Zealand has already come from studies of larger crustal earthquakes, usually by exploiting the linear time-distance relationship for rays critically refracted at the Mohorovicić discontinuity, or Moho, the boundary between crust and mantle. For example, Hamilton (1969) found the $P n$ velocity to be $8.3 \mathrm{~km} / \mathrm{s}$ for waves travelling to the southwest from the 1966 Gisborne earthquake, and therefore higher than the velocity of about $7.8 \mathrm{~km} / \mathrm{s}$ used in the Jeffreys-Bullen (1958) tables and observed for stations to the west and northwest. The higher apparent velocity was similar to an earlier estimate of $8.1 \mathrm{~km} / \mathrm{s}$ (Hamilton, 1966) for waves from the southwest. It was suggested the apparent velocity to the west could have been even lower and due to a west-dipping Moho, but examination reveals that emergent arrivals from aftershocks down to $M_{L} 4.2$ were needed for that result, determined using only three stations. Nevertheless, a correlation between seismic velocity and thermal activity, volcanism and deep seismic activity was recognised, although anisotropy was also considered.

In a more recent study, Haines (1979) determined regional velocities in the uppermost mantle, using differences in seismic arrival-times at pairs of New Zealand seismographs, together with station terms (Haines, 1980) that were required to account for variations in crustal thickness and velocity. $P n$ velocities, time-terms and regions used in modelling the North Island were shown in Figure 5.4; a low Pn velocity of $7.4 \mathrm{~km} / \mathrm{s}$ distinguished the zone of recent volcanism from adjacent areas. As ray-paths were mainly along northeast-southwest azimuths, the regional differences in $P n$ velocity beneath the North Island were ascribed to lateral inhomogeneity rather than anisotropy.

The data for the above analysis were mostly taken from readings made for Observatory locations of crustal earthquake origins for 1971. Arrival-time intervals for ray-paths between $\mathrm{CNZ}$ and WTZ, for sources to the southwest, were excluded, because they were presumed to have been affected by lateral refraction. Thus data for the station pair WTZ-CNZ came exclusively (Haines, 1976) from several earthquakes occurring in a sequence about $160 \mathrm{~km}$ north of WTZ in 1974 . Whereas these later earthquakes also contributed arrival-time intervals at some other selected pairs of 
stations, desirable observations in reversals of path direction for several additional pairs (e.g., WTZ \& TUA, WTZ \& TRZ; events 74/112, 113, 115, 116 etc.) were not included, despite satisfying the design requirements. It is not clear what trade-offs occur between $P n$ velocities and crustal station-terms resolved in such a case of low information redundancy.

Too few regional earthquakes occurred during the 1977 microearthquake survey to provide a reliable and independent estimate of local $P n$ velocity within the volcanic region. The largest and by far the best recorded regional event (see Fig. 1.3), the $M_{L} 5.1$ earthquake of June $04^{\mathrm{d}} 17^{\mathrm{h}} 25^{\mathrm{m}}$ (77/353), was located about $80 \mathrm{~km}$ south of GNZ by Observatory procedures, and assigned a focal depth of $33 \mathrm{~km}$. This event yielded an apparent velocity of $8.4 \pm 0.3 \mathrm{~km} / \mathrm{s}$ across the western seismograph network, extended here to include KRP, and thus seems to exclude a low $P$ n velocity, despite probable errors of hypocentre estimation. (That the KRP arrival appears not to have been relatively delayed is seen also in the Observatory solution with reference to arrivaltimes at closer stations.) Haines (1979) also noted that few $S n$ phases for earthquakes originating near the east coast had been observed at KRP; in the present instance an arrival onset near the appropriate time could be seen, particularly on the long-period seismogram of the north-south component, and the difficulty at short periods lay not so much in that it was attenuated but obscured in the preceding $P$ coda.

The ISC solution of hypocentre for the above event indicated a depth of $52 \mathrm{~km}$, and listed arrivals at ASP and TOO consistent with that depth and the phase $p P$. Such a focal depth is not unexpected following discovery of deeper seismicity along the coast (Reyners, 1980), and the complicated signal recorded at KRP is presumably due to scattering of waves passing through the heterogeneity of a subduction margin. An apparent velocity close to, or higher than, the velocity in the source medium should also be not unexpected if the source was below the principal refractor. Preferably, though, the complexities so introduced should be removed from efforts to account for the influence of near structure on travel-times from the Matata mainshock.

\section{Refraction from sources within the volcanic region}

Large-scale refraction experiments conducted within the volcanic region using controlled sources have generally been restricted by poor recording conditions, and by a lack of spread length for a large depth of sounding. The reconnaissance survey reported by Stern (1982) consisted of charges as large as $410 \mathrm{~kg}$ fired near White Island at differing offset distances from a line of recording sites extending towards the southwest. Figure 7.1 indicates the travel-times after shot and near-station corrections had been made, including an extra adjustment of $-0.5 \mathrm{~s}$ to one origin-time (Shot 2). Apart from the sonobuoy data, for which site corrections may have large uncertainty, the observed arrivals were confined to three temporary seismographs spread over $15 \mathrm{~km}$ at an offset range of $48 \mathrm{~km}$ to $76 \mathrm{~km}$, and were supplemented by arrivals at stations of the national network remote from the line of profile; arrivals at GNZ were notably 


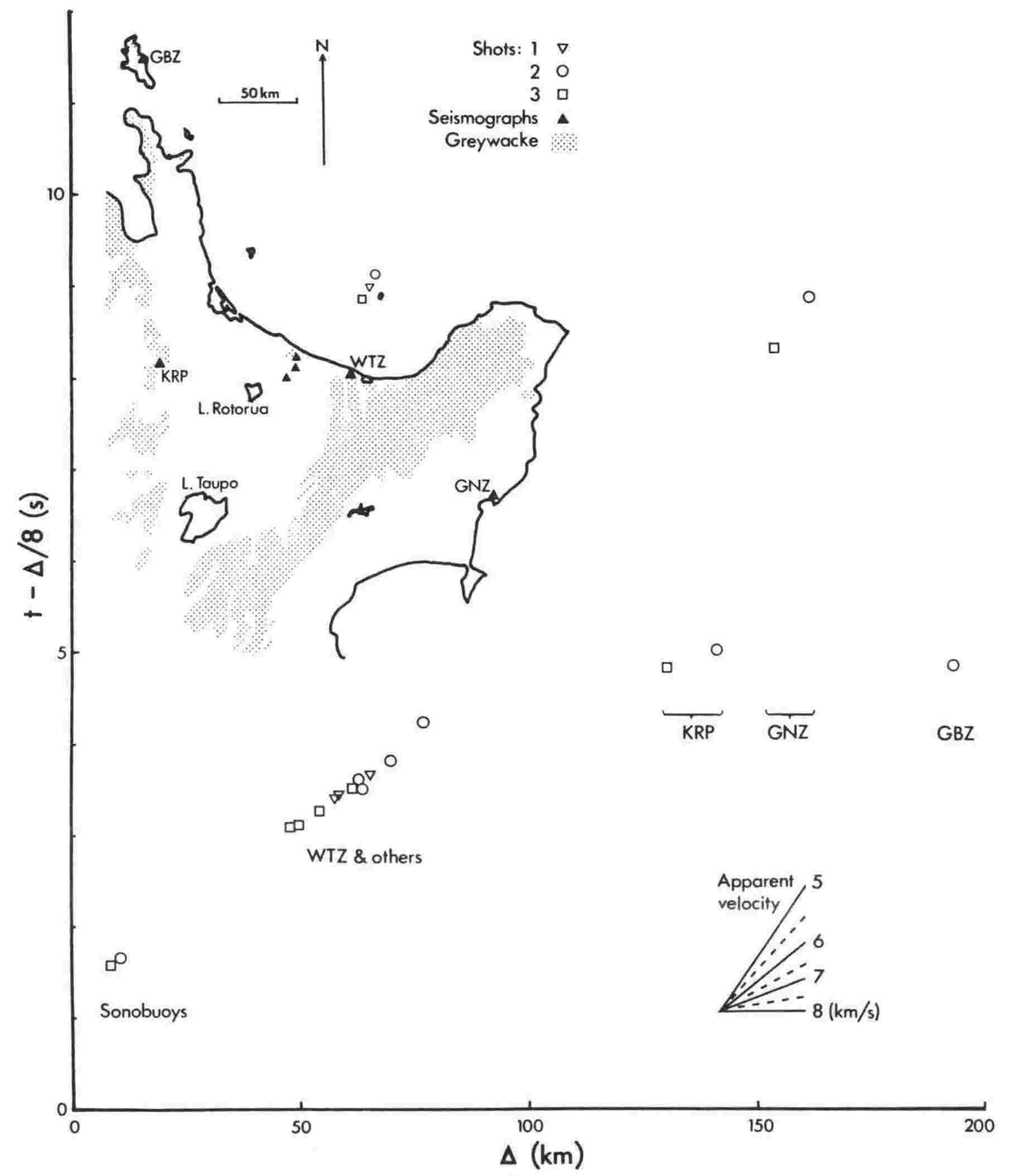

Figure 7.1. Reduced travel-times from the Bay of Plenty explosions (after Stern, 1982). The inset figure identifies the three shots and the seismographs recording them; greywacke exposures are shown shaded.

later than arrivals at stations similarly distant. However, the low density of traveltime observations does not allow, other than subjectively, the establishment of slope breaks in the time-distance curve and thus time intercepts at zero offset, and hence estimates of refractor velocity and depth for a model necessarily layered horizontally.

Stern (1985) presented travel-times from a similar shot fired in Lake Taupo for arrivals recorded on a line extending northeast but not overlapping the line previously used. As the propagation distance was again not great, an estimated travel-time of $P$ across to KRP for an earthquake originating approximately $1 \mathrm{~km}$ [sic] beneath WTZ 
was appended to the set of measured times. Despite these deficiencies, the combined data from the two surveys were interpreted as indicating a $15 \mathrm{~km}$ thick crust that was composed chiefly of $6.0 \mathrm{~km} / \mathrm{s}$ material and underlain by a $7.4 \mathrm{~km} / \mathrm{s}$ upper mantle. Support for the thin crust model was drawn by extrapolating a relationship formulated (Woollard, 1970) between crustal thickness and $P n$ velocity, a relationship of low predictive precision because of the inherent spread in the observations. Because the Matata sequence earthquakes originated at about $10 \mathrm{~km}$ depth, the shallow existence postulated for the mantle should have been evident in refracted arrivals at seismograph stations of this study.

The small initial amplitudes for the Matata sequence events that were recorded at sites $\mathrm{KAO}$ and $\mathrm{KAH}$ (e.g., Fig. 3.3), situated at $44-59 \mathrm{~km}$ range west of the source region (Fig. 2.1), suggested that the first-arriving rays had been critically refracted, such that an estimate of refractor velocity would be obtained when first arrival-times for the larger earthquakes were related to the arrival-times at KRP, $60 \mathrm{~km}$ further westward. Suitable onsets at KRP were produced by the 12 events of $M_{L} 3.5$ or more in the sequence that were located using the Bay of Plenty network of seismographs: trace amplitudes at that magnitude threshold were then greater at KRP than those recorded during the seismic-profiling experiment. An apparent velocity of $7.1 \pm 0.1 \mathrm{~km} / \mathrm{s}$ was the result, which is not unrepresentative of the lower crust. Albeit an unreversed estimate of refractor velocity, this estimate should be an upper limit in the absence of refractor dip, irrespective of any event mislocation, because the observational sites were near the same azimuth from the source region. Other than those sources of error, an excessive site delay due to the rhyolite and ignimbrite foundations at the closer sites in contrast to the greywacke under KRP would cause an overestimation of refractor velocity. Nevertheless, some regard for structure near KRP may also be needed, in view of the importance of KRP in all of the above analysis. As to whether it is lower crust or upper mantle that has been sampled, the answer perhaps comes from analysis for events of deeper origin.

\section{Mode conversion at an interface}

The deeper events occurring during the microearthquake survey were not sufficiently well distributed to permit use of methods jointly determining the velocities and hypocentres (e.g., Crosson, 1976a, b). Nevertheless, other pertinent clues to structure were present in the seismograms in the form of phases intermediate to the arrivals of $P$ and $S$. These intermediate-arriving phases may be caused through conversion of $P$ to vertically polarised $S$ waves $(S V)$, and vice versa, just as for reflection at the free surface, but on transmission through an internal boundary across which there is a sharp change in seismic impedance. Such phase-conversion is usually most favourable at near-critical incidence, and the Moho is often a good candidate for the interface, because of the contrasts there in velocities and density accompanying a change in chemical composition. The particular value of the converted phases lies in their 
sensitivity of arrival-time to depth of mode conversion.

Intermediate-phase arrivals that were observed for events forming the subcrustal sequence southeast of the Bay of Plenty array (Fig. 1.1) are exemplified in Figure 7.2; certainly there is some advantage in observing such a sequence, for it eliminates the possibility of multiple rupture as a cause of the additional arrivals, and the range of recorded amplitudes ensures that the intermediate phases are not always unobservable at each of the seismographs. Timings of prominent intermediate-phase arrivals, limited to the eastern stations of the temporary network, are indicated in Figure 7.3. A horizontal slowness of $0.12 \pm 0.01 \mathrm{~s} / \mathrm{km}$ across the network was found on fitting lines with common slope to the four sets of time-distance correlations by the method of least-squares, suggesting the intermediate arrival was of $S$ converted to $P$, denoted by Sp. Modelling of the arrival-time (after modification to the HYPO71 program to enable ray tracing through what is in effect a velocity inversion), by adjusting the crustal thickness while locating the events using the $P$ and $S$ times, indicated such wave-mode conversion occurred at a depth of $28.5 \mathrm{~km}$. Although the velocity model used was standard except for a Jeffreys-Bullen type mantle, changes in hypocentres and the depth to mantle were subtle for other velocities: if the faster mantle was used, for example, the computed hypocentres moved less than $5 \mathrm{~km}$ further away from the Bay of Plenty array of seismographs, and the estimated crustal thickness decreased by less than $1 \mathrm{~km}$. (The alternative possibility of a conversion of $P$ to $S$ should have had a corresponding slowness of about $0.10 \mathrm{~s} / \mathrm{km}$, with mode conversion occurring at around $18 \mathrm{~km}$ depth.)

The $S p$ conversion depth suggested by the analysis is reasonable for the Moho depth for the region of conversion beneath the greywacke region of the eastern ranges. Table 7.1 gives the revised origin for the subcrustal mainshock, as well as amplitude ratios predicted at the vertical-component seismometers for the source mechanism in Figure 4.9 , assuming densities of $2.6 \mathrm{Mg} / \mathrm{m}^{3}, 2.9 \mathrm{Mg} / \mathrm{m}^{3}$ and $3.3 \mathrm{Mg} / \mathrm{m}^{3}$ for the successively deeper layers of the velocity model (Fig. 7.3). Amplitude ratios not involving $S$ are not so dependent on the near-surface velocities, or on any preferential attenuation of $S$ within the volcanic region. Variability in observed ratios at individual stations for the smaller earthquakes nevertheless contributed to there being only 16 intermediate arrivals used in the modelling of $S p$ times, and hinders refinement of the focal mechanism. Initially, however, the low $S$-to- $P$ conversion coefficients should have been compensated by the strength of the $S$ radiation; further west $S$ will have become near-nodal and thus obscured in the $P$ coda (see Table 6.1a), together with the other phases. For even larger distances to the west, the radiated $P$ amplitudes should have diminished, to the extent such that at KRP, for example, the intermediate phase should again have been distinct.

Relevant seismograms recorded at KRP are reproduced in Figure 7.4: an intermediate phase can indeed be observed arriving $6.0 \mathrm{~s}$ after the $P$ onset, and the $S$ onset another $10.0 \mathrm{~s}$ later. The intermediate arrival-time remains consistent with $S p$ 

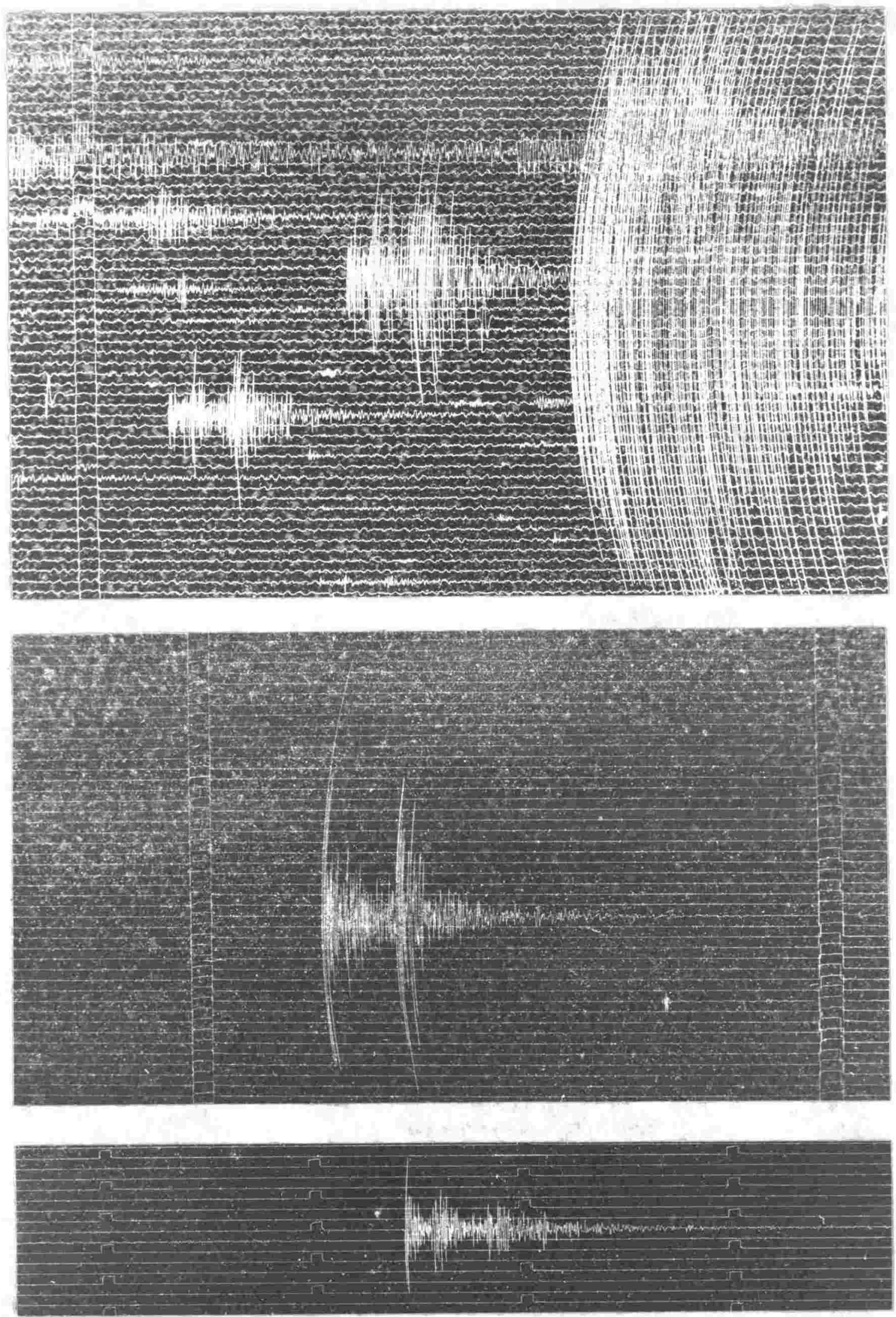

Figure 7.2. Seismograms of the subcrustal sequence of earthquakes displaying an intermediate phase. These seismograms show (top) aftershocks of the $M_{L} 4.4$ earthquake of June $02^{\mathrm{d}} 13^{\mathrm{h}} 17^{\mathrm{m}}$, as recorded at a nearby station (WAI), with the largest aftershock (June $02^{\mathrm{d}} 13^{\mathrm{h}} 46^{\mathrm{m}}, M_{L} 3.8$ ) to the right; and the $M_{L} 2.7$ foreshock of May $28^{\mathrm{d}} 18^{\mathrm{h}} 40^{\mathrm{m}}$, as recorded at RAW (centre) and at AWA (bottom). 

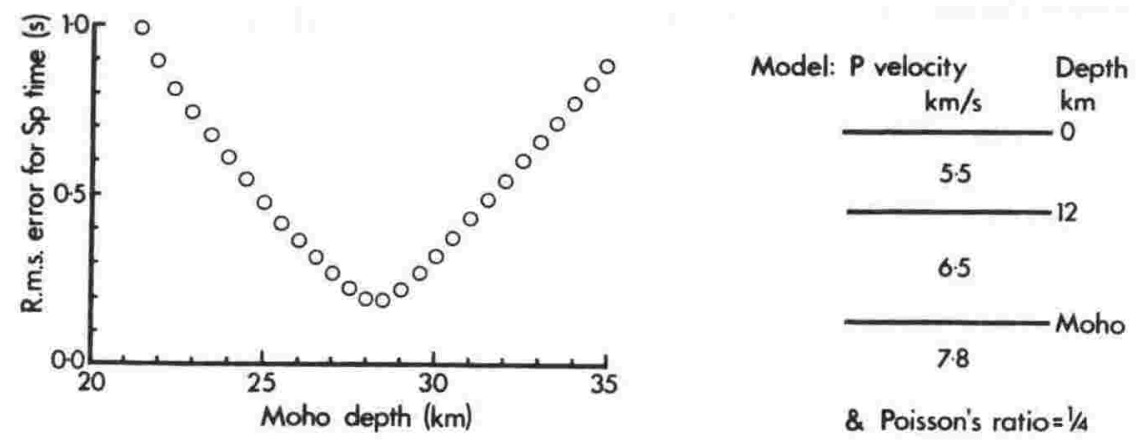

\&. Poisson's ratio $=1 / 4$

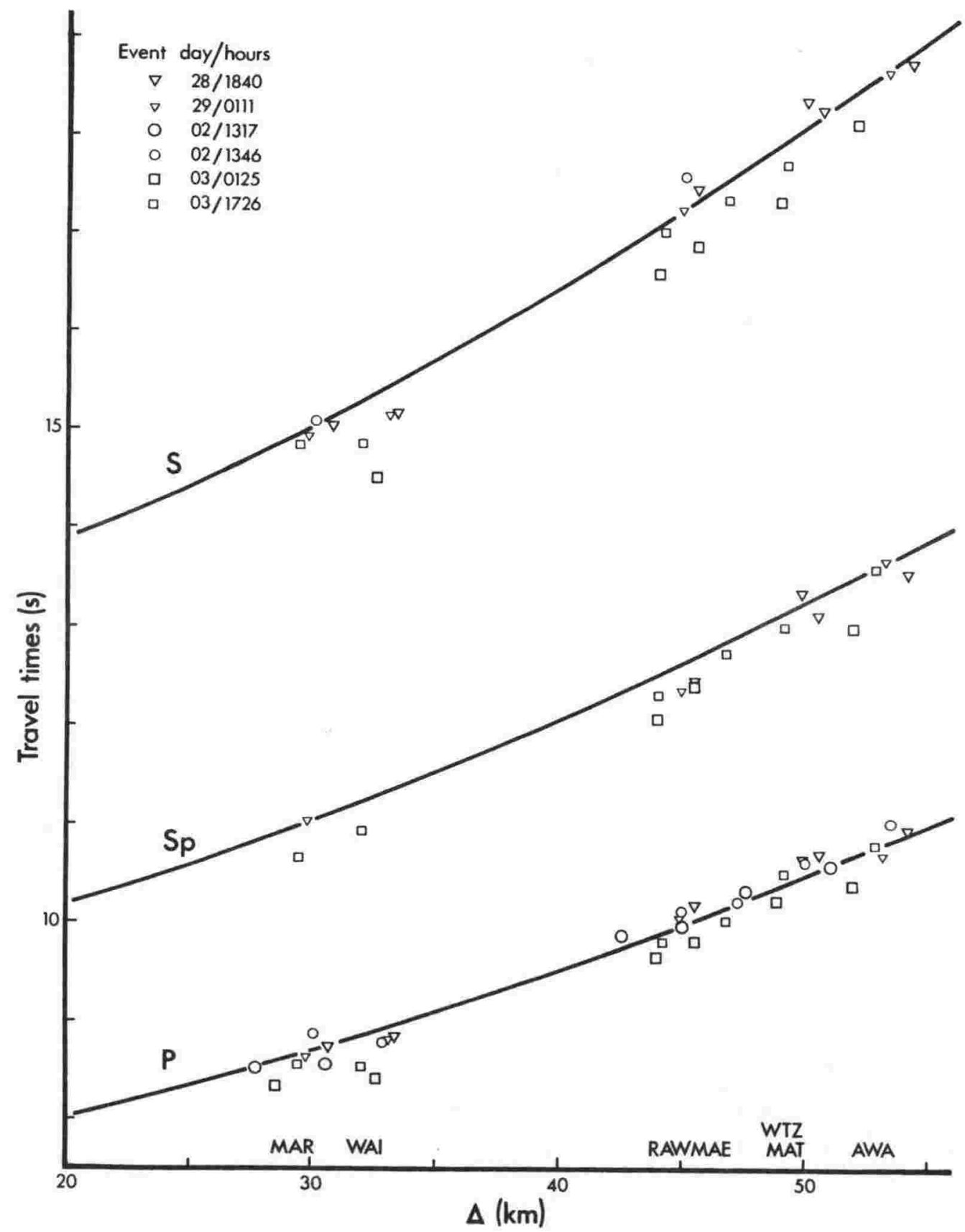

Figure 7.3. The match of the intermediate phase and the $S p$ arrival-time. The inset diagram shows the change in root-mean-square error of $S p$ arrival-time with change in assumed crustal thickness. Calculated travel-times for the mainshock for the best solution are given by the solid curves shown on the composite of observed times. 
Table 7.1. Origin, arrival-times and vertical-component amplitude ratios calculated for the subcrustal mainshock of 1977 June 02 and the revised crustal model.

ORIGIN TIME LATITUDE LONGITUDE DEPTH

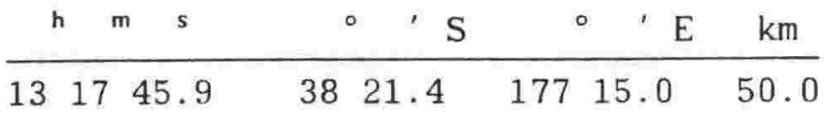

\begin{tabular}{rrrr} 
PLANE & DIP & RAKE & STRIKE \\
\hline $1:$ & $76^{\circ}$ & $80^{\circ}$ & $\mathrm{N} 4^{\circ} \mathrm{E}$ \\
$2:$ & $17^{\circ}$ & $126^{\circ}$ & $\mathrm{N} 221^{\circ} \mathrm{E}$
\end{tabular}

RESIDUAL AMPLITUDES

SURFACE AND TAKEOFF NAME $\triangle$ AT PHASE ARRIVAL $(0-C)$ logIRATIOI PATH FACTORS ANGLES ${ }^{\circ}$

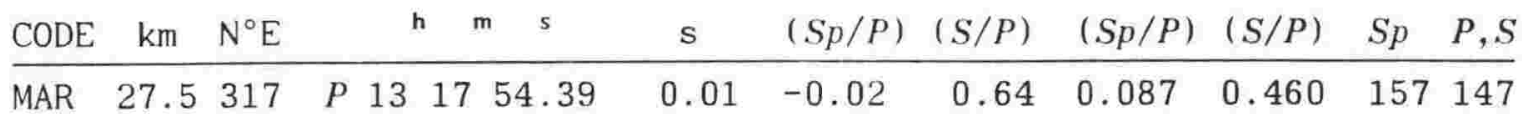

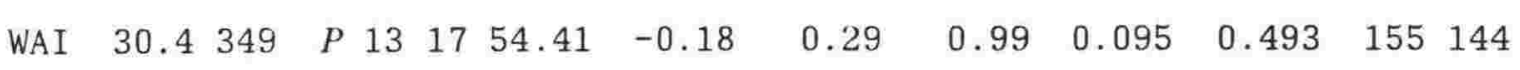

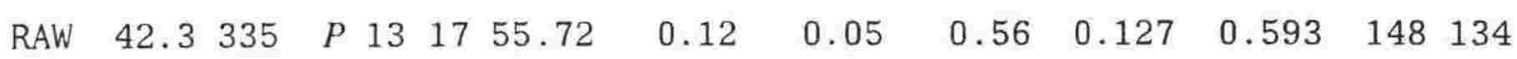
$\begin{array}{llllllllllllll}\text { MAE } & 44.7 & 308 & P & 13 & 17 & 55.82 & -0.01 & -0.18 & 0.21 & 0.134 & 0.596 & 147 & 132\end{array}$

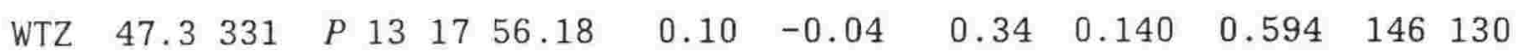
$\begin{array}{llllllllllllll}\text { AWA } & 50.8 & 318 & P & 13 & 17 & 56.44 & 0.00 & -0.15 & 0.04 & 0.147 & 0.559 & 145 & 127\end{array}$ MAN $\quad \begin{array}{llllllllllllll} & 7.4 & 311 & P & 13 & 17 & 58.23 & 0.00 & -0.08 & -1.35 & 0.219 & 1.020 & 141 & 118\end{array}$

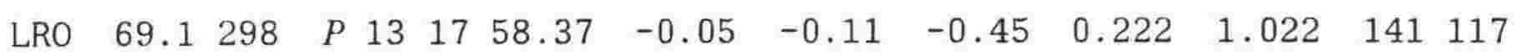
$S \quad 18 \quad 07.0 \quad-0.6$

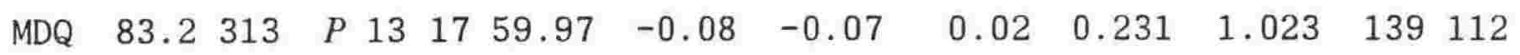
$\begin{array}{llll}S & 18 & 10.9 & 0.5\end{array}$

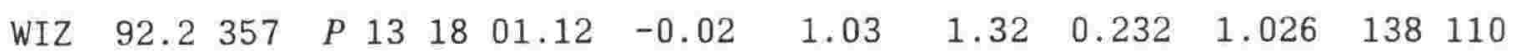
$\begin{array}{lll}S & 12.2 \quad-0.0\end{array}$

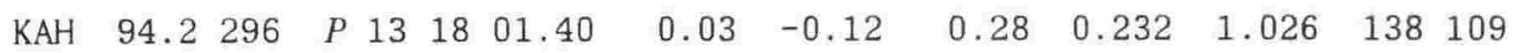
$\begin{array}{lll}S & 12.4 & -0.3\end{array}$

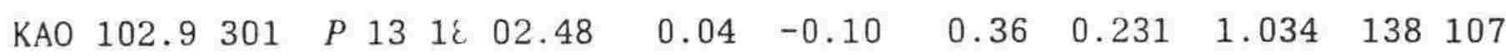
$\begin{array}{lll}S & 14.7 \quad 0.1\end{array}$

\begin{tabular}{|c|c|c|c|c|c|c|c|c|c|}
\hline TUA & $50.8 \quad 190$ & $\begin{array}{lll}P & 13 & 17\end{array}$ & 57.0 & * $\quad 0.6$ & 0.51 & 0.93 & 0.146 & 0.561 & 145 \\
\hline GNZ & $74.5 \quad 115$ & $\begin{array}{lll}P & 13 & 18\end{array}$ & 01.0 & * 2.0 & 0.18 & 1.24 & 0.227 & 1.022 & 140 \\
\hline KRP & $157.7 \quad 288$ & $\begin{array}{lll}P & 13 & 18\end{array}$ & 09.0 & $*-0.3$ & -0.08 & 0.66 & 0.226 & 1.103 & 137 \\
\hline & & $S p$ & 15.0 & * 0.1 & & & & & \\
\hline & & $S$ & 25.0 & $*-1.4$ & & & & & \\
\hline
\end{tabular}

Note: starred times were not used in the hypocentre solution; takeoff angles for $S p, P$ and $S$ are measured from the downward vertical.

(Table 7.1), but it is too late generally to have been due to conversion of $P$ to $S$ at the base of the crust. Because the point of conversion is then again beneath the adjoining greywacke region to the southeast, this may not seem to advance any model for the volcanic region. However, it is important to recognise that the $S p$ arrival-time is sensitive to velocity in the lower crust.

The geometry of the ray paths is indicated in Figure 7.5. $P$ and $S p$ will have 

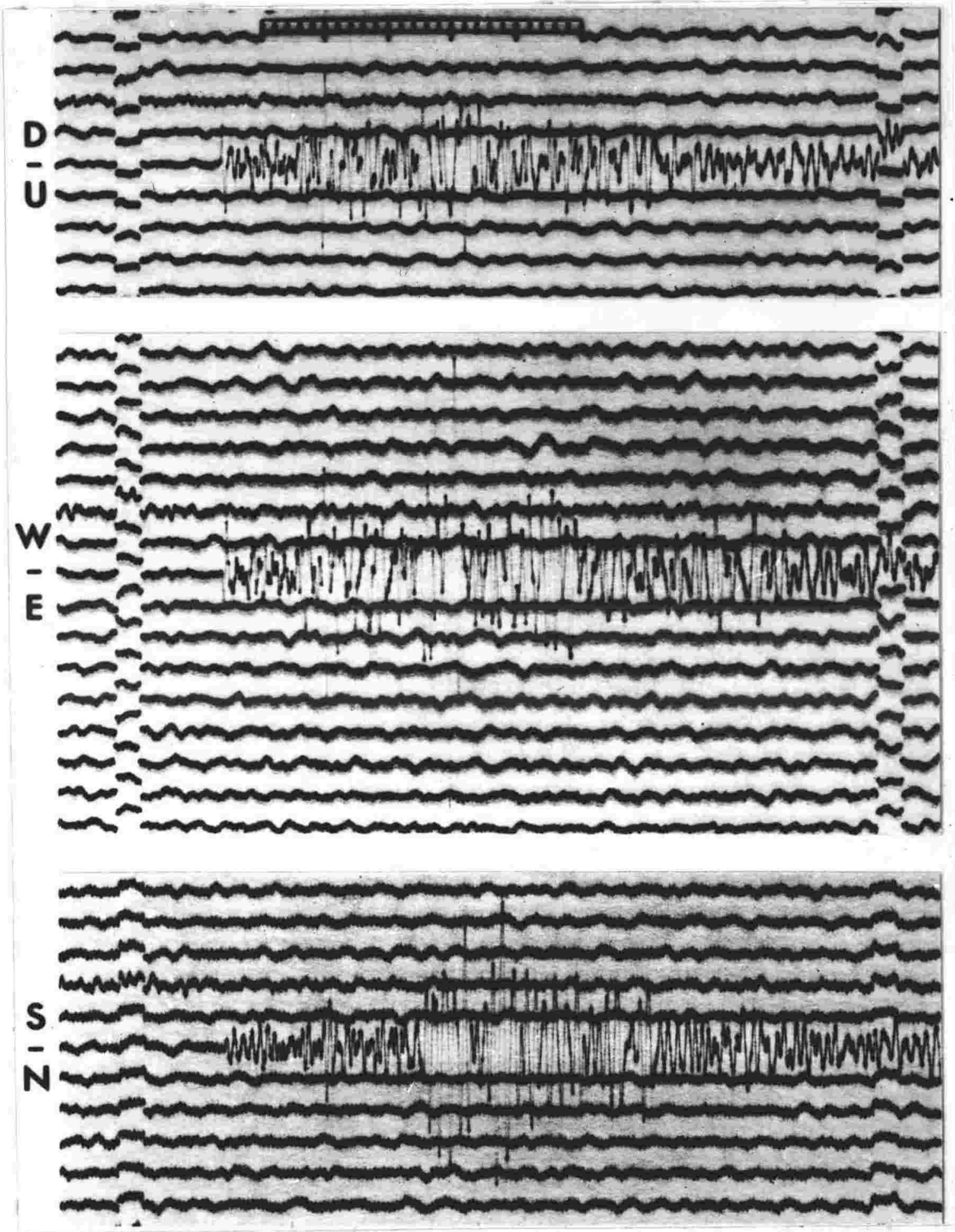

Figure 7.4. Short-period records at KRP of the 1977 June $02^{\mathrm{d}} 13^{\mathrm{h}} 17^{\mathrm{m}}$ mainshock, showing the $P$, intermediate and $S$ arrival. Directions of motion are indicated. The bar scale is graduated in seconds. 

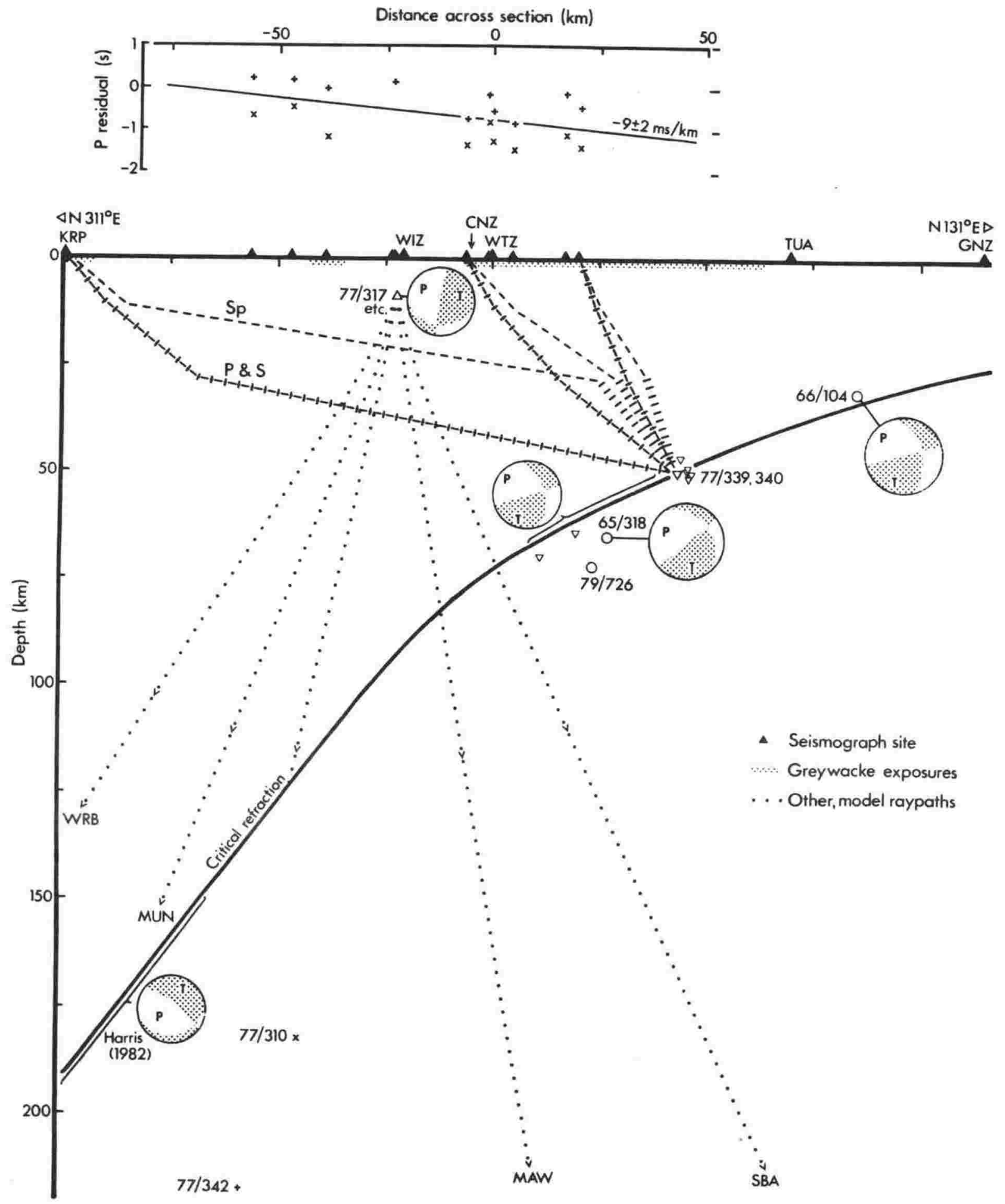

Figure 7.5. Intermediate-depth seismicity projected onto a vertical section approximately perpendicular to subduction-zone strike. Dashed rays indicate modelled paths from the subcrustal sequence and suggest wave polarisations. The form of the inferred plate interface (solid line) is after Reyners (1980). Also represented (crosses) are deep events occurring during the 1977 survey and their arrival-time residuals across the Bay of Plenty, and the ISC locations of several moderate-magnitude earthquakes (circles), referenced by year/number (N.Z. catalogue). Near-hemisphere projections of focal mechanisms have compressional quadrants shaded. 
traversed similar near-surface material beneath KRP, and the origin-time error is likewise a common component of the respective travel-times. The relative arrival-times should therefore have been controlled mainly by the velocities in the almost parallel path-legs closest to horizontal. That the $S p$ time needs to have been earlier by at least $1.0 \mathrm{~s}$ if much upper-mantle material had been sampled can be appreciated by replacing $55 \mathrm{~km}$ of the upper path of $6.5 \mathrm{~km} / \mathrm{s}$ velocity in the model with, say, material of velocity $7.4 \mathrm{~km} / \mathrm{s}$. Otherwise, either the deeper structure beneath $\mathrm{KRP}$ or near the region of wave-mode conversion must be extraordinary, or the computed focal depth grossly in error for each of the earthquakes in the sequence. The only station at teleseismic distance listed (in the ISC Bulletin) for the subcrustal mainshock, SPA (South Pole), reported two arrivals with interval $11.0 \mathrm{~s}$. For the given focal mechanism (Fig. 4.9), $p P$ should there have been comparable to $P$, with $s P$ having about half its amplitude. Thus, if the second arrival was of $p P$, a depth of $45 \mathrm{~km}$ is resolved for the focus of the subcrustal mainshock.

\section{Subduction structure}

The $S p$ phase observed for earthquakes of the subcrustal sequence should not have been so conspicuous for a focal mechanism having a greater strike-slip component; indeed, the thrust mechanism that was deduced for the first-motion directions (Fig. 4.9) was consistent with the subcrustal earthquake sequence having been an interplate event, which helps fix the local position of the boundary between the two lithospheric plates underlying New Zealand. It is generally assumed under the hypothesis of plate tectonics that mantle-zone earthquakes originate near the cool upper surface of the descending plate, and thus outline its attitude at depth. The zone of deep earthquake activity beneath the North Island is usually determined as striking within a few degrees of northeast-southwest (e.g., Ansell \& Smith, 1975; Adams \& Ware, 1977; Spencer \& Gubbins, 1980), but becoming more north-striking to the northeast (e.g., Ansell, 1978: Fig. 1).

In Figure 7.5 the form of the interface between the Indian plate to the northwest and the Pacific plate to the southeast is that due to Reyners (1980), inferred (for depth less than $100 \mathrm{~km}$ ) for the microseismicity detected during a traverse $200 \mathrm{~km}$ to the southwest of the Bay of Plenty region: the microseismicity occurred at about $70 \mathrm{~km}$ depth beneath CNZ, which is situated on the northern flank of Mt Ruapehu, an active andesitic volcano marking the southern limit of the volcanic front. Although the original section projects $10 \mathrm{~km}$ farther to the northwest than is depicted here, the match is adequate considering the effects of the different velocity models that have been used, and the means by which the original section was ascertained. Because the line of most recent volcanism trends $\mathrm{N} 35^{\circ} \mathrm{E}$ locally, the depth to the Pacific plate below the volcanic front is evidently greater in the Bay of Plenty region.

Hypocentres computed for deep earthquake origins using arrival-times at permanent network seismographs usually yield origin depths of about $100 \mathrm{~km}$ (e.g., Adams \& 
Ware, 1977) or more (e.g., Ansell, 1978) beneath WTZ, and greater depths towards the northwest with rate depending on the model velocities. Using the homogeneous station method and the Jeffreys-Bullen travel-time model, Ansell \& Smith (1975) found the North Island deep seismic zone below $120 \mathrm{~km}$ to be less than $20 \mathrm{~km}$ thick, and dipping to the northwest at about $67^{\circ}$. That dip, however, is apparently nearer $50^{\circ}$ if velocities in the subducted oceanic lithosphere are $11 \%$ faster than for the adjacent mantle, as adopted in the laterally inhomogeneous model of Adams \& Ware (1977) and for the profile of Figure 7.5. Moreover, this is why the Observatory locations included in Figure 7.5, for origins occurring near $200 \mathrm{~km}$ depth during the 1977 survey, appear to be $50 \mathrm{~km}$ too far to the southeast. Nevertheless, the volcanism seems to bear some affinity with a large change in dip of the Pacific plate.

The value of $11 \%$ for the contrast in velocities in the subducted plate above velocities in the surrounding mantle is the extreme of estimates obtained using various techniques and assumptions (e.g., Adams \& Ware, 1977; Smith, 1977; Spencer \& Gubbins, 1980). A major consequence of that contrast is that the subducted oceanic lithosphere may act in guiding seismic waves. That rays were refracted in the dipping structure appears to be the case from waveforms of the deep events recorded at eastern stations of the temporary network: this was suggested by small amplitude arrivals up to $0.3 \mathrm{~s}$ ahead of the main $P$ arrivals. Also, the higher velocities were apparently expressed by the trend in $P$ arrival-time residuals, indicated in Figure 7.5 for the Observatory origins for the deep events, and calculated using a horizontally layered velocity model that included an approximate Jeffreys-Bullen mantle (Jeffreys, 1976: p. 156). The common gradient of $9 \pm 2 \mathrm{~ms} / \mathrm{km}$ in trend of residuals across the Bay of Plenty network of seismographs, for the $M_{L} 4.2$ earthquake of May $28^{\mathrm{d}} 22^{\mathrm{h}} 35^{\mathrm{m}}$ (77/310) and the $M_{L} 3.9$ earthquake of June $02^{\mathrm{d}} 21^{\mathrm{h}} 46^{\mathrm{m}}(77 / 342)$, is less than was apparent in the crustal $P$ delay experiment (Robinson et al., 1981) conducted further southwest to detect magma bodies. Any estimate of velocity contrast from the time difference between the small amplitude $P$ arrivals and the main $P$ arrivals at the eastern stations would depend on the geometry of the subducted plate and the ray paths that are taken by those phases. Although there seems from the pattern of residuals at adjacent stations to be a need for local site corrections, the effect of the subducted plate must clearly be isolated before specifying a crustal origin for the anomaly. High frequencies featured in all of the waveforms. Notice too that $S$ in Figure 7.4 for the subcrustal mainshock was not entirely absent, even though the ray-paths passed beneath the volcanically active Rotorua-Tarawera district.

All this has some relevance also for the teleseismic waveform recorded for the Matata mainshock (Fig. 5.1). Direct and surface-reflected ray-paths to seismographs in central Australia did not, it seems, intersect the subducted plate: $P$ waves critically refracted at about $120 \mathrm{~km}$ depth should have been delayed by about $1.1 \mathrm{~s}$ in reaching the plate interface, but have been as much as $1.0 \mathrm{~s}$ earlier than direct $P$ because of the faster path in the plate (e.g., Robinson, 1976). Relatively small amplitudes should be 
expected for such refractions, especially if the dip of the plate increases with depth; thus, although the plate may serve to focus incoming seismic energy to favourably placed New Zealand sites (e.g., Ansell \& Gubbins, 1986), outgoing energy may be directed down and possibly away from detection. In contrast, rays to seismographs in Antarctica and southwest Australia all intersected the subducted plate. However, because of the shallowness of the Matata mainshock, the converted and reflected phase ray-paths for any station should not have been widely separated from the $P$ ray-path, and the deep structure sampled by the depth phases should therefore not have been altogether different from that sampled by the direct $P$. Such may not always be the case, of course, for deeper origins down in the mantle zone, with the departure from assumed lateral homogeneity causing problems in the assignment of focal depths (e.g., Engdahl \& Billington, 1986) and affecting analysis of source mechanism (e.g., Kennett, 1983: p. 75).

Now that the approximate position of the Pacific plate has been identified, it is clear that the $S p$ conversion depth relates to a boundary in the overlying lithosphere. Haines (1979) surmised that upper-mantle material thick enough to transmit $P n$ and $S n$ phases was present in the region northwest of GNZ (Fig. 5.4). (In that study, greater mantle velocities to the southwest of GNZ were taken as deriving from the subducted oceanic lithosphere, though part of the interpretation (Haines, 1976) concerned the placing of the southwestern boundary, which may have benefited from the stationpair reversals yielded by the 1974 data.) $S p$ phases observed at GNZ for earthquakes in the deep seismic zone, indicating (Smith, 1970) a conversion depth of $31 \pm 4 \mathrm{~km}$ about $50 \mathrm{~km}$ northwest of GNZ could, however, have been generated just as easily at the plate interface. It is noteworthy therefore that the GNZ seismograms for aftershocks of the subcrustal mainshock of this study exhibited an arrival $5.0 \mathrm{~s}$ after $P$, whereas the $S-P$ interval was $13.2 \mathrm{~s}$. Departure angles, depending on the actual velocity structure near the source region, may nevertheless have been substantially different from those modelled (e.g., Fig. 4.9).

\section{The local model}

Conversions of $S$ to $P$ have also been noted elsewhere in New Zealand (e.g., Smith, 1970; Calhaem et al., 1977), providing important constraints for crustal models. The vertical incidence of first arrivals apparent at GNZ (Fig. 5.5) for Matata sequence earthquakes can now be explained as due to low-velocity sediments near GNZ in combination with relatively high velocities for the mantle of the dipping oceanic lithosphere. For instance, critical refraction in an $8.5 \mathrm{~km} / \mathrm{s}$ refractor dipping at $20^{\circ}$, and in the plane normal to refractor strike, will give an angle of incidence within $1^{\circ}$ of vertical at the free surface, when combined with a surface layer of $3.0 \mathrm{~km} / \mathrm{s}$, this latter velocity being the highest measured (Garrick, 1969) for the thick Tertiary sequence near GNZ. Waves critically refracted in the subducted plate would have been travelling almost horizontally in overlying mantle before entering the oceanic 
lithosphere, and thus near the Moho interface that was defined by the converted phases: second arrivals, $1.0 \mathrm{~s}$ later, registered strongly on the horizontal-component seismographs (Fig. 5.5), suggesting a slower, crustal path.

Details such as whether or not GNZ falls within the shadow zone for waves critically refracted from the northwestern Moho of the overlying lithospheric plate (an effect which is possibly caused by the local replacement of mantle material by subducted crust in the region of plate interaction) must await the more comprehensive study undertaken for other active margins (e.g., Spence et al., 1985). In spite of the inferred fast path in the overlying mantle, arrivals at GNZ from the Matata sequence earthquakes appeared to be late compared to times given by the standard model (Fig. 5.4). This was also the case with the Bay of Plenty shot data (Fig. 7.1), a site correction of $-0.7 \mathrm{~s}$ having been applied already (Stern, 1982) to account for the nearsurface sediments. There is, however, no need, as yet, to invoke anisotropy, as was done (Robinson, 1983) to explain discrepancies between crustal velocities from an inversion study and those from a large-scale refraction experiment parallel to the plate margin further to the southwest: here broad Bouguer and isostatic gravity anomalies of $-500 \mu \mathrm{N} / \mathrm{kg}$ to $-750 \mu \mathrm{N} / \mathrm{kg}$ (Reilly, 1965a, b) presumably reflect the low density and velocities in an extensive prism of accreted sedimentary melange along the east coast of North Island.

The data from the Bay of Plenty explosions will not, of course, be necessarily of first arrivals, through lack of signal strength. (It is thus doubtful whether that refraction experiment provides an indirect check on travel-times from the Matata mainshock.) The existence of an arrival at GBZ (Great Barrier) at least $0.4 \mathrm{~s}$ earlier than was used in the analysis has now been acknowledged (Stern \& Davey, 1985), as have the errors inherent in using travel-times from earthquakes of uncertain origintime, depth and epicentre. Errors for the explosion data, particularly for arrivals at sites remote from the profile line, are compounded by uncertainty in shot position, such as that suspected to be responsible for the problem with the Shot 2 instant, and no $S$ timings or $S-P$ intervals appeared for WTZ in the Observatory solutions $(83 / 247,248$, 249) for the earthquakes used to augment the explosion data, the largest earthquake being only of $M_{L} 3.4$.

For the Lake Taupo shot it is clear that beyond $70 \mathrm{~km}$ the arrivals were to KRP and thus along the western greywacke margin of the volcanic region for much of the path; other arrivals were taken to be later-arriving phases, or were described as "extremely weak." Furthermore, arrivals identified as reflections from the Moho (PmP) come just as readily and with comparable amplitude from intermediate boundaries within the crust (e.g, Berry \& West, 1966; Braile \& Smith, 1975). The interpretations for the volcanic region from the large-scale refraction projects were therefore not unambiguous, and may thus be subject to considerable revision, a situation not without precedent in New Zealand (e.g., Garrick, 1968).

The standard crustal model, although found unsatisfactory from the point of view 
of velocity ratios and local site corrections, cannot be dispensed with in favour of an alternative for the purpose of locating the Matata sequence earthquakes for the reasons that were discussed earlier. An upper-mantle velocity somewhat lower than that found for the subducted lithosphere can be expected purely on grounds of elevated temperature, but the depth to the Moho, if the Moho exists and can be resolved in the Bay of Plenty region, thus far remains unclear. Station terms resulting from the study of interval velocities (Haines, 1980) are of little assistance in this regard. For example, the $P$ term for WTZ (Fig. 5.4) could apply for the volcanic region through the inclusion of the 1974 readings, or equally for the greywacke region further southeast, such as from where the observed $S p$ phases originated. The $+0.5 \mathrm{~s}$ time-term for WTZ relative to that assumed for MNG (i.e., $0.0 \mathrm{~s}$ ), where the standard crustal model was considered valid, implies a greater crustal thickness or crustal velocities lower than standard, yet there is no Tertiary sequence near. WTZ as exists near GNZ, which had the same time-term (Fig. 5.4). For comparison, the equivalent quantity for WTZ from mantle-zone earthquakes was $-0.1 \mathrm{~s}$ (Smith, 1977: p. 148), indicating no great difference from the standard, though possibly through having to account also for irregularities in the modelled mantle. Differences of crustal origin in the time residuals for deep earthquakes recorded at sites either side of the volcanic front were similarly obscured by the near-surface and deeper contributions, the main difficulty being primarily one of meagre contrast in velocity.

Because the Matata mainshock was located in this study using only seismographs within about $50 \mathrm{~km}$, and thus independently of mantle velocities, it could be argued that the arrival-time residuals at more distant seismographs (Fig. 5.4) indicate the departures from the velocity model directly: no trade-off in residuals between sites east and west of the Bay of Plenty would then be required, and the mantle velocity southwest within the volcanic region would be truly known. However, that proposal relies on the assumed local model being adequate, which was shown not to be the case in the analysis of residuals determined using the homogeneous station method, and it depends again on the actual station-terms. Thus little can be done to improve either the absolute locations or the estimates of origin-time for the Matata sequence events. If a local model having, say, a $P$ velocity of $7.4 \mathrm{~km} / \mathrm{s}$ at $15 \mathrm{~km}$ depth was adopted, however, computed hypocentres were forced very shallow to avoid having fast paths in the nearby high velocity layer. While some of the aftershocks may indeed have originated close to the free-surface, similar depths were not indicated for the foreshocks in the study of relative locations (Fig. $4.3 \& 4.4$ ), which yielded depths consistent with the depth phases observed for the mainshock (Fig. 5.1).

Despite not knowing the travel-times absolutely, an attempt can be made to interpret qualitatively the relative times shown in Figure 5.4 for recording sites of similar azimuth, and the relative times of different phases observed at individual sites. As previously noted, the $P n$ velocity for most of the western North Island appears to be not greatly different from that given by the Jeffreys-Bullen model, and even 
southwards to WEL, which occupies much the same position as GNZ with respect to the underthrust lithosphere (e.g., Robinson, 1978). Some care is required, however, for seismic waves travelling in the mantle of the overlying lithosphere will at some stage be overtaken by those travelling along and up-dip in the subducted plate; such an occurrence is indeed suggested by the relatively early arrivals at the sensitive seismographs of the permanent network recording microearthquakes near WEL (Fig. 5.4). On the other hand, arrivals of phases travelling in the lower crust seem to be poorly recorded or absent, in contrast to the arrivals of phases travelling in the upper crust, possibly because of poorly developed intracrustal layering. Moreover, the crustal phases do not fit the model particularly well, as is common in many Observatory solutions of hypocentre, and notable also in early studies of crustal velocities in New Zealand (e.g., Bullen, 1939; Hamilton, 1966). More intriguing are the arrivals about $4.3 \mathrm{~s}$ after Pn. The delay and its uniformity with epicentral distance suggest these are the arrivals of the phase $s P n$.

\section{Further reflections and conversions}

The corresponding $p P n$ phase should be about $2.7 \mathrm{~s}$ after $P n$, but of relatively small amplitude because the strength of the source radiation does not compensate for the freesurface reflection coefficient as well as it does for $s P n$. Anyway, both $P n$ and $p P n$ will of ten have been near-nodal for many of the recording sites, and will therefore have been poorly recorded. Figure 7.6 shows several of the short-period records for seismographs of the New Zealand network: these recordings are aligned along what are inferred to be the times of arrivals from the (overlying) mantle. (For CRZ it is the east-west component that is presented by virtue of its superior signal-to-noise ratio; the others are vertical-component seismograms except at ONE (Onerahi), where only the east-west component was recorded.) Whereas $P n$ for TNZ and central North Island sites was from near the null axis, and consequently very small in those records, at WEL (WWSSN Benioff instrument) there is some suggestion of the earlier arrival emanating from the subducted plate. Predicted amplitude ratios for the Matata mainshock mechanism (Fig. 5.3) are given in Table 7.2 (for the standard crustal model, but with a Jeffreys-Bullen mantle and densities as assumed for Table 7.1). This is not to say that these ratios are definitive, since that depends on the precise focal mechanism, crustal structure and departure angles, but merely to indicate that $s P n$ can attain amplitudes large enough to be seen in the $P n$ coda; the phase $s P n$ has similarly been interpreted for earthquakes of shallow origin at regional distances from the broadband Gräfenburg array in southern Germany (Kind, 1979, 1984). The free-surface phases having been explained, the question then arises as to the nature of the arrivals about $1.7 \mathrm{~s}$ after $P$ n.

The intermediate phase in the $P n$ waveform is clearly seen for COB and CRZ, is discernable for MNG and CAZ, and is interpreted for NGZ, if it is there not of a crustal phase, and for TNZ, where it is apparently the first arrival. Its arrival-time, 

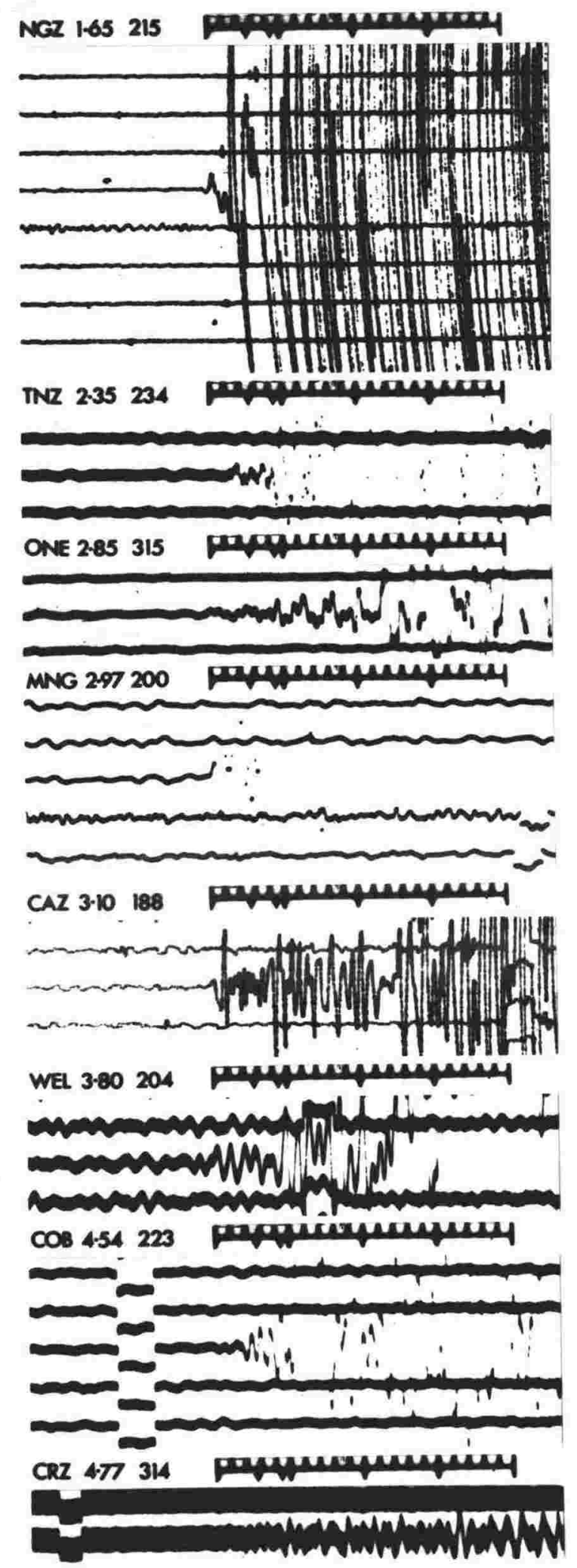

Figure 7.6. The $P n$ waveform of the Matata mainshock. Seismograms are identified by the station code, epicentral distance ( $\Delta$ in degrees) and azimuth ( ${ }^{\circ} E$ ) from the source. Bar scales are graduated in seconds: triangles indicate inferred arrivals of $P n$, $p P n$ and $s P n$ respectively. 
Table 7.2. Relative amplitudes in the $P n$ waveform for the Matata mainshock.

DIP $100^{\circ}$, RAKE $150^{\circ}$, STRIKE N45 E; or DIP $119^{\circ}$, RAKE $12^{\circ}$, STRIKE N309 ${ }^{\circ}$.

STATION

CALCULATED

NAME $\triangle$ AT $\log \mid$ AMPLITUDE RATIOI

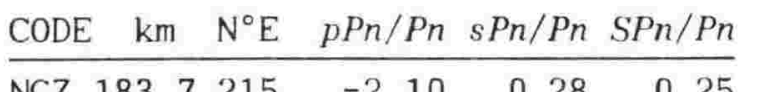

NGZ 183.721

TNZ 261.1234

1.26

1.71

1.25

ONE 316.7315

$-0.54$

$-0.11$

$-0.00$

$-0.33$

0.55

0.18

MNG 330.6200

STATION

CALCULATED

NAME $\triangle$ AT $\log \mid$ AMPLITUDE RATIO|

CODE $\mathrm{km} \quad \mathrm{N}^{\circ} \mathrm{E} \quad p P n / P n \quad s P n / P n \quad S P n / P n$

$\begin{array}{lllll}\text { CAZ } 345.2 & 188 & -0.11 & 0.70 & 0.19\end{array}$

WEL 422.4204

$-0.43$

0.50

0.19

COB 504.7223

$-0.16-1.02$

0.38$$
(33
$$

wherein: the path factor was 0.286 for $p P n / P n, 0.370$ for $s P n / P n$, and 0.204 for $S P n / P n$. Takeoff angles were either $45^{\circ}$ or $24^{\circ}$ from vertical for the assumed model.

however, is too late relative to $P n$ to be associated with the stopping phase of rupture, recalling that bilateral faulting was inferred for a fault of $3.5 \mathrm{~km}$ half-length, and that the rupture velocity lies somewhere between the Rayleigh velocity $(0.92 \beta$ for shear velocity $\beta$ and equal Lamé moduli) and the compressional velocity $(\alpha=\sqrt{3} \beta)$. Moreover, consequences of a propagating rupture are usually better seen for larger earthquakes, and on broadband seismograms (e.g., Douglas et al., 1981). In any case, there was no sign of any corresponding surface-reflected phases expected for such a discrete event, which also discounts the possibility of a multiple rupture. Alternatively, it is too early at the greater distances to be the wide-angle reflection from the Moho, and a lateral refraction in the subducted plate along a path to COB, which occupies much the same position above the subducted plate as WIZ (Fig. 7.5), does not explain the arrival at CRZ. Finally, of all phases having the same ray parameter as $P n$, none reflected above the source will be as strong as the one reflected from the free surface, and those leaving downwards as $P$ will not be larger than $P n$. It thus seems the intermediate phase is none other than $S P n$, the $S$-to- $P$ converted wave originating at the Moho near the source.

Satisfactory amplitudes for $S P n$ relative to $P n$ are indicated in Table 7.2, where the path factor is now just the appropriate ratio of head-wave coefficients for plane waves (Cervený \& Ravindra, 1971), since the ratio of transmission coefficients at other interfaces is equal or near to unity, and the difference in critical distances (the distances along the refractor at which the headwaves begin to exist) was small compared to path lengths in the refractor. The analogous phase at teleseismic distances can be designated $S P m$, where the appended " $m$ " emphasises conversion is at the Moho near the source (with travel thereafter through the mantle) and distinguishes it from the more distant conversion at the free surface $(S P)$. There were hints of this $S P m$ phase (about $1.5 \mathrm{~s}$ after $P$ ) for the Matata mainshock: it was one of the features used in correlating across records of the teleseismic waveform (Fig. 5.1). In the experience 
of Douglas et al. (1981), and of Pearce (1981), the SPm phase is often observed for intracrustal earthquakes, especially when $P$ is near-nodal, and it sometimes produces the apparent first-motion.

The depth of the Moho beneath the source is thus indicated to be $11.5 \mathrm{~km}$, which means the crustal thickness is about $22 \mathrm{~km}$ in the Bay of Plenty region. Although this estimate increases with average crustal velocities higher than assumed, it varies little with moderate changes in the velocities. The estimate of crustal thickness is therefore greater than the $15 \pm 3 \mathrm{~km}$ found in the recent refraction interpretations (Stern \& Davey, 1985), for which the error bounds appeared to be $90 \%$ tolerance limits. Besides, depths inferred using $S$ to $P$ conversions are comparatively robust, because of the difference between shear and compressional velocities, and relatively independent of station terms, because arrival-time intervals at individual sites are used.

All that has been done here is to interpret the arrival intervals in the $P n$ waveforms, showing that the amplitudes of converted waves are plausible. Detailed modelling of the actual amplitudes and their frequency dependence is more difficult, and requires additional knowledge about velocities, densities, and their gradients in transitional regions. A full treatment is beyond the scope of this study, but it would involve the matching of theoretical seismograms to waveforms composed of interference head-waves from the Moho locally and interacting waves from the subducted plate, and include the free-surface reflections near the source as well as the conversion SPn.

The waveform produced for the Matata sequence mainshock, because of the size and position of the earthquake, may well be one of the best available for the volcanic region. The $M_{L} 5.1$ Waiotapu earthquake of 1983 (83/1231), although smaller in magnitude and occurring further southwest, had a direction of first motion listed for $\mathrm{COB}$, presumably used in analysis of the focal mechanism (Smith et al, 1984) However, that first motion may not have been of the first arrival, given the waveform recorded at $\mathrm{COB}$ for the Matata sequence mainshock (Fig. 7.6), as $\mathrm{COB}$ was apparently also near-nodal for the Waiotapu earthquake. This points to the dangers of uncritically using time intervals of apparent first-arrivals when measuring seismic velocities between pairs of stations, especially when the observation sites are at different azimuths from the source.

Adoption of a model involving mantle type velocities at a depth of $22 \mathrm{~km}$ does not alter the computed origins for the Matata sequence earthquakes found earlier. For example, a mantle with a $P$-wave velocity of $7.8 \mathrm{~km} / \mathrm{s}$ at $22 \mathrm{~km}$ depth in the model does not yield $P n$ as the first-arriving phase at any of the Bay of Plenty stations that were used for the event locations and were within about $50 \mathrm{~km}$ of the hypocentres, suggesting that the apparent refractions observed for $\mathrm{KAO}$ and $\mathrm{KAH}$ (e.g., Fig. 3.3)- were from a shallower unresolvable refractor. Hence a further revision of the hypocentres and the model was not required. Further observations in favourable circumstances leading, as in this study, to the identification of phases constraining the crustal thickness in other regions of New Zealand should assist in the determination of regional models serving as suitable replacements for the standard crustal model. 


\section{Relationship to regional tectonics}

The Matata earthquake might be considered unusual, since it was not the typical event expected for the volcanic region. The occurrence of the sequence is here examined in the light of some theoretical and observational results for deformation in the region. The regional variation that was observed in focal mechanisms may have been advantageous for resolving the stress regime.

\section{The Moho}

The proposal of a Moho shallowing from about $28.5 \mathrm{~km}$ depth in the region of the subcrustal sequence (Fig. 1.1) to about $22 \mathrm{~km}$ in the region of the Matata sequence would be strengthened if there was some evidence for its continuity beneath the volcanic front. There is. Intermediate phases were recorded for the deepest of the events located using the temporary seismograph network: observations that may not have been easily explained in isolation.

The $M_{L} 1.7$ earthquake of 1977 May $29^{\mathrm{d}} 21^{\mathrm{h}} 17^{\mathrm{m}}$ was located at about $70 \mathrm{~km}$ depth south of Whakatane (Fig. $1.1 \& 7.5$ ). Figure 8.1 shows that the $P$ arrivals at the nearby recording sites were relatively small. This near-nodality for $P$ justified the inclusion of the first-motion data for this earthquake in the composite for Figure 4.9 . Moreover, the first-motion data helped to indicate the dip-slip component and further constrain the auxiliary plane for the thrust mechanism for the plate interface (Fig. 7.5). (This mechanism also provides the large $S$ radiation that compensates for the low transmission coefficients for $S p$ in the region of wave-mode conversion and for $S$ on vertical-component instruments at the free surface.) Clearly the event is not a multiple event, since there are only three sets of phases recorded. $\mathrm{H}$. wever, the small number of ubserving sites and the steepness of the ray paths, together with the likelihood of nearstation site terms, precluded reliable determination of the slowness of the intermediate phase across the network.

The hypocentre solution for the earthquake is given in Table 8.1, showing a satisfactory fit for the interpretation of $S$-to- $P$ conversion at the Moho occurring at a depth of about $24 \mathrm{~km}$ beneath the eastern network of seismographs: furthermore, the near-nodal character of $P$ is corroborated by the apparent lateness of the arrival onsets that were observed for the stations RAW and WTZ. A southeastward dip of about $7^{\circ}$ is thus indicated for the Moho, if the strike is taken to be roughly parallel to the volcanic front and the axis of subduction (Fig. 7.5). Implications of this observation will be briefly examined later, after consideration is given to the stresses acting in the region. In particular, the thrusting on the plate interface has to be reconciled with the strike-slip and normal faulting that was observed for the shallow earthquakes within the volcanic region (e.g., Fig. 5.11, 5.12 \& 7.5). First, however, the immediate effects of stress changes arising from the Matata sequence mainshock are explored, using 

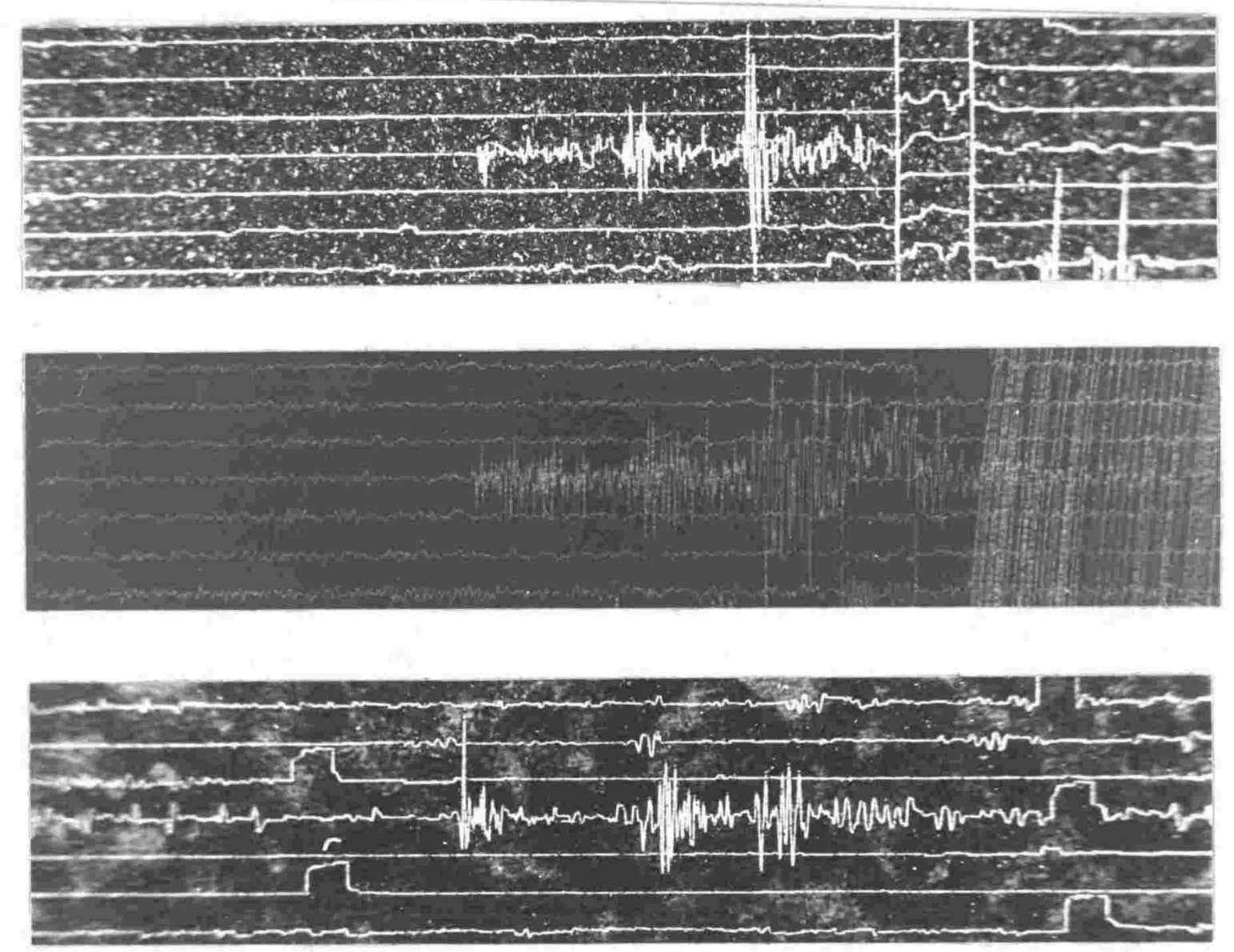

Figure 8.1. Seismograms showing the intermediate phase, interpreted as $S p$, for the deep event of 1977 May $29^{\mathrm{d}} 21^{\mathrm{h}} 17^{\mathrm{m}}$, as recorded at RAW (top), MAR (centre), and AWA (bottom).

Table 8.1. Origin, arrival-times and residuals for the deepest event, 1977 May 29.

ORIGIN $21^{\mathrm{h}} 17^{\mathrm{m}} 43^{\mathrm{s}}: 6$ LATITUDE $38^{\circ} 05^{\prime}: 6 \mathrm{~S}$ LONGITUDE $177^{\circ} 04^{\prime}:$ OE DEPTH $71.5 \mathrm{~km}$

\begin{tabular}{|c|c|c|c|c|c|c|c|c|c|c|c|c|}
\hline \multicolumn{3}{|c|}{ STATION } & \multicolumn{3}{|c|}{$P$ ARRIVAL-TIME } & \multicolumn{3}{|c|}{$S p$ ARRIVAL-TIME } & \multicolumn{4}{|c|}{$S$ ARRIVAL-TIME } \\
\hline \multirow{2}{*}{$\begin{array}{l}\text { NAME } \\
\text { CODE }\end{array}$} & \multirow{2}{*}{$\begin{array}{r}\Delta \\
\mathrm{km}\end{array}$} & \multirow{2}{*}{$\begin{array}{l}\mathrm{AT} \\
\mathrm{N}^{\circ} \mathrm{E}\end{array}$} & \multicolumn{2}{|c|}{ OBSERVED } & \multirow{2}{*}{$\begin{array}{c}\text { RES. } \\
\mathrm{s}\end{array}$} & \multicolumn{2}{|c|}{ OBSERVED } & \multirow{2}{*}{$\begin{array}{c}\text { RES. } \\
\mathrm{s}\end{array}$} & \multicolumn{3}{|c|}{ OBSERVED } & \multirow{2}{*}{$\begin{array}{c}\text { RES . } \\
s\end{array}$} \\
\hline & & & h & s & & h & s & & & $\mathrm{n}$ & s & \\
\hline RAW & 9.2 & 347 & 2117 & 54. & 0.43 & 2117 & 58.2 & $*-0.2$ & 21 & 18 & 01.4 & 0.0 \\
\hline MAR & 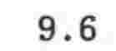 & 196 & 2117 & 53. & 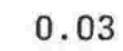 & $21 \quad 17$ & 5 & * 0 & 4 & 18 & 0 & . \\
\hline WAI & 10.5 & 8 & $21 \quad 17$ & 53.68 & -0.22 & & & & & & & \\
\hline WTZ & 13 & 33 & 2117 & 54. & 0 & & & & 21 & 18 & 01.4 & -0 \\
\hline MAE & 19.1 & 266 & 2117 & 54.13 & -0.01 & & & & 21 & 18 & 01.9 & 0.1 \\
\hline AWA & 19.9 & 295 & $21 \quad 17$ & 54.00 & -0.17 & 2117 & 58.9 & 0.1 & 21 & 18 & 01.8 & -0.1 \\
\hline$M D Q$ & 52.7 & 301 & $21 \quad 17$ & 56.2 & -0.0 & & & & & & & \\
\hline
\end{tabular}

Note: starred times were not used in the hypocentre solution; the standard crustal model was assumed, but with a Jeffreys-Bullen mantle below $24 \mathrm{~km}$ depth. 
results that derive from the elasticity theory of dislocations (Steketee, 1958a, b), as these effects may have been important for the aftershock occurrences.

\section{Off-fault aftershocks}

Aftershock epicentres situated to the sides of a mainshock rupture, but within its rupture length, are apparently characteristic of strike-slip faulting and due to the increase in horizontal shear-stress at those sites as a result of the main rupturing (Das \& Scholz, 1981). The increase in shear stress to the sides of the mainshock rupture region was earlier shown by Chinnery (1963) for a vertical strike-slip fault intersecting the free surface. Analytical expressions used here for modelling the stress fields associated with the Matata mainshock were derived from the displacement formulations of Mansinha \& Smylie (1967, 1971) for a rectangular dislocation of arbitrary orientation in a Poisson halfspace.

Changes in horizontal shear stress attributable to the Matata mainshock slip are shown at two depths in Figure 8.2. The requisite off-fault changes in shear stress are indeed evident, in addition to the well-known changes beyond the ends of the fault, which represent the tendency for extension of the main fault. The increase in rightlateral shear parallel to the mainshock strike is greater on the down-dip side of the fault, and displaced from the positions of symmetry, in accord with the sense of offset observed for the Matata sequence aftershocks (Fig. 4.2 \& 4.3). Das \& Scholz (1981) speculated that aftershocks on the up-dip side of a fault should be the shallower: i.e., the opposite to that observed here. A simple test revealed, however, that the result here was due mainly to the dip-slip component for the Matata mainshock rupture.

The situation here is somewhat different to that already described, in that the eastern aftershocks indicated fault planes that were different in strike to that of the mainshock (Fig. 5.9 \& 5.11). This poses no problem insofar as the relative dilatation in quadrants east and west of the mainshock rupture will have effectively decreased the normal stress across planes of weakness at those sites, as indicated by Figure 8.3, reducing the frictional strength. The following analysis has been restricted to rightlateral motion on vertical planes, since the dips and rakes of the focal mechanisms for the aftershocks were not well constrained, and because the greatest simplification then results. Changes in stress with depth (e.g., Vetter \& Ryall, 1983) are therefore neglected, as are associated changes in pore pressure; a value of $\mu_{s}=0.75$ is an appropriate value for the coefficient of friction (Byerlee, 1978).

The Coulomb failure function $\tau_{s}+\mu_{s} \sigma_{n}$, where $\tau_{s}$ and $\sigma_{n}$ are respectively the appropriate changes in right-lateral shear stress and normal stress across a pre-existing fault plane, is shown in Figure 8.4 for the two cases of interest. The correspondence of aftershock occurrence with increase in right-lateral failure stress is good, with regard to strike of fault plane. The magnitude of the changes in failure stress involved suggests that the region around the mainshock rupture must have been already close to failure. It can be expected that inflow of pore fluid from the quadrants of relative 

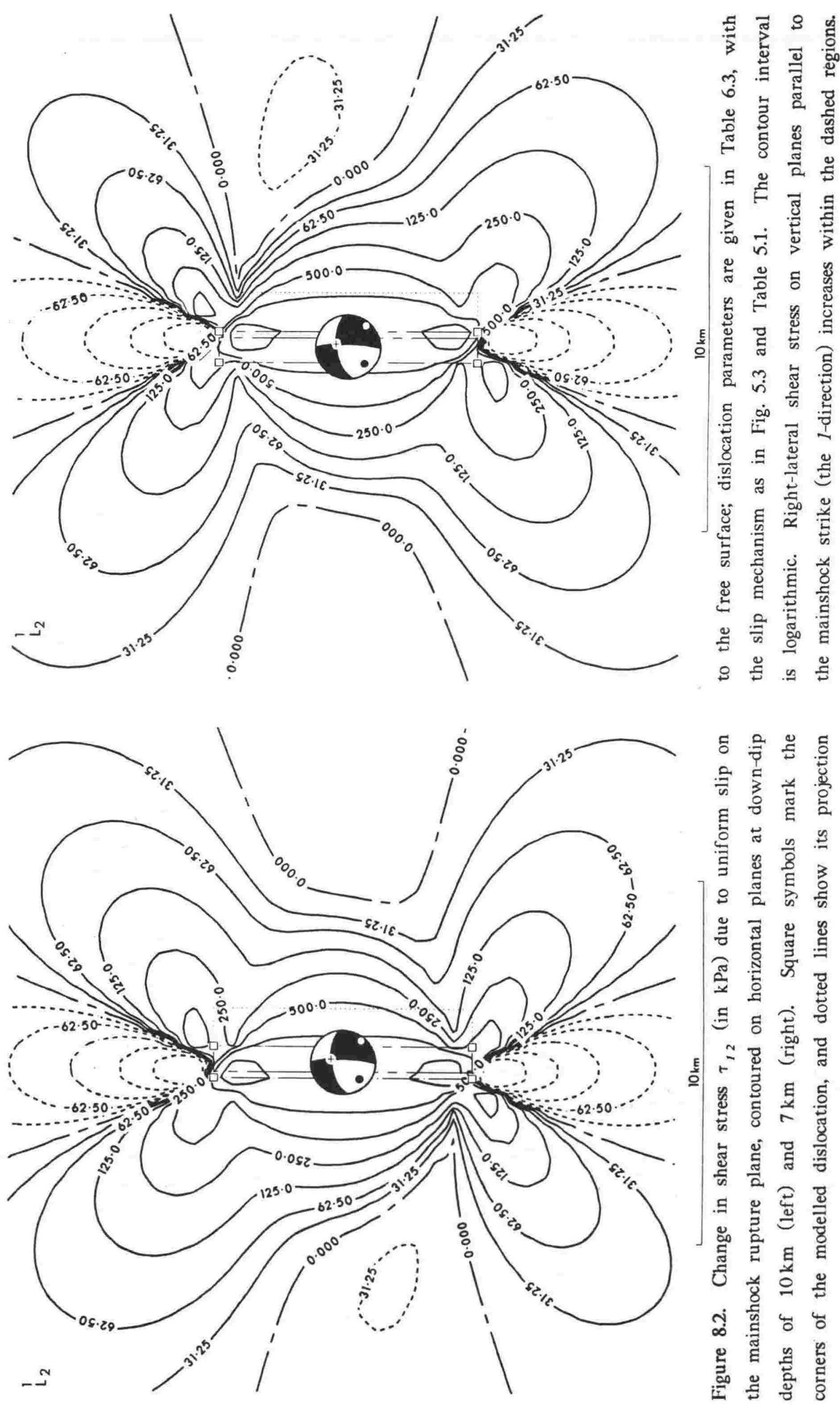


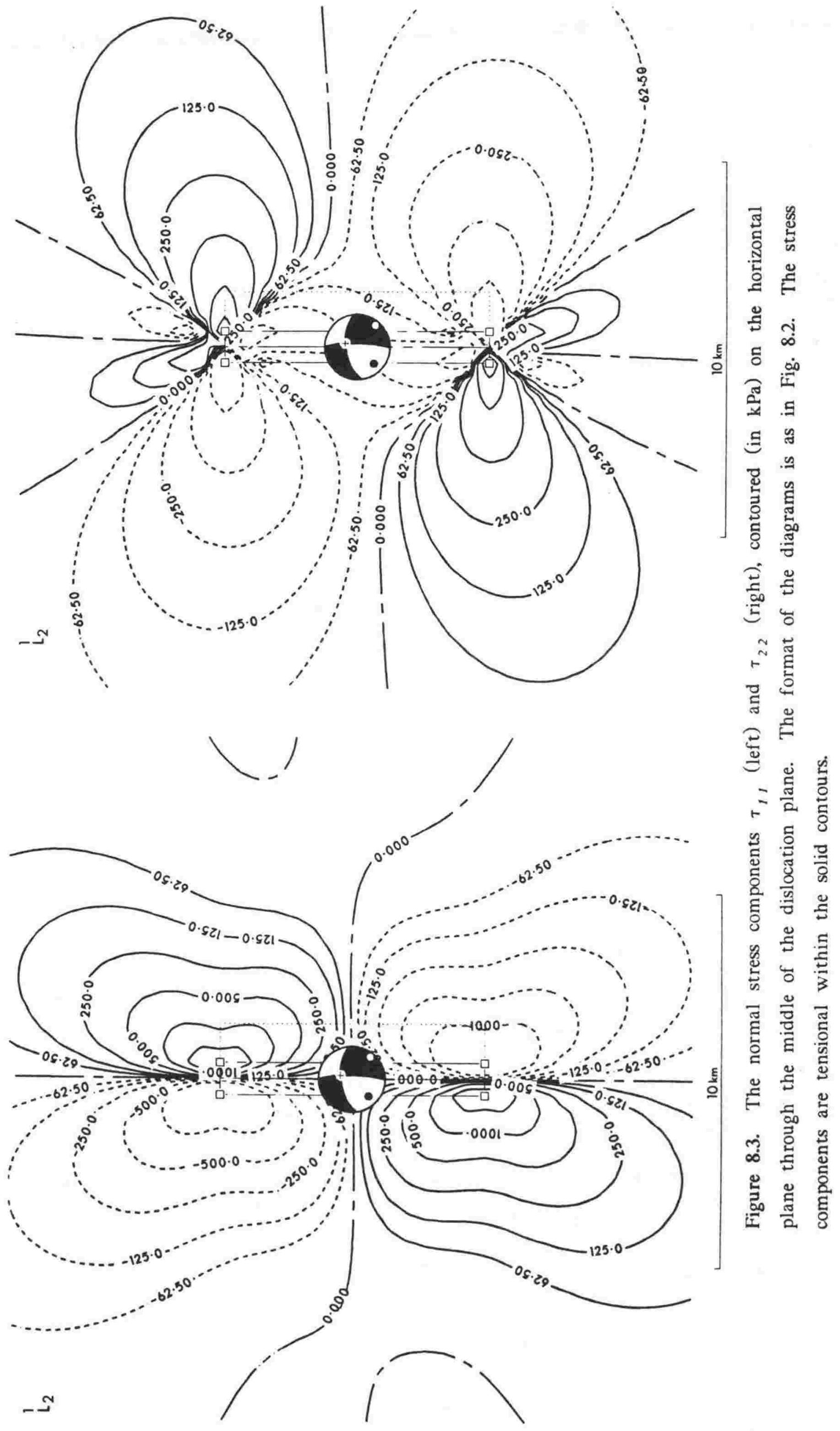




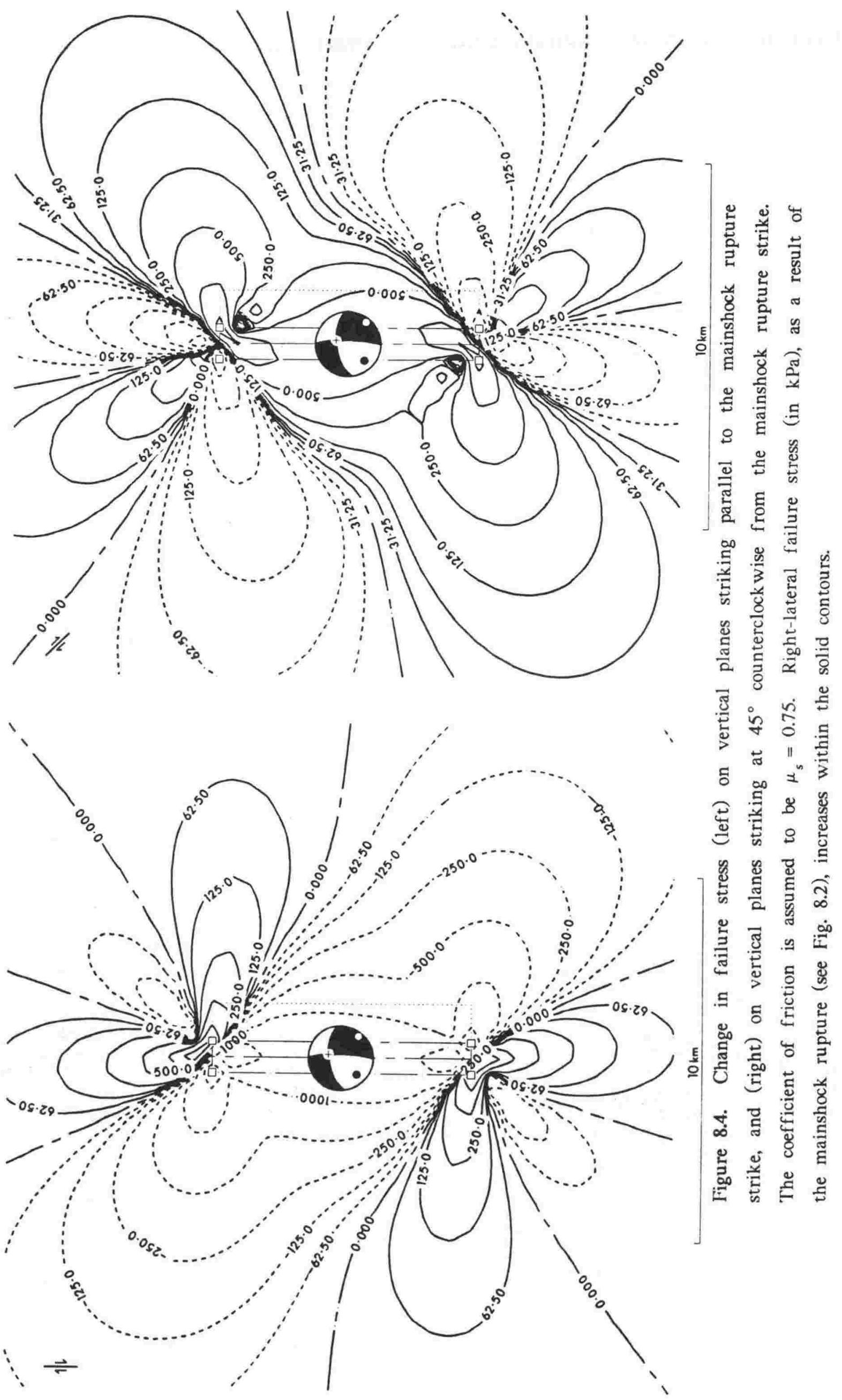


compression should, after some delay, have further reduced the effective normal stresses, leading to the triggering of the off-fault aftershocks. Off-fault activity would then have diminished the stresses available for activity on the mainshock rupture plane.

The concentration of stress near the ends of the main rupture may have given rise to a secondary orientation of new fracturing (e.g., Chinnery, 1966a, b), and in the sense suggested by the deviations from the main epicentral trend in Figure 4.2 , or it may have been absorbed there by slip on pre-existing planes of different orientation. However, a full (three-dimensional) analysis for new planes of fracture, and for probable pre-existing planes of failure, requires detailed knowledge of the regional stress field existing in the region before the mainshock occurrence. Although methods have recently been presented (e.g., Gephart \& Forsyth, 1984) for determining principal stress directions and relative stress magnitudes, by requiring slip on a fault plane to be in the direction of maximum resolved shear stress for a suitable range of fault orientations, these methods cannot be used here because the focal mechanisms were too few and too poorly constrained. Limited progress could be made by imposing special conditions: the mainshock slip (Fig. 5.3 \& Table 5.1), for example, could have been caused by a uniaxial tensile stress directed horizontally at $N 151^{\circ} \mathrm{E}$. However, the stress field is likely in general to be triaxial, and none of the principal stress directions need be horizontal or vertical in regions away from the free surface. Hence an examination of source components of the regional stress that are expected to have been acting is in order.

\section{The subduction thrust}

Savage (1983) indicated how to model the deformation along a subduction margin, by imposing a slip solution opposite to that usually observed on the subduction thrust: the deformation field is then given by a straightforward application of dislocation modelling. Figure 8.5 shows results for the case that is appropriate to the North Island region of New Zealand, corresponding to east-west convergence of about $5 \mathrm{~cm} /$ year (Walcott, 1978a) along a margin striking roughly northeast-southwest (Fig. 7.5). Obviously this is a gross model, deficient in that there is no curvature of slip plane, no taper of slip function at the bottom edge, and no account of viscoelastic effects in an underlying asthenosphere. Nevertheless, principal features near the free surface include a region of compression near the position corresponding to uplift of the axial ranges, and a region of pure shear above the deepest edge of the dislocation, giving dextral strike-slip motion parallel to the subduction zone strike. (The small region of extension at the free surface is attributed to flexure.) A similar pattern of deformation, involving partitioning of the strike-slip and dip-slip components of oblique convergence on subduction, was indicated by Walcott (1978b), using the simple model of Fitch (1972), but dislocation modelling is clearly the correct approach.

There may be some objection to the extent of the model, taken here as extending as far southwest as Wellington to exclude edge effects, but the degree of coupling 

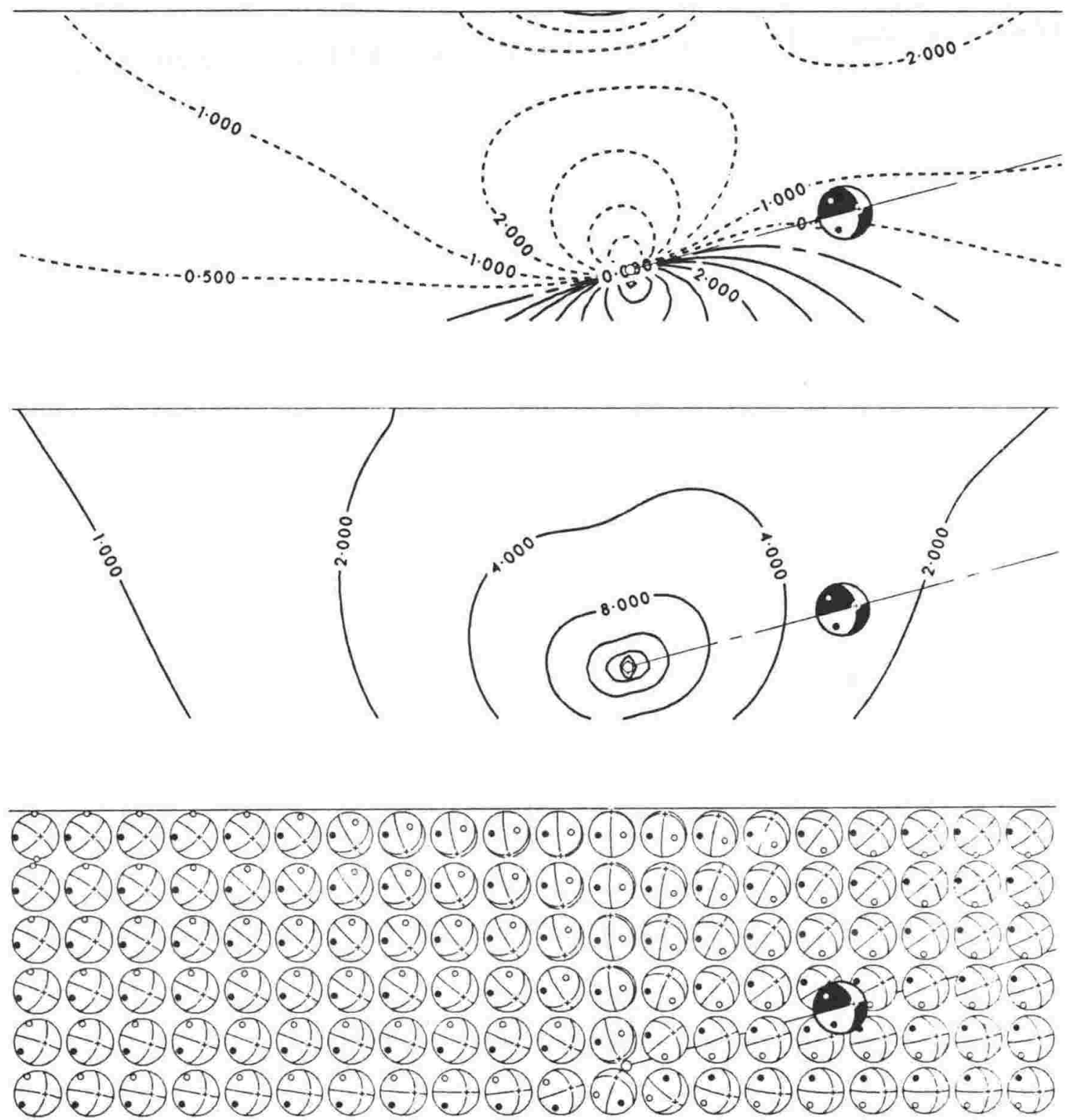

$100 \mathrm{~km}$

Figure 8.5. Deformation due to oblique subduction, modelled using $1 \mathrm{~m}$ dip-slip and $1 \mathrm{~m}$ strike-slip on a plane of $100 \mathrm{~km}$ half-width and $400 \mathrm{~km}$ half-length. A nearhemisphere projection of the slip mechanism is shown on the dislocation plane extending from the right through vertical mid-section. Contoured strains $\left(\times 10^{-6}\right)$ are the dilatational component $e_{i i}$ (top, with solid contours extensional) and the maximum shear (centre); the bottom diagram shows the orientations of the principal strain axes and the planes of maximum shear.

across the subduction thrust underlying the North Island is poorly known. Geodetic shear strains (where significant) and the inferred directions of principal axes given by Walcott (1978b) were varied, depending on the observation period, and were not consistent with the focal mechanism for the 1966 Gisborne earthquake, which was one of three focal mechanisms with which they were compared. Moreover, it is not clear why the results for the eastern North Island region for the total interval under study 
were not some average of the results in the same region for the periods before and after about 1931 (see Walcott, 1978b: Fig. 3). Further south the key focal mechanism that was supposed (Walcott, 1978b; Reyners, 1980) to mark an "unlocked" region has subsequently been reinterpreted (Reyners, 1984: Fig. 8 \& 10a) as representing internal deformation within the subducted plate. The purpose of the dislocation modelling presented here, however, is merely to indicate the effect of oblique convergence and subduction east of the Bay of Plenty region, as indicated by the subcrustal earthquakes of this study. Some of the relative plate motion elsewhere may have been aseismic, but corresponding stresses will be transmitted across the subduction thrust so long as there is sufficient frictional contact for generating events such as the 1979 earthquake $(79 / 726)$ and the smaller earthquakes that were spread over the broader region and produced similar first-motions (e.g., Fig. 4.9, 4.10).

Focal mechanism solutions can reasonably be attempted for only the larger earthquakes occurring in the eastern region of Figure 8.6. Figure 8.7 shows that two of them were consistent with slip in the direction of relative plate motion on the plate interface for the ISC determinations of hypocentre; side projections of these mechanisms were included in Figure 7.5, indicating the geometrical change of relative slip direction with change in dip of plate interface. For the Gisborne earthquake (Fig. 8.7b), the interpretation of an $18 \mathrm{~km}$ focal depth (Webb et al., 1985) seems

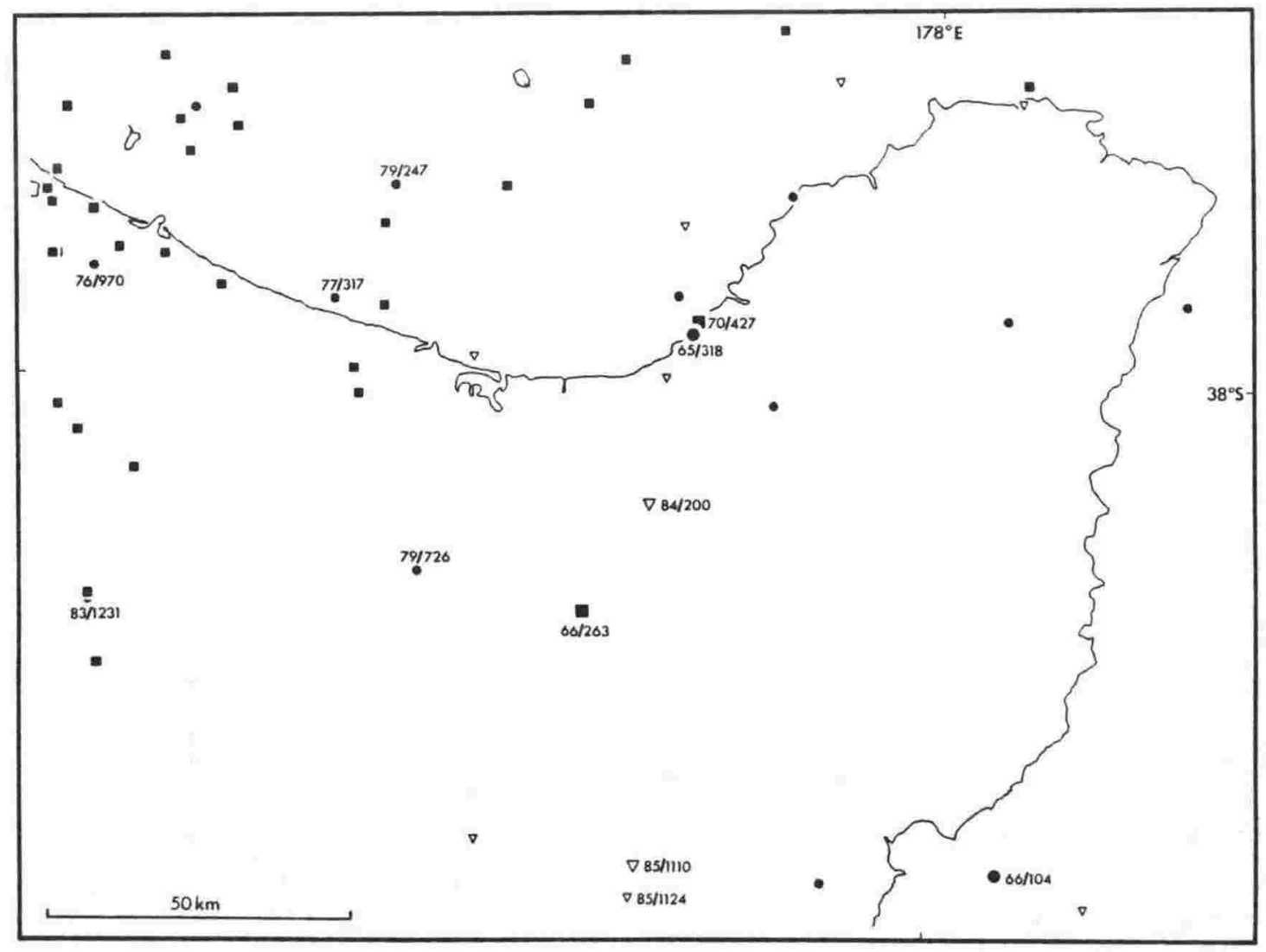

Figure 8.6. Larger earthquakes, $M_{L} \geqslant 5.0$, in the eastern North Island region, 1964-1986. Symbols for these Observatory epicentres are larger for $M_{L} \geqslant 5.7$ - notable events are identified by year/number (N.Z. catalogue). Circles denote depths $\leqslant 33 \mathrm{~km}$, squares depths $>100 \mathrm{~km}$. 


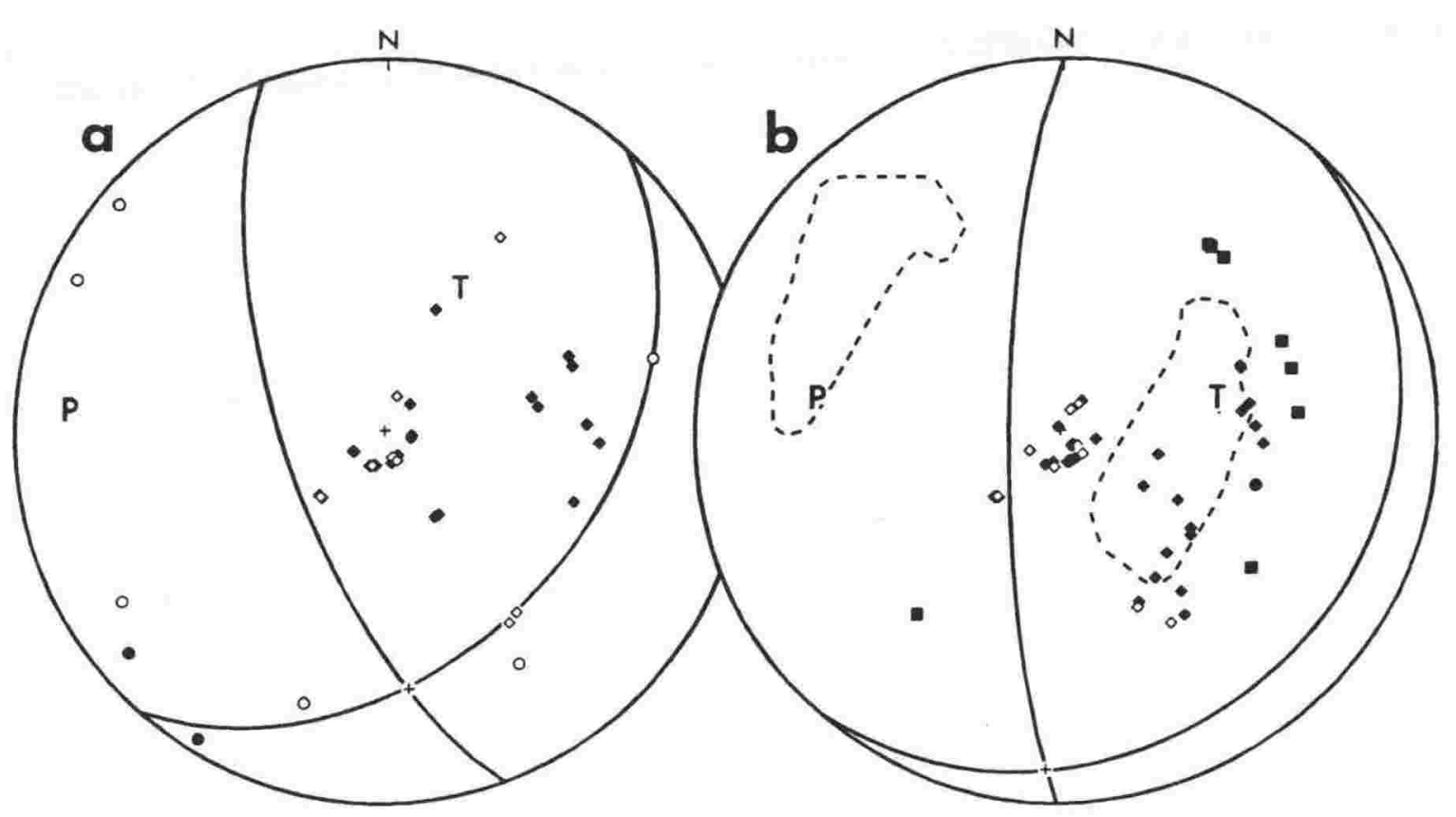

Figure 8.7. First motions and focal mechanisms, consistent with thrusting on the plate interface, for the events (a) of 1965 June $15^{\mathrm{d}} 09^{\mathrm{h}} 20^{\mathrm{m}}(65 / 318)$ and (b) of 1966 March $04^{\mathrm{d}} 23^{\mathrm{h}} 58^{\mathrm{m}}(66 / 104)$. First motions are mostly from the ISC Bulletin; symbols are as in Fig. 4.5 \& 4.7. In (b), acceptability limits (dashed) for the $P$ and $T$ axes, based on body-wave modelling, are from Webb et al. (1985).

dependent on the waveforms that were susceptible to interference caused by phases reflected from the Earth's core: if this shallow depth is correct, the question then arises as to just what it was that Hamilton (1969) identified as depth phases for $P^{\prime}$. The interpretation here of slip in the direction of relative plate motion causes one local discrepant first-motion (for ECZ), which may be due to station polarity or to takeoff angle.

Two further focal mechanisms are shown in Figure 8.8. The respective $p P-P$ depths of $95 \mathrm{~km}$ and $39 \mathrm{~km}$ place these events within the subducted plate; the focal mechanisms have been interpreted (Reyners \& Hodder, 1985; Perin, 1987) as indicating deformation within the subducted plate. Focal mechanisms for the remaining two larger earthquakes in Figure $8.6(66 / 263 \& 70 / 427$, but with $p P-P$ depths of $99 \mathrm{~km}$ and $64 \mathrm{~km}$ ) are similarly not well constrained by the reported first motions, but they can both be fitted with thrust solutions with one nodal plane striking north-south and the other striking northwest-southeast. Thrust mechanisms near the plate interface have been interpreted (e.g., Bannister, 1988: Fig. 14B, C) for some microearthquakes occurring south of Gisborne, but they were poorly constrained by the observations. Stress orientations for earthquakes in the deep seismic zone (e.g., Fig. 5.6) have been attributed to down-dip tension in the subducted plate (Harris, 1982); however, resistance in the direction of plate motion relative to the asthenosphere could be a factor in addition to the modifications caused by a sloping bottom edge for the subducted plate. 


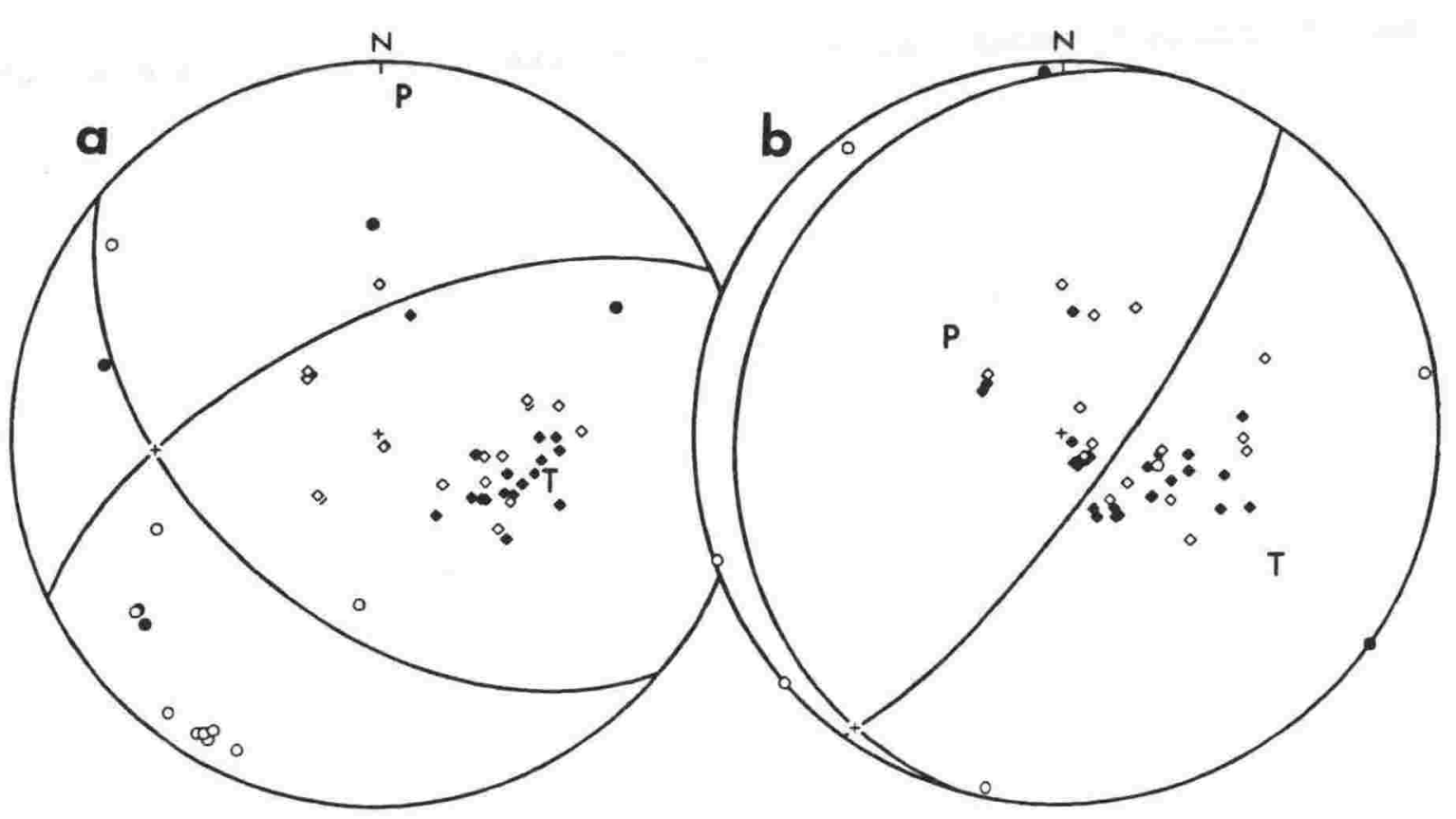

Figure 8.8. First motions and focal mechanisms, consistent with deformation within the subducted plate, for the events (a) of 1984 March $08^{\mathrm{d}} 00^{\mathrm{h}} 40^{\mathrm{m}}(84 / 200)$ and (b) of 1985 July $19^{\mathrm{d}} 14^{\mathrm{h}} 33^{\mathrm{m}}$ (85/1110). First motions (see Fig. $4.5 \& 4.7$ ) are from the $I S C$ Bulletin; focal mechanisms are the best double-couple solutions from the (Harvard) centroid moment tensor solutions.

The important result here is that thrusting on the plate interface extends to a depth of about $70 \mathrm{~km}$ in the Bay of Plenty region. Above the region of decoupling the deviatoric stress regime resulting from the oblique plate convergence and subduction will have been almost one of pure shear (i.e., $\sigma_{1}=-\sigma_{3}$, with vertical $\sigma_{2}=0$ ). While such a stress regime should have been favourable for the strike-slip component of the Matata sequence mainshock, especially as it involves zero cross pressure for a vertical fault (e.g., Chinnery, 1964), it is unlikely to have been conducive to the Type 2 and Type 4 faulting in the same region (e.g., Fig. 5.10 to 5.12).

The normal component of slip for the Type 3 and Type 4 mechanisms must be ascribed to a basal shear traction acting at depth in addition to the pure shear superimposed by the oblique convergence and subduction. The resulting uniaxial tension, if directed across the volcanic front, should have caused the axes of greatest and least compressive stress to be rotated anticlockwise from their otherwise northern and eastern trends, thereby facilitating slip for the eastern events, which would be conjugate in the geological sense for only the east-trending planes. For example, an equal amount of tensile stress perpendicular to the volcanic front in addition to the shear stress parallel to the volcanic front would lead to a $13^{\circ}$ rotation for the horizontal stress axes. However, the relative contributions of these sources to the effective stresses cannot be determined (e.g., McGarr, 1980; McGarr et al., 1982) without some further constraints and assumptions. 


\section{Bay of Plenty faulting}

Dextral motion on northeast-trending faults is reasonable for the Bay of Plenty region, because no existing faults further eastward are so favourably oriented; moreover, this motion should be concentrated in the Bay of Plenty region, as strike-slip faulting is generally not stable if it is distributed (see McKenzie \& Jackson, 1983). The major faults further eastward trend north-south in the Mesozoic greywacke region (Fig. 2.1), forming part of the North Island shear belt, which curves to become more northeasttrending further south. Movement on these faults, which have been relatively aseismic along the axial ranges (e.g., Reyners, 1980), will have been inhibited under the prevailing stress region in the Bay of Plenty region.

Thus the regional shear across the North Island may promote the development of the volcanic axis further southwest, with the zone of weakness so created subject to further weakening by thermal stresses. However, such shear should be minor compared to the plate convergence rate, if, as is suggested by the apparent steady-state occurrence of thrusting on the plate interface, the plates are weakly coupled. Nevertheless, it is difficult to see how there can be wholesale sinistral motion along the southeastern margin as envisaged in the Smith \& Webb (1986: Fig. 10b) proposal for widening of the Central Volcanic Region. The only supporting evidence seems to have been the mechanisms interpreted for first-arrival data for the 1983 Waiotapu sequence (Smith et al., 1984) and for a later swarm sequence near Lake Taupo (Webb et al., 1986), about $60 \mathrm{~km}$ further southwest.

Generally, as explained by Jackson \& McKenzie (1983) for extensional regimes, there is a geometrical restriction for finite motions on intersecting faults: two distinct systems cannot both remain active unless the slip on one set also lies in the plane of the other set. The alternative - the opening up of voids - seems to have been countered in the present case by the Type 4 mechanisms (Fig. 5.8), which acted as an intermediary set but were also indicative of general collapse and infilling of material following from the general relief of stress. The main-shock mechanism (Fig. 5.3) was pre-eminent here, by virtue of magnitude, and the Type 2 faulting merely an integral element of the structure of the media. Only at greater depths, as the crustal ductility increases, will intersecting faults be accommodated, possibly by their becoming listric.

The coexistence of strike-slip through oblique-slip to normal-slip mechanisms, all with the null axis confined approximately in the plane of the main rupture (see Fig. 5.8 to 5.11), suggests the deviatoric stress field became almost axially symmetric, with the maximum and intermediate principal stresses nearly of equal magnitude (cf. Harmsen \& Rogers, 1986). The similar suite of mechanisms suggested for the Kawerau and Te Teko earthquakes (Fig. 5.12) further argues for low deviatoric stress levels, and again implies that the tensile stress across the volcanic front was a substantial component of the regional stress regime. This analysis contrasts with that of Smith \& Webb (1986), where it was maintained that both thrust and normal faulting were acceptable for earthquake occurrence in the Central Volcanic Region for an assumed 
stress regime that was considered to be generated by the subduction of the Pacific plate beneath the North Island.

Further modelling is desirable to determine whether a near-total stress drop occurred for the Matata mainshock, and hence whether the faulting is driven by low deviatoric stress levels (e.g., Raleigh \& Evernden, 1981).

\section{Back-arc spreading}

Stick-slip motion beyond the main thrust zone on a plate interface is of ten required to explain uplift profiles across subduction margins. However, it is also often observed (e.g., Nakamura \& Uyeda, 1980) that the transmitted compressional stress (e.g., Fig. 8.5) does not extend far into the interior of the overriding plate, and that the horizontal stresses become tensional: such regions are back-arc basins or marginal seas where crustal extension by back-arc spreading is occurring (e.g., Uyeda \& Kanamori, 1979).

Karig (1970a, b) noted that the central North Island volcanic region appeared to be a direct continuation into New Zealand of the Havre Trough, an active oceanic basin associated with the Tonga-Kermadec trench-arc system. Evidence from magnetic anomalies (Malahoff et al., 1982) indicates, however, that the axis of symmetric spreading from a central ridge in the Havre Trough is offset $50 \mathrm{~km}$ left-laterally north of White Island from the active margin of the Central Volcanic Region, where asymmetric spreading is envisaged as occurring (e.g., Calhaem, 1973; Evison et al., 1976). Complex structure similar to that of the present study was indicated for the region north of White Island by the Type 2 mechanism for the $M_{L} 6.3$ mainshock with the ISC origin-time of 1984 December $30^{\mathrm{d}} 21^{\mathrm{h}} 36^{\mathrm{m}} 53^{\mathrm{s}} .8(84 / 1254)$ and by the Type 4 mechanisms observed for accompanying foreshocks and aftershocks (see Dziewonski et al., 1985). The region between White Island and the Bay of Plenty is relatively undisturbed magnetically (Roberts, 1967; Hunt, 1978: Fig. 2).

Strike-slip regimes are often observed to be intermediate between the tensional and compressional regimes across subduction margins (e.g., Nakamura \& Uyeda, 1980), representing the regions of arc volcanism. The transition from compressional to strikeslip regime was indicated (Fig. 8.5) to be the result of oblique convergence. The existence of this strike-slip regime in the volcanic region in the Bay of Plenty region during the Matata sequence suggests kinematic processes involving the oceanward retreat of the subduction axis from the margin or the retreat of the back-arc plate away from the subducting plate (e.g., Ruff \& Kanamori, 1980) may be unimportant here.

Other models proposed for back-arc spreading involve local asthenospheric flows. A secondary hydrodynamic flow induced in the upper mantle above a subducting plate (e.g., McKenzie, 1969; Sleep \& Toksöz, 1971) would generate a transitional stress regime in the overlying material (e.g., McGarr, 1982). However, for the geometry shown in Figure 7.5 and for a reasonably large cell dimension, the stresses would be compressional across the volcanic front, with back-arc extension further west as in the Havre Trough region; it might also be expected that active spreading should be more in 
the direction of plate convergence. A diapiric flow of material rising from the subducting plate (e.g., Karig, 1971) would, on the other hand, generate a tensional stress across the volcanic front, but the flow would need to counter that induced by subduction, which occurs at a decreasing rate southwestwards. In any case, the asthenospheric flows need not be great, as back-arc spreading ridges, once established, could simply be passive features similar to the mid-oceanic ridges (e.g., McKenzie, 1967). Thus it seems that back-arc spreading may involve a delicate balance of different processes, especially in transitional regions such as may be the case for the Bay of Plenty region. The resultant of the various plate boundary forces will have been amplified in the upper lithosphere due to stress decay resulting from ductile deformation in the lower lithosphere (Kusznir \& Park, 1984).

The southeastward dipping Moho (closely paralleling the $S p$ ray-path to KRP in Fig. 7.5 as far as the western seismograph network) in the Bay of Plenty region suggests continental extension and crustal thinning has occurred by stretching of the lithosphere; it also means that the southeastern margin of the volcanic region is not necessarily a sharp rift boundary along its length. The indicated amount of thinning by itself is unlikely to have resulted in a great amount of partial melting by decompression of passively upwelling asthenosphere (e.g., White et al., 1987; McKenzie $\&$ Bickle, 1988). Further west, however, as was suggested by the different Poisson's ratio (Fig. 3.2), the crust may have been appreciably altered by widespread intrusions into the crust. Some magma contribution from deeper in the mantle seems necessary for the andesitic volcanism.

Stratovolcanoes are consistent with the region of strike-slip faulting because the $\sigma_{1}-\sigma_{2}$ plane is still approximately vertical. It is unlikely that the occurrence of the Matata mainshock should have had much effect on the volcanic activity at White Island (Clark et al., 1979), which was by then erupting ash: because White Island was nearly on strike from the Matata mainshock, the (compressional) stress there resulting from the mainshock rupture was much smaller than the tidal stress of about $3 \mathrm{kPa}$ (e.g., McNutt \& Beavan, 1981). The significant activity at White Island, together with the earlier seismicity near Te Puke (Fig. 1.1), must be regarded as manifestations of the continuing regional deformation rather than as events directly triggering and foreshadowing the occurrence of the Matata sequence. 


\section{Conclusion}

The Matata mainshock occurrence was consistent with North Island tectonics, in that it reflected a dextral regional shear together with a component of back-arc spreading. The regional shear results from oblique convergence and subduction of the Pacific plate beneath the volcanic region and accords with andesitic volcanism.

The crustal medium in which the sequence occurred was indicated to be highly fractured and heterogeneous. Focal mechanisms therefore reflected pre-existing fault orientations rather than greatly varying orientations of stress field. The complexity of structure in the Bay of Plenty region can be expected to attract repeated activity, manifest as multiple sequences, but together with the fine balance of plate convergence stresses and local tensional stresses acting in the region it frustrates specific predictions of earthquakes.

The relative amplitude method, which serves as a useful adjunct to body-wave modelling, proved useful here in yielding the focal mechanism for the mainshock (Fig. 5.3). The method can now be also applied for locally recorded waveforms, with the introduction of digital seismographs of wide dynamic range into the New Zealand network. More use should be made of the depth phases $p P$ and $s P$ recorded at Australian stations for New Zealand earthquakes, particularly as these phases can provide the indication of the depth extent of faulting for larger crustal earthquakes that is not always determinable from observations of ground deformation.

Identification of interplate thrust faulting (Fig. 7.5) for the subcrustal sequence of earthquakes placed stronger constraints on the position of the lithospheric plate boundary underlying the North Island than could have been be gained by the fitting of an envelope to diffuse seismicity in the subducted plate. The few subcrustal earthquakes that were observed allowed extension of the Reyners (1980) profile northeastwards. A further study is needed to fulfil the objectives of the original project, including a critical examination of differences in interplate morphology and of the role of the deep thrust zone in decoupling the main thrust. There was no evidence for lateral segmentation of the subducted plate (e.g., Reyners, 1983) or for any extensive body of molten magma above the plate.

Heat flow provides important controls for thermal models of the region. It should be recognised, however, that short-period seismic signals provide a high resolution of structural boundaries and depths. The depths to the Moho inferred here using wavemode conversions are exactly the constraints that are needed for the modelling of geophysical phenomena such as gravity anomalies and mantle velocity. The $S p$ phase, in particular, seems to have been undervalued for determining crustal velocities from travel-time inversions. Further studies are desirable for similar constraints further

southwest. Seismic reflection studies, though expensive, are feasible across the Bay of Plenty for extensive detailing of a rifting continental margin and its suggested 
transition into the Havre Trough. With the placing here of the Moho at not less than $22 \mathrm{~km}$ depth, and with the identification of a $12 \mathrm{~km}$ initiation depth for the 1987 March 02 Edgecumbe mainshock in the adjacent region (from a $p P-P$ interval of $4.1 \mathrm{~s}$ at Warramunga Array), it is questionable whether the Edgecumbe mainshock ruptured the whole crustal thickness as has been suggested (e.g., Smith, 1987).

Normal faulting on a northeast-striking plane for the Edgecumbe mainshock (Dziewonski et al., 1988: solution 117) attests to the importance of the extensional component in the stress field. The possible role of gravity in overcoming friction on the fault plane is one factor for the earlier occurrence of the Matata mainshock, because of the difference in dip $-80^{\circ}$ to the northwest as opposed to $58^{\circ}$ for the Edgecumbe mainshock. (The plane with dip $32^{\circ}$ that Crook \& Hannah (1988) took to be in excellent agreement when modelling the horizontal deformation actually dips southeastwards.) Another factor may have been a subtle change in the plate coupling in the intervening period, diminishing the regional shear component seen for the Matata mainshock. Subcrustal events of 1985 in the eastern Bay of Plenty region (the triangles in Fig. 8.6) are therefore of interest, but it is unlikely that focal mechanisms can be determined satisfactorily for them.

Focal mechanism results for the volcanic region are an important indicator of the coupling of the plate interface to the east, because the shallow seismicity there may only have reflected internal deformation in the subducted plate. The weak coupling of the plates indicated in this study suggests that large thrust events east of the volcanic region should be rare, as is suggested also by the historical seismicity. This state of affairs could easily change, however. Further south, in the Wellington region, where it has been proposed (Robinson, 1986) there is a $7 \mathrm{~km}$ step in the plate morphology transverse to the direction of relative plate motion, the present state of coupling is not so clear. The lack of interplate events has been interpreted (Robinson, 1986) as strong coupling, but an episode of aseismic slip on the plate interface has also been proposed (Robinson, 1987) to explain changes in geophysical indicators of stress level: composite focal mechanisms for shallow events in the overlying plate are insufficient to give any indication of net compression.

The range of focal mechanisms observed for the Matata sequence earthquakes suggested that the stress field became axially symmetric about a southeast-trending tensional axis. Together with the normal faulting for the Edgecumbe earthquake it implies that the spreading component is dominant and that the faulting is driven by low stresses. The brittle upper crust above the deforming Moho region is therefore susceptible to small temporal and spatial variations of the stress field caused by changes in the plate boundary forces and by variations in the strength of the crust as underplated and intruded igneous material cools. 


\section{Appendix}

The column " $S$ " in Table A.1 denotes the sample under which the earthquake was drawn (see sampling); a starred item indicates that the earthquake was not considered as belonging to the Matata sequence. An " $A$ " appended to the estimate of magnitude (MAG) indicates an assignment on the basis of a single observation. The type of firstmotion pattern (for Fig. 5.8), where determined, is given in the last column: the other column headings are either self-explanatory or were described in Table 2.2 . Hypocentres for the homogeneous station method study are given in Table A.2, with residuals (in seconds) given in Table A.3.

Because of their importance in constraining the focal mechanism (Fig. 4.9), Figure A.1 shows first motions at TUA for the subcrustal sequence. For the Matata sequence, the events of Type 2 with opposing first-motions at AWA and MAE were (by day-ofmonth/hours) 01/1616, 03/0853,03/1516, 03/1657, 04/0050,04/1415 and 05/0355; the events of Type 3 with opposing first-motions at MAN and LRO were 30/1142, 01/0905, 02/2058, 03/0558, 03/1543, 03/1556, 04/0736 and 06/1134: corresponding events for Type 4 were $03 / 0717$ and $06 / 1444$.

Regional events more than $50 \mathrm{~km}$ from both WTZ and WIZ recording opposite first motions at those stations (see Fig. 5.7) were (NZSO) 77/391, 577, 590, 619, 681, 689; $78 / 243,244 ; 79 / 114,161,429 ; 80 / 074,726,727,739 ; 81 / 155,327,417,494,498,855$, $870,920,983$; and $82 / 011,151,443,690,737,752$. Intermediate depth events with a first-motion at AUC used for Figure 5.6 were 76/167, 372, 656; and 77/080, 506, 510, 597. 
Table A.1. List of earthquakes studied using the Bay of Plenty seismographs.

\begin{tabular}{|c|c|c|c|c|c|c|c|c|c|c|c|c|c|c|}
\hline $\begin{array}{l}\text { ORIGIN TIME } \\
\text { h m } \mathrm{m} \\
1977 \text { MAY } 26\end{array}$ & MAG & $\mathrm{s}$ & $\begin{array}{l}\text { LAT I } \\
\text { deg }\end{array}$ & $\begin{array}{l}\text { ITUDE } \\
\text { min }\end{array}$ & $\begin{array}{l}\text { LONGI } \\
\text { deg }\end{array}$ & $\begin{array}{l}\text { ITUDE } \\
\text { min E }\end{array}$ & $\begin{array}{c}\text { DEPTH } \\
\quad \mathrm{km}\end{array}$ & NO & $\begin{array}{l}\mathrm{DM} \\
\mathrm{km}\end{array}$ & $\begin{array}{l}\text { GAP } \\
\text { deg }\end{array}$ & $\begin{array}{l}\text { RMS } \\
\text { S }\end{array}$ & $\begin{array}{l}\text { ERH } \\
\mathrm{km}\end{array}$ & $\begin{array}{l}\text { ERZ Q } \\
\mathrm{km}\end{array}$ & Q F \\
\hline $04 \quad 44 \quad 40.8$ & 1.5 & 0 & 37 & 51.0 & 175 & 49.8 & 11.2 & 9 & 19 & 304 & 0.14 & 2.0 & $0.7 \mathrm{C}$ & C \\
\hline $05 \quad 52 \quad 49.5$ & 2.2 & 0 & 37 & 50.2 & 176 & 48.9 & 11.0 & 11 & 19 & 221 & 0.11 & 1.0 & $0.5 \mathrm{C}$ & c \\
\hline $06 \quad 24 \quad 53.1$ & $2.0 \mathrm{~A}$ & $0 *$ & 37 & 51.1 & 176 & 37.3 & 9.0 & 8 & 6 & 208 & 0.10 & 1.8 & $0.8 \mathrm{C}$ & 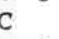 \\
\hline $16 \quad 34 \quad 48.3$ & 1.7 & 0 & 37 & 49.5 & 176 & 53.9 & 11. & 5 & 22 & 258 & 0.05 & 1.8 & $1.0 \mathrm{C}$ & $c$ \\
\hline 1977 MAY 27 & & & & & & & & & & & & & & \\
\hline $05 \quad 1134.7$ & 1.9 & 0 * & 38 & 09.5 & 176 & 39.8 & 10.5 & 10 & 14 & 224 & 0.10 & 0.8 & 1.1 & $C$ \\
\hline $\begin{array}{lll}05 & 17 & 25.8\end{array}$ & 2.2 & 0 * & 38 & 09.4 & 176 & 39.6 & 11.0 & 11 & 14 & 224 & 0.12 & 0.9 & $0.8 \mathrm{C}$ & 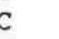 \\
\hline $\begin{array}{llll}05 & 17 & 46.7\end{array}$ & 1.7 & $0 *$ & 38 & 09.7 & 176 & 39.5 & 11.0 & 7 & 14 & 225 & 0.05 & 0.7 & $0.9 \mathrm{C}$ & C \\
\hline $\begin{array}{lll}09 & 44 & 07.2\end{array}$ & 0.94 & 0 * & 38 & 00 & 176 & 59 & 8.4 & 7 & 4 & 192 & 0.15 & 1.5 & $1.8 \mathrm{C}$ & C \\
\hline $\begin{array}{lll}20 & 41 & 32.7\end{array}$ & 1.8 & 0 & 37 & 49.6 & 176 & 49.6 & 10. & 7 & 20 & 234 & 0.04 & 0.6 & $0.3 \mathrm{C}$ & \\
\hline $\begin{array}{lll}21 & 02 & 10.4\end{array}$ & 1.1 & 0 * & 37 & 59.2 & 176 & 29.2 & 10.8 & 6 & 10 & 154 & 0.07 & 1.0 & $1.5 \mathrm{~B}$ & $B$ \\
\hline
\end{tabular}

\section{MAY 28}

\begin{tabular}{|c|c|c|c|c|c|c|c|c|c|c|c|c|c|c|}
\hline 00 & 49.0 & 1.8 & 0 * & 38 & 01.9 & 176 & 52.7 & 0.7 & 9 & 2 & 102 & 0.22 & 0.3 & 4. 4 \\
\hline 10 & 09.7 & 1.8 & 0 & 37 & 48.4 & 175 & 50.1 & 7. & 11 & 23 & 234 & 0.11 & 1.3 & 3.3 \\
\hline 4 & 15.1 & 2.4 & 0 * & 33 & 08.5 & 176 & 42.2 & 8. & 17 & 10 & 197 & 0.14 & 0.8 & 1.0 \\
\hline 2 & 04. & 1.4 & 0 & 37 & 49.2 & 176 & 49.7 & 7.0 & 10 & 22 & 236 & 0.27 & 3.3 & 7.8 \\
\hline 4 & 07.8 & 2.7 & 0 * & 38 & 23.0 & 177 & 16.4 & 49.4 & 16 & 31 & 313 & 0.12 & 2.1 & 1.5 \\
\hline 5 & 25. & 1.7 & 0 * & 38 & 05.0 & 175 & 45.0 & 5.0 & 16 & 5 & 148 & 0.11 & 0.4 & 0.8 \\
\hline
\end{tabular}

1977 MAY 29

$\begin{array}{llllllllllllllllll}01 & 11 & 39.3 & 2.2 & 0 * & 38 & 22.9 & 177 & 15.6 & 48.8 & 9 & 30 & 325 & 0.03 & 2.4 & 1.3 & \mathrm{C} \\ 07 & 16 & 50.0 & 1.9 \mathrm{~A} & 0 * & 37 & 59.5 & 177 & 17.6 & 65.4 & 7 & 14 & 315 & 0.05 & 2.5 & 1.3 & \mathrm{D} \\ 03 & 44 & 06.1 & 1.3 & 0 * & 38 & 04.1 & 176 & 41.6 & 12.0 & 7 & 12 & 151 & 0.13 & 2.6 & 0.9 & \mathrm{C} \\ 14 & 38 & 59.9 & 1.7 & 0 * & 38 & 06.5 & 175 & 39.8 & 9.7 & 7 & 16 & 202 & 0.07 & 3.2 & 2.3 & 0 \\ 14 & 57 & 53.8 & 1.8 & 0 * & 38 & 06.2 & 176 & 40.5 & 10.8 & 7 & 15 & 199 & 0.09 & 5.4 & 3.5 & \mathrm{D} \\ 15 & 07 & 30.4 & 1.7 & 0 * & 38 & 04.6 & 175 & 42.0 & 13.1 & 6 & 14 & 138 & 0.03 & 0.4 & 0.6 & \mathrm{C} \\ 15 & 53 & 07.6 & 2.0 & 0 * & 38 & 05.0 & 176 & 40.9 & 13.1 & 11 & 11 & 173 & 0.15 & 1.4 & 1.5 & \mathrm{C} \\ 16 & 13 & 44.8 & 1.8 & 0 * & 38 & 08.4 & 176 & 37.1 & 10.1 & 9 & 10 & 230 & 0.16 & 3.5 & 4.1 & \mathrm{D} \\ 16 & 51 & 07.7 & 1.5 & 0 * & 38 & 04.3 & 176 & 41.8 & 14.1 & 8 & 13 & 187 & 0.03 & 0.4 & 0.5 & \mathrm{C} \\ 16 & 52 & 01.3 & 1.5 & 0 * & 38 & 06.4 & 175 & 39.6 & 5.9 & 7 & 10 & 194 & 0.03 & 0.4 & 1.0 & \mathrm{C} \\ 15 & 52 & 08.0 & 2.4 & 0 * & 38 & 09.3 & 176 & 36.1 & 4.6 & 13 & 11 & 221 & 0.24 & 3.2 & 8.3 & \mathrm{D} \\ 18 & 38 & 32.2 & 3.2 & 0 * & 33 & 07.7 & 176 & 39.0 & 6.2 & 10 & 19 & 209 & 0.09 & 1.7 & 3.0 & \mathrm{C} \\ 18 & 53 & 27.4 & 2.0 & 0 * & 38 & 05.2 & 176 & 41.5 & 11.7 & 10 & 14 & 192 & 0.15 & 1.8 & 0.7 & \mathrm{C} \\ 21 & 17 & 43.6 & 1.7 \mathrm{~A} & 0 * & 38 & 06.4 & 177 & 03.9 & 71.8 & 10 & 8 & 119 & 0.20 & 6.1 & 2.4 & \mathrm{C} \\ 22 & 06 & 00.9 & 2.7 & 0 * & 38 & 07.0 & 176 & 40.1 & 6.8 & 11 & 16 & 204 & 0.19 & 1.9 & 4.8 & \mathrm{C}\end{array}$

1977 MAY 30

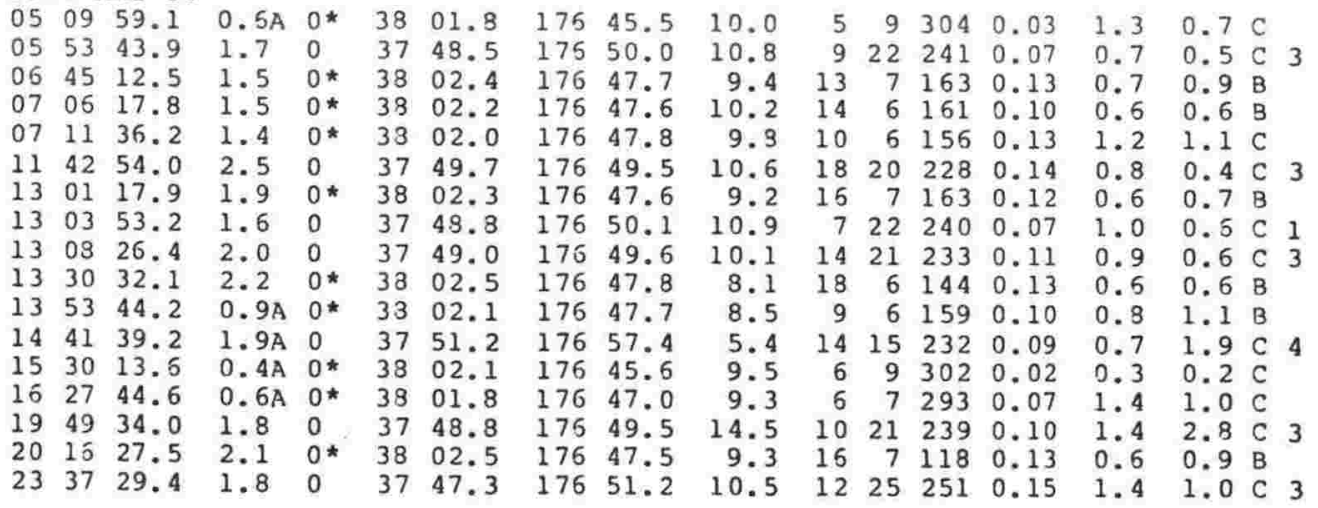

1977 MAY 31

\begin{tabular}{|c|c|c|c|c|c|c|c|c|c|c|c|c|c|c|c|}
\hline $\begin{array}{lll}0 & 0\end{array}$ & $09 \quad 10.8$ & $0.3 \mathrm{~A}$ & 0 * & 38 & 01. & 17 & 45 & 9. & & & & f & 7 & 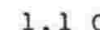 & \\
\hline 5 & $56 \quad 12$. & $0.6 \mathrm{~A}$ & $0 *$ & 38 & & 176 & & & 5 & 11 & 309 & & & 0.5 & \\
\hline 1 & 1957 & & 0 & 37 & 49 & 17 & 4 & 10 & 21 & 21 & 230 & & & 0.5 & \\
\hline 2 & 20 & 1. & 0 & 37 & 50. & 17 & & 35 & 11 & 18 & 227 & 0. & 1. & 2. 4 & 3 \\
\hline & 35 & 0 & 0 * & 7 & 38 & 1 & & & 13 & 16 & 1. & & 5.1 & 20.3 & D \\
\hline & 275 & 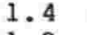 & 0 & 37 & & & & & 6 & 22 & & & & 0.4 & \\
\hline & 350 & 1 & 0 & 37 & 48 & 1 & & & 15 & 22 & 3 & & 0 . & 0.8 & \\
\hline & 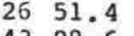 & 2. & & & & & & & 15 & 19 & & & & 0.5 & \\
\hline & 4308 & 7 & 0 & 37 & 49 & & 4 & & 21 & 21 & 0 & & 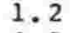 & $1.0 \mathrm{c}$ & \\
\hline & 44 & & 0 & 37 & & 1 & & & 9 & 21 & 238 & & 0 . & 0.5 & \\
\hline & $44 \quad 25$ & 1.5 & 0 & 3 & 5 & 1 & & 1] & 10 & 18 & 22 & & & & \\
\hline & 09 & & & & & & & & & 23 & 234 & & 1. & & \\
\hline & 35 & 2. & 0 * & 38 & 15 & 1 & & & 9 & 22 & 250 & & & 4. & \\
\hline & 55 & & 0 & & & & & 10 & 20 & 22 & 232 & & & 0. & \\
\hline & 50 & 5. & 0 & & & & & & & 20 & & & $?$ & 2.0 & \\
\hline & 17 & 3 & 0 & 37 & 40 & 10 & & & 17 & 21 & 138 & .23 & .9 & 6. & \\
\hline
\end{tabular}



Table A.1 continued

ORIGIN TIME MAG $S$ LATITUDE LONGITUDE DEPTH
$\mathrm{h} \mathrm{m} \mathrm{s}$ 1977 JUN 02

$\begin{array}{lllll}02 & 34 & & 2.8 & 2 \\ 02 & 54 & & 2.7 & 2 \\ 03 & 03 & 50.5 & 3.5 & 2 \\ 03 & 58 & 13.0 & 2.9 & 1 \\ 04 & 31 & 18.2 & 2.9 & 1 \\ 06 & 32 & & 2.9 & 2 \\ 07 & 56 & & 2.8 & 2 \\ 08 & 54 & 24.2 & 2.5 & 1 \\ 09 & 03 & 22.0 & 2.0 & 1 \\ 09 & 10 & & 2.8 & 2 \\ 10 & 45 & & 2.4 & 2 \\ 11 & 25 & 36.0 & 2.7 & 1 \\ 11 & 41 & & 2.8 & 2 \\ 12 & 10 & 45.5 & 2.8 & 1 \\ 13 & 17 & 45.7 & 4.4 & 1 \\ 13 & 38 & 32.6 & 2.4 & 1 \\ 13 & 46 & 41.6 & 3.8 & 1 \\ 18 & 38 & 19.0 & 2.5 & 1 \\ 20 & 37 & 41.2 & 2.8 & 1 \\ 20 & 58 & 52.5 & 3.6 & 1 \\ 20 & 59 & 41.6 & 2.5 & 1 \\ 21 & 06 & 55.0 & 2.0 & 1 \\ 22 & 00 & 04.1 & 2.2 & 1 \\ 22 & 26 & 40.1 & 2.2 & 1\end{array}$

\begin{tabular}{|c|c|c|c|c|c|c|c|c|c|c|}
\hline $\begin{array}{l}37 \\
37 \\
37\end{array}$ & $\begin{array}{l}51.0 \\
51.0 \\
52.1\end{array}$ & $\begin{array}{l}175 \\
176 \\
176\end{array}$ & $\begin{array}{l}49.3 \\
50.7 \\
49.0\end{array}$ & $\begin{array}{r}10.1 \\
10.4 \\
8.4\end{array}$ & $\begin{array}{l}14 \\
20 \\
17\end{array}$ & $\begin{array}{l}18 \\
19 \\
16\end{array}$ & $\begin{array}{l}133 \\
131 \\
127\end{array}$ & $\begin{array}{l}0.14 \\
0.25 \\
0.12\end{array}$ & $\begin{array}{l}0.7 \\
1.0 \\
0.6\end{array}$ & $\begin{array}{l}0.6 \\
0.7 \\
0.7\end{array}$ \\
\hline & $\begin{array}{l}49.2 \\
49.2\end{array}$ & $\begin{array}{l}176 \\
176\end{array}$ & $\begin{array}{l}48.3 \\
46.0\end{array}$ & $\begin{array}{l}7.7 \\
5.4\end{array}$ & $\begin{array}{l}20 \\
17\end{array}$ & $\begin{array}{l}20 \\
18\end{array}$ & $\begin{array}{l}229 \\
227\end{array}$ & $\begin{array}{l}0.17 \\
0.20\end{array}$ & $\begin{array}{l}1.1 \\
1.3\end{array}$ & $\begin{array}{l}2.5 \\
4.5\end{array}$ \\
\hline & 52.3 & 176 & 48.8 & 8.6 & 21 & 16 & 127 & 0.14 & 0.6 & 0.7 \\
\hline & & 7 & & & 9 & 17 & 148 & & 2 & \\
\hline & & 17 & 15 & 49 & 16 & 30 & 300 & & & 1 \\
\hline & 49. & 176 & 45. & 10. & 20 & 17 & 226 & 0.22 & 1. & 0.7 \\
\hline & 23 & 177 & 16 & 49 & 18 & 31 & 301 & 0. & & 1.0 \\
\hline & 50 & 176 & 54. & 8. & 20 & 18 & 232 & 0.17 & 1.0 & 0.8 \\
\hline & & 175 & & & 19 & 16 & 123 & & & 0.4 \\
\hline 37 & 50. & 176 & 44. & 10.0 & 18 & 14 & 140 & 0.19 & 0.8 & 0.7 \\
\hline & & 17 & 45 & & 11 & 17 & 227 & & & \\
\hline & 48 & 176 & 46 & & 10 & 13 & 229 & 0.13 & 1. & 59.4 \\
\hline 3 & 50 & 176 & 44 & & 17 & 15 & 222 & 0.19 & 1.3 & 0.6 \\
\hline 7 & 49. & 176 & 45.0 & 9.7 & 18 & 17 & 225 & 0.19 & 1.1 & 0.6 \\
\hline
\end{tabular}

1977 JUN 03

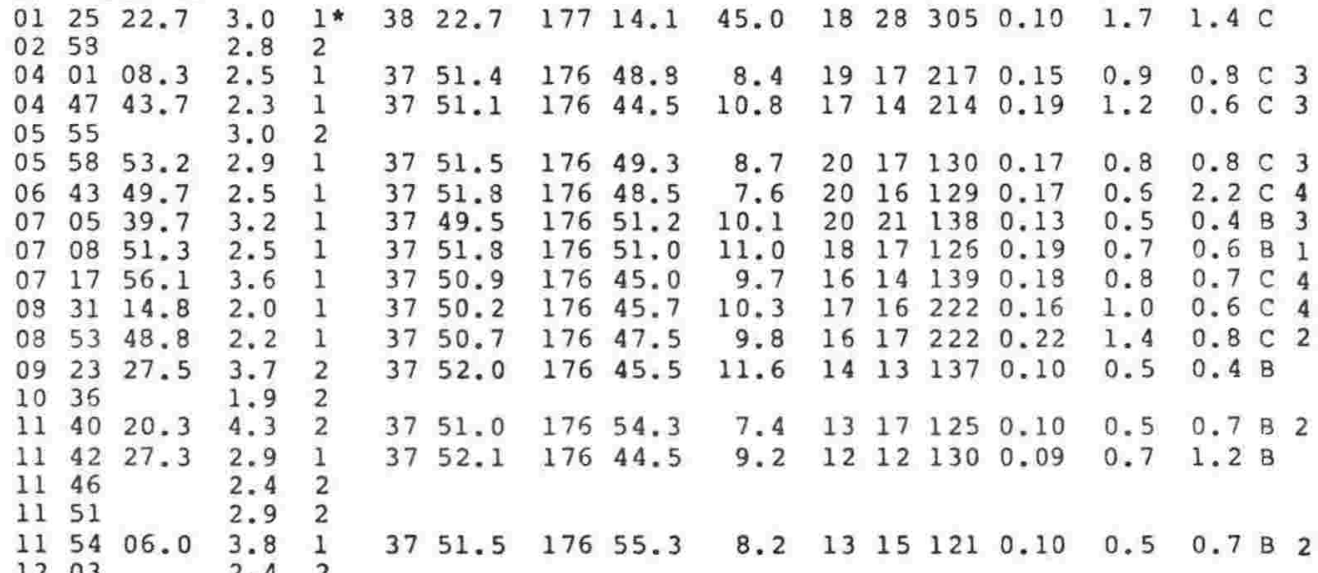

$\begin{array}{lll}12 & 03 & 2.4\end{array}$

$1204 \quad 2.12$

$\begin{array}{llll}12 & 10 & 2.5 & 2\end{array}$

$\begin{array}{llll}12 & 33 & 3.0 & 2\end{array}$

$\begin{array}{lllll}12 & 36 & 25.7 & 3.2 & 1\end{array}$

$\begin{array}{llll}12 & 52 & 2.9 & 2\end{array}$

$\begin{array}{llll}13 & 21 & 2.8 & 2\end{array}$

$\begin{array}{llll}13 & 22 & 50.2 & 2.1\end{array}$

$\begin{array}{llll}13 & 32 & 2.32\end{array}$

$\begin{array}{lllll}14 & 19 & 27.3 & 2.8 & 1\end{array}$

$\begin{array}{llll}14 & 32 & 2.5 \quad 2\end{array}$

$\begin{array}{llll}1436 & 2.8 \quad 2\end{array}$

$\begin{array}{lll}15 & 05 & 2.7 \quad 2\end{array}$

$\begin{array}{llll}15 & 15 & 19.3 & 3.0\end{array}$

$\begin{array}{lllll}15 & 43 & 22.8 & 2.6 \\ 15 & 49 & 07.7 & 2.5\end{array}$

$\begin{array}{lllll}15 & 49 & 07.7 & 2.5 & 1 \\ 15 & 56 & 44.3 & 2.5 & 1\end{array}$

$\begin{array}{llll}16 & 57 & 23.4 & 3.0\end{array}$

$\begin{array}{llll}17 & 22 & 53.8 & 3.1\end{array}$

$\begin{array}{lllll}17 & 26 & 26.8 & 2.7 & 1\end{array}$ *

$\begin{array}{llll}18 & 09 & 3.0 & 2\end{array}$

$\begin{array}{llll}18 & 24 & 07.9 & 2.8\end{array}$

$\begin{array}{lllll}13 & 24 & 19.8 & 2.9 & 1\end{array}$

$\begin{array}{lllll}19 & 01 & 35.6 & 3.0 & 1\end{array}$

$\begin{array}{lllll}20 & 40 & 10.7 & 3.2 & 1 \\ 21 & 41 & 47.8 & 3.1 & 1\end{array}$

$\begin{array}{lllll}21 & 41 & 47.8 & 3.1 & 1 \\ 23 & 15 & & 2.8 & 2\end{array}$

$\begin{array}{lllllllllllll}37 & 51.6 & 176 & 54.5 & 9.0 & 15 & 16 & 122 & 0.15 & 0.7 & 0.9 & \text { B } & 3\end{array}$

$\begin{array}{llllllllllllll}37 & 49.8 & 176 & 45.5 & 9.8 & 16 & 16 & 224 & 0.15 & 1.0 & 0.6 & 6 & 4\end{array}$

$\begin{array}{llllllllllll}37 & 50.4 & 176 & 44.6 & 9.6 & 21 & 15 & 143 & 0.21 & 0.9 & 0.7 & \mathrm{C}\end{array}$

$\begin{array}{rrrrrrrrrrrrr}37 & 51.6 & 176 & 54.7 & 9.2 & 19 & 16 & 122 & 0.13 & 0.5 & 0.7 & \mathrm{~B} & 2\end{array}$ $\begin{array}{lllllllllllll}37 & 51.1 & 176 & 44.7 & 10.6 & 20 & 14 & 138 & 0.20 & 0.9 & 0.7 & \mathrm{C} & 3\end{array}$

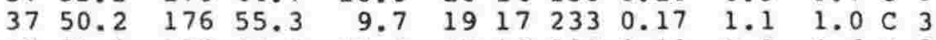

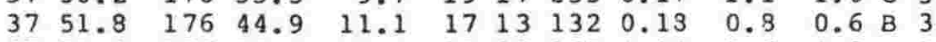
$\begin{array}{lllllllllllll}37 & 51.6 & 176 & 55.0 & 9.2 & 11 & 15 & 125 & 0.10 & 0.6 & 0.8 & \text { B } & 2\end{array}$

$\begin{array}{llllllllllllll}37 & 51.1 & 176 & 55.1 & 7.9 & 17 & 16 & 124 & 0.10 & 0.4 & 0.5 & \text { B }\end{array}$

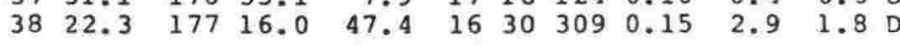
$\begin{array}{lllllllllllll}37 & 50.6 & 176 & 49.6 & 10.3 & 20 & 19 & 134 & 0.19 & 0.7 & 0.6 & \text { B } & 4\end{array}$ $\begin{array}{llllllllllll}37 & 51.1 & 176 & 54.5 & 9.5 & 24 & 15 & 125 & 0.23 & 0.8 & 1.0 & B\end{array}$ $\begin{array}{lllllllllllll}37 & 50.0 & 176 & 49.7 & 7.4 & 19 & 20 & 138 & 0.16 & 0.6 & 3.3 & \mathrm{C} & 4\end{array}$ $\begin{array}{lllllllllllll}37 & 50.9 & 176 & 44.7 & 8.5 & 17 & 14 & 139 & 0.17 & 1.2 & 1.8 & \mathrm{C}\end{array}$

1977 JUN 04

$\begin{array}{lllllllllllllllll}00 & 02 & 57.8 & 2.4 & 1 & 37 & 57.3 & 176 & 48.6 & 7.1 & 15 & 8 & 182 & 0.17 & 1.0 & 1.7 & \mathrm{C}\end{array}$

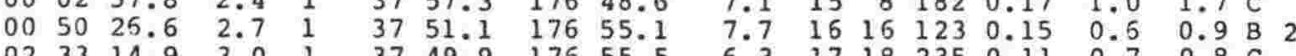

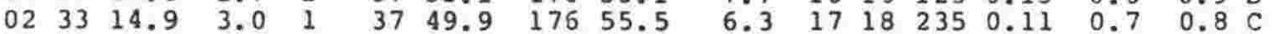


Table A.1 continued

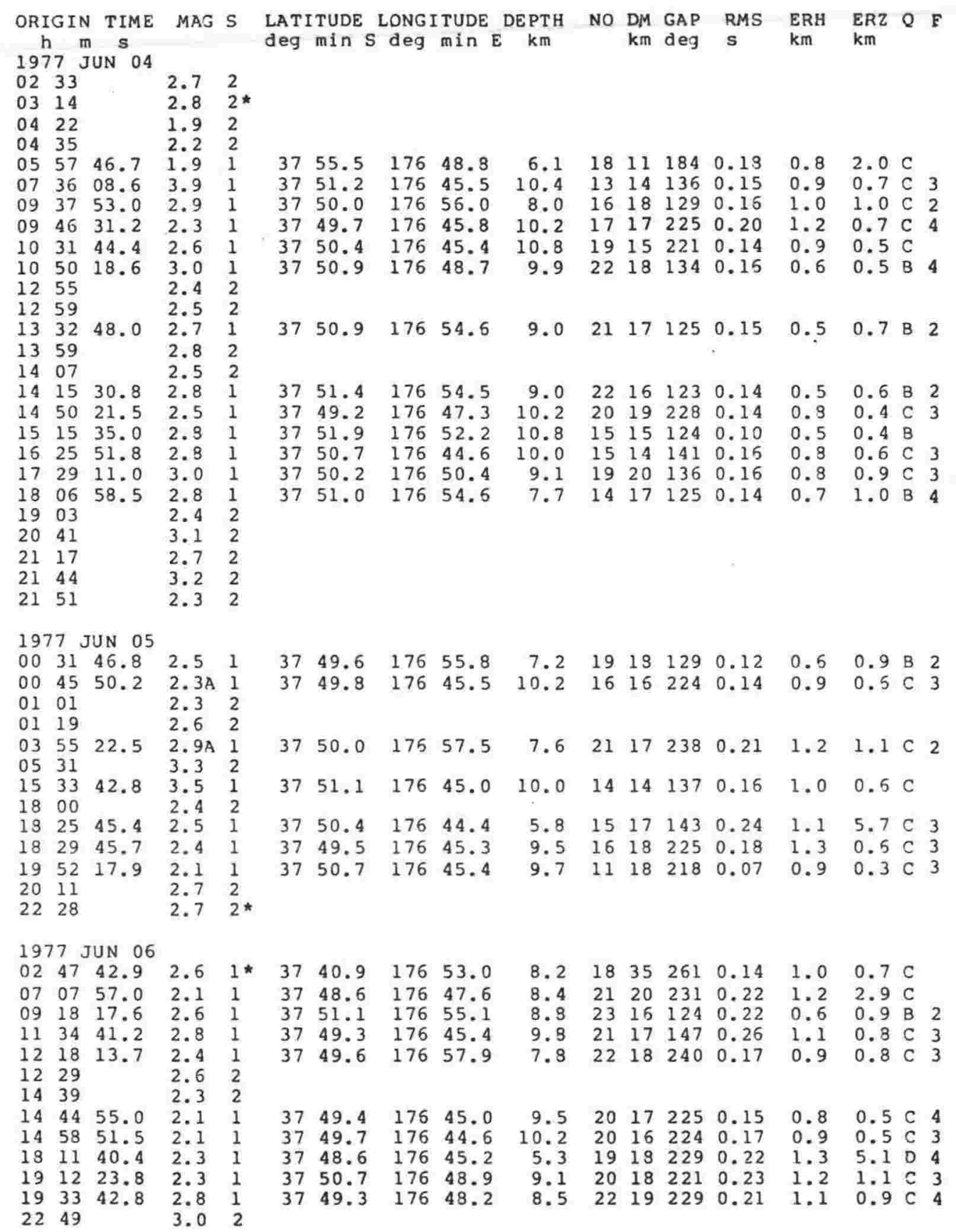

Note: the event at June $04^{\mathrm{d}} 03^{\mathrm{h}} 14^{\mathrm{m}}$ was evidently another near Kawerau, and the event at June $05^{\mathrm{d}} 22^{\mathrm{h}} 28^{\mathrm{m}}$ another in the subcrustal sequence. 
Table A.2. Hypocentres determined using the homogeneous station method.

\begin{tabular}{|c|c|c|c|c|c|c|c|c|c|c|c|c|c|c|c|}
\hline & & TIM & & & $\mathrm{AT}$ & E & ING & DE & PTH & NO & DM & GAP & RMS & ERH & ERZ \\
\hline & & & m & 3 & ieg & nin & deg & $\min E$ & $\mathrm{~km}$ & & $\mathrm{~km}$ & deg & & $\mathrm{km}$ & \\
\hline $\begin{array}{l}\text { MAY } \\
\text { MAYY }\end{array}$ & 31 & 09 & 19 & 57.4 & 37 & 49.0 & 176 & 49.9 & 9.9 & 11 & 21 & 232 & 0.13 & 1.6 & 0.8 \\
\hline $\begin{array}{l}\text { MAX } \\
\text { JUN }\end{array}$ & 31 & 16 & 43 & 08.6 & 37 & 49.2 & 176 & 50.2 & 9.8 & 11 & 21 & 231 & 0.18 & 2.2 & 1.1 \\
\hline $\begin{array}{l}\text { JUN } \\
\text { JUN }\end{array}$ & 01 & 00 & 09 & 48.0 & 37 & 48.3 & 176 & 52.1 & 9.6 & 11 & 23 & 237 & 0.21 & 2.6 & 1.4 \\
\hline JUN & 01 & 03 & 52 & 52.9 & 37 & 50.8 & 176 & 49.5 & 10.9 & 11 & 18 & 221 & 0.13 & 1.4 & 0.7 \\
\hline JUN & 01 & 06 & 56 & 22.1 & 37 & 46.1 & 176 & 51.9 & 7.8 & 11 & 26 & 244 & 0.15 & 2.3 & 1.9 \\
\hline JUN & 01 & 09 & 05 & 04.1 & 37 & 47.9 & 176 & 51.6 & 7.3 & 11 & 24 & 238 & 0.14 & 1.7 & 1.5 \\
\hline JUN & 01 & 09 & 20 & 49.7 & 37 & 48.5 & 176 & 51.4 & 7.3 & 11 & 23 & 235 & 0.13 & 1.5 & 4.3 \\
\hline JUN & 01 & 10 & 17 & 52. & 37 & 57.5 & 176 & 48.8 & 8.6 & 11 & 8 & 163 & 0.17 & 1.3 & 1.2 \\
\hline JUN & 01 & 10 & 41 & 35.6 & 37 & 48.7 & 176 & 49.9 & 10.1 & 11 & 22 & 233 & 0.12 & 1.5 & 0.7 \\
\hline JUN & 01 & 14 & 18 & 46. & 37 & 52.2 & 176 & 49.2 & 0.9 & 11 & 17 & 212 & 0.16 & 1.4 & 28.4 \\
\hline JUN & 01 & 14 & 22 & 06.5 & 37 & 48.5 & 176 & 51.0 & 8.3 & 11 & 23 & 235 & 0.11 & 1.4 & 1.2 \\
\hline JUN & 01 & 14 & 30 & 20.3 & 37 & 48.6 & 176 & 50.9 & 7.9 & 11 & 23 & 234 & 0.16 & 2.0 & 1.7 \\
\hline JUN & 01 & 18 & 49 & 52. & 37 & 47.5 & 175 & 52.0 & 7.2 & 11 & 24 & 240 & 0.13 & 1.7 & 1.5 \\
\hline JUN & 01 & 19 & 43 & 55.4 & 37 & 48.8 & 176 & 52.3 & 9.9 & 11 & 22 & 235 & 0.15 & 1.9 & 1.0 \\
\hline JUN & 02 & 1.3 & 38 & 32.5 & 37 & 48.8 & 176 & 45.5 & 10.3 & 11 & 18 & 228 & 0.20 & 2.4 & 1.1 \\
\hline JUN & 02 & 20 & 37 & 41.0 & 37 & 51.9 & 176 & 49.3 & 10.3 & 11 & 17 & 214 & 0.11 & 1.1 & 0.6 \\
\hline JUN & 02 & 20 & 58 & 52. & 37 & 49.4 & 176 & 45.0 & 9.7 & 11 & 17 & 225 & 0.15 & 1.8 & 0.9 \\
\hline JUN & 02 & 22 & 26 & 40. & 37 & 49.2 & 176 & 45.4 & 9.6 & 11 & 17 & 227 & 0.18 & 2.0 & .0 \\
\hline JUN & 03 & 01 & 25 & 22. & 38 & 22.6 & 177 & 14.6 & 47.2 & 11 & 29 & 309 & 0.10 & 3.1 & .4 \\
\hline JUN & 03 & 04 & 01 & 08 & 37 & 51.0 & 176 & 49.2 & 8.8 & 11 & 18 & 220 & 0.13 & 1.4 & 1.2 \\
\hline JUN & 03 & 05 & 58 & 53. & 37 & 50.5 & 176 & 49.8 & 8.5 & 11 & 19 & 224 & 0.14 & 1.5 & .4 \\
\hline JUN & 03 & 07 & 05 & 39 & 37 & 47.9 & 176 & 52.0 & 9.8 & 11 & 23 & 238 & 0.08 & 1.1 & 0.5 \\
\hline JUN & 03 & 14 & 19 & 27. & 37 & 49.0 & 176 & 45.2 & 9.5 & 11 & 17 & 227 & 0.15 & 1.7 & .9 \\
\hline JUN & 03 & 17 & 26 & 26 & 20 & 22.7 & 177 & 17.7 & 49.8 & 11 & 32 & 315 & 0.17 & 6.0 & 4.3 \\
\hline JUN & 03 & 18 & 24 & 07. & 7 & 48.7 & 176 & 50.5 & 8.8 & 11 & 22 & 233 & 0.15 & 1.9 & 1.5 \\
\hline JUN & 03 & 19 & 01 & 35 & & 49.5 & 176 & & 7. & 11 & 21 & 230 & 0.17 & 1.9 & 5.0 \\
\hline JUN & 03 & 21 & 41 & 47. & 7 & 50.1 & 176 & 55.4 & 7.4 & 11 & 17 & 234 & 0.12 & 1.5 & 1.4 \\
\hline JUN & 04 & 00 & 50 & 26 & 37 & 50.2 & 176 & & 7.3 & 11 & 17 & 234 & 0.13 & 1.6 & 1.4 \\
\hline JUN & 04 & 02 & 33 & 14. & 37 & 50.0 & 176 & 55.4 & 6.8 & 11 & 18 & 234 & 0.08 & 1.0 & 0.9 \\
\hline JUN & 04 & 05 & 57 & 46.8 & 37 & 55.8 & 176 & 48.6 & 3.0 & 11 & 11 & 180 & 0.13 & .0 & 4.5 \\
\hline JUN & 04 & 10 & 50 & 18. & 37 & 50.0 & 176 & 49.3 & 10.3 & 11 & 19 & 226 & 0.09 & .0 & .5 \\
\hline JUN & 04 & 13 & 32 & 47. & 37 & 50.4 & 176 & 54.8 & 7.4 & 11 & 17 & 231 & 0.10 & .3 & .1 \\
\hline JUN & 04 & 14 & 15 & 30 & 2 & 51.1 & 176 & 54.7 & 8.0 & 11 & 16 & 228 & 0.11 & 1.3 & 1.1 \\
\hline JUN & 04 & 14 & 50 & 21. & 37 & 48.7 & 176 & 47.7 & 8.7 & 11 & 20 & 231 & 0.15 & 1.8 & 1.5 \\
\hline JUN & 04 & 17 & 29 & 10. & 3 & 48.8 & 176 & & 9.5 & 11 & 23 & 234 & 0.18 & 2.1 & 1.2 \\
\hline JUN & 04 & 18 & 06 & 58. & 37 & 49.9 & 176 & 55.2 & 7.9 & 11 & 18 & 234 & 0.10 & 1.3 & 1.1 \\
\hline JUN & 05 & 00 & 31 & 46. & 37 & 49.8 & 176 & & 7. & 11 & 18 & 236 & & 1.3 & \\
\hline JUN & 05 & 03 & 55 & 22. & 3. & 50. & 176 & 57 & 7. & 11 & 16 & 236 & 0.18 & 2.4 & 2.1 \\
\hline JUN & 06 & 07 & 07 & 56. & 37 & 48.2 & 176 & 48.1 & 9.3 & 11 & 21 & 233 & 0.22 & 2.8 & 1.4 \\
\hline JUN & 06 & 09 & 18 & 17. & 37 & 49.9 & 176 & 55.7 & 7.2 & 11 & 18 & 235 & 0.14 & 1.8 & 1.6 \\
\hline . & 06 & 11 & 34 & 40.8 & 37 & 47.9 & 176 & & 9.4 & 11 & 20 & 232 & 0.22 & 2.8 & 1.4 \\
\hline JUN & 06 & 12 & 18 & 13. & 37 & 49.2 & 176 & 58.4 & 7.2 & 11 & 18 & 234 & 0.13 & 1.8 & 1.6 \\
\hline 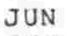 & 05 & 18 & 11 & 40 & 37 & & 17 & & & & 18 & 229 & & 2.4 & 1. \\
\hline S & 06 & 19 & 33 & 42.8 & 37 & 48.8 & 176 & $700 \%$ & 7.0 & 11 & 20 & 231 & 0.19 & 2.1 & 6. \\
\hline
\end{tabular}


Table A.3. Arrival-time residuals for the homogeneous station method analysis.

\begin{tabular}{|c|c|c|c|c|c|c|c|c|c|c|c|}
\hline Event & MAN & AWA & WTZ & MDQ & RAW & MAE & LRO & WAI & MAR & KAO & RAWS \\
\hline $02 / 1338$ & -0.19 & -0.12 & 0.30 & -0.15 & -0.07 & -0.15 & 0.35 & 0.03 & -0.22 & 0.14 & 0.33 \\
\hline $02 / 2058$ & -0.16 & 0.02 & 0.14 & -0.17 & -0.06 & -0.07 & 0.20 & -0.09 & -0.15 & 0.23 & 0.45 \\
\hline $02 / 2226$ & -0.05 & 0.09 & 0.32 & -0.23 & -0.14 & -0.03 & -0.01 & -0.14 & -0.14 & 0.27 & 0.25 \\
\hline $03 / 1419$ & 0.09 & -0.13 & 0.27 & -0.20 & -0.07 & -0.08 & 0.17 & 0.04 & -0.19 & 0.11 & -0.01 \\
\hline $04 / 1450$ & -0.01 & -0.06 & 0.29 & -0.09 & -0.00 & -0.05 & 0.23 & -0.08 & -0.26 & 0.02 & 0.11 \\
\hline $06 / 0707$ & 0.01 & -0.16 & 0.18 & -0.26 & 0.02 & -0.28 & 0.44 & 0.11 & -0.24 & 0.10 & 0.25 \\
\hline $06 / 1134$ & -0.15 & -0.30 & 0.30 & -0.18 & -0.01 & -0.12 & 0.44 & 0.09 & -0.21 & 0.10 & 0.15 \\
\hline $06 / 1811$ & -0.10 & -0.23 & 0.27 & -0.22 & -0.04 & -0.09 & 0.37 & -0.02 & -0.18 & 0.13 & 0.34 \\
\hline $06 / 1933$ & -0.12 & -0.13 & 0.28 & -0.11 & -0.07 & -0.04 & 0.38 & 0.05 & -0.28 & 0.00 & 0.21 \\
\hline Mean & -0.076 & -0.113 & 0.261 & -0.130 & -0.049 & -0.101 & 0.286 & -0.001 & -0.209 & 0.122 & 0.231 \\
\hline Std dev. & . 0.092 & 0.119 & 0.060 & 0.055 & 0.048 & 0.077 & 0.150 & 0.086 & 0.046 & 0.087 & 0.137 \\
\hline \multicolumn{12}{|l|}{ GROUP 2} \\
\hline Event & MAN & AWA & WTZ & MDQ & RAW & MAE & LRO & WAI & MAR & KAO & RAWS \\
\hline $01 / 0009$ & -0.18 & -0.02 & 0.32 & -0.30 & -0.10 & 0.06 & 0.20 & 0.08 & -0.26 & 0.26 & -0.21 \\
\hline $01 / 0656$ & 0.03 & -0.01 & 0.27 & -0.15 & -0.02 & -0.02 & 0.16 & 0.07 & -0.31 & 0.03 & -0.21 \\
\hline $01 / 0905$ & 0.06 & -0.07 & 0.23 & -0.19 & -0.05 & -0.00 & 0.07 & 0.05 & -0.25 & 0.14 & 0.06 \\
\hline $01 / 0920$ & -0.00 & -0.09 & 0.25 & -0.12 & -0.11 & 0.07 & 0.07 & 0.03 & -0.22 & 0.09 & 0.10 \\
\hline $01 / 1422$ & -0.04 & -0.10 & 0.24 & -0.08 & -0.02 & 0.03 & 0.14 & -0.06 & -0.17 & 0.04 & 0.07 \\
\hline $01 / 1430$ & -0.03 & 0.04 & 0.21 & -0.13 & -0.12 & -0.03 & 0.23 & 0.15 & -0.30 & 0.02 & 0.01 \\
\hline $01 / 1849$ & -0.03 & -0.04 & 0.26 & -0.14 & -0.13 & -0.01 & 0.13 & 0.04 & -0.20 & 0.10 & 0.06 \\
\hline $01 / 1943$ & -0.13 & -0.02 & 0.25 & -0.10 & -0.25 & 0.09 & 0.05 & 0.11 & -0.18 & 0.17 & 0.04 \\
\hline $03 / 0705$ & 0.03 & 0.01 & 0.07 & -0.15 & 0.02 & 0.02 & -0.02 & 0.00 & -0.13 & 0.14 & 0.05 \\
\hline $03 / 1824$ & -0.11 & -0.04 & 0.25 & -0.11 & 0.03 & -0.04 & 0.25 & 0.00 & -0.27 & 0.02 & 0.05 \\
\hline $04 / 1729$ & 0.09 & -0.12 & 0.24 & -0.31 & -0.02 & -0.01 & 0.08 & -0.03 & -0.24 & 0.27 & 0.17 \\
\hline Mean & -0.028 & -0.042 & 0.235 & -0.163 & -0.070 & 0.010 & 0.125 & 0.040 & -0.230 & 0.116 & 0.017 \\
\hline Std dev. & .0 .033 & 0.049 & 0.061 & 0.076 & 0.082 & 0.050 & 0.084 & 0.061 & 0.056 & 0.090 & 0.119 \\
\hline \multicolumn{12}{|l|}{ GROUP 3} \\
\hline Event & MAN & AWA & WTZ & MDQ & RAW & MAE & LRO & WA I & MAR & KAO & RAWS \\
\hline $31 / 0919$ & 0.02 & -0.12 & 0.19 & -0.15 & -0.04 & -0.02 & 0.16 & 0.10 & -0.21 & 0.08 & 0.03 \\
\hline $31 / 1643$ & -0.00 & 0.00 & 0.22 & -0.33 & 0.07 & -0.08 & 0.21 & -0.02 & -0.21 & 0.22 & -0.26 \\
\hline $01 / 0352$ & -0.05 & 0.17 & 0.09 & -0.16 & 0.01 & -0.18 & 0.18 & 0.06 & -0.14 & 0.07 & -0.22 \\
\hline $01 / 1041$ & -0.14 & 0.00 & 0.24 & -0.09 & -0.08 & -0.01 & 0.15 & 0.01 & -0.15 & 0.10 & -0.09 \\
\hline $01 / 1418$ & -0.28 & 0.00 & 0.19 & -0.01 & -0.10 & 0.07 & 0.13 & -0.16 & -0.13 & 0.17 & 0.45 \\
\hline $02 / 2037$ & -0.22 & 0.07 & 0.15 & -0.03 & -0.11 & 0.03 & 0.06 & -0.09 & -0.04 & 0.14 & -0.08 \\
\hline $03 / 0401$ & -0.11 & 0.00 & 0.21 & -0.07 & 0.01 & -0.01 & 0.18 & -0.15 & -0.19 & 0.05 & 0.30 \\
\hline $03 / 0558$ & -0.05 & 0.11 & 0.20 & -0.17 & 0.02 & -0.07 & 0.14 & -0.05 & -0.23 & 0.15 & 0.08 \\
\hline $03 / 1901$ & -0.07 & -0.03 & 0.23 & -0.20 & -0.01 & -0.03 & 0.16 & -0.05 & -0.31 & 0.23 & 0.36 \\
\hline $04 / 1050$ & -0.05 & -0.02 & 0.14 & -0.07 & -0.12 & 0.02 & 0.02 & -0.03 & -0.09 & 0.13 & 0.27 \\
\hline Mean & -0.095 & 0.018 & 0.186 & -0.129 & -0.035 & -0.023 & 0.139 & -0.038 & -0.176 & 0.134 & 0.084 \\
\hline Std dev. & .0 .095 & 0.081 & 0.046 & 0.095 & 0.065 & 0.076 & 0.058 & 0.083 & 0.082 & 0.061 & 0.250 \\
\hline \multicolumn{12}{|l|}{ GROUP 4} \\
\hline Event & MAN & AWA & WTZ & MD2 & RAW & MAE & LRO & WA I & MAR & KAO & RAWS \\
\hline $03 / 2141$ & 0.10 & -0.13 & 0.22 & -0.17 & -0.04 & 0 & 0 . & 0.02 & -0.18 & 0.05 & 0.01 \\
\hline $04 / 6$ & 0.18 & -0.17 & 0.15 & -0.15 & -0.03 & 0.08 & 0.02 & 0.02 & -0.19 & 0.05 & 0.18 \\
\hline $04 / 0233$ & 0.10 & -0.07 & 0.13 & -0.09 & -0.04 & -0.03 & 0.03 & -0.02 & -0.10 & 0.05 & 0.23 \\
\hline $04 / 1332$ & 0.05 & -0.05 & 0.15 & -0.13 & -0.05 & -0.05 & 0.16 & 0.01 & -0.16 & 0.04 & 0.1 \\
\hline $04 / 1415$ & 0.01 & -0.12 & 0.07 & -0.10 & -0.07 & 0.02 & 0.19 & 0.03 & -0.18 & 0.02 & 0.29 \\
\hline $04 / 1806$ & 0.08 & 0.08 & 0.06 & -0.13 & -0.06 & -0.01 & 0.05 & 0.13 & -0.22 & 0.04 & -0.02 \\
\hline $05 / 0031$ & 0.08 & -0.16 & 0.05 & -0.10 & 0.01 & 0.05 & 0.12 & 0.12 & -0.15 & -0.00 & 0.04 \\
\hline 355 & -0.01 & -0.19 & 0.08 & -0.14 & 0.04 & 0.07 & 0.31 & 0.07 & -0.36 & 0.02 & 0.42 \\
\hline $06 / 0918$ & 0.04 & -0.13 & 0.18 & -0.17 & -0.17 & -0.01 & 0.25 & 0.12 & -0.15 & 0.01 & 0.08 \\
\hline $06 / 1218$ & 0.12 & -0.17 & 0.02 & -0.11 & -0.15 & -0.04 & 0.19 & 0.23 & -0.06 & -0.04 & 0.04 \\
\hline Mean & 0.075 & -0.111 & 0.111 & -0.129 & -0.056 & 0.009 & 0.144 & 0.073 & -0.176 & 0.024 & 0.144 \\
\hline Std dev. & .0 .055 & 0.080 & 0.064 & 0.029 & 0.064 & 0.046 & 0.095 & 0.075 & 0.079 & 0.029 & 0.140 \\
\hline \multicolumn{12}{|l|}{ GROUP 5} \\
\hline Event & MAN & AW: & WTZ & MDQ & RA & MA & L & WAI & MAR & KAO & RAWS \\
\hline $01 / 1017$ & -0.02 & -0.43 & 0.07 & 0.07 & -0.02 & 0.09 & 0.22 & 0.11 & 0.04 & -0.18 & 0.18 \\
\hline $04 / 05$ & & -0 . & 0.20 & -0.06 & -0 & -0 . & 0.20 & -0.09 & -0.09 & -0.01 & \\
\hline Mean & -0.020 & -0.305 & 0.135 & 0.005 & -0.035 & 0.045 & 0.210 & 0.010 & -0.025 & -0.095 & 0.295 \\
\hline Std de & .0 .000 & 0.177 & 0.092 & 0.092 & 0.021 & 0.064 & 0.014 & 0.141 & 0.092 & 0.120 & 0.163 \\
\hline \multicolumn{12}{|c|}{ ALL ABOVE } \\
\hline & MAN & AWA & WTZ & MDQ & RAW & MAE & LR & WAI & MAR & KAO & RAW \\
\hline Me & -0.029 & -0.072 & 0.195 & -0.142 & -0.052 & -0.020 & 0.171 & 0.020 & -0.190 & 0.090 & 0.122 \\
\hline & .0 .101 & 0.112 & 0.081 & 0.077 & 0.064 & 0.075 & 0.113 & 0.085 & 0.079 & 0.092 & 0.183 \\
\hline \multicolumn{12}{|l|}{ SUMMARY } \\
\hline & & & WTZS & & Linos & WAIS & MARS & KAOS & KAH & HS & WIZS \\
\hline $\begin{array}{l}\text { Mean } \\
\text { Std de }\end{array}$ & $\begin{array}{r}-0.10 \\
.0 .49\end{array}$ & $\begin{array}{r}-0.16 \\
0.28\end{array}$ & $\begin{array}{l}0.26 \\
0.23\end{array}$ & $\begin{array}{rr}41 & -0.07 \\
24 & 0.25\end{array}$ & $\begin{array}{rr}7 & -0.18 \\
5 & 0.37\end{array}$ & $\begin{array}{l}0.29 \\
0.28\end{array}$ & $\begin{array}{l}0.02 \\
0.30\end{array}$ & $\begin{array}{r}-0.42 \\
0.28\end{array}$ & $\begin{array}{rr}0.09 & -0 \\
0.15 & 0 .\end{array}$ & $\begin{array}{l}0.73 \\
0.42\end{array}$ & $\begin{array}{l}0.96 \\
0.58\end{array}$ \\
\hline No.obs. & 35 & 26 & 30 & 34 & 38 & 25 & 32 & 27 & 36 & 26 & 19 \\
\hline
\end{tabular}

Note: events are identified by day-of-month/hours; an " $\mathrm{S}$ " appended to a station code signifies $S$ arrival-time data. 


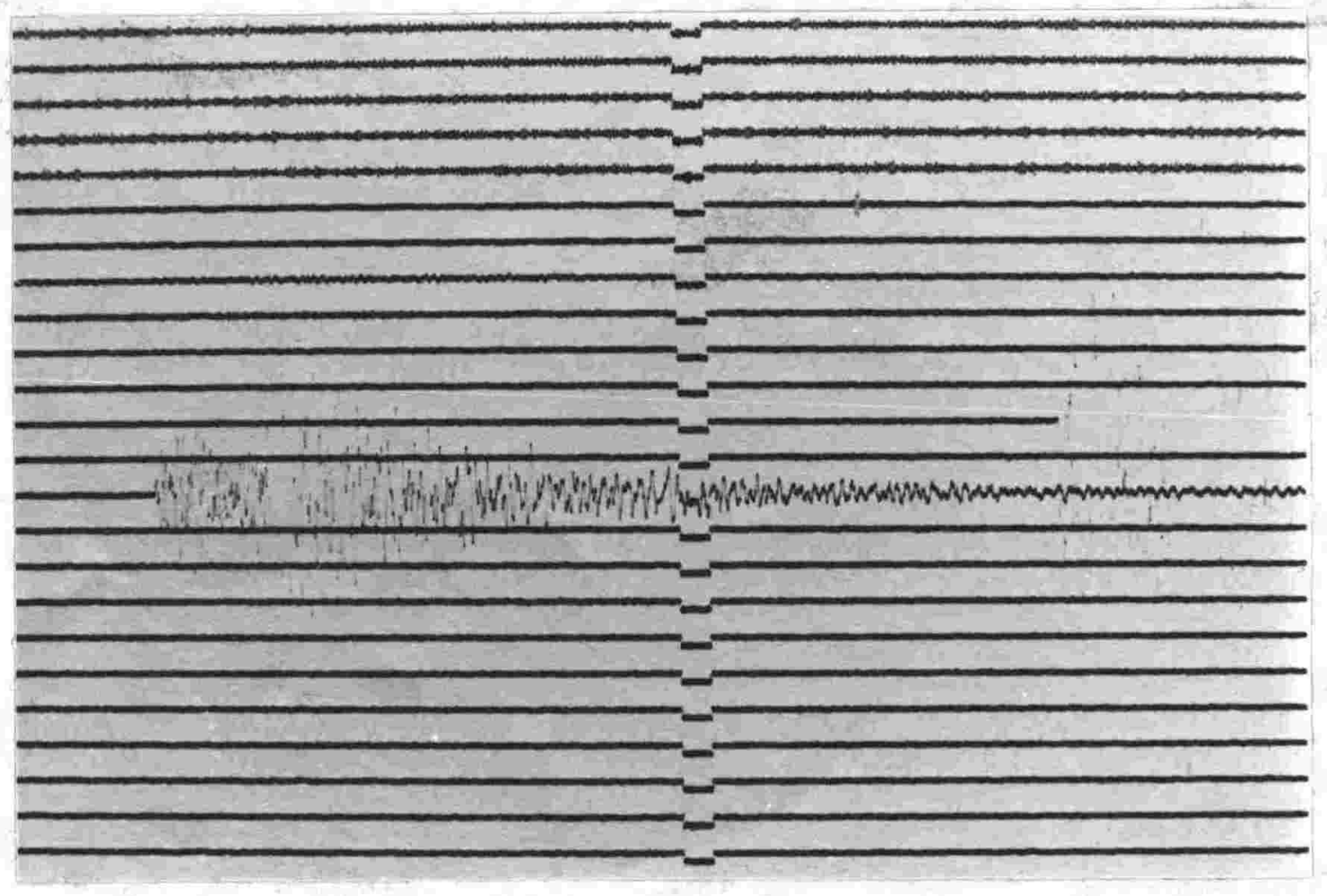

Figure A.1. TUA seismogram showing the dilatational first-motion for the subcrustal mainshock (right) and the compressional first-motion for the largest aftershock (left). 


\section{Bibliography}

Adams, D. A., 1984: Some methods of analysis of geodetic data and their applications to the measurement of crustal deformation. M.Sc. thesis, Victoria University of Wellington, New Zealand.

Adams, R.D., 1979: The New Zealand seismograph network. Physics Earth and planet. Interiors, 18: 114-120.

Adams, R.D. 1982: Source properties of the Oates Land earthquake, October 1974. In: Craddock, C. ed. pp.955-958. Antartic Geoscience. The University of Wisconsin Press, Madison.

Adams, R. D., \& Hatherton, T. 1973: Seismological and geothermal research in New Zealand. Nature, 246: 262-264. (Original attributed to R.D. Adam \& T. Hatherton.)

Adams, R. D., Hughes, A. A, \& McGregor, D.M. 1982: Analysis procedures at the International Seismological Centre. Physics Earth and planet. Interiors, 30: 85-93.

Adams, R.D., \& Lowry, M.A., 1971. The Inangahua earthquake sequence, 1968. In: Collins, B.W., \& Fraser, R. ed. Recent crustal movements. International Symposium on Recent Crustal Movements and Associated Seismicity, Wellington, 1970. Bull. Roy. Soc. N.Z., 9: 129-135.

Adams, R.D., Muir, M.G., \& Kean, R. J., 1972: Te Aroha earthquake, 9 January 1972. Bull. N.Z. natn. Soc. Earthq. Engng, 5: 54-58.

Adams, R.D., \& Randall, M.J. 1964: The fine structure of the Earth's core. Bull. seism. Soc. Am., 54: 1299-1313.

Adams, R.D., \& Ware, D.E. 1977: Subcrustal earthquakes beneath New Zealand: locations determined with a laterally inhomogeneous velocity model. N.Z. $\mathrm{Jl} \mathrm{Geol}$. Geophys., 20: 59-83.

Aggarwal, Y.P., Sykes, L.R., Armbruster, J., \& Sbar, M.L. 1973: Premonitory changes in seismic velocities and prediction of earthquakes. Nature, 241: 101-104.

Aki, K. 1965: Maximum likelihood estimate of $b$ in the formula $\log N=a-b M$ and its confidence limits. Bull. Earthq. Res. Inst. Tokyo Univ., 34: 237-239.

Ansell, J.H. 1978: The location and mislocation of subcrustal earthquakes. Physics Earth and planet. Interiors, 17: P1-P6.

Ansell, J.H., \& Gubbins, D. 1986: Anomalous high-frequency wave propagation from the Tonga-Kermadec seismic zone to New Zealand. Geophys. J. R. astr. Soc., 85: 93-106.

Ansell, J.H., \& Smith, E.G.C. 1975: Detailed structure of a mantle seismic zone using the homogeneous station method. Nature, 253: 518-520.

Bannister, S. 1988: Microseismicity and velocity structure in the Hawkes Bay region, New Zealand: fine structure of the subducting Pacific plate. Geophys. J., 95: 45-62. 
Banwell, C.J. 1963: Thermal energy from the Earth's crust (Part 1). N.Z. Jl Geol. Geophys., 6: 52-69.

Barley, B.J., \& Pearce, R.G. 1977: A fault plane solution using theoretical $P$ seismograms. Geophys. J. R. astr. Soc., 51: 653-668.

Berry, M. J., \& West, G.F. 1966: Reflected and head wave amplitudes in a medium of several layers. In: The Earth beneath the continents. Geophys. Monogr., 10. American Geophysical Union.

Bibby, H.M. 1973: The reduction of geodetic survey data for the detection of earth deformation. Geophysics Division Report 84. New Zealand Department of Scientific and Industrial Research.

Bibby, H.M. 1975: Crustal strain from triangulation in Marlborough, New Zealand. Tectonophysics, 29: 529-540.

Bibby, H.M. 1976: Crustal strain across the Marlborough faults, New Zealand. N.Z. Jl Geol. Geophys., 19: 407-425.

Bibby, H.M. 1981: Geodetically determined strain across the southern end of the Tonga-Kermadec-Hikurangi subduction zone. Geophys. J. R. astr. Soc., 66: 513-533.

Bibby, H.M. 1982: Unbiased estimate of strain from triangulation data using the method of simultaneous reduction. Tectonophysics, 82: 161-174.

Bibby, H.M., Dawson, G.B., Rayner, H.H., Stagpoole, V.M., \& Graham, D. J. 1984: The structure of the Mokai geothermal field based on geophysical observations. $J$. Volc. geotherm. Res., 20: 1-20.

Billington, S. 1982: A method to objectively sort $P$-wave first-motion data for composite focal mechanism solutions. Bull. seism. Soc. Am., 72: 399-411.

Billington, S., Engdahl, E.R., \& Price, S. 1981: Changes in the seismicity and focal mechanism of small earthquakes prior to an $M_{s} 6.7$ earthquake in the central Aleution island arc. In; Simpson, D. W., \& Richards, P.G. ed. pp.348-356. Earthquake prediction: an international review. Maurice Ewing Series, American Geophysical Union.

Birch, F. 1966: Compressibility; elastic constants. In; Clark, S.P. ed. Handbook of physical constants (revised ed.). Mem. geol. Soc. Am., 97: 97-174.

Bolt, B.A., \& Herraiz, M. 1983: Simplified estimation of seismic moment from seismograms. Bull. seism. Soc. Am., 73: 735-748.

Boore, D.M., \& Dunbar, W.S. 1977: Effect of the free surface on calculated stress drops. Bull. seism. Soc. Am., 67: 1661-1664.

Brace, W.F., \& Kohlstedt, D.L. 1980: Limits on lithospheric stress imposed by laboratory experiments. J. geophys. Res., 85: 6284-6252.

Braile, L.W., \& Smith, R.B. 1975: Guide to the interpretation of crustal refraction profiles. Geophys. J. R. astr. Soc., 40: 145-176.

Brune, J.N. 1970: Tectonic stress and the spectra of seismic shear waves from earthquakes. J. geophys. Res., 75: 4997-5009.

Brune, J.N. 1971: Correction. J. geophys. Res., 76: 5002. 
Brune, J.N., \& Allen, C.R. 1967: A micro-earthquake survey of the San Andreas fault system in Southern California. Bull. seism. Soc. Am., 57: 277-296.

Bullen, K.E. 1939: The crustal structure of the New Zealand region as inferred from studies of earthquake waves. In: Proceedings of the Sixth Pacific Science Congress, pp. 103-110.

Byerlee, J. 1978: Friction of rocks. Pure appl. Geophys., 116: 615-626.

Calhaem, I.M. 1973: Heat flow measurements under some lakes in North Island, New Zealand. Ph.D. thesis, Victoria University of Wellington, New Zealand.

Calhaem, I. M., Haines, A.J., \& Lowry, M. A. 1977: An intermediate-depth earthquake in the central region of the South Island used to determine a local crustal thickness. N.Z. Jl Geol. Geophys., 20: 353-361.

Cervený, V., \& Ravindra, R. 1971: Theory of seismic head waves. University of Toronto Press.

Chatterjee, S. N., Pitt, A.M., \& Iyer, H.M. 1985: $V_{p} / V_{s}$ ratios in the Yellowstone National Park region, Wyoming. J. Volc. geotherm. Res., 26: 213-230.

Chen, W-P., \& Molnar, P. 1983: Focal depths of intracontinental and intraplate earthquakes and their implications for the thermal and mechanical properties of the lithosphere. J. geophys. Res., 88: 4183-4214.

Chinnery, M. A. 1963: The stress changes that accompany strike-slip faulting. Bull. seism. Soc. Am., 53: 921-932.

Chinnery, M.A. 1964: The strength of the Earth's crust under horizontal shear stress. J. geophys. Res., 69: 2085-2089.

Chinnery, M. A. 1966a: Secondary faulting: I. Theoretical aspects. Can. J. Earth Sci., 3: 163-174.

Chinnery, M. A. 1966b: Secondary faulting: II. Geological aspects. Can. J. Earth Sci., 3: $175-190$.

Christensen, D.H., \& Ruff, L.J. 1985: Analysis of the trade-off between hypocentral depth and source time function. Bull. seism. Soc. Am., 75: 1637-1656.

Clark, R.H., Cole, J.W., Nairn, I.A., \& Wood, C.P. 1979: Magmatic eruption of White Island Volcano, New Zealand, December 1976-April 1977. N.Z. Jl Geol. Geophys., 22: $175-190$.

Creasy, M.A. 1956: Confidence limits for the gradient in the linear functional relationship, J. R. Statist. Soc., B18: 65-69.

Crook, C.N., \& Hannah, J. 1988: Regional horizontal deformation associated with the March 2, 1987, Edgecumbe earthquake, New Zealand. Geophys. Res. Lett., 15: 361-364.

Crosson, R.S. 1976a: Crustal structure modeling of earthquake data: 1. Simultaneous least squares estimation of hypocenter and velocity parameters. J. geophys. Res., 81: 3036-3046.

Crosson, R.S. 1976b: Crustal structure modeling of earthquake data: 2. Velocity structure of the Puget Sound region, Washington. J. geophys. Res., 81: 3047-3054. 
Das, S., \& Scholz, C.H. 1981: Off-fault aftershock clusters caused by shear stress increase? Bull. seism. Soc. Am., 71: 1669-1675.

Das, S., \& Scholz, C.H. 1983: Why large earthquakes do not nucleate at shallow depths. Nature, 305: 621-623.

Davies, O.L., \& Goldsmith, P.L. (ed.) 1976: Statistical methods in research and production with special reference to the chemical industry. (4th revised ed.) Longman Group Limited, London.

Douglas, A. 1981: Seismic source identification: a review of past and present research efforts. In: Husebye, E.S., \& Mykkeltveit, S., ed. pp.1-48. Identification of seismic sources - earthquake or underground explosion. D. Reidel Publishing Company.

Douglas, A., Hudson, J.A., \& Marshall, P.D. 1981: Earthquake seismograms that show Doppler effects due to crack propagation. Geophys. J. R. astr. Soc., 64: 163-185.

Dziewonski, A.M., Ekström, G., Franzen, J.E., \& Woodhouse, J.H. 1987: Global seismicity of 1977: centroid-moment tensor solutions for 471 earthquakes. Physics Earth and planet. Interiors, 45: 11-36.

Dziewonski, A.M., Ekström, G., Woodhouse, J.H., \& Zwart, G. 1988: Centroid-moment tensor solutions for January-March 1987. Physics Earth and planet. Interiors, 50: 116-126.

Dziewonski, A.M., Franzen, J.E., \& Woodhouse, J.H. 1985: Centroid-moment tensor solutions for October-December, 1984. Physics Earth and planet. Interiors, 39: 147-156.

Dziewonski, A.M., \& Woodhouse, J.H. 1983: An experiment in systematic study of global seismicity: centroid-moment tensor solutions for 201 moderate and large earthquakes of 1981. J. geophys. Res., 88: 3247-3271.

Eaton, J.P., O’Neill, M.E., \& Murdock, J.N. 1970: Aftershocks of the 1966 ParkfieldCholame, California, earthquake: a detailed study. Bull. seism. Soc. Am., 60: 1151-1197.

Eiby, G.A. 1966a: Earthquake swarms and volcanism in New Zealand. Bull. volcan., 29: 61-74.

Eiby, G.A. 1966b: The Modified Mercalli Scale of earthquake intensity and its use in New Zealand. N.Z. Jl Geol. Geophys., 9: 122-129.

Elder, J.W. 1965: Physical processes in geothermal areas. Structure and volcanism in the Taupo Volcanic Zone, New Zealand. In: Lee W.H.K. Terrestrial heat flow. Geophys. Monogr., 8: 211-239. American Geophysical Union.

Engdahl, E. R., \& Billington, S. 1986: Focal depth determination of central Aleutian eathquakes. Bull. seism. Soc. Am., 76: 77-93.

Evison, F.F. 1970: Seismogenesis. Tectonophysics, 9: 113-128.

Evison, F.F. 1975: Determination of precursory velocity anomalies in New Zealand from observatory data on local earthquakes. Geophys. J. R. astr. Soc., 43: 957-972. 
Evison, F.F. 1977: The precursory earthquake swarm. Physics Earth and planet. Interiors, 15: P19-P23.

Evison, F.F., Robinson, R., \& Arabasz, W.J. 1976: Microearthquakes, geothermal activity, and structure, central North Island, New Zealand. N.Z. Jl Geol. Geophys., 19: 625-637.

Evison, F.F., \& Webber, S. J. 1986: Seismogenic stress conditions in central New Zealand. In: Reilly, W. I., \& Harford, B.E. ed. Recent crustal movements of the pacific region. Proceedings of the International Symposium on Recent Crustal Movements of the Pacific Region, New Zealand, 9-14 February 1984. Bull. Roy. Soc. N.Z., 24: 553-565.

Ewart, A., \& Stipp, J.J. 1968: Petrogenesis of the volcanic rocks of the central North Island, New Zealand, as indicated by a study of $\mathrm{Sr}^{87} / \mathrm{Sr}^{86}$ ratios, and $\mathrm{Sr}, \mathrm{Rb}, \mathrm{K}$, $\mathrm{U}$ and Th abundances. Geochim. et Cosmochim. acta, 32: 699-736.

Fitch, T.J. 1972: Plate convergence, transcurrent faults, and internal deformation adjacent to southeast Asia and the western Pacific. J. geophys. Res., 77: $4432-4460$.

Flinn, E. A. 1965: Confidence regions and error determinations for seismic event locations. Rev. Geophys., 3: 157-185.

Forsyth, D.W. 1982: Determinations of focal depths of earthquakes associated with the bending of oceanic plates at trenches. Physics Earth and planet. Interiors, 28: 141-160.

Frank, F.C. 1966: Deduction of Earth strains from survey data. Bull. seism. Soc. Am., 56: 35-42.

Garrick, R.A. 1968: A reinterpretation of the Wellington crustal refraction profile. N.Z. Jl Geol. Geophys., 11: 1280-1294.

Garrick, R.A. 1969: Some physical properties of rocks in the East Cape-Mahia Peninsula region, North Island, New Zealand. N.Z. Jl Geol. Geophys., 12: 738-760.

Geophysics Division, New Zealand Department of Scientific and Industrial Research (Annual): New Zealand Seismological Report. Seismological Observatory Bulletin (E-Series). Wellington, New Zealand.

Gephart, J.W., \& Forsyth, D.W. 1984: An improved method for determining the regional stress tensor using earthquake focal mechanism data: application to the San Fernando earthquake sequence. J. geophys. Res., 89: 9305-9320.

Gibowicz, S.J. 1973: Stress drop and aftershocks. Bull. seism. Soc. Am., 63: 1433-1446.

Gibowicz, S.J. 1975a: Variation of source properties: the Inangahua, New Zealand, aftershocks of 1968. Bull. seism. Soc. Am., 65: 261-276.

Gibowicz, S.J. 1975b: Determination of seismic moment and related source parameters of shallow local earthquakes from Wellington records. Geophysics Division Report 99. New Zealand Department of Scientific and Industrial Research.

Gibowicz, S. J., \& Hatherton, T. 1975: Source properties of shallow earthquakes in New 
Zealand and their tectonic associations. Geophys. J. R. astr. Soc., 43: 589-605.

Grindley, G.W. 1960: Sheet 8, Taupo (1st ed.): Geological map of New Zealand $1: 250,000$. New Zealand Department of Scientific and Industrial Research.

Grindley, G.W. 1965: The geology, structure, and exploitation of the Wairakei geothermal field, Taupo, New Zealand. Geological Survey Bulletin 75. New Zealand Department of Scientific and Industrial Research.

Grindley, G.W., \& Hull, A.G. 1986: Historical Taupo earthquakes and earth deformation. In: Reilly, W.I., \& Harford, B.E. ed. Recent crustal movements of the pacific region. Proceedings of the International Symposium on Recent Crustal Movements of the Pacific Region, New Zealand, 9-14 February 1984. Bull. Roy. Soc. N.Z., 24: 173-186.

Gutenberg, B., \& Richter, C.F. 1942: Earthquake magnitude, intensity, energy, and acceleration. Bull. seism. Soc. Am., 32: 163-191.

Gutenberg, B., \& Richter, C.F. 1944: Frequency of earthquakes in California. Bull. seism. Soc. Am., 34: 185-188.

Haines, A.J. 1976: Compressional and shear velocities in the upper mantle beneath New Zealand determined using local crustal earthquakes. M.Sc. thesis, Victoria University of Wellington, New Zealand.

Haines, A.J. 1979: Seismic wave velocities in the uppermost mantle beneath New Zealand. N.Z. Jl Geol. Geophys., 22: 245-57.

Haines, A.J. 1980: Differences in time terms between New Zealand seismograph stations and implications for crustal structure. N.Z. Jl Geol. Geophys., 23: 541-549.

Haines, A.J. 1981a: A local magnitude scale for New Zealand earthquakes. Bull. seism. Soc. Am., 71: 275-294.

Haines, A.J. 1981b: Systematic effects of the introduction in 1977 of a new magnitude scale for New Zealand earthquakes. N.Z. Jl Geol. Geophys., 24: 141-153.

Hamilton, R.M. 1966: The Fiordland earthquake sequence of 1960, and seismic velocities beneath New Zealand. N.Z. Jl Geol. Geophys., 9: 224-38.

Hamilton, R.M. 1969: Seismological studies of the Gisborne earthquake sequence, 1966. Bull. N.Z. Dep. scient. ind. Res., 194: 7-23.

Hanks, T.C., \& Kanamori, H. 1979: A moment magnitude scale. J. geophys. Res., 84: 2348-2350.

Harmsen, S.C., \& Rogers, A.M. 1986: Inferences about the local stress field from focal mechanisms: applications to earthquakes in the southern Great Basin of Nevada. Bull. seism. Soc. Am., 76 1560-1572.

Harris, F. 1982: Focal mechanisms of subcrustal earthquakes in the North Island, New Zealand. N.Z. Il Geol. Geophys., 25: 325-334.

Hatherton, T. 1970: Upper mantle inhomogeneity beneath New Zealand: surface manifestations. J. geophys. Res., 75: 269-284. 
Hatherton, T. 1980: Shallow seismicity in New Zealand, 1956-75. Jl. R. Soc. N.Z., 10: $19-25$.

Healy, J. 1961: Geology and geothermal energy in the Taupo volcanic zone, New Zealand. Paper G/28, U.N. Conference on New Sources of Energy, Rome. Proceedings of the United Nations Conference on New Sources of Energy (Solar energy, wind power and geothermal energy; Rome, 21-31 August) pp. 250-258, Vol. 2, Geothermal Energy: I. United Nations, 1964, New York.

Healy, J., 1962. Structure and volcanism in the Taupo Volcanic Zone, New Zealand. In MacDonald, G.A., \& Kuno, H. ed. The Crust of the Pacific basin. Geophys. Monogr., 6: 151-157. American Geophysical Union.

Healy, J. 1964: Volcanic mechanisms in the Taupo Volcanic Zone, New Zaland. N.Z. $J l$ Geol. Geophys., 7: 6-23.

Healy, J., Schofield, J.C., \& Thompson, B.N., 1964. Sheet 5, Rotorua (1st ed.): Geological map of New Zealand 1:250,000. New Zealand Department of Scientific and Industrial Research.

Herrmann, R.B. 1975: The use of duration as a measure of seismic moment and magnitude. Bull. seism. Soc. Am., 65: 899-913.

Hochstein, M.P., \& Hunt, T.M. 1970: Seismic, gravity and magnetic studies, Broadlands geothermal field, New Zealand. U.N. Symposium on the Development and Utilization of Geothermal Resources. (special issue 2) Geothermics 2: 333-346.

Hunt, T. 1978: Stokes magnetic anomaly system. NZ. Jl Geol. Geophys., 21: 595-606. Hunt, T.M., \& Latter, J.H. 1982: A survey of seismic activity near Wairakei Geothermal Field, New Zealand. J. Volc. geotherm. Res., 14: 319-334.

Hyndman, R.D. 1979: Poisson's ratio in the oceanic crust - a review. Tectonophysics, 59: $321-333$.

International Seismological Centre (monthly issue, annual volume): Bulletin of the International Seismological Centre. Newbury, United Kingdom.

International Seismological Centre (six monthly): Regional Catalog of Earthquakes. Newbury, United Kingdom.

Imoto, M. 1986: Change in focal mechanism preceding the Izu-Oshoma-Kinkai earthquake of January 14, 1978. Earthq. Predict. Res., 4: 95-109.

Ishimoto, M., \& lida, K. 1939: Observations sur les séismes enregistrés par le microsismographe construit dernièrement (1). Bull. Earthq. Res. Inst. Tokyo Univ., 17: 443-478. (In Japanese with French abstract.)

Jackson, J., \& McKenzie, D. 1983: The geometrical evolution of normal fault systems. J. struct. Geol., 5: 471-482.

Jeffreys, H. 1976: The Earth. (6th ed.) Cambridge University Press.

Jeffreys, H., \& Bullen, K.E. 1958: Seismological tables. British Association for the Advancement of Science, London.

Jin, A., \& Aki, K. 1986: Temporal change in coda $Q$ before the Tangshan earthquake of 1976 and the Haicheng earthquake of 1975. J. geophys. Res., 91: 665-673. 
Julian, B.R. 1983: Evidence for dyke intrusion earthquake mechanisms near Long Valley caldera, California. Nature, 303: 323-325.

Kanamori, H., \& Anderson, D.L. 1975: Theoretical basis of some empirical relations in seismology. Bull. seism. Soc. Am., 65: 1073-1095.

Karig, D.E. 1970a: Ridges and basins of the Tonga-Kermadec island arc system. J. geophys. Res., 75: 239-254.

Karig, D.E. 1970: Kermadec arc-New Zealand tectonic confluence. N.Z. Jl Geol. Geophys., 13: 21-29.

Karig, D.E. 1971: Origin and development of marginal basins in the western Pacific. J. geophys. Res., 76: 2542-2561.

Kear, D. 1959: Stratigraphy of New Zealand's Cenozoic volcanism northwest of the volcanic belt. N.Z. Jl Geol. Geophys., 2: 578-589.

Kennett, B.L.N. 1983: Seismic wave propagation in stratified media. Cambridge University Press.

Kern, H., \& Richter, A. 1981: Temperature derivatives of compressional and shear wave velocities in crustal and mantle rocks at $6 \mathrm{kbar}$ confining pressure. $J$. Geophys., 49: 47-56.

Kind, R. 1979: Observations of $s P n$ from Swabian Alb earthquakes at the GRF Array. J. Geophys., 45:337-340.

Kind, R. 1984: Observation and interpretation of depth phases at regional distances. Terra cogn., 4: 272-273. (Abstract \& one figure.)

Kisslinger, C. 1980: Evaluation of $S$ to $P$ amplitude ratios for determining focal mechanisms from regional network observations. Bull. seism. Soc. Am., 70: 999-1014.

Kisslinger, C. 1982: Errata (to Kisslinger, 1980; and Kisslinger et al., 1981). Bull. seism. Soc. Am., 72: 344.

Kisslinger, C., Bowman, J.R., \& Koch, K. 1981: Procedures for computing focal mechanisms from local $(S V / P)_{Z}$ data. Bull. seism. Soc. Am., 71: 1719-1729.

Kisslinger, C., Bowman, J.R., \& Koch, K. 1982: Determination of focal mechanism from SV/P amplitude ratios at small distances. Physics Earth and planet. Interiors, 30: 172-176.

Kisslinger, C., \& Engdahl, E.R. 1973: The interpretation of the Wadati diagram with relaxed assumptions. Bull. seism. Soc. Am., 63: 1723-1736.

Kusznir, N.J., \& Park, R.G. 1984: Intraplate lithosphere deformation and the strength of the lithosphere. Geophys. J. R. astr. Soc., 79: 513-538.

Langston, C. A., \& Franco-Spera, M. 1985: Modeling of the Koyna, India, aftershock of 12 December 1967. Bull. seism. Soc. Am., 75: 651-660.

Lee, W.H.K., Bennett, R.E., \& Meagher, K.L. 1972: A method of estimating magnitude of local earthquakes from signal duration. United Stated Geological Survey OpenFile Report.

Lee, W.H.K., \& Lahr, J.C. 1975: HYP071(revised): a computer program for 
determining hypocenter, magnitude, and first motion pattern of local earthquakes. United States Geological Survey Open-File Report 75-311.

Lindh, A.G., Fuis, G., \& Mantis, C. 1978: Seismic amplitude measurements suggest foreshocks have different focal mechanisms than aftershocks. Science, 201: 56-59.

Malahoff, A., Feden, R.H., \& Fleming, H.S. 1982: Magnetic anomalies and tectonic fabric of marginal basins north of New Zealand. J. geophys. Res., 87: 4109-4125.

Mansinha, L., \& Smylie D.E. 1967: Effect of earthquakes on the Chandler wobble and the secular polar shift. J. geophys. Res., 72: 4731-4743.

Mansinha, L., \& Smylie, D.E. 1971: The displacement fields of inclined faults. Bull. seism. Soc. Am., 61: 1433-1440.

Mavko, G.M. 1980: Velocity and attenuation in partially molten rocks. J. geophys. Res., 85: 5173-5189.

McGarr, A. 1980: Some constraints on levels of shear stress in the crust from observations and theory. J. geophys. Res., 85: 6231-6238.

McGarr, A. 1982: Analysis of states of stress between provinces of constant stress. $J$. geophys. Res., 87: 9279-9288.

McGarr, A., Zoback, M.D., \& Hanks, T.C. 1982: Implications of an elastic analysis of in situ stress measurements near the San Andreas fault. J. geophys. Res., 87: 7797-7806.

McKenzie, D.P. 1967: Some remarks on heat flow and gravity anomalies. J. geophys. Res., 72: 6261-73.

McKenzie, D.P. 1969: Speculations on the consequences and causes of plate motions. Geophys. J. R. astr. Soc., 18: 1-32.

McKenzie, D., \& Bickle, M.J. 1988: The volume and composition of melt generated by extension of the lithosphere. J. Petrology, 29: 625-679.

McKenzie, D., \& Jackson, J. 1983: The relationship between strain rates, crustal thickening, paleomagnetism, finite strain and fault movements within a deforming zone. Earth planet. Sci. Lett., 65: 182-202.

McNutt, S.R., \& Beavan, R.J. 1981: Volcanic earthquakes at Pavlof Volcano correlated with the solid earth tide. Nature, 294: 615-618.

Mikumo, T., \& Miyatake, T. 1979: Earthquake sequences on a frictional fault model with non-uniform strengths and relaxation times. Geophys. J. R. astr. Soc., 59: 497-522.

Modriniak, N., \& Studt, F.E. 1959: Geological structure and volcanism of the TaupoTarawera district. N.Z. Jl Geol. Geophys., 2: 654-684.

Mogi, K. 1963a: The fracture of a semi-infinite body caused by an inner stress origin and its relation to the earthquake phenomena (Second paper) - The case of the materials having some heterogeneous structures. Bull. Earthq. Res. Inst. Tokyo Univ., 41: 595-614.

Mogi, K. 1963b: Some discussions on aftershocks, foreshocks and earthquake swarms the fracture of a semi-infinite body caused by an inner stress origin and its 
relation to the earthquake phenomena (Third paper). Bull. Earthq. Res. Inst. Tokyo Univ., 41: 615-658.

Mogi, K. 1967: Regional variation of aftershock activity. Bull. Earthq. Res. Inst. Tokyo Univ., 45: 711-726.

Molnar, P., \& Wyss, M. 1972: Moments, source dimensions and stress drops of shallowfocus earthquakes in the Tonga-Kermadec arc. Physics Earth and planet. Interiors, 6: 263-278.

Murase, T., \& McBirney, A.R. 1973: Properties of some common igneous rocks and their melts at high temperatures. Bull. geol. Soc. Am., 84: 3563-3592.

Nairn, I. A., \& Cole, J.W. 1981: Basalt dikes in the 1886 Tarawera rift. N.Z. Jl Geol. Geophys., 24: 585-592.

Nakamura, K., \& Uyeda, S. 1980: Stress gradient in arc-back arc regions and plate subduction. J. geophys. Res., 85: 6419-6428.

Nur, A. 1972: Dilatancy, pore fluids, and premonitory variations of $t_{s} / t_{p}$ travel times. Bull. seism. Soc. Am., 62: 1217-1222.

O’Connell, R.J., \& Budiansky, B. 1974: Seismic velocities in dry and saturated cracked solids. J. geophys. Res., 79: 5412-5426.

O’Connell, R.J., \& Budiansky, B. 1977: Viscoelastic properties of fluid-saturated cracked solids. J. geophys. Res., 82: 5719-5735.

Otway, P.M., Grindley, G.W., \& Hull, A.G. 1984: Earthquakes, active fault displacement and associated vertical deformation near Lake Taupo, Taupo Volcanic Zone. Geological Survey Report 110. New Zealand Department of Scientific and Industrial Research.

Page, E.S. 1954: Continuous inspection schemes. Biometrika, 41: 100-115.

Pandey, O.P. 1981: Terrestrial heat flow in New Zealand. Ph.D. thesis, Victoria University of Wellington, New Zealand.

Pearce, R.G. 1977: Fault plane solutions using relative amplitudes of $P$ and $p P$. Geophys. J. R. astr. Soc., 50: 381-394.

Pearce, R.G. 1980: Fault plane solutions using relative amplitudes of $P$ and surface reflections: further studies. Geophys. J. R. astr. Soc., 60: 459-487.

Pearce, R.G. 1981: Complex $P$ waveforms from a Gulf of Aden earthquake. Geophys. J. R. astr. Soc., 64: 187-200.

Perin, B.J. 1987: Body-wave modelling of earthquakes, Hikurangi margin, New Zealand. M.Sc. thesis, Victoria University of Wellington, New Zealand.

Prescott, W.H. 1976: An extension of Frank's method for obtaining crustal shear strains from survey data. Bull. seism. Soc. Am., 66: 1847-1853.

Raleigh, B., \& Evernden, J. 1981: Case for low deviatoric stress in the lithosphere. In: Carter, N.L., Freidman, M., Logan, J.M. \& Stearns, D.W. ed. Mechanical behaviour of crustal rocks: the Handin volume. Geophys. Monogr., 24: 174-186.

Randall, M. J. 1973: The spectral theory of seismic sources. Bull. seism. Soc. Am., 63: 1133-1144. 
Reilly, W.I. 1965a: Gravity map of New Zealand 1:4,000,000 - Bouguer anomalies. New Zealand Department of Scientific and Industrial Research.

Reilly, W.I. 1965b: Gravity map of New Zealand 1:4,000,000 - Isostatic anomalies. New Zealand Department of Scientific and Industrial Research.

Reyners, M. 1980: A microearthquake study of the plate boundary, North Island, New Zealand. Geophys. J. R. astr. Soc., 63: 1-22.

Reyners, M. 1983: Lateral segmentation of the subducted plate at the Hikurangi margin, New Zealand: seismological evidence. Tectonophysics, 96: 203-223.

Reyners, M. 1984: The Hawke's Bay, New Zealand, earthquake of 1982 September 02 and deformation in the interior of the subducted Pacific plate. Tectonophysics, 106: $259-273$.

Reyners, M., \& Hodder, S. 1985: The Motu River earthquake of 8 March 1984. Bull. N.Z. natn. Soc. Earthq. Engng, 18: 41-54.

Richter, C.F. 1935: An instrumental earthquake magnitude scale. Bull. seism. Soc. Am., 25: 1-32.

Richter, C.F. 1958: Elementary Seismology. W.H. Freeman and Company, San Francisco.

Roberts, N.L. 1967: Magnetic survey of the Bay of Plenty. Geophysics Division Technical note 40. New Zealand Department of Scientific and Industrial Research.

Robinson, R. 1976: Relative teleseismic travel-time residuals, North Island, New Zealand, and their relation to upper-mantle structure. Tectonophysics, 31: T41-T48.

Robinson, R. 1978: Seismicity within a zone of plate convergence - the Wellington region, New Zealand. Geophys. J. R. astr. Soc., 55: 693-702.

Robinson, R. 1983: Velocity structure of the Wellington region, New Zealand, from local earthquake data and its implications for subduction tectonics. Geophys. J. $R$. astr. Soc., 75: 335-359.

Robinson, R. 1986: Seismicity, structure and tectonics of the Wellington region, New Zealand. Geophys. J. R. astr. Soc., 87: 379-409.

Robinson, R. 1987: Temporal variation in coda duration of local earthquakes in the Wellington region, New Zealand. Pure appl. Geophys., 125: 579-596.

Robinson, R., Arabasz, W.J., \& Evison, F.F. 1975: Long-term behaviour of an aftershock sequence: the Inangahua, New Zealand, earthquake of 1968. Geophys. J. R. astr. Soc., 41: 37-49.

Robinson, R., Calhaem, I.M., \& Thomson, A.A. 1976: The Opunake, New Zealand, earthquake of 5 November 1974. N.Z. Jl Geol. Geophys., 19: 335-345.

Robinson, R., Smith, E.G.C., \& Latter, J.H. 1981: Seismic studies of the crust under the hydrothermal areas of the Taupo volcanic zone, New Zealand. J. Volc. geotherm. Res., 9: 253-267.

Rogan, M. 1982: A geophysical study of the Taupo Volcanic Zone, New Zealand. $J$. geophys. Res., 87: 4073-4088.

Ruff, L., \& Kanamori, H. 1980: Seismicity and the subduction process. Physics Earth 
and planet. Interiors, 23: 240-252.

Saikia, C.K., \& Herrmann, R.B. 1985: Application of waveform modeling to determine focal mechanisms of four 1982 Miramichi aftershocks. Bull. seism. Soc. Am., 75: 1021-1040.

Savage, J.C. 1983: A dislocation model of strain accumulation and release at a subduction zone. J. geophys. Res., 88: 4984-4996.

Savarensky, E.F. 1968: On the prediction of earthquakes. Tectonophysics, 6: 17-27.

Scholz, C.H. 1968: The frequency-magnitude relation of microfracturing in rock and its relation to earthquakes. Bull. seism. Soc. Am., 58: 399-415.

Seber, G.F. 1977: Linear regression. Wiley series in probability and mathematical statistics.

Semenov, A.N. 1969: Variations in the travel-times of transverse and longitudinal waves before violent earthquakes. Izvestiya of the Academy of Sciences, USSR. (English Translation) Physics of the Solid Earth, pp.151-157. American Geophysical Union, Washington.

Sibson, R.H. 1986: Earthquakes and rock deformation in crustal fault zones. A. Rev. Earth Planet. Sci., 14: 149-175.

Sipkin, S. A. 1986: Interpretation of non-double-couple earthquake mechanisms derived from moment tensor inversion. J. geophys. Res., 91: 531-547.

Sissons, B. A. 1979: The horizontal kinematics of the North Island of New Zealand. Ph.D. thesis, Victoria University of Wellington, New Zealand.

Sleep, N., \& Toksöz, M.N. 1971: Evolution of marginal basins. Nature, 233: 548-550.

Smith, E.G.C. 1977: The theory of multi-earthquake location by least squares and application to groups of North Island, New Zealand, mantle earthquakes. Ph.D. thesis, Victoria University of Wellington, New Zealand.

Smith, E.G.C. 1979: A micro-earthquake survey of the Rangitikei and Manawatu basins. N.Z. Jl Geol. Geophys., 22: 473-478.

Smith, E.G.C. 1981: Foreshocks of shallow New Zealand earthquakes. N.Z. Jl Geol. Geophys., 24: 579-584.

Smith, E.G.C. 1983: Joint determination of seismic velocity ratios: theory and application to an aftershock sequence. Bull. seism. Soc. Am., 73: 405-417.

Smith, E.G.C. 1984: Rules for the analysis of local earthquakes. Geophysics Division Technical note 91. New Zealand Department of Scientific and Industrial Research.

Smith, E.G.C. (Comp.) 1987: Research in seismology and the physics of the Earth's interior in New Zealand, 1983-1986. The Report of the New Zealand National Committee for Geodesy and Geophysics on behalf of the Royal Society of New Zealand to the International Association of Seismology and Physics of the Earth's Interior, presented at the Vancouver Assembly of the International Union of Geodesy and Geophysics, August 1987. New Zealand Department of Scientific and Industrial Research.

Smith, E.G.C., Scott, B. J., \& Latter, J.H. 1984: The Waiotapu earthquake of 1983, 
December 14. Bull. N.Z. natn. Soc. Earthq. Engng, 17: 272-279.

Smith, E.G.C., \& Webb, T.H. 1986: The seismicity and related deformation of the

Central Volcanic Region, North Island, New Zealand. In: Smith, I.E.M. ed. Late Cenozoic volcanism in New Zealand. Bull. Roy. Soc. N.Z., 23: 112-133.

Smith, W.D. 1970: $S$ to $P$ conversion as an aid to crustal studies. Geophys. $J$. $R$. astr. Soc., 19: 513-519.

Smith, W.D. 1976: Computer file of New Zealand earthquakes. N.Z. Jl Geol. Geophys., 19: 393-394.

Spence, G.D., Clowes, R.M., \& Ellis, R.M. 1985: Seismic structure across the active subduction zone of western Canada. J. geophys. Res., 90: 6754-6772.

Spencer, C., \& Gubbins, D. 1980: Travel-time inversion for simultaneous earthquake location and velocity structure determination in laterally varying media. Geophys. J. R. astr. Soc., 63: 95-116.

Staff of DSIR 1987: The March 2, 1987, earthquake near Edgecumbe, North Island, New Zealand. Eos. Trans. Am. geophys. Un., 68: 1162-1171.

Stein, R.S., \& Lisowski, M. 1983: The 1979 Homestead Valley earthquake sequence, California: control of aftershocks and postseismic deformation. J. geophys. Res., 88: $6477-6490$.

Steketee, J.A. 1958a: On Volterra's dislocations in a semi-infinite elastic medium. Can. J. Phys., 36: 192-205.

Steketee, J. A. 1958b: Some geophysical applications of the elasticity theory of dislocations. Can. J. Phys., 36: 1168-1198.

Stern, T.A. 1979: Regional and residual gravity fields, central North Island, New Zealand. N.Z. Jl Geol. Geophys., 22: 479-485.

Stern, T.A. 1982: Seismic and gravity investigations of the Central Volcanic Region, North Island, New Zealand. Ph.D. thesis, Victoria University of Wellington, New Zealand.

Stern, T. A. 1985: A back-arc basin formed within continental lithosphere: the Central Volcanic Region of New Zealand. Tectonophysics, 112: 385-409.

Stern, T.A. 1986: Geophysical studies of the upper crust within the Central Volcanic Region, New Zealand. In: Smith, I.E.M. ed. Late Cenozoic volcanism in New Zealand. Bull. Roy. Soc. N.Z., 23: 92-111.

Stern, T.A., \& Davey, F.J. 1985: Crustal structure studies within the central North Island: the Central Volcanic Region. Geophysics Division Report 207. New Zealand Department of Scientific and Industrial Research.

Studt, F.E. 1958: Geophysical reconnaissance at Kawerau, New Zealand. NZ. Jl Geol. Geophys., 1: 217-246.

Studt, F.E., \& Thompson, G.E.K. 1969: Geothermal heat flow in the North Island of New Zealand. N.Z. Jl Geol. Geophys., 12: 673-83.

Suyehiro, S. 1966: Difference between aftershocks and foreshocks in the relationship between magnitude to frequency of occurrence from the great Chilean earthquake 
of 1960. Bull. seism. Soc. Am., 56: 185-200.

Thatcher, W., \& Hanks, T.C. 1973: Source parameters of southern California earthquakes. J. geophys. Res., 78: 8547-8576.

Thompson, B.N. 1964: Quaternary volcanism of the Central Volcanic Region. N.Z. Jl Geol. Geophys., 7: 45-66.

Thomson, A.A., \& Evison, F.F. 1962: Thickness of the Earth's crust in New Zealand. N.Z. Jl Geol. Geophys., 5: 29-45.

Ukawa, M., \& Fukao, Y. 1981: Poisson's ratios of the upper and lower crust and the sub-Moho mantle beneath central Honshu, Japan. Tectonophysics, 77: 233-256.

United States Geological Survey (monthly issue): Preliminary determination of epicentres. United States Department of the Interior.

Utsu, T. 1961: A statistical study on the occurrence of aftershocks. Geophys. Mag., 30: 521-605.

Utsu, T. 1966: A statistical significance test of the difference in $b$-value between two earthquake groups. J. Phys. Earth, 14: 37-40.

Utsu, T. 1970: Aftershocks and earthquake statistics (II) - Further investigation of aftershocks and other earthquake sequences based on a new classification of earthquake sequences. J. Fac. Sci. Hokkaido Univ., Series VII (Geophysics), 3: 197-266.

Utsu, T. 1971: Aftershocks and earthquake statistics (III) - Analyses of the distribution of earthquakes in magnitude, time, and space with special consideration to clustering characteristics of earthquake occurrence (1). J. Fac. Sci. Hokkaido Univ, Series VII (Geophysics), 3: 379-441.

Uyeda, S., \& Kanamori, H. 1979: Back-arc opening and the mode of subduction. $J$. geophys. Res., 84: 1049-1061.

Vetter, U.R., \& Ryall, A.S. 1983: Systematic change of focal mechanism with depth in the western Great Basin. J. geophys. Res., 88: 8237-8250.

Walcott, R.I. 1978a: Present tectonics and Late Cenozoic evolution of New Zealand. Geophys. J. R. astr. Soc., 52: 137-164.

Walcott, R.I. 1978b: Geodetic strains and large earthquakes in the axial tectonic belt of North Island, New Zealand. J. geophys. Res., 83: 4419-29.

Walcott, R.I. 1984: The kinematics of the plate boundary zone through New Zealand: a comparison of short- and long-term deformations. Geophys. J. R. astr. Soc, 79: 613-633.

Warren, N.W., \& Latham, G.V. 1970: An experimental study of thermally induced microf racturing and its relation to volcanic seismicity. J. geophys. Res., 75: 4455-4464.

Webb, T.H., Wesnousky, S.G., \& Helmberger, D.V. 1985: A body-wave analysis of the 1966 Gisborne, New Zealand, earthquake. Tectonophysics, 113: 271-282.

Webb, T.H., Ferris, B.G., \& Harris, J.S. 1986: The Lake Taupo, New Zealand, earthquake swarms of 1983. N.Z. Jl Geol. Geophys., 29: 377-389. 
Welch, B.L. 1947: The generalization of 'Student's' problem when several different population variances are involved. Biometrika, 34: 28-35.

Whitcomb, J.H., Garmany, J.D., \& Anderson, D.L. 1973: Earthquake prediction: variation of seismic velocities before the San Fernando earthquake. Science, 180: 632-635.

White, R.S., $\quad$ Spence, G.D., $\quad$ Fowler, S.R., $\quad$ McKenzie, D.P., $\quad$ Westbrook, G.K., \& Bowen, A.N. 1987: Magmatism at rifted continental margins. Nature, 330: 439-444.

Woollard, G.P. 1970: Evaluation of the isostatic mechanism and role of mineralogic transformations from seismic and gravity data. Physics Earth and planet. Interiors, 3: 484-498. 